\title{
XV \\ Modern Literature
}

\author{
MATTHEW LEVAY, ANDREW RADFORD, \\ CAROLINE KRZAKOWSKI, ANDREW KEESE, \\ MARIA-DANIELLA DICK, CATRIONA LIVINGSTONE, \\ HANNAH TWEED, GUSTAVO A. RODRÍGUEZ MARTÍN, \\ GRAHAM SAUNDERS, WILLIAM BAKER, \\ MATTHEW CREASY, KARL O'HANLON, AND \\ ADAM HANNA
}

This chapter has 8 sections: 1. General; 2 Pre-1945 Fiction; 3. Post-1945 Fiction; 4. Pre-1950 Drama; 5. Post-1950 Drama; 6. British Poetry 1900-1950; 7 British Poetry Post-1950; 8. Irish Poetry. Section 1 is by Matthew Levay; section 2(a) is by Andrew Radford; section 2(b) is by Caroline Krzakowski; section 2(c) is by Maria-Daniella Dick; section 2(d) is by Andrew Keese; section 2(e) is by Catriona Livingstone; section 3(a) is by Hannah Tweed; section 3(b) is by Samuel Cooper and William Baker; section 4 is by Gustavo A. Rodríguez Martín; section 5 is by Graham Saunders and William Baker; section 6 is by Matthew Creasy; section 7 is by Karl O'Hanlon; section 8 is by Adam Hanna.

\section{General}

Since the arrival of the New Modernist Studies roughly two decades ago, scholarship in modernism has been reliably eclectic, founded on a combination of interdisciplinarity and historicism that equally attends to global and local phenomena in constructing a robust cultural history of the period. Modernism, according to contemporary critics, flourishes across continents, time periods, and the arts, its boundaries moving in a constant yet welcome state of flux. While the emphasis of any single critical account can fall more heavily on some of these characteristics than others, and while scholars are increasingly taking greater care to situate their versions of modernism within a tighter conceptual framework, the field has proven remarkably consistent in producing work that imagines the idea of 'modernism' as a far-reaching, often 
conflicted enterprise that one can view from any number of perspectives. Not surprisingly, then, the books in modernist studies published in 2016 are extraordinarily diverse in style and subject, and demonstrate how an essentially restless field continues to redefine itself even as that gesture has become familiar.

One of the most notable trends in 2016 was a steady focus on modernist print culture, as critics mined the archives in an effort to reveal the publishing and authorial networks that brought modernism into being and disseminated it to readers. Perhaps the most comprehensive book in this area is Faye Hammill and Mark Hussey's Modernism's Print Cultures, part of Bloomsbury's series in 'New Modernisms', which offers detailed surveys of significant issues in the history of modernism and modernist criticism. Serving as a guide to students and researchers, Hammill and Hussey's book casts a wide net over the various cultures of print that dominated the period, from periodical and fine book publishing to book clubs and political journals. They begin with a chapter on 'Sensuous Print', which addresses the materiality of modernist print cultures - typography, design, and the physical dimensions of a printed text - and then turn to chapters on 'Print in Circulation' and 'Purposeful Print', which deliver helpful, clearly articulated overviews of how various publications made their way through the public sphere, and of how those works aimed to address specific kinds of audiences, respectively. The range of publications under discussion gives a solid impression of the period while still leaving room for readers to explore other areas and contexts, and the volume's back matter-which includes a substantial bibliography, a list of societies and associations devoted to the subject, and a compendium of databases and digital archives - makes the book an invaluable resource for beginning and advanced scholars alike. As Hammill and Hussey note at the outset, the 'networks that produced and sustained modernism are being reconstructed from [publishers' and magazines'] archives, and this work is having a profound effect on our conceptions of the literary, requiring us to acknowledge that a modernist book, magazine, poem or novel is simultaneously a defamiliarizing art object and a commodity' (p. 35). Their book is a welcome and well-timed contribution to these efforts at reconstruction, taking stock of where modernist studies has been and where it might turn as it continues to probe an abundance of heretofore untapped archival materials in order to understand the origins and contributions of the period.

Similarly, Patrick Collier's Modern Print Artefacts: Textual Materiality and Literary Value in British Print Culture, 1890-1930s is a rigorous account of how various textual forms from the modernist period negotiate conflicting systems and arbiters of literary value in ways that exceed and, necessarily, revise the conventional narrative of twentieth-century art. Turning his attention to newspapers, magazines, anthologies and mass-market books, Collier outlines a vast network of overlapping publishing ecosystems that permeated the lives of everyday British readers, and within which the formal properties of material objects could make claims about how the content of those objects should be understood and accorded various degrees of value. Perhaps unsurprisingly, given its author's considerable work in periodical studies, Modern Print Artefacts is especially rich in its account of early 
twentieth-century newspapers and magazines, offering up impressive and thickly historicized interpretations of the Illustrated London News, John O'London's Weekly and the London Mercury. Each of the book's chapters provides a compelling analysis of these periodicals, and demonstrates how we can more fully grasp the debates over literature, culture and society that shaped the contours of the century's opening decades by examining publications like these, given their prominence among British readers, the material forms in which they presented information to those readers and the value they were granted or denied as print artefacts. The book's most provocative section, however, is its conclusion, in which Collier makes a passionate yet precise case against 'modernism' as a totalizing descriptor of early twentieth-century literary culture. He argues that the New Modernist Studies' tendency to situate any aesthetic object produced during the period in relation to modernism has led not only to a necessary expansion of the modernist canon, but also to a more worrying tendency to ignore those objects that do not fit into it. As Collier notes, some of the best-known modernist authors were undeniably against 'ordinary print culture: the world of popular periodicals, mainstream publishing houses, libraries, booksellers and other locations where a vast majority of the reading and writing in the period got done' (p. 235). As a result, he maintains, we would do well to displace modernism from its position of critical prominence, if only to ensure that the literary history of the early twentieth century is appropriately inclusive.

Whereas Modern Print Artefacts offers a meticulous assessment of print culture in early twentieth-century Britain, John Lurz's The Death of the Book: Modernist Novels and the Time of Reading takes a more formalist approach to modernist novels' unique investment in exchanges between the material form of the book and the phenomenological experience of reading. Through a detailed set of close readings of novels by Proust, Joyce and Woolf, Lurz shows how the book as object became a central conceit of modernist fiction. As he argues, each of these novelists represents within his or her narrative moments of textual engagement that can mirror our own experience of reading, drawing us into and out of the book in a heady give-and-take. For Lurz, these novels 'plot their own readerly consumption', taking special note of their embodiment within the pages of a particular kind of material artefact, and of the various ways in which readers might engage with them as objects (p. 2). The 'death' of Lurz's title, meanwhile, refers to the overriding concern with temporality that permeates the novels under consideration. For instance, a chapter on Woolf's Jacob's Room ends with an account of that novel's conclusion, in which the narrator alludes to the title character's death during the Great War through a scene in which another character takes in the sight of Jacob's letters spread haphazardly across the floor of his room. As Lurz explains, the pages littering Jacob's room correspond to the pages of Jacob's Room and, by extension, to the reader currently handling them, painfully aware of Jacob's absence and thus of his or her own eventual demise. Here 'we are given an impression of the way our own inanimate objecthood entails less a last-minute escape from than an ultimate accession to temporality', an impression available to us through a representation of scattered pages that echoes the bounded set of sheets we hold in our hands (p. 134). Despite its 
ominous title, The Death of the Book is a subtle, absorbing meditation on how modernist novels register their status as physical books as well as readers' possibilities for engaging them. It is also fine proof of the continued efficacy of close reading as a critical practice, and of the pleasures that the modernist text affords when understood in light of its own self-referentiality, as a book to be handled, read and experienced.

In contrast to other studies of modernist textuality, Eyal Amiran's Modernism and the Materiality of Texts connects the body of the modernist text to the body of its author, arguing that the modernists' struggle with the marked, sexualized, and racialized body finds its outlet in the body of the literary text, which becomes symptomatic of psychic crisis. The book is a lithe yet intense exploration of how 'the material text focuses and serves as the locus for disavowed features of identity and of psychic failure associated in the period with physicality and the body', taking moments of 'nonsense' in the modernist text as powerfully indicative of such features (p. 1). To support his argument, Amiran examines a host of authors both canonical and popular, including Woolf, Gertrude Stein, Rudyard Kipling, Arthur Conan Doyle, J.M. Barrie, P.G. Wodehouse, Sigmund Freud, and cartoonist George Herriman. Each makes a clear and productive contribution to the overall argument, and the chapter on Herriman is particularly noteworthy, as it brings an artist long considered peripheral to modernism squarely into its orbit. Describing how Herriman's Krazy Kat newspaper strip 'elaborates a theory of legibility based on the physical features of literary art', Amiran demonstrates that Krazy Kat's anarchic nonsense - a constant cycle of violence and absurdity - stages a substantial meditation on blackness, wherein 'colour, and ink in particular, is constitutive of meaning and subtends a systemic reading of culture' (p. 92). In these and other readings, Amiran proffers a version of modernist materiality that feels quite new compared with other recent studies in the field. The brevity of this book belies its depth, and the force of its interpretations reflects a vigorous approach to the interconnections of author and material object that play out within the modernist text.

If modernist scholarship in 2016 was intensely interested in the materiality of the text, it was also distinguished by its attention to modernism across the arts, as critics roamed from literature, to painting, to music, to film, from the late nineteenth century to the present, and from the ultra-canonical to work rarely if ever recognized as art. One of the most impressive, and, indeed, necessary books of the year was Richard Begam and Matthew Wilson Smith's Modernism and Opera, an edited collection that ably illustrates how what is arguably the most lavish and sentimental of modern art forms shares surprising affinities with the 'cool formalism and streamlined geometry we so often associate with modernism' (p. 2). As the editors acknowledge in their introduction, the idea of modernist opera seems like a 'quasi-oxymoron in which modernism's tension between timeless myth and commodified ephemerality vibrates with peculiar force', and the precise nature of this vibration animates the many perceptive essays that follow (p. 2). The list of contributors is particularly distinguished, bringing together scholars in literary studies, musicology, theatre, and law: in addition to individual chapters from Begam and Smith, we have contributions from Daniel Albright, Klára Móricz, Bryan 
Gilliam, Bernadette Meyler, Derek Katz, Cyrena N. Pondrom, Herbert Lindenberger, Linda Hutcheon and Michael Hutcheon, Irene Morra, and Joy H. Calico. And while the subjects of their essays are necessarily wide-ranging, marching across centuries, nations, and art movements, the volume as a whole is remarkably consistent in its focus on crucial affinities between modernism and opera. Both, the editors and contributors argue, prize collaboration across the arts, pressure the formal parameters of any given medium by positing new modes of representation, and bring together elements of multiple aesthetic forms within a single work. As a result, Modernism and Opera achieves that rare balance of historicism and aesthetic critique, and should prove indispensable for specialists and novices alike. Begam and Smith have provided readers with a detailed and passionate introduction to a pairing that deserves far more attention than it has so far received, and have accomplished the laudable task of expanding modernist studies even further into areas that, in light of the arguments contained in this book, now seem fundamental to the field.

Similarly, Jed Rasula's History of a Shiver: The Sublime Impudence of Modernism also finds its definition of modernism through the example of music. While 'dizzying' is an adjective frequently applied to monographs of ambitious scope, it absolutely applies to Rasula's learned, comprehensive, and at times even funny study of modernism across the arts. The book's main claims are founded on a seemingly simple notion: that modernism is usefully understood as a synesthetic endeavour animated by the spirit of music, and in particular the concept of 'melomania', or 'the nineteenth-century elevation of music to top-dog status' (p. 19). According to Rasula, one can trace the origins of modernism not just to the late nineteenth century, as several critics have maintained, but even further back in time, to the Romanticist impulse to rebel against dominant forces and insist upon the work of art as a self-defined original, a sublime object containing within itself the conditions of its own making and meaning. Modernism is thus linked to Romanticism via what Rasula dubs 'Wagnerism', and, more explicitly, to the faith that modernists placed in Wagner's conception of the Gesamtkunstwerk, or the 'total work of art' that encompasses all other arts. To make his case, Rasula draws upon one of the most ample and eclectic archives seen in recent books in modernist studies - no small feat given the continued expansion of the field-and he moves swiftly yet confidently from Joyce to Kandinsky, Rilke to Schoenberg, Fuller to Kerouac. The swell of examples is so great, in fact, that Oxford University Press provides a companion website featuring additional visual art, film clips, and music, all of which are mentioned in the book but deliver their greatest effects when encountered more directly, in connection to Rasula's commentary on them. The website is an especially useful resource for a monograph like this one, as it takes advantage of the affordances of Web publishing to give room to artwork that either can't be reproduced in print or whose reproduction would make the book's cost prohibitive. It is also a fitting testament to the idiosyncrasy of History of a Shiver more generally, in that the book never settles into the typical structure we might expect of an academic study, but instead prowls restlessly and intelligently across a variety of topics and works, and in so doing reflects all the energy of its subject. 
One might productively compare Rasula's account of modernism as permeated with synesthetic aspiration with Jesse Matz's searching and elegant Lasting Impressions: The Legacies of Impressionism in Contemporary Culture, which charts the curious longevity of impressionism's characteristic fusion of emotion, sensation, and idea. Part of Columbia University Press's excellent Literature Now series, Lasting Impressions builds upon the considerable work of Matz's first book, Literary Impressionism and Modernist Aesthetics [2001], by asking how impressionism has continued to influence the visual and literary culture of the late twentieth and early twenty-first centuries. Deftly shifting from painting to advertising, fiction to memoir, Matz makes a dazzling case for impressionism as 'the folk art of modernity itself', which registers the fleeting experiences and immediacies of a technologically mediated age at the same time as its aesthetic can seem incontestably traditional, and therefore the product of a bygone era that persists thanks to its comforting inoffensiveness (p. 18). Matz begins with a striking and beautifully written introduction that details his personal experience with pseudo-impressionism-specifically, two 1960s-era impressionist paintings by Hungarian artist (and former avant-gardist) Béla Kontuly that decorated his childhood home, which Matz takes as the basis of a thoughtful meditation on why a painter devoted to an objective, even cold constructivism early in his career might adopt an impressionist's style after the Second World War - and later chapters explore the contemporary forms of impressionism found in the work of W.G. Sebald, Zadie Smith, David Mitchell, James Frey, Colm Tóibín, Chimamanda Ngozi Adichie, Oliver Sacks, and Malcolm Gladwell, among others. But Matz is equally at ease with visual art, and his detailed analyses of works by Peter Doig, Yves Klein, and (yes) Thomas Kinkade advance lucid, compelling arguments for understanding impressionism's legacy as intimately informing some of our most pressing questions regarding the cultural valuation of art.

Jeremy Rosen's Minor Characters Have Their Day: Genre and the Contemporary Literary Marketplace appears in the same book series as Matz's, and the virtues shared between the two works are considerableparticularly in the ways that each presents an expansive, authoritative argument on a topic central to our understanding of the contemporary arts that has inexplicably gone unnoticed until now. Whereas Matz describes one of contemporary art's most ubiquitous yet under-studied phenomena, Rosen draws our attention to a similar issue in the literary world: the rewriting of canonical texts through the perspective of a minor character, who can elaborate upon the events and conditions of the original work in ways that speak to the desires of both a contemporary popular readership and a literary marketplace buoyed by the genre's profitability. Beginning with Jean Rhys's Wide Sargasso Sea, the genre that Rosen dubs 'minor-character elaboration' has become a vital yet potentially troubling feature of the contemporary literary landscape, since Rosen notes that this genre, which can seem to offer a political counterpoint to the earlier texts it revisits by delivering a staunch critique of canonicity, often functions as a tool for opposite purposes. As he explains, when reading works of minor-character elaboration, '[o]ne is forced to confront the (seemingly obvious) fact that a great many intertextual works do not launch a critique of the canon and that even those that do may not be 
performing the political work we think they are'; rather, these works 'instead serve to prop up liberal individualism and are deeply embedded in the massproduction cycles of multinational capitalism' ( $p$. 4). Rosen's mastery of a staggering number of contemporary fictions is evident in every chapter, and the range of examples he provides testifies to a genre that is flourishing if not exactly serving the purposes for which critics might hope. One of the book's most notable achievements is its rigorous theorization of genre. First in his introduction and then in later chapters, Rosen advances a clear case for the genre of minor-character elaboration as possessing a unique social logic, in which 'the genre's conventional form of imaginatively constructing a formerly minor character's perspective ... indicates the extension of a liberal individualist project for the realist novel' (p. 7). From that observation on form, he pivots to context, and mounts a stimulating argument for the necessity of examining these and other genre fictions in light of the literary institutions and publics that produce and consume them. What emerges is a fascinating portrait of the literary marketplace as it currently stands, and a monograph that will quickly become a foundational work for genre theory, reception history, and the history of contemporary publishing.

Also planted firmly in the contemporary is Mark Seltzer's The Official World, which, as its title suggests, tracks the formal conditions through which the world conceives, regulates, and describes itself into being. Theoretically nuanced and enthralling in its ability to manoeuvre between popular culture, literary fiction, and those works that stand somewhere in between, Seltzer's study of officialdom is one of the most intellectually dynamic books of 2016, and, for its wholly distinct prose, also one of the most pleasurable to read. Its archive is eclectic yet befitting the argument it supports, and includes novels by J.G. Ballard, Agatha Christie, Patricia Highsmith, Kazuo Ishiguro, Tom McCarthy, and Karl Ove Knausgaard, in addition to a wide variety of midcentury and contemporary films. Highsmith receives considerable attention as a practitioner of suspense, which Seltzer characterizes as the official world's defining genre. If, Seltzer proposes, the 'official world' describes a state of 'selfconditioning and self-reporting', or a contemporary world that is constituted by its constant description, then suspense serves as the violent, moody register of those processes (p. 6). Highsmith, who has always deserved more critical attention, is here provocatively understood as staging in her fiction the modes of description, inscription, and self-analysis that become overwhelming yet necessary features of the official world. Equally important to Seltzer's argument are the fiction and performance art of Tom McCarthy, now an almost canonical figure for theorists of the avant-garde. Like Highsmith, McCarthy's novels also obsessively describe the world through its official, material objects: documents, reports, messages, and other studies transmitted through multiple communication technologies. But Seltzer compares them, in characteristically unexpected fashion, to those of Christie, in that both fixate on phenomena like clocks, timetables, and transportation technologies, and in so doing measure and chart the contours of a world that cannot stop performing such actions. A short synopsis like this one inevitably fails to do justice to the achievement of Seltzer's book, and gives only a hint of the astonishing variety, complexity, and wit of this disquieting record of how 
contemporary art stages the conditions of its singular moment in modernity. But suffice it to say that this work is utterly captivating, and forces critics to reimagine practically every aspect of the modern that we may have taken for granted.

Adding to the list of 2016 titles invested in the contemporary is Joel Burges and Amy J. Elias's Time: A Vocabulary of the Present, an intriguing edited collection that theorizes the contemporary from a different angle by exploring how critical conceptions of time after 1945 have indubitably shaped the lived experience of it. Proposing in their introduction an increased critical attention to 'time studies', Burges and Elias offer their collection as an effort to 'guide readers historically and critically toward understanding (especially in the study of the arts, technology, and culture) how the post-war period-our present-is animated by certain kinds of time consciousness' (p. 2). As a means of parsing those different strands of time consciousness, each contributor to the volume pairs two keywords 'addressing the specificity of time today, in the interest of glimpsing the unique textures that post-war temporality has assumed' (p. 3). Thus we have twenty chapters, each of which brings together a set of oppositions in order to explore where our current perceptions of temporality and scale originate, and where they might lead our critical practice, moving forward: Elias on 'Past/Future', Ursula K. Heise on 'Extinction/Adaptation', David James on 'Modern/Altermodern', Burges on 'Obsolescence/ Innovation', Mark Currie on 'Anticipation/Unexpected', Jimena Canales on 'Clock/Lived', Elizabeth Freeman on 'Synchronic/Anachronic', Heather Houser on 'Human/Planetary', Jared Gardner on 'Serial/Simultaneous', Ben Anderson on 'Emergency/Everyday', Aubrey Anable on 'Labour/Leisure', Mark McGurl on 'Real/Quality', Jesse Matz on 'Aesthetic/Prosthetic', James Phelan on 'Analepsis/Prolepsis', Michelle Stephens and Sandra Stephens on 'Embodied/Disembodied', Stanley Hauerwas on 'Theological/Worldly', Anthony Reed on 'Authentic/Artificial', Nick Montfort on 'Batch/ Interactive', Rachel Haidu on 'Transmission/Influence', and Paul D. Miller, aka DJ Spooky, That Subliminal Kid on 'Silence/Beat'. The pairings are a heady mixture of idiosyncrasy and conceptual rigour, and always produce compelling results. The collection as a whole is admirably rich and varied, and yields ample rewards to scholars working at the intersections of art, time, and critical theory.

We can also think of time in a narrower register, as in Rachel Bowlby's latest book, Everyday Stories. In this slim volume, part of the Oxford University Press series The Literary Agenda, Bowlby investigates the concept of the ordinary day as a specific kind of narrative, begetting and informed by broader cultural narratives. In the process, she asks poignant questions about the scale and scope of everyday life: how a day counts as a discrete instance of time, how its events impress themselves as mundane or unique, and how we construct a relationship to the past by reference to its specific days. The authors Bowlby consults to pose and then answer these questions range from the eighteenth century to the contemporary, which reflects a remarkably sweeping approach for such a compact monograph; she pays abundant attention to Jane Austen, George Eliot, Charles Baudelaire, Sigmund Freud, Virginia Woolf, and Christopher Isherwood, with shorter forays into Oscar 
Wilde, James Joyce, and Alan Hollinghurst, among other essential modernist and contemporary figures. In putting all of these authors together in their shared emphasis on everyday stories, Bowlby crafts a lyrical and beautifully argued tribute to the narrative potential of ordinary days, filled with events and scenes 'so obvious that they can pass unnoticed', yet are 'in reality ... always in flux, just as they differ, starkly or slightly, from one culture or place to another' (p. 176).

Yet another trend of 2016's scholarship in modern and modernist literature was the continued emphasis on global approaches to the field, and two books serve as particularly welcome reference points for those interested in modernism's global reach. The first is Eric Hayot and Rebecca L. Walkowitz's A New Vocabulary for Global Modernism, a collection each of whose seventeen chapters focuses on a single keyword that offers numerous possibilities for theorizing modernism within a global framework. Some chapters deal with familiar concepts - the book includes entries on 'Alienation', 'Form', 'Style', and 'Tradition'-while others turn to topics less obviously tied to modernism in order to mount stirring defences of their relevance for the period - 'Animal', 'Puppets', and 'Slum'. Yet in every chapter one encounters a dynamic argument for how contemporary critics might still push modernist studies into new territory. The volume is organized by concept rather than place, which yields a refreshingly comparative approach within individual chapters that exemplifies the payoff of approaching modernism across multiple geographies rather than within an isolated location. As Hayot and Walkowitz note in their introduction, "[t]he "global" is never some fixed centre around which other ideas revolve (even when it is conceived that way); it is instead a shifting concept of fixity and centrality, a set of claims made about the world (another concept) and how it works, whose force depends in every case on the situation and context of its elaboration' (p. 3). In other words, the editors and contributors take the concept of the global as a thing to be demonstrated rather than assumed a priori, and each essay builds on that foundation by pursuing its subject across multiple geographical and national borders. Perhaps the most illuminating chapters of the book are those that show how thinking globally entails a fundamental rethinking of method. For instance, Christopher Bush observes in his essay on 'Context' that the global turn in modernist studies 'reinforces ... the field's dominant tendency to valorise historical context against that aesthetic autonomy said to have been valued in the bad old days' at the same time that it 'implies new conceptions of history so unimaginably vast and complex that we can hardly rely on them to perform their traditional function of explanatory, clarifying, context' (p. 76). As a result, 'the global need not be understood as the sum total of all that is knowable about the world'; rather, '[t]he challenge of reading modernism more globally is often more a question of how we know than of how much' (p. 76). Here and elsewhere, A New Vocabulary for Global Modernism forces modernist critics to interrogate their methods as opposed to, more simply, the objects to which they apply them. In this sense it is a genuinely useful book, showing rather than telling the paths criticism might pursue and inviting readers to ponder how their own work might benefit from such direction. The fact that Hayot and Walkowitz also include an appendix, which lists forty-three other 
terms one might employ to theorize modernism's global presence, testifies to how much work remains to be done, and where other critics might take up the charge.

The other significant introduction to global modernism is Peter Kalliney's Modernism in a Global Context, which, like Hammill and Hussey's Modernism's Print Cultures, is part of Bloomsbury's New Modernism series. Given the scope of Kalliney's previous work in modernist, postcolonial, and transnational studies, he is a fine choice to author an authoritative guide to the subject, and one deliberately attuned to the needs of general readers in the field (that is, students, teachers, and anyone seeking immersion in a new area of study). Beginning with an introduction to some of the key theorists of global and transnational studies as well as the chief issues their work has raised, Kalliney divides his later chapters among four central concepts: imperialism, cosmopolitanism, cultural institutions, and media. Each offers a valuable survey of significant works, movements, and themes, opening with essential questions that animate the topic and continuing with a series of fascinating case studies that emphasize their implications, all in order to make plain Kalliney's opening contention that 'modernism is an aesthetics of motion' (p. 1). In this way, Modernism in a Global Context mirrors the concerns found in Hayot and Walkowitz's collection, as it sets as its broader goal the rethinking of the 'global' as a fundamentally methodological issue. Part of achieving that goal entails putting forward a wide-ranging set of examples, and the book's chapters smartly pivot from canonical Anglo-Americans like Eliot and Woolf to equally transformative authors whose connection to modernism is less critically acknowledged but no less secure; turn to Kalliney's chapter on imperialism, to name just a single example, and one finds vital figures like Karel Čapek, Aimé Césaire, Pramoedya Ananta Toer, and M.G. Vassanji alongside more expected choices like Olive Schreiner, Joseph Conrad, and Elizabeth Bowen. These selections, Kalliney acknowledges, are by no means the only ones he could have made, and yet their juxtaposition exposes the values by which one makes them, and challenges the critic to think more carefully about what it might mean to perceive modernism globally without placing undue emphasis on traditional notions of cultural centres and canons. 'A truly global perspective', Kalliney argues, should alter our perceptions of the cultural centre, whatever that might be, as well as the cultural margins, whatever those might be' (p. 24). In the end, Kalliney succeeds beautifully in proposing solid ways to practise that perspective by understanding how it has risen to such critical prominence, and how comparative, transnational approaches can offer exciting new ways to reconceive of modernism using more inclusive models.

Modernist studies in 2016 also demonstrated the continued relevance of historicism as a tool for interpreting modernism in relation to broader cultural contexts. This is not a surprise given that the New Modernist Studies arose largely as an effort to historicize a period traditionally constructed through a narrow range of works and oeuvres, but the persistence of historicism as a critical approach - its adaptability to so many different kinds of intellectual projects - is notable. In this regard, one of the most striking monographs of the year is James Purdon's Modernist Informatics: Literature, Information, and 
the State, which presents an absorbing history of information and the cultures surrounding it. This book posits that our current era of information technologies traces its roots back to the early twentieth century, when the nineteenth-century fascination with statistics gave way to bureaucratic offices tasked with managing, processing, and facilitating the spread of information among various constituencies. Purdon terms this shift in informatics control 'the government of information', which 'call[s] to mind the way information has emerged as both the basis of modern political power and one of its primary objects of attention and control' (p. 6). The government of information is not only a signal of state practice, however, but also a phenomenon in which modernist authors actively participated, both in their writing and in their professional lives. To prove the point, Purdon turns to the work of Joseph Conrad, Ford Madox Ford, Graham Greene, and Elizabeth Bowen, in addition to the documentary films of director John Grierson and the mountains of material produced in service of the Mass Observation movement. His chapters explore how these authors engage with informatics as a central concern, arguing that each 'was profoundly affected both by the political regulation of information systems and by the use of information systems as instruments of political authority' (p. 16). Their work embodies a mounting realization that there exists no easy escape from these systems, and that, in fact, the aesthetics of fiction might be productively influenced by them. Each chapter contains a wealth of references and unexpected connections, and the fact that each is lucidly written and painstakingly researched means that the information of Purdon's argument is always clear, consistent, and impressively presented. His close readings of Bowen's The Heat of the Day, a novel he describes as 'an almanac of informatic pathologies' centred on an idea of information suppression made legible through the novel's structure, are particularly evocative, and readers are consistently rewarded by these and other moments of critical insight (p. 156).

Skilfully blending historicism and critical theory is Thomas S. Davis's timely study of late modernism, The Extinct Scene: Late Modernism and Everyday Life, which asks why so many late modernists, working at a time of profound geopolitical crisis, instead turned their attention to the everyday. As an answer to this question, Davis proposes that 'the depth, scale, and particularity of late modernism's encounter with everyday life become apparent only by way of a dialectical inquiry into the interrelationships between late modernism's use of various genres - documentary cinema, the historical novel, auto-ethnography, travel writing, the gothic, vernacular fiction - and the accumulating pressures attending the breakup of the British world-system', as late modernist authors represent simmering and eventually overflowing geopolitical tensions by paradoxically revealing them through sustained accounts of everyday experience in a broad range of textual and visual forms (pp. 3-4). Davis makes the convincing case that such accounts can help us explain why late modernism so clearly lacks a single, unifying aesthetic, since an emphasis on the external conditions of geopolitical disorder necessarily requires multiple aesthetic approaches in order to render the complexities of those conditions. In the process, he offers one of the book's most valuable arguments when he maintains that the external gaze of late modernism is not just a belated realism, 
but rather an 'outward turn' that seeks to describe how the everyday emerges within 'an articulated network of political, economic, and social life' (p. 5). Significantly, he also makes the point that this outward turn was not intended as an act of defamiliarization or an effort to proclaim the virtue of ordinary experience, as was the case for an earlier, high, modernism. Instead, the outward turn of late modernism casts the everyday as powerfully inscribed by one's position within various overlapping political systems, and thereby represents a way of conceiving the individual as part of a vast political order through a fusion of avant-garde experimentation and multilayered description. The book's archive is voluminous yet tightly conceived, ranging from documentary filmmakers associated with Mass Observation to literary touchstones like Bowen, Henry Green, Christopher Isherwood, Colin MacInnes, W.H. Auden, George Orwell, Sam Selvon, Vic Reid, and George Lamming. Throughout, Davis constructs one of the most original and penetrating accounts of late modernism since that term first came to critical prominence, building an instructive history and theory of the period that should quickly become the standard with which other scholars interested in late modernism must reckon.

Whereas Davis judiciously carves out a framework for theorizing late modernism, Ben Hutchinson's perceptive new book, Lateness and Modern European Literature, takes broader aim at the concept of lateness more generally. He begins by revising one of modernist studies' most cherished critical commonplaces: that modernism, as a period and as an aesthetic response to it, is above all else an attempt to 'make it new', a celebration of novelty and an exhortation to defy anything associated with tradition. By contrast, Hutchinson argues that modernism is actually a period plagued by the burden of lateness, one whose authors are weighed down by 'the implications of coming after a past perceived as more meaningful' (p. 1). Modernism, then, is ultimately regarded as untimely, perpetually in a crisis of legitimacy brought on by authors' fears of existing in an already exhausted epoch (a late period) and writing in an outdated fashion (a late style). Much of the book deals with the nineteenth century - the first two of its three sections are devoted to Romanticism and Decadence, respectively-but the last section, on modernism, marshals a wealth of examples drawn from a wide swath of European literature in order to establish its case. Covering Wyndham Lewis, Thomas Mann, D.H. Lawrence, T.S. Eliot, and Hermann Broch, to name only the most canonical figures, Hutchinson's chapters on modernism provide sweeping examples taken from French, Italian, German, and English contexts, and as such convey the depth of Hutchinson's argument. Closing with an epilogue on Sebald (who, perhaps tellingly, appears in a number of 2016's monographs on modern literature), Hutchinson reminds the reader that, as '[c]reatures facing backwards, modern authors thus appear as the 'latest' in both progressive and regressive terms', poised to advance art's claims on the twentieth century while at the same time recognizing themselves as struggling for legitimation against the example of prior generations (p. 339). Hutchinson's study of this peculiar modernist 'anxiety of lateness' represents a significant step towards positioning modernism within a larger literary 
history, and the fact that it cuts across so many national contexts only solidifies the broad applicability of its claims (p. 14).

Though published in 2015, Charles Ferrall and Dougal McNeill's co-written volume Writing the 1926 General Strike: Literature, Culture, Politics deserves special mention here, as another outstanding example of how the history of modernism is still in the process of being written. In contrast to the breadth of Hutchinson's work on lateness and Davis's brilliant periodization of late modernism, Ferrall and McNeill's book offers a captivating reading of a single historical event: the nine-day national strike of 1926, which the authors scrutinize as a benchmark in British political thought between the wars. 'The climax of a decade or more of radicalism and rebellion across Britain', they argue, 'memories of the General Strike point forward to the miseries of the thirties and back to the insurgency of the Great Unrest' (p. 3). While everyone living in Britain at the time possessed at least some memories of the strike, Ferrall and McNeill are most interested in how it was figured as a literary event in the work of several authors, whom they divide between those who wrote about the strike at a kind of remove, as a social phenomenon to be reported on (for instance, Arnold Bennett, G.K. Chesterton, D.H. Lawrence, and Virginia Woolf), and those working-class writers who attempted to communicate an insider's knowledge of current labour conditions to a broader, more general audience (Hugh MacDiarmid, Rhys Davies, and B.L. Coombes). In approaching the strike from these two vantage points - and while acknowledging the inevitable crossovers between them-the book conveys both the profound significance of the strike as a contemporary event and the complicated lessons of its legacy. Perhaps more importantly, it also provides a model for how one might write a work of literary and cultural history that truly attends to the variety of its evidence rather than attempting to shove it within a more homogeneous, tidy narrative of the past. 'We need fewer repetitions of the same Strike stories', the authors urge in their introduction, 'and more attention paid to the wayward, difficult, partial narratives still too often under-read' (p. 18). In Writing the 1926 General Strike, they have produced a vital resource not only for understanding the conflicted literary history of British labour in the 1920s and after, but also for writing literary history more generally.

Given the multiple strands of modernist scholarship apparent in 2016, it seems fitting to conclude this review with Vincent Sherry's magnificent collection, The Cambridge History of Modernism, which accepts the laudable if daunting task of providing as complete a view of its subject as is possible in any single book. Boasting forty-three individual chapters as well as a substantive introduction and epilogue, the volume is a commanding survey of what Sherry aptly characterizes as a 'fighting word': namely, the term 'modernism', 'fraught from the start with strident and contestable claims about the meaning of the experience of history in general and contemporary history in particular' (p. 1). Cutting across national contexts and time periods, and featuring topics such as modernist literature, architecture, painting, music, theatre, periodicals, and film, the essays included offer up a diverse set of focal points for experiencing the history of modernism in all its complexity. Indeed, it is impossible to convey just how impressive this volume is in its ambition, 
both as an attempt to record the intricacies of modernist thought and practice and as a challenge to approach modernism systematically, insofar as any study of such a vexed category could ever be systematic. And yet, regarding the latter point, The Cambridge History of Modernism does an exceptional job of clarifying the sprawl of modernism without sacrificing its complexity. The book begins with essays devoted to 'Modernism in Time', each of which focuses on a specific decade, before proceeding to 'Modernism in Space', which examines its subject in two related senses: first, in terms of space as it informs the visual arts, and second, in terms of space as a physical descriptor that applies to individual places, borders, and the globe. The next section of the book tackles the subject of genre, while the final and longest section, 'Modernism in Person, Modernism in Community', offers captivating snapshots of those collectives and iconoclasts that helped to shape, and indeed continue to shape, our conception of the period. Without fail, each contribution is lively, assured, and meticulous, and the volume as a whole leaves one confident that ours has always been an unusually rich field, with ample opportunity for exploration still available. It is no small feat to finish a nearly 1,000-page history of modernism with the sense that we can do more, as a community, to flesh out our subject, and to be excited about that prospect. The editor and contributors to this book should be commended for the accomplishment, as should the authors of the books already mentioned, which, taken together, prove the value of multiplicity, heterogeneity, and diversity as cornerstones of contemporary critical practice.

\section{Pre-1945 Fiction}

\section{(a) British Fiction 1900-1930}

This year offered aficionados of avant-garde and interwar women's writing a plethora of shrewdly angled criticism. Amongst this material, the voluminous Edinburgh Edition of the Collected Works of Katherine Mansfield, assembled under the editorial supervision of Gerri Kimber and Claire Davison, represents an absorbing, even game-changing, academic resource, especially with the appearance of The Collected Poems of Katherine Mansfield in 2016. These volumes mirror and extend a notable 'textual turn' in modernist literary scholarship that has radically reshaped our grasp of the career and avantgarde tendencies of a formidably prolific and versatile author. First of all, this 'textual turn' affords access to unpublished, rare, or out-of-print sources. It also prompts us expansively to reappraise Mansfield's highly original stylistic repertoire - especially how she depicted, and sought inspiration from, various friendship networks, counter-publics, and subcultures of civic activism, advocacy and resistance to prevailing religious or moral credos. The Edinburgh Edition also raises urgent questions about Mansfield's subtle portrayals of private and public history, the gravitational pull of elegiac nostalgia, feminist and queer temporalities, diverse forms of authority, persecution, and transgression. 
Closer scrutiny of Mansfield's oeuvre allows readers to weigh the often complex processes by which some literary luminaries (Virginia Woolf, Wyndham Lewis, Joseph Conrad, Henry James), receive lavish editorial repackaging, while others - such as the adventurously eclectic interwar writers Mary Butts, Olive Moore, Storm Jameson, Rose Macaulay, and Sylvia Townsend Warner-are wilfully misconstrued or languish at the very edges of aesthetic modernism. Josephine M. Guy ponders this very issue in her persuasively structured essay 'Challenges in Editing Late Nineteenth- and Early Twentieth-Century Prose Fiction: What is Editorial "Completeness?", (ELT 59:iv[2016] 435-55).

Guy's thoughtful article should be scrutinized alongside volume 7 of Palgrave's History of British Women's Writing, 1880-1920, edited by Holly A. Laird, which assembles a striking array of pundits who investigate, appraise, and affirm, in often vivid detail, "the turn-of-the-century New Women, women activists, aesthetes, and suffrage workers, mapping the locations and writing traditions in which they emerged' (p. 12). Here Mansfield emerges as an author who attempts to parse the civic convulsions brought about by technological modernity and geopolitical strife. Mansfield appears alongside a remarkable cluster of female authors who merit more sustained textual analysis, for example Sarah Grand, Vernon Lee, Marie Corelli, Charlotte Mew, and Sara Maria Saunders. This volume also weighs important questions about cultural ambivalence, identity conflict, and the very category of the 'British woman writer' as well as the accuracy of gender and nation-based abstractions in our contemporary critical moment.

Also edited by Gerri Kimber and Claire Davison, The Diaries of Katherine Mansfield confidently repositions Mansfield as a trenchant and often impishly witty diarist, as well as a suspicious close reader of contemporary AngloAmerican and European literatures. Kimber and Davison have done sterling work in packaging texts that were once only accessible as unedited transcripts or imperfectly rendered snippets. Mansfield's diaries and notebooks are retranscribed here with ample biographical and contextual data. Mansfield scholars will find especially useful the materials never previously published, such as poem-cycles, Mansfield's own illustrations, and the texts she was drafting during the fraught last months of her life. Overall, The Diaries supplies a vibrant reminder of how Mansfield's extraordinary cast of mind resonated with those established and evolving methods, tendencies and tropes currently exercising 'new modernist' scholars. Mansfield's intellectual curiosity is such that we find telling engagements with, for example, racial and imperial politics; the intricacies of print culture, especially book history and the crowded marketplace for 'little magazines'; competing definitions of mimesis; the dialogues and disputes between cutting-edge science and avant-garde composition. In short, this volume demonstrates how thoroughly Mansfield mapped what we call nowadays 'the modernist field' as one marked by myriad intersecting and multi-directional cultural energies.

Mansfield's editor Gerri Kimber has also written a biography, Katherine Mansfield: The Early Years, which charts the first two decades of Mansfield's life, from her birth in 1888 to her final departure from New Zealand in 1908. Kimber is characteristically diligent in uncovering the significance of 
Mansfield's childhood and adolescent encounters in a colonial environment where burgeoning industrial modernity and archaic indigenous custom coexisted in a sometimes awkward 'tenancy' (p. 34). These experiences are seen to have had a decisive impact on how 'Katherine Mansfield' the formally inventive author evolved from the socially inquisitive 'Kass Beauchamp'. Indeed, Kimber's approach probes well the autobiographical dimension of her fictional and journalistic writings - for example the influence of her natal culture, history, and locality on her representation and dissection of heightened emotion. This delicately nuanced portrait of the artist as a young woman also reveals Mansfield's ability to recall and record not just the colonial hinterlands, but also those polyglot modernist metropoles that manifest the dialectic of the transient and the enduring, the derelict and the populous, the endemic and the exotic.

Kimber's biography also poses technically attentive questions that reverberate through some of the most persuasive scholarship on Mansfield over the past decade, especially her dramatizations of 'movement' as bodily and psychic odyssey. The Early Years positions Mansfield as a restive frontier-crosser whose formal and cultural concerns subvert populist and paranoid tropes of ethno-nationalism by querying tenets of selfless patriotism and citizenship. In this account Mansfield is an author equipped with rhetorical gifts that enable her to evoke her own migration experiences, as well as those eerie 'borders' between conscious and unconscious by which libidinal potencies seek to overturn the fragile sway of the sovereign self.

Edited by Sarah Ailwood and Melinda Harvey, Katherine Mansfield and Literary Influence furnishes a convincing and crisply realized account of a writer whose 'growing literary ambition lead her to identify other people's examples to emulate' (p. 2). This essay collection confronts the often striking 'ways Mansfield's life and work were affected, and have themselves impacted upon, other writers and their writing' (p. 2). As many of the contributors acknowledge, insufficient critical attention has been paid to 'tracing the influence of prior literary texts on her fiction' (p. 3). Deborah Pike considers " "Objectless Love": The Vagabondage of Colette and Katherine Mansfield' (pp. 105-18), while Gerry Kimber focuses on 'Circles of Influence: Katherine Mansfield, S.S. Koteliansky and Russia' (pp. 78-92). Other elegantly structured essays include Michael Hollington's 'Mansfield Eats Dickens' (pp. 155-67); Jessica Gildersleeve's " "Where is she?": Katherine Mansfield and Elizabeth Bowen' (pp. 35-50), and Naomi Milthorpe's "'The twilight of language": The Young Evelyn Waugh on "Catherine" Mansfield' (pp. 21-34).

Kate Krueger's wide-ranging yet scrupulously researched 'Material Negotiations: Women Writing the Short Story' (in Laird, ed., pp. 203-12) situates Mansfield as 'the modernist short story writer par excellence' who shared with May Sinclair an unswerving dedication 'to the exploration of literature's formal possibilities regarding the representation of the human mind' (p. 209). Krueger demonstrates how these two women writers' technical 'achievements and their contributions to the short story were enabled by the venues in which they published' (p. 210).

Sarah Barnette's 'Vernon Lee's Composition of "The Virgin of the Seven Daggers": Historic Emotion and the Aesthetic Life' (19 23[2016] 26 paras) 
attests to a recent burgeoning of scholarly fascination with interactions between modernist literature and sciences of the mind. Likewise, contributors to Katherine Mansfield and Psychology, edited by Claire Hanson, Gerri Kimber and Todd Martin, variously gauge Mansfield's corpus through the prism of writings by figures such as William James and Henri Bergson. The most incisive contributions are attuned to Mansfield and the politics of difference; especially how feelings of social stigma, marginality, grief, existential ennui, and embittered non-belonging are woven into the imaginative fabric of Mansfield's short stories. While many of these essays ponder influences, dialogues, and affinities within the cultural climate in which Mansfield came of age, others document the intricate interplay between Mansfield's fictional motifs and Freudian theory, seeing her stories as typical of 'the uncanny doubling' (p. 4) of modernist literature and psychoanalysis. Todd Martin's “"The thing needed": Katherine Mansfield, Psychology and Relationships' (pp. 189-202) parses Mansfield's sophisticated narrative modes using findings of affect theory and phenomenology. Other eye-catching contributions to this volume include Setara Pracha's 'Apples and Pears: Symbolism and Influence in Daphne du Maurier's " "The Apple Tree" and Katherine Mansfield's "Bliss", (pp. 172-86); Avishek Parui's "For the life of him he could not remember": Post-War Memory, Mourning and Masculinity Crisis in Katherine Mansfield's "The Fly", (pp. 113-24), and Louise Edensor's 'Me or I? The Search for the Self in the Early Writings of Katherine Mansfield' (pp. 82-99).

Gerardo Rodríguez-Salas's " "I am just as much dead as he is": Community, Finitude and Sibling Intimacy in Katherine Mansfield' (Atlantis 38:ii[2016] 63-82) canvasses the varied depictions of intimacy and death in selected short stories. Kirsty Martin's 'Modernism and the Medicalization of Sunlight: D.H. Lawrence, Katherine Mansfield, and the Sun Cure' (Mo/Mo 23:ii[2016] 423-41) explores how a venerable belief that exposure to sunlight reshapes our affective register was eagerly debated in the early years of the twentieth century. Martin's lively discussion throws into bolder relief the "medicalization of sunlight' (p. 63) and how heliotherapy features in visual and verbal texts from this period. Martin's insights harmonize with those interdisciplinary perspectives that not only weigh the social, historical, and cultural dimensions of medicine, but also pay closer attention to tropes of the 'healthy body' in interwar British fiction. Mansfield also features as a useful case study by Julie W. de Sherbinin, 'Chekhov and the Anglophone Short Story' (in Finke and Holquist, eds., Approaches to Teaching the Works of Anton Chekhov pp. 34-40). Other searching contributions to Mansfield scholarship in 2016 include Isobel Maddison's 'Complementary Cousins: Constructing the Maternal in the Writing of Elizabeth von Arnim and Katherine Mansfield' (in Ehland and Wächter, eds., Middlebrow and Gender, 1890-1945, pp. 79-98), and Annabelle Lukin and Adriana Pagano's 'Inner and Outer Worlds: Speech and Thought Presentation in Mansfield's Bliss' (JLS 45:ii[2016] 97-116).

Like recent research on Mansfield's elaborate textual strategies, Rebecca Bowler's Literary Impressionism: Vision and Memory in Dorothy Richardson, Ford Madox Ford, H.D. and May Sinclair says much about the sciences of memory, affect, and visual perception. Bowler contends that early 
twentieth-century innovations in the visual arts, cinema, and photography triggered 'a crisis in the relationship between what was seen and what was known' (pp. 3-4). Literary Impressionism chronicles this modernist crisis of perception and describes how Richardson, Ford Madox Ford, and May Sinclair variously employed fresh ideas about memory in order to bring into closer kinship the powers of perception and textual representation. Bowler's project benefits from a bright readiness to explore not only literature as a memorial medium, but also how these prolific literary impressionists made forays into mainstream and radical journalism, as well as manifesto writing and diaries.

Edited by Rebecca Bowler and Claire Drewery, May Sinclair: Re-thinking Bodies and Minds tackles the full range of Sinclair's literary output, including cultural criticism, stringent philosophical enquiry, poetry, psychoanalysis, and experimental fiction. Contributors ask why this formally ambitious author and eloquent public intellectual, whose work chronicles in granular detail diverse modes of corporeality and mindedness, sensory experience and mentation, 'falls between the established categories of literary modernism' (p. 4). This is an issue that Suzanne Raitt explores in "Dying to live": Remembering and Forgetting May Sinclair' (pp. 21-38). Elise Thornton contributes a fine chapter on 'Learning Greek: The Woman Artist as Autodidact in May Sinclair's Mary Olivier: A Life' (pp. 39-58). Other notable contributions to this crisply organized and coherent volume include Emma Liggins's " "Odd how the War changes us": May Sinclair and Women's War Work' (pp. 194-212); Faye Pickrem's 'Disembodying Desire: Ontological Fantasy, Libidinal Anxiety, and the Erotics of Renunciation in May Sinclair' (pp. 11938); and Charlotte Beyer's 'Dolls and Dead Babies: Victorian Motherhood in May Sinclair's Life and Death of Harriett Frean' (pp. 156-76).

Jen-yi Hsu's 'Beautiful Losers: Queer Utopianism and the Politics of Failure in Sylvia Townsend Warner's Mr. Fortune's Maggot and Summer Will Show' (NTU 36[2016] 71-100) explores Townsend Warner's remarkable colonial critique, Mr Fortune's Maggot [1927], and its textual tropes, which mingle exotic otherness, the fantastic, the queer, and the utopian. That 'politics' is foregrounded by the title of this essay is a salutary reminder of Townsend Warner's abiding concern with the complex and clandestine workings of ideology in diurnal mundane life. Hsu's discerning thesis reflects Warner's often overlooked significance for academic studies of interwar modernism and its informal and official networking clusters, colonial politics, and gendered subjectivity.

E.M. Forster scholarship in 2016 also scrutinized his narrative practice in relation to the often pernicious fictions of empire. Maryam Wasif Khan's 'Enlightenment Orientalism to Modernist Orientalism: The Archive of Forster's A Passage to India' (MFS 62:ii[2016] 217-35) construes Forster's A Passage to India as a vivid 'example of modernist Orientalism' (p. 217), that draws signal inspiration from works such as Fay's Original Letters from India and Gibbes's Hartly House, Calcutta. Khan concludes that A Passage does not strive to resolve intractable questions of gender inequality and empire. Rather Forster broods over and recalibrates the exact 'place of the bourgeois woman to the metropolis by way of the colony' (p. 217). 
Gemma Moss's 'Music in E.M. Forster's A Room with a View and Howards End: The Conflicting Presentation of Nineteenth-Century Aesthetics' (ELT 59:iv[2016] 493-509) details how Forster's characters experience Beethoven in different ways. This engaging article should be read alongside Michelle Fillion's Difficult Rhythm: Music and the Word in E.M. Forster [2010], which addresses Forster's abiding preoccupation with the politics of music, and explores how his myriad musical tropes, allusions, and references offer striking insight into Forster's ideas about imperialism, national temperament, class and camaraderie, sexual and romantic relationships, pacifism, and heroism. Moss's contribution assesses and affirms the arresting ways in which Forster's narratives and musical motifs interact to fashion complex semantic resonances. Moss is particularly shrewd when positioning $A$ Room with a View and Howards End as cryptic commentaries on rival conceptions of what music signifies to different audiences and cultural groups. Moss prompts us to view Adorno's writing on Beethoven and Mahler as a means of understanding music as a locus of tension, ambiguity, and fracture in Forster's narrative practice.

Ted Howell's 'An Imperialist Inherits the Earth: Howards End in the Anthropocene', (MLQ 77:iv[2016] 547-72) focuses well on the apocalyptic tropes in Forster's novel. 'Anthropocene' is a useful term for Howell, because it not only directs us to a geological age shaped by the interests of global capitalism, but is synonymous with a cluster of sociopolitical, ontological, and theological notions that colour our perception of tangible localities and the human impact upon them. Howell discusses not only how Forster's textual strategies confront critical issues of urban sprawl and environmental decay, but also how the conscious disruption of traditional narrative techniques mirrors and embraces a strikingly different conception of the nation-state, one attuned to deeply ethical questions about responsibly depicting 'the singularity of the other' (pp. 547-8). Howell's lucid and learned essay is a helpful reminder that aesthetic modernism, while addressing the elliptical rhythms of human consciousness - to the point of solipsistic self-indulgence - also grapples with mysteries of the non-human, representations of numinous pre-Christian sites, and indigenous wisdom. Howell's essay is a timely and trenchant intervention, given that recent Forster scholars are paying close attention to his ecological tropes. And, as Kelly Sultzbach contends in Ecocriticism in the Modernist Imagination: Forster, Woolf, and Auden, 'the notion of modernity ... suffers from a narrative that oversimplifies its "patterns of constant change" and fluctuation by relegating it to a singular movement away from one end of the binary, a Romantic foregrounding of organic nature, toward its opposite, the rise of an urban culture of detached aestheticism' (p. 4).

Mark Hopwood's 'Only Connect: Moral Judgment, Embodiment, and Hypocrisy in Howards End' ( $P \& L$ 40:ii[2016] 399-414) rightly notes that the overwhelming bulk of critical analyses of Forster's Howards End alights upon the resonant epigraph, 'Only connect...' without explicating how we are supposed to construe it. Hopwood supplies a lively and persuasive interpretation of the epigraph, one in which the desire to connect is anchored in a layered recognition of one's own embodied experience and affective register. 
Rudyard Kipling's Kim features in David Damrosch's 'A Sinister Chuckle: Sherlock in Tibet' (in Nilsson, Damrosch, and D'haen, eds., Crime Fiction as World Literature, pp. 257-70), which addresses the interlinked issues of imperial misgiving, otherness, and the geographical imagination, especially the fictional mapping of Tibet. Jessica Howell's 'The Boy Doctor of Empire: Malaria and Mobility in Kipling's Kim' (L\&M 34:i[2016] 158-84) interprets Kim [1901] in relation to colonial anxieties about sickness and healing. This essay is part of a special issue on 'Literature and Bioethics'.

Harry Ricketts's 'The Persistence of Kim' (in Crane, Stafford, and Williams, eds., The World Novel in English to 1950, pp. 324-32) furnishes a patiently plotted account of Kipling's narrative tactics. Jarad Zimbler's 'Mythology, Empire, and Narrative' (in Marcus, Mendelssohn, and Shepherd-Barr, eds., Victorian into Modern, pp. 38-54) also looks at Kim in relation to Conrad's early fiction. Zimbler's contribution benefits from an editorial strategy that unites several of the most polished chapters in this volume; for example a judicious stress on Kipling's textual sophistication along with an assured grasp of extra-textual components such as 'press and publishing history, performance events and visual culture' (p. 5).

U.C. Knoepflmacher's 'Kipling's "Just-So" Partner: The Dead Child as Collaborator and Muse' (KJ 90[2016] 25-48) considers the 'Just-So' stories [1902] in relation to audience expectations. Alicia Rix's " "Disturbing Traffic": Kipling's Stories' (CritQ 58:iv[2016] 50-67) is part of a special issue on 'Traffic in Modernity'. Rix considers the complex trope of transportation as an energy that discloses a significant interplay between 'commodities, communities, and commerce' (pp. 50-1). Such interplay creates, according to Rix, a sense of the urban as a transient and nebulous site, while reinforcing its status as an unnerving seat of power and patronage because of the traffic that flows through it (p. 51).

Karen Leenders's 'Rudyard Kipling and the Indian Corps' (KJ 90[2016] 4859) analyses Kipling's striking and emotionally resonant response to the First World War in 'The Eyes of Asia' [1918], and explores how bodies matter on both the battlefront and in different 'home fronts'. Leenders posits that Kipling is especially fascinated, in 'The Eyes of Asia', by how language moulds, refines, or marginalizes embodied experience, and the essay makes a compelling case for the narrative intricacy of this text and how it raises pressing questions about the fragility of the human mind in combat.

Nasser Mufti's 'Kipling's Art of War' (NCL 70:iv[2016] 496-519) canvasses the story 'A Sahib's War' [1901] as means of gauging the 'ungentlemanly' tactics adopting both by British and Boer soldiers at the war front in the Second Anglo-Boer conflict (p. 496). As Mufti suggests, this text says much about 'the British empire's most ambitious years, when it saw Britain and its settler colonies as belonging to a global nation-state, most commonly referred to as "Greater Britain", (pp. 496-7). Mufti throws into relief Kipling's elaborate and darkly witty linguistic tactics in this story, especially his 'translingual puns' across English, Afrikaans, and Urdu/Hindi registers. Such puns underscore, Mufti concludes, the irresolvable "tensions between the intranational and extra-national, domestic and foreign, civil and imperial that characterized Greater British discourse at the turn of the century' (p. 496). 
Andrew Scragg's 'Rudyard Kipling and Shell Shock: "More than a man could bear" ' (ELT 59:ii[2016] 175-90) discusses how Kipling 'thinks with' the short story mode, using genre and figuration to dramatize shell shock, an experience that Scragg and other recent commentators specify as denoting mental trauma specific to the First World War. This article recalibrates Kipling's aesthetic response to the traumas of shell shock, focusing on four linked stories, 'In the Interests of the Brethren' and 'A Madonna of the Trenches' in Debits and Credits [1926], and 'Fairy Kist' and 'The Tender Achilles' in Limits and Renewals [1932]. Scragg shows that Kipling employs these narratives to confront and process the psychological impact of the war on men on the Western Front. What makes Scragg's account distinctive is his resolve to situate these stories against the backdrop of contemporary military, clinical, and social responses to shell shock.

Bill Phillips's 'Rudyard Kipling's War, Freemasonry and Misogyny' (in Owen and Pividori, eds., Writings of Persuasion and Dissonance in the Great War, pp. 17-30) looks at Kipling's attitude to patriotism and the nation-state in his fictional writings. Alexander Bubb's Meeting Without Knowing It: Kipling and Yeats at the Fin de Siècle also casts these concerns into bolder relief.

Rod Rosenquist's 'The Ordinary Celebrity and the Celebrated Ordinary in 1930s Modernist Memoirs' (Genre 49:iii[2016] 359-83) says much about Wyndham Lewis's authorial self-construction in the interwar period, as does Gregory Betts, Paul Hjartarson and Kristine Smitka's edited collection, Counterblasting Canada: Marshall McLuhan, Wyndham Lewis, Wilfred Watson, and Sheila Watson. In Lateness and Modern European Literature, Ben Hutchinson construes Lewis's aesthetic as a sustained engagement with the 'hollowing out' of modernism (p. 274). Erich Hertz's 'The Gender of Form and British Modernism: Rebecca West's Vorticism and Blast' (WS 45:iiv[2016] 356-69) canvasses the West short story 'Indissoluble Matrimony' and examines how it is framed by Lewis's highly charged conception of Vorticism.

Emily Hayman's "Under four eyes" (Unter vier Augen): Ford Madox Ford, Propaganda, and the Politics of Translation' (MFS 62:i[2016] 25-52) notes that the phrase 'under four eyes' appears twice in the text of Ford Madox Ford's most formally ambitious novel, The Good Soldier. This phrase prompts sustained critical reflection on the text's obsession with the processes of 'witnessing', the fragility of the impression, and competing discourses of privacy. Hayman shows that in its translation from the German idiom unter vier Augen, the phrase is revealing about Ford's radically ambivalent and slippery staging of national belonging during the First World War. Hayman's elegantly structured account should be read alongside Cristina Pividori's 'Impressions from the Front: The Crisis of the Witness in Ford Madox Ford's Parade's End' (in Owen and Pividori, eds., pp. 106-20).

Ashley Chantler and Rob Hawkes's edited collection War and the Mind: Ford Madox Ford's 'Parade's End', Modernism, and Psychology not only recognizes how 'modernist literature has long been recognized for its acute interest in psychology', it also furnishes some exceptionally resourceful readings of the authorial and emotional 'readjustments' Ford had to make in relation to the 'nerve tangle' of the Great War (p. 4). Of especial worth here is 
Karolyn Steffens's chapter on 'Freud Madox Ford: Impressionism, Psychoanalytic Trauma Theory, and Ford's Wartime Writing' (pp. 35-49); Eve Sorum's 'Empathy, Trauma, and the Space of War in Parade's End' (pp. 50-62); Charlotte Jones's 'Representing Shell Shock: A Return to Ford and Rebecca West' (pp. 127-41); and Leslie de Bont's "II hate soldiering": Ford, May Sinclair, and War Heroism' (pp. 142-58).

Andrew Thacker's "A true magic chamber": The Public Face of the Modernist Bookshop' (ModCult 11:iii[2016] 429-51) shows a commanding grasp of the nature and subtle operations of bookshops in the fashioning of an eager public for aesthetic modernism. Thacker demonstrates a deep knowledge of the bookshops synonymous with efforts to promote the formal innovations of modernist culture, for example Sylvia Beach's Shakespeare and Company, Adrienne Monnier's La Maison des Amis des Livres, and Frances Steloff's Gotham Book Mart.

John Nash's 'Arnold Bennett and Home Management: Domestic Efficiency' (ELT 59:ii[2016] 210-33) foregrounds Bennett's statement that 'Domesticity is inescapable', and how this novelist rendered, in often searching detail, household rituals, rhythms, and encounters. Yet Nash is correct to posit that the precise contours of Bennett's abiding engagement with domestic spaces and issues has not been thoroughly elucidated and contextualized. This article shows that Bennett's fiction goes well beyond the mere chronicle of domestic dramas or recesses.

Brian Hudson's 'Arnold Bennett's Literary Journey into World War I Transport' (ELT 59:i[2016] 87-98) reveals how Bennett did not only engage with wartime experiences in works such as The Roll-Call [1918] and Lord Raingo [1926], but also in a frequently overlooked travelogue, Over There: War Scenes on the Western Front [1915]. Hudson's signal achievement in this article is to show how acutely and precisely Bennett documented 'the largescale use of technologically advanced weaponry and the development of a range of vehicles designed for war' (p. 87).

Michael Shallcross's 'G.K. Chesterton's Assimilation of Fin-de-Siècle Voices in The Man Who Was Thursday: The Dialogic Sensibility' (ELT 59:iii[2016] 320-43) makes a convincing and highly readable case for how G.K. Chesterton's The Man Who Was Thursday [1908] absorbs and interrogates a diverse array of generic strategies and devices, from Victorian nonsense fiction to Decadence and vernacular archives, including 'the nursery rhyme and folktale' (p. 320). Shallcross is especially astute in his assessment of how Chesterton's complex endeavour to find his own authorial voice necessitates the imaginative excavation of admired literary predecessors, such as Lewis Carroll and Oscar Wilde.

Don Adams's 'Somerset Maugham's Ethically Earnest Fiction' ( $C Q$ 45:i[2016] 42-67) and Daniel Blackburn and Alexander Arsov's 'Somerset Maugham's Apocryphal "Second-Rate" Status: Setting the Record Straight' (ELT 59:ii[2016] 139-52) variously ponder Maugham's uncertain place in recent studies of twentieth-century British fiction. These essays are especially useful in detailing the precise nature of Maugham's literary legacy, and how this most prolific, generically versatile, and popular author has been misread or underestimated by modernist commentators. Wendy Gan's 'The Painted 
Veil: Re-inventing the Colonial Woman and the Hinterland Narrative' (in Ehland and Wächter, eds., pp. 187-201) scrutinizes Maugham's On a Chinese Screen [1922] and The Painted Veil [1925] in terms of his treatment of gendered subjectivity against a backdrop of European imperialism. Also relevant in this regard is Tamara Wagner's 'The Novel in English in Malaya and Singapore to 1950' (in Crane et al., eds., pp. 73-90), which surveys selected narratives by Maugham and Conrad.

Like Sam Wiseman's The Reimagining of Place in English Modernism [2015] and Jeffrey Mathes McCarthy's Green Modernism [2015], Chris Campbell's 'Glancing Backwards: George Lamming, John Cowper Powys and Vexed Visions of Labour in the Capitalist World-Ecology' (GreenL 20:ii[2016] 17082 ) is interested in expanding the disciplinary and national boundaries of intermodernist scholarship. Campbell gauges Powys's interwar fiction in terms of its commentary on environmental crisis and bitter class struggle. This probing contribution to Powys scholarship will cheer eco-critics who focus on how British interwar fiction depicts and describes utopian or bucolic hinterlands as spaces to critique the globalized inequality that is synonymous with advanced capitalism.

Gabriel Lovatt's 'From Experiment to Epidemic: Embodiment in the Decadent Modernism of Arthur Machen's The Great God Pan and The Inmost Light' (Mosaic 49:i[2016] 19-35) argues that in Machen's Decadent horror texts 'contagion' becomes a modern form of transmutation that aggressively subverts 'Cartesian dualism' (pp. 19-20). Lovatt's intelligent discussion should be read alongside Ilse Bussing's 'Complicit Bodies: Excessive Sensibilities and Haunted Space' (Horror Studies 7:i[2016] 41-59).

Nidesh Lawtoo's 'Conrad's Neuroplasticity' (Mo/Mo 23:iv[2016] 771-88) locates textual complexities in even the most canonical and frequently taught narratives by Joseph Conrad. Avram Alpert's stylish essay, 'Empires of Enlightenment: On Illumination and the Politics of Buddhism in Heart of Darkness' (JML 40:ii[2016] 1-21), reminds us that, in the frame story of Heart of Darkness, Marlow is compared on a number of crucial occasions to 'a meditating Buddha' (p. 1). Critics have in the recent past steered towards a philosophical analysis of these curious tropes, but Alpert offers a more nuanced sense of how such links and comparisons reflect ominously upon the tangled politics of colonial governance (p. 3).

Katherine Baxter's " "Senseless Speech" and Inaudibility in Conrad's Amy Foster: Rethinking Trauma and the Unspeakable in Fiction' (TPr 30:v[2016] 879-95) revisits the trope of the 'unspeakable' in representations of trauma in order to put conceptual pressure on traditional readings from literary trauma theory. Employing Conrad's short story 'Amy Foster' as an illustrative instance, Baxter posits that trauma is triggered by the failure or collapse of 'speech itself' (p. 879) and invokes Derrida's Monolingualism of the Other; or, The Prosthesis of Origin, to scrutinize the ramifications of silence, silencing, and the inaudible in Conrad's narrative practice.

Lorenzo Servitje's “"Triumphant Health": Joseph Conrad and Tropical Medicine' (L\&M 34:i[2016] 132-57) registers that Heart of Darkness is 'plagued' by vivid, even lurid, figurations of 'sickness' which reveal not only ailing human bodies but also an infected body politic (pp. 132-3). From the 
outset, Servitje is preoccupied by Conrad's brooding emphasis on the 'sensory regime of pain' at a time of environmental poisoning and seismic political ferment (p. 134).

Katherine Baxter and Robert Hampson's edited collection Conrad and Language weighs how the trilingual Conrad, fluent in Polish, French, and English, exploited the semantic and cultural resonances of a dizzying array of registers, including maritime argot, the disturbing slogans of terror, and abstract, pseudo-scientific terminologies. This volume throws into sharper relief Conrad's often slyly sardonic and pointed deployment of foreign languages, as well as the implications of his resolve to write and publish in English. Contributors also ponder his reception through translation. Andrew Glazzard's 'Navigating the "Terroristic Wilderness": Conrad's Language of Terror' (pp. 28-43) focuses on that term from the political lexicon which is used frequently nowadays in the print and broadcast media. Glazzard explains that the word 'terrorist', while being a familiar label, is also peculiarly problematic when viewed in relation to Conrad's textual trajectories. In " "Soundless as shadows": Language and Disability in the Political Novels" (pp. 99-116), Katherine Baxter takes the deafening of Razumov in Under Western Eyes as her starting point. At the end of the novel's penultimate chapter Nikita exclaims 'He [Razumov] shall never be any use as a spy on any one. He won't talk, because he will never hear anything'. Baxter argues that the 'synaesthesic logic' of Nikita's claim, in which seeing ('spy') and speaking are quashed through deafness, prompts us to gauge the complex links between verbal articulation, hearing, insurgency, and disability in the political fiction (pp. 99-100). Claude Maisonnat's contribution, 'Gallicisms: The Secret Agent in Conrad's Prose' (pp. 151-67), reappraises the macaronic dimension of Conrad's narratives.

John G. Peters's 'Joseph Conrad and the Epistemology of Space' ( $P \& L$ 40:i[2016] 98-123) supplies a methodically plotted account of Conrad's distinctive conception of material space. Peters also provides a useful 'Bibliography of Books, Pamphlets, and Broadsides about Joseph Conrad' (Conradian 41:ii[2016] 151-6). Other worthwhile contributions this year include Owen Knowles's 'Three New Conrad Letters, 1919-23' (Conradian 41:ii[2016] 84-8); Remy Arab-Fuentes's “"Think of us ... of us ... of us!": The First-Person-Plural Hauntology in Conrad's Fiction' (Conradian 41:ii[2016] 47-62); Gene M. Moore's 'History and Legend in "The Duel", (Conradian 41:ii[2016] 28-46); Jennifer A. Janechek's 'The Horror of the Primal Sound: Proto-Telephony and Imperialism in Heart of Darkness' (Conradian 41:ii[2016] 8-27); and David Mason's 'Man of Action, Man of Letters' (HudR 69:ii[2016] 197-205). Emily Ennis's 'Conrad Writing Photography: Authenticity and Identity in The Inheritors and "The Black Mate" ' (Conradian 41:i[2016] 32-52) probes anxieties about self-perception in The Inheritors [1901].

Queer Bloomsbury, edited by Brenda Helt and Madelyn Detloff, presents a number of compellingly readable essays that helped establish queer studies of the Bloomsbury Group together with engaging new interventions that extend or nuance this influential research. For aficionados of E.M. Forster's work, George Piggford's 'Camp Sites: Forster and the Biographies of Queer Bloomsbury' (pp. 64-88) appraises the 'queerness' of Forster's biographical 
narratives, especially its 'campy tendencies, present in early experiments', though 'all but extinguished by the time he published Marianne Thornton (1956)' (p. 64). Jodie Medd's ' "I didn't know there could be such writing”: The Aesthetic Intimacy of E.M. Forster and T.E. Lawrence' (pp. 258-75) examines not only Forster's 'relationship with Lawrence', but also 'many of the questions that crowd around the idea of queer Bloomsbury and its relation to cultural production' (p. 259).

Vincent Trott's " "The market is getting flooded with them": Richard Aldington's Death of a Hero and the War Books Boom' (in Wilson, ed., The Book World: Selling and Distributing British Literature, 1900-1940, pp. 95116) focuses on Aldington's acclaimed war novel in relation to publishing history.

Victoria Margree's 'Metanarratives of Authorship in Fin-de-Siècle Popular Fiction: "Is that all you do, write stories?" ' (ELT 59:iii[2016] 362-89) employs Richard Marsh's novel A Duel [1904] to analyse the 'question of professional authorship at the fin de siècle', from the perspectives of Marsh and Guy Boothby. As Margree sets out with emphatic assurance, both writers 'captured the public imagination with stories of crime, adventure and the supernatural that helped shape the emerging genres of popular fiction' (pp. 362-3).

Angela Fowler's 'Arthur Conan Doyle's Spiritualist British Commonwealth: "The great unifying force" (ELT 59:iv[2016] 456-72) reminds us that Conan Doyle's post-First World War literary career 'becomes more focused on spiritualism', as well 'increasingly global' in scope, his overseas lecture tours foregrounding 'his global concerns' (p. 456). Conan Doyle's marked stress is, according to Fowler, 'not just on the veracity of psychic phenomena but on spiritualism as an avenue of forming a global community, both on earth and on the "other side", where people keep their own identities, but identities are unifying, not divisive' (pp. 456-7).

Douglas Kerr's 'Conan Doyle's Challenger Tales and the End of the World' (ELT 59:i[2016] 3-24) proposes that science and spiritualism were 'practices and discourses and ideologies' that were by no means antagonistic to Conan Doyle. Indeed, he 'insisted [such activities] regularly and radically grappled with beginnings and endings in the shape of questions about origins, survival, and extinction' (p. 3). These 'questions' resonate powerfully through the Challenger narratives, such as 'The Lost World' [1912], 'The Poison Belt' [1913], and 'The Land of Mist' [1926].

Chapter 6 of K.D.M. Snell's Spirits of Community: English Senses of Belonging and Loss, 1750-2000 examines 'Weeding Out Village Life: Detective Fiction and Murderous Community' (pp. 129-58). Snell is insightful regarding the fiction of G.K. Chesterton, Agatha Christie, and Dorothy L. Sayers, as well as Arthur Conan Doyle, who was publishing Sherlock Holmes stories until 1927, as Jonathan Cranfield notes in Twentieth-Century Victorian: Arthur Conan Doyle and the 'Strand Magazine', 1891-1930. Snell is alert to how interwar women writers such as Sheila Kaye-Smith test or subvert the reader's affective and generic expectations. Kaye-Smith's The End of the House of Alard [1923] addresses the 'country house' trope, which also resonates through more formally avant-garde texts such as Mary Butts's first published novel Ashe of Rings [1925], and Pastors and Masters [1925] by the defiantly 
unsentimental Ivy-Compton Burnett. Barbara Hardy's book-length study Ivy Compton-Burnett reveals how many of this stubbornly strange and stylistically austere author's interwar texts return to a generalized late Victorian English country mansion as a locus where galling memories crystallize around the quirks of a petty domestic tyrant.

Compton-Burnett features in Patricia Waugh's eloquent and wide-ranging chapter 'Precarious Voices: Moderns, Moods, and Moving Epochs' (in Bradshaw, Marcus and Roach, eds., Moving Modernisms: Motion, Technology, and Modernity, pp. 191-216). Waugh's stress on 'moving epochs' furnishes a searching 'critique of literary periodization and of approaches to modernist literature and culture which have rendered the rich and complex novels' of the interwar years mere footnotes to the muchgarlanded works of so-called high modernism (p. 191). Waugh's chapter prompts us to reconsider formally ambitious authors such as Mary Butts and John Cowper Powys, whose fictions deploy complex romance and regional tropes that seemed wilfully out of step with the aesthetic conventions of their era. As Waugh demonstrates, 'periodizing terms have served' such writers poorly, leaving them 'capsized in a dead sea of default realism' (p. 194).

Finally, Adrian Hunter's 'The Rise of Short Fiction' (in Marcus, Mendelssohn, and Shepherd-Barr, eds., pp. 204-17) focuses on the literary career of George Egerton. And Lisa Stead's Off to the Pictures: Cinemagoing, Women's Writing and Movie Culture in Interwar Britain examines the writings of Elinor Glyn, as does Molly Youngkin's British Women Writers and the Reception of Ancient Egypt, 1840-1910: Imperialist Representations of Egyptian Women.

\section{(b) British Fiction 1930-1945}

This year saw a number of studies reconsidering the period variously known as late modernism and the mid-century. Emily Bloom's The Wireless Past: AngloIrish Writers and the $B B C, 1931-1968$, which won the Modernist Studies Association book prize, explores the political and aesthetic dimensions of radio, particularly the effect of radio's influence on twentieth-century literature. With chapters on W.B. Yeats, Louis MacNeice, Elizabeth Bowen, and Samuel Beckett, Bloom argues that the new medium of radio created a tension between past and future as these writers experimented with new technology of radio while also re-examining the literary past. In chapter 3, which focuses on the work of Elizabeth Bowen, Bloom creates a conceptual link between broadcasting and the novel, arguing that Bowen takes a 'radiogenic approach to literary history' (p. 94). Bloom finds that Bowen's dedication to the present and resistance to nostalgia are strengthened by her experience of work in radio broadcasting. Bowen's experience of the radio influenced her concept of the novel, resulting in her greater valuing of the 'now' about fiction. Bowen's interest in the occult was also shaped by the new medium of the radio, as was her thinking about the Gothic in her later fiction.

Emily Cuming's Housing Class and Gender Modern British Writing 18801920 also examines the literature of the home front with a focus on housing. 
Chapter 2, 'Boarding and Lodging Houses: At Home with Strangers', reads Patrick Hamilton's The Slaves of Solitude in the context of wartime and postwar urban boarding houses. Hamilton's wartime domestic spaces, Cuming claims, represent a microcosm of the nation at war. His unheroic and unproductive minor characters engage in strife and class warfare. Cuming's chapter also reads The Slaves of Solitude as upending traditional notions of gender. Cuming argues that the narrative disrupts the seemingly heteronormative social arrangements of the boarding house. Drawing on the theories of René Girard and Eve Kosofsky Sedgwick, she finds that the novel's triangular love narrative between Miss Roach, the American lieutenant, and Vicki in fact 'articulates latent sexual desire between the two women' (p. 95).

Jonathan Greenberg and Nathan Waddell's edited collection Brave New World: Contexts and Legacies brings together a range of essays that examine the ambivalence of Huxley's narrative. The editors explain in their introductory chapter that the novel has alternately been read as satire and as a revelation of the author's views. They propose to examine the contradictions inherent in the novel as well as its anachronisms in order to situate it in the context of its production since, they argue, the contexts and legacies of the novel have been under-studied. Subsequent contributions take up questions about dystopia and utopia, the anthropocene, John Dewey's influence on Huxley's ideas about education, questions of reproduction and eugenics, and state power.

Michael G. Brennan's Graham Greene: Political Writer centres on the political dimensions of Greene's work, reading Greene in the context of his shifting political convictions and his espionage work. Brennan argues that, whereas there exists a substantial body of critical literature about Greene's religious influences, less is understood about his political commitments. Brennan's study illuminates Greene's work by reading it alongside his correspondence and drafts of his novels, as well as his journalism. Chapter 2 reads Stamboul Train [1932] and England Made Me [1935] alongside his travelogues and his work in espionage, whereas chapter 3 turns to Greene's preoccupation with provincial English cities in Brighton Rock [1938]. Chapter 4 concerns Greene's intelligence work for MI6 (where he worked alongside Kim Philby) as well as his preoccupation with corruption, and with the tensions between communism and Catholicism, in The Power and the Glory [1940].

Naomi Milthorpe's Evelyn Waugh's Satires: Texts and Contexts examines Waugh's late modernist satirical fiction published between 1928 and 1963. As Milthorpe points out in her introductory chapter, Waugh's satirical novels from this period 'are exemplary of the particular affective movement of both literary late modernism and literary satire in the twentieth century' (p. 2). Moving away from biographical criticism, Milthorpe instead pays attention to the targets of Waugh's satires as well as to his techniques. The book situates Waugh's satirical language not only in the literary history of satire, but also in the context of modernism and late modernism. Waugh's language, a mix of 'ornate phraseology and slang' (p. 4), according to Milthorpe, creates narrative detachment while still targeting the social and political ills of the interwar period. 
Peter Boxall and Bryan Cheyette's volume of The Oxford History of the Novel in English, covering British and Irish Fiction since 1940, brings together essays on the modern and contemporary novel. The collection is divided into two major sections, the first covering the period from 1940 to 1973 and the second from 1973 to the present. Andrew Nash's essay, 'The Material History of the Novel' (pp. 21-36), looks at the impact of the publishing market on writers during and after the war, pointing out that despite paper shortages, writers such as Graham Greene and Elizabeth Bowen found employment in government agencies and continued to write. He also discusses the rise of publishing companies such as Penguin, the impact of the American market on British writers, and the rise of cinema. Lara Feigel's chapter, 'Fiction During the Second World War' (pp. 37-52), joins recent studies by Marina MacKay, Adam Piette, Lyndsey Stonebridge, and Petra Rau in arguing that the war had a marked impact on literary production and periodization. Feigel focuses on the literature of the home front to show that the war was 'often [as] exhilarating, as it was enervating or degrading' (p. 38) for writers such as Patrick Hamilton, Henry Green, Graham Greene, and Elizabeth Bowen. In his chapter 'The Question of Evil in Post-War British Fiction' (pp. 53-63), Robert Eaglestone explores how writers such as J.R.R. Tolkien and his contemporaries adapted literary genres to represent evil. Using Hannah Arendt's conceptualization of evil, Eaglestone points out that, in Tolkien's fiction in particular, post-war evil is represented as a form of invisibility.

The growing body of critical literature reassessing the post-Second World War period continued to develop this year, with the publication of Long Shadows: The Second World War in British Fiction and Film, a collection edited by Petra Rau in the series Cultural Expressions of World War II: Preludes, Responses, Memory. In the introductory chapter, Rau explains that the volume examines 'how the war has been interpreted and remembered; what is at stake is the way in which the war has been emplotted as a hegemonic cultural narrative about Britain' (p. 4). Taken together, the diverse range of essays attests to the ongoing project of coming to terms with the aftermath of the conflict and its enduring geopolitical effects. The collection includes Eluned Summers-Bremner's " Drinking and drinking and screaming": Wartime Sociality in Patrick Hamilton's The Slaves of Solitude' (pp. 81101), which considers domestic hatred and hidden violence among boarders living in temporary housing in the context of Mass Observation diaries.

Around 1945: Literature, Citizenship, Rights, edited by Allan Hepburn, also considers the longue durée of the war after its official conclusion. The collection brings together essays about the mid-century preoccupation with human rights. Mitchell C. Brown's 'Human Rights and Postwar Internationalism in The Third Man' (pp. 197-215) takes up Graham Greene's novel in the context of a developing discourse of humanitarianism as articulated by institutions such as the United Nations. In Brown's reading of Greene's novel, rogues and refugees are both victimized in post-war Vienna.

A special forum in Modernism/Modernity, 'Camp Modernism', featured Chris Freedman's 'Christopher Isherwood and the Limits of Camp' (Mo/Mo 24:i[2016] 14-17), which argues that in Goodbye to Berlin [1939] and Berlin Stories [1945] Isherwood represents camp against the background of Weimar 
Germany. The playfulness of camp, Freedman argues, cannot withstand the seriousness and violence of emerging Nazism in Berlin.

Jay Clayton's 'The Modern Synthesis' (Mo/Mo 24:iv[2016] 875-96) argues for the importance of satire in our understanding of Huxley's representation of genetics in Brave New World. Historically, the 'modern synthesis' refers to the philosophical position, prevalent in the interwar period, which brought together Darwinian evolution and genetics. Huxley's novel, Clayton argues, also has to be understood as creating a generic synthesis of dystopia and naturalism.

Faye Hammill's 'Noël Coward, Rebecca West, and the Modernist Scene' (ModCult 11:iii[2016] 351-69) examines Rebecca West's and Noël Coward's social connections, which developed both in print and through 'the social scene of modernism' (p. 353), that is, through the social events and parties that created literary networks. Both Coward and West garnered social capital through their celebrity, but a closer look at their interactions in periodicals, as well as in the diaries, memoirs, and essays of their contemporaries, reveals very different and competing ideas about aesthetic value which in turn underlines important ambiguities about modernism.

A number of new articles on the fiction of Jean Rhys came out this year. Lauren Elkin's 'Getting the Story Across: Jean Rhys's Paranoid Narrative' (JNT 46:i[2016] 70-96) examines the phenomenon of paranoia in Rhys's fiction and argues that paranoia constitutes a rhetorical mode for Rhys, rather than a psychological condition of her characters. In contrast to other recent criticism, Elkin's article suggests that Rhys's fiction is in fact autobiographical, insofar as her female characters share Rhys's experience of marginalization. Their paranoia manifests itself as a desire for knowledge, Elkin shows, and structures characters' movements in urban spaces.

Lauren Rosenblum's 'Photography and Gender in Voyage in the Dark and Quartet' (SpBLC 12[2016] n.p.) argues that Rhys's fiction was influenced by the advent of photography and that Rhys's marginalized characters engage in photographic self-fashioning. Discussing Rhys's Quartet [1928] and Voyage in the Dark [1934] alongside Eugene Atget's images of ordinary Paris storefronts, Rosenblum finds that female characters in Rhys's novels fashion a uniformity and become consumers of their own images.

Finally, Sophie Oliver's 'Fashion in Jean Rhys/Jean Rhys in Fashion.' (ModCult 11:iii[2016] 312-30) examines the reception of Rhys's interwar fiction from the point of view of the 1960s and 1970s, when Rhys's work became fashionable through the popular medium of television, as well as through Rhys's own presence in fashion magazines.

\section{(c) James Joyce}

Genetic criticism continues to illuminate the creation of the Joycean text. In 2016 scholars attended especially to the interactive process of creation, centring on cognitive approaches to the text, intertextuality and exogenesis, and the materiality of the word. The mapping of the mind as it is materialized on the page is the subject of Dirk Van Hulle's James Joyce's 'Work in 
Progress': Pre-Book Publications of Finnegans Wake Fragments. Part of Van Hulle's wider project of fusing genetic criticism with cognitive philosophy (utilizing Mark Rowlands's distinction of the Embodied, Embedded, Enactive, and Extended mind), it uses the theory of the Extended mind in conjunction with genetic analysis to chart the development of 'Work in Progress' as a psychic process traceable in the archive. Encompassing three levels of extension - the fictional characters' minds, those of the reviewers, and that of the material matter surrounding Joyce-Van Hulle demonstrates how the mind is embodied on the level of the text, its reception and its production (pp. 6-8). Accordingly, Part I traces the publication history of 'Work in Progress' between Ulysses and Finnegans Wake, in their earliest formulations, the pirated Roth fragments, and those in transition, whereas Part II is devoted to 'Work in Press', the separate publication of instalments as they appeared in the small presses. The book contains rich appendices of the publication history, the place of the fragments in relation to the Wake, and the textual variants between the two. Ultimately, Van Hulle displays how "the workings of Joyce's extended mind served as a model of the mind as evoked in "Work in Progress" explicitly includes the interaction with notebooks and drafts, with the cultural and material circumstances of the production process, the publication history and the immediate reception' (p. 203).

The spring 2016 issue of the online Genetic Joyce Studies focuses on Joyce's note-taking, and particularly on a Scandinavian excavation of the same. Viviana Braslasu and Robbert-Jan Henkes offer two articles on the subject: "How the "Offsprout of Vikings" Went "East-Viking": Joyce's Notes on A. Mawer's The Vikings' (GJS 16[2016] 1-26) details Mawer's influence on the Wake, while 'The "meanderthalltale" of the Scandinavian Kingdom of Dublin in Joyce's Notetaking' (GJS 16[2016] 1-65) notes in turn the influence of Charles Haliday on notebook VI.B.29. Braslasu contributes a further cowritten piece, with Geert Lernout, 'Dublin, Norwegians, Anglo-Saxons, Danes, Tristram and Medieval Nuns in Notebook VI.B.18' (GJS 16[2016] 1$65)$, which traces the manifold sources and constellations of interest comprising the constitution of VI.B.18. Further articles in the issue concentrate on textual ephemera: Scarlett Baron's 'In Pursuit of Fact: Joyce and Flaubert's Documentary Letter-Writing' (GJS 16[2016] 1-65) argues for a 'documentary passion' (p. 1) in both writers, manifesting as a concern, as expressed in their letter-writing, with historical accuracy in their respective corpuses. William S. Brockman addresses this passion for the documentary in another fashion, elaborating on the importance of the newspaper clipping in 'Press Cutting: "From Noise about Joyce" to "Tress Clippings", (GJS 16[2016] 1-7), while Dipanjan Maitra asks what the study of Joyce's notebook from a single, though incendiary, year might tell us of his political views on Ireland and Britain in 'Of Contorted Politics: A Note on the VIII.A Notebooks of 1916' (GJS 16[2016] 1-10). Continuing the excavation of external sources in 'The Virtual Bookcases of James Joyce and Samuel Beckett' (Quarendo 46:ii-iii[2016] 192-204), Van Hulle interrogates to what extent genetic criticism might offer insight to library studies, vis-à-vis the possibility of recreating the virtual libraries of Joyce and Beckett and, in the process, of creating a library history from the digitization process. 
The theme of 'exogenesis' is also the guiding principle of the twenty-fifth volume in the European Joyce Studies series, New Quotatoes: Exogenesis in the Digital Age, edited by Ronan Crowley and Van Hulle. This collection of fourteen essays in genetic criticism makes textual connections between the Joycean archive and its sources, but also progresses important broader trends, including studies on note-taking, cognitive theory, and digital scholarship. The volume comprises, inter alia, Daniel Ferrer on trivia and reconstructing the Joycean library in 'A Library of Indistinction' (pp. 11-17); Scarlett Baron on the letter unit in 'Joyce and the Rhythms of the Alphabet' (pp. 18-44); Ronan Crowley on source-tracing for Portrait in "Human pages, human fingers": Stephen's Schoolbooks in a Portrait' (pp. 66-74); and John Simpson on Joyce and the $O E D$, "“And words. They are not in my dictionary": James Joyce and the $O E D^{\prime}$ ' (pp. 45-65). It includes three works on 'Oxen of the Sun' and Joyce's composition practices, by Luca Crispi ('The Notescape of Ulysses', pp. 75-87), Sarah Davison, who writes on Defoe in "The true-born Englishman" and the Irish Bull: Daniel Defoe in the "Oxen of the Sun" Episode of Ulysses' (pp. 111-40), and Chrissie Van Mierlo on 'Joyce and Malory: A Language in Transition' (pp. 88-110); and a further essay, by Wim Van Mierlo, tapping the modernist middlebrow, 'James Joyce and the Middlebrow' (pp. 141-62). The final essays are on genetic studies and the Wake, tracing writing processes and sources and focusing especially on the cognitive concept of exogenesis as a theoretical framework for the text. They include 'A Secretful of Sources, or More Books at the Wake' (pp. 201-12) by Robbert-Jan Henkes, 'An ActionOriented Approach to James Joyce's Reading Notes’ (pp. 213-25) by Tom de Keyser, and a discussion of the Antwerp digitization project, 'A James Joyce Digital Library' (pp. 226-42) by Dirk van Hulle. This is one of two European Joyce Studies volumes from Brill in 2016, the other being A Long the Krommerun: Selected Papers from the Utrecht James Joyce Symposium, edited by Onno Kosters, Tim Conley, and Peter de Voogd. Contributors include David Spurr and Catherine Flynn on De Stijl; Austin Briggs on male domestic spatiality in Joyce and Defoe; So Onose, Stephanie Boland, Boriana Alexandrova, and Maria Kager on Joycean language; political readings from Sam Slote and Philip Keel Geheber; and a variety of methodological approaches to Finnegans Wake by Tim Conley, Robbert-Jan Henkes, and Katherine O'Callaghan.

It was a rich and thematically diverse year for Joycean articles in the dedicated fora and wider modernist journals alike. Amongst scholarship addressing theories of affect studies and animality, the summer issue of the Journal of Modern Literature was dedicated to trauma and psychoanalysis. Two interrelated essays here speak to the persistence of psychoanalytical readings of Joyce: 'The Failure of the Parental Metaphor: A Lacanian Reading of "Eveline", (JML 39:iv[2016] 33-48), by Josephine Sharoni, argues that the Lacanian parental metaphor and the Dubliners short story are mutually illuminating. Through a close reading of 'Eveline' that postulates the story as a means of explaining the Lacanian formula, and its failure in this instance, Sharoni suggests both that the ending of 'Eveline' can be read in its light and that it can be read as a means to invest affect into Lacanian theory. In 'Her "Bisexcycle", Her Body, and Her Self-Propulsion in Finnegans Wake' 
(JML 39:iv[2016] 49-66), Julie McCormick Weng examines the feminist properties of the bicycle as it is represented in the Wake, connecting the act of female cycling to biological cycles and positing that Joyce's female cyclists represent not only the self-liberated 'New Woman' but also the artist figure. Cliff Mak hunts down the animal figures of Finnegans Wake in 'Joyce's Indifferent Animals: Boredom and the Subversion of Fables in Finnegans Wake' (ModCult 11:ii[2016] 179-205), focusing particularly on the way in which Joyce replicates the classical beast fable and subverts its moralistic message by granting authority to the animals of the Wake. Mak proposes that in doing so Joyce evinces an ethics of writing that is interrelated to literature's ethical responsibility to the figure of the animal.

Within James Joyce Quarterly, the articles published in 2016 are as usual varied in subject, methodology, and range. Poignant tributes also appeared, marking the deaths of contributors and prominent Joyceans Simon Loekle, Rosa Maria Bollettieri Bosinelli, Joseph A. Kestner, and Clive Hart. Many $J J Q$ articles ventured outside the novel this year. Jonathan Goodwin's 'Exiles in the Grey Area' (JJQ 51:ii-iii[2014] 297-316) addresses financial speculation by way of Franco Moretti, to argue for Richard Rowan as Ibsenite 'artist as failed speculator' (p. 297), while in a 'New Light on Lyric XXXVI in Joyce's Chamber Music: The Influences of Paul Gregan and James Clarence Mangan' (JJQ 51:ii-iii[2014] 455-72), Martin Connolly eschews Yeats to investigate an alternative aesthetics of nation in the final lyric of Joyce's first published collection of poetry. James Horton's 'Free Indirect Style in Joyce's Book Reviews' (JJQ 51:ii-iii[2014] 395-417) considers the 1902-3 Daily Express reviews as incubators of a nascent stylistics. Alison Lacivita's 'Trouble in Paradise: Violence and the Phoenix Park in Finnegans Wake' (JJQ 51:iiiii[2014] 317-31) locates the place of conflict in the novel through a study of the early drafts, whereas in 'Joyce's Panarchy: Time, Ecological Resistance and Finnegans Wake' (JJQ 51:ii-iii[2014] 333-52), Adam Barrows suggests an ecological temporality in the cyclical history of the Wake. Barrows meditates further on this theme in 'Modernist Panarchies: Woolf, Joyce and Rhythm', a chapter in his monograph Time, Literature and Cartography after the Spatial Turn: The Chronomatic Imaginary (pp. 59-92).

Three articles in JJQ centre on Ulysses: Julia Panko's 'Curating the Colony: Museums in Ulysses' (JJQ 51:ii-iii[2014] 353-70) imagines an alternative reconfiguration of the National Library of Ireland in the novel, and by extension an alternative Irish identity; in "Eat it and get all pigsticky": The Spinozist Body and Contagious Metaphor in "Circe", (JJQ 51:ii-iii[2014] 371-93), Rasheed Tazudeen problematizes the human-animal distinction via a reading of 'Circe' by means of Spinoza; and Jordan Brower's 'An Immodest Proposal: The Politics of the Portmanteau in Ulysses' (JJQ 51:ii-iii[2014] 43754) argues for an anti-colonial politics embedded at the level of the word, which would function to destabilize Standard English and its imperial project. Like John Simpson in New Quotatoes, Natasha Rose Chenier examines Joyce's place in the $O E D$ through "And words. They are not in my dictionary": A Lexicographical Study of James Joyce and the Oxford English Dictionary' (JJQ 51:ii-iii[2014] 419-36), suggesting that they are exemplary of shifting attitude towards modernist literature. 
In a subsequent issue of $J J Q$ James Fairhall's investigation of nature, mastery, and 'bog consciousness', 'The Bog of Allen, the Tiber River, and the Pontine Marshes: An Ecocritical Reading of "The Dead", (JJQ 51:iv[2014] 567-600), provides further evidence of continuing interest in the ecological turn within Joyce studies. Michelle McSwiggan Kelly's 'A Prompt from a Primer: A Sociolinguistic Approach to Finnegans Wake' (JJQ 51:iv[2014] 64160) links the language of the novel to gendered sociolinguistics through the model of the primer. This issue also contains a clutch of articles on Ulysses: Luke Thurston's 'Demonic Joyce' (JJQ 51:iv[2014] 601-11) reads 'Cyclops' as a site of political subjectivity and its dissolution, utilizing Ewan Fernie's concept of the 'demonic'; Susan L. Solomon's 'Inverted Commas, Unreality, and Chiasmus in "Aeolus", (JJQ 51:iv[2014] 613-30) is an Adornian interrogation of modernist realism; Jonathan Beall investigates 'Ernest Hemingway's Reading of James Joyce's Ulysses' (JJQ 51:iv[2014] 661-72) as a more profound engagement than heretofore thought; and Jonathan Bricke Rowan asks 'Who is M'Intosh?' (JJQ 51:iv[2014] 631-40) in order to venture an Odyssean answer. Alongside them is a 'revisiting' by William Baker of an interview with Richard Ellmann conducted by Peter Jackman: 'Richard Ellmann's James Joyce: An Interview Revisited' (JJQ 51:iv[2014] 673-88). Relating to this, Carl Rollyson's chapter, 'Richard Ellmann and the Advent of Ruthless Biography' in Confessions of a Serial Biographer (pp. 7-11) also expands the portrait of Joyce's great biographer.

Katherine Ryan's psychoanalytic reading of 'Milly Bloom as Blind Spot in Ulysses' (JJQ 52:i[2014] 17-35) suggests that Leopold Bloom's daughter offers a disruptive potential for traditional kinship and inheritance models. Blake Leland's " "An abode of bliss": Plumtree's Potted Meat and the Allegory of the Theologians' (JJQ 51:iv[2014] 37-53) argues for the expansion of the Plumtree's motif in the later compositional history of Ulysses, linking it to Dantean allegory in the novel. James Nikopolous's 'The Stability of Laughter in A Portrait of the Artist as a Young Man, or Quis est in malo humore ... ego aut vos?' (JJQ 51:iv 2014] 55-74) utilizes social theory of affect to analyse the tension between laughter and joy in the novel. In 'Ordovico or Viricordo: Joyce's Road from Newman to Vico' (JJQ 51:iv[2014] 75-87), John D. Schaeffer follows Joyce's philosophical trajectory, while in 'Credible Resonance, or Believable Euphony in the Joycean Oeuvre' (JJQ 51:iv[2014] 89-104) Jeffrey Simons discusses phonological resonance in a series of examples from across the works. A bibliographical article by George Monteiro on 'Reviews and Notices of James Joyce in the United States, 1916-1920' (JJQ 51:iv[2014] 105-28) and Neil R. Davison's 'With Joyce in Saint-Gérand-lePuy: Maria Jolas's “Joyce en 1939-1940” in Translation' (JJQ 51:iv[2014] 129-42) round out the scholarship in this issue.

This year heralded the fourth edition of Roland McHugh's Annotations to Finnegans Wake, which for the first time provides a synopsis of the diegesis of the Wake and bolsters its glosses through the incorporation of digital resources. Further milestones were marked as two Joyce journals had significant birthdays. Volume 15 of Hypermedia Joyce Studies marks the journal's twentieth-anniversary issue. To celebrate, $H M J$ uses a triple division. The first fittingly gives space to theoretically inclined considerations of 
genetics and hypertext, with articles by Jesse Chase on 'Illustrating TechnoPoetic-Scapes: Acousmatic Rhizomes Behind Ulysses' Text' (HMJ 15[2016]) and by Finn Fordham on 'The Writing of Growth and the Growths of Writing: A Genetic Exegesis of Finnegans Wake 503.30-505.29' (HMJ 15[2016]), supplemented by Mary Libertin's discussion of synecdoche in 'Two Planes Joined: The Turn of the Screw of Synecdoche in James Joyce and Roman Jakobson' (HMJ 15[2016]) and Fritz Senn's account of the expression of linguistic evasion in 'Logodaedalian Bypaths: Evading the Obvious' (HMJ 15[2016]). Darren Tofts offers a mediated reading of Joyce through McLuhan, in "'Where are we at all? \& whenabouts in the name of space?": Looking at McLuhan and the Media Present in Joyce Prior to the Onset of the Television Epidemic' (HMJ 15[2016]), whereas Bahman Zarrinjooee provides a disquisition on Persian language and linguistic self-reflection in 'James Joyce's Finnegans Wake: A Universal Culture' (HMJ 15[2016]). The second tranche of studies is devoted to catalogues and databases, broadly conceived, with contributions from Steven Bond, whose 'V.I.T.R.I.O.L.: Joyce's Hermetic Acronym' (HMJ 15[2016]) argues for a Joycean mysticism, and Gray KocharLindgren, who forwards a Derridean reconsideration of teletechnology and literature in 'Reading, Technology and Literature@Yes-Yes.Edu' (HMJ 15[2016]). A second article by Fritz Senn, 'Notes on Joycean Cataloguing' (HMJ 15[2016]), joins two which address Ulysses' penultimate episode, Sam Slote's 'Questioning Technology in "Ithaca", (HMJ 15[2016]) and 'A Cultured Allroundman at the University of Life: Schematic Knowledge and Self-Culture in "Ithaca", by Gregory O. Smith (HMJ 15[2016]). Where Slote examines an 'ambivalence' towards technology, Smith offers a typology of Bloom. The third section is dedicated to what its editors term 'Correspondences and Resonances'. It contains Silvia Annavini's " "Proteus": Signs and Signatures of Modern Allegory: A Portrait of the Artist as an Interpreter' (HMJ 15[2016]), on allegory and its subversive function and Louis Armand's 'James Joyce \& the Obscene Object of Post/Humanism' (HMJ 15[2016]), which problematizes the logic of posthumanism as it pertains to the humanistic. Valerie Benejam's " "Don't be talking!": Gravity, Eccentricity, and the Expanding Margin of Joycean Discourse' (HMJ 15[2016]) examines group speech as it introduces paradigms of individual and collective and of centre and margin. These are complemented by work on poetic interrelations, in David Vichnar's 'From Poetriarchy to Proteiformity: Joyce, Jolas, Stein and McCaffery' (HMJ 15[2016]), and a Jungian reading of Ulysses, in Steven F. Walker's “"Art thou real, my ideal?": Jung's Animus in Joyce's "Nausicaa", (HMJ 15[2016]), which picks up on a thread of psychoanalytic interest in this year's studies.

The Joyce Studies Annual also celebrated in 2016, and the scope of its tenthanniversary volume is, once again, catholic. Topics range from family and sexuality, as in Hailey Haffey's 'Speak, Suck, Bite ... Kiss: Mother-Son Love in Joyce' (JoyceSA [2016] 206-30), to Michael F. Davis's 'A Little Cloud of Queer Suspicion' (JoyceSA [2016] 231-61) on entitling, and to musicology and poetics in Patrick Millan's 'Bronze by Goldenhair: Music as Language in Chamber Music and "Sirens", (JoyceSA [2016] 175-205). Michael Opest's 'Epiphanic Ulysses: Joyce's Trail of Breadcrumbs' (JoyceSA [2016] 154-74) 
considers epiphany and transubstantiation in Ulysses, whereas Timothy Morton treats of elegiac form in 'Elegiac Ulysses' (JoyceSA [2016] 130-52). Elsewhere, Leonid Osseny's 'Real Time in Ulysses' (JoyceSA [2016] 153) discusses his own illustrations of Joyce's novel in relation to the patterning, real and figural, of time. Marion Quirici's 'Degeneration, Decadence, and Joyce's Modernist Disability Aesthetics' (JoyceSA [2016] 84-109) draws Joyce's approach to modernism and decadence into the burgeoning field of disability studies. Morton P. Levitt reflects on a life devoted to scholarly work on Joyce in 'My Life in Joyce Studies, Such As It Is' (JoyceSA [2016] 1-44).

This volume also contains a troika of articles on the Wake, from 'Joyce's "meanderthalltale": Tracing the Passed/Past in Finnegans Wake' (JoyceSA [2016] 45-65), Kimberly J, Devlin's musing on time, to 'Textual Authority and Diagnostic Joyce: Re-Reading the Way We Read the Wake' (JoyceSA [2016] 66-83), Jeremy Colangelo's exploration of reader reception, and a treatment of 'patriarchal dissolution' by Rodney X. Sharkey in 'Patriarchal Dissolution in Finnegans Wake: Reading Joyce's "Porterpeace", (JoyceSA [2016] 110-29).

Contributions in the non-specialist journals and in book chapters are multiform, and a selection of work on Ulysses alone exemplifies the range: Charles Travis shows how social media has extended the mapping of Ulysses across Dublin in 'Bloomsday's Big Data: GIS, Social Media and James Joyce's Ulysses' (in Cooper, Donaldson, and Murrieta-Flores, eds., Literary Mapping in the Digital Age, pp. 102-21). Andrés Péréz-Simón's '(Mis)Reading Joyce in the Context of the "Arte Nuevo" Narrative' (in Gregori and Herrero-Senés, eds., Avant-Garde Cultural Practices in Spain (1914-1936), pp. 35-46) evidences part of the notable breadth and depth of scholarship on offer. This includes Stephanie Nelson's 'Time and Memory in the Odyssey and Ulysses' (in Gross and Ostovich, eds., Time and Trace: Multidisciplinary Investigations of Temporality, pp. 130-51), which offers a reading of Joycean temporality, and Dipanjan Maitra's “ “...like an egg without salt”: On Joyce's Scandal Works' (Sanglap 2:ii[2016] n.p.), which explores Joyce's treatments of scandal. Further examples includes 'Bloom's CV: Mimesis, Intertextuality and the Overdetermination of Character in Ulysses' (ES 97:viii[2016] 877-91), in which Matthew Hayward argues that Joyce portrays in Leopold Bloom a realistic career path for a second-generation Jewish Hungarian immigrant of the period. For Hayward, this mimeticism can ultimately be viewed as a formal hinge between Joyce's early realism and the stylistics of the Wake. Teresa Winterhalter examines the fragmentation of self and the potential for narrative unification in 'Leopold Bloom's Dark Riddle: Joyce, Levinas, and the Storytelling Self' (TCL 62:iv[2016] 359-78), using Levinas to argue for Bloom as the constructor of his own narrative coherence, and therefore identity. In regard to Dubliners, Kenneth Pellow examines the use of patterns of pairs, such as linguistic, character, and visual detail, in 'Joyce's Doubling' (Ren 68:i[2016] 27-48), suggesting that such doublings function as a covert moral device in Dubliners. Christopher Michael Elias asks 'What Makes Them Dubliners? James Joyce's "An Encounter" and the Foundations of Masculinist Nationalism in Ireland' (JMS 24:iii[2016] 229-40), in an article that examines national identity construction under colonialism as tied to masculinity and gender formation. 
Several monographs deliver a novel perspective on constant thematics in Joyce studies, and in fact address the overdetermination of these strands in the rationale for their projects. In Joyce and Betrayal, James Alexander Fraser delivers a more positive perspective on the enduring theme, describing it first as a problematic 'given' within Joyce studies and orienting it away from biography towards literary thematic. Across the early non-fiction, Portrait, Exiles, and Ulysses, Fraser makes the case for associating betrayal with dramatization and thus reading it as a structuration of Joycean narrative. As always, influence studies are a perennial trend in short- and long-form work. Two monographs return to Italianate and classical roots, Randall $\mathrm{J}$. Pogorzelski's Virgil and Joyce: Nationalism and Imperialism in the Aeneid and Ulysses and James Robinson's Joyce's Dante: Exile, Memory and Community. The former is a slant on Virgilian influence that seeks to connect Joyce and the Roman poet through the lens of imperial politics and the role of epic in the construction of nation, by means of an intertextual network of affiliation. Pogorzelski claims that, though Joycean criticism has attended to the politics of the Irish nation in his work, there has previously existed 'an artificial divide in criticism of Ulysses between Irish modernism and the classical European tradition', yet that 'what is at stake' in Joyce's adoption of that tradition 'is precisely the future of the Irish nation' (p. 13). Mapping the shared textual territories of Ulysses and the Aeneid, Pogorzelski builds an argument for each as a nation-building text but also for a transhistorical community between the two. Robinson's book is judiciously framed as a consideration of responses to Joyce's use of Dante which historicizes the engagement as one conditioned not by the medieval Dante but rather by the nineteenth-century reception of the Florentine. According to Robinson, this produces a different Dante in Joyce, one whose figuration persists throughout the scope of his oeuvre, in a 'historically complex and contextually determined interaction' (p. 4). Distinguishing his work from previous scholarship in this area by Mary Reynolds and Lucia Boldrini, Robinson adopts a materialist textual approach and situates it within recent developments in Dante studies, to produce a construction of the nineteenth-century Dante as he appears in the Joycean text. With a focus on thematics of exile and community, Robinson reads the Dantean form from Dubliners to Finnegans Wake, finally concluding that Joyce's particular Dante has an afterlife in the work of Seamus Heaney.

Jean-Michel Rabatés “ "A cage went in search of a bird”: How Do Kafka's and Joyce's Aphorisms Move Us?' (in Bradshaw, Marcus, and Roach, eds., Moving Modernisms, pp. 143-56) examines the parallels between Kafka's aphorisms and the Joycean epiphany, suggesting that both present an encounter with the Real, while in the same volume Wai Chee Dimock's 'Gibraltar and Beyond: James Joyce, Ezra Pound, Paul Bowles' (pp. 59-68) proposes a view of influence as 'networked modernism' (p. 59). Annalisa Ederici depicts another modernist network in 'The Transatlantic Review and the Nouvelle Revue Francaise - Between Tradition and Modernity: The FordLarbaud-Joyce Connection' (in Becquet and Davison, eds., Ford Madox Ford's Cosmopolis: Psycho-geography, Flânerie and the Cultures of Paris, pp. 115-28), while Joori Joyce Lee argues for a contemporary intertextuality in 'Invoking Joyce, Avoiding Imitation: Junot Díaz's Portrait of Nerds in The 
Brief Wondrous Life of Oscar Wao' (ArielE 47:iii[2016] 23-43). Audrey McNamara's 'Quirke, the 1950s, and Leopold Bloom' (in Mannion, ed., The Contemporary Irish Detective Novel, pp. 135-48) draws parallels between the Quirke detective series by John Banville (writing as Benjamin Black) and Joyce's Ulyssean protagonist. Brad Tuggle returns to the Renaissance to read 'The Faerie Queene at Finnegans Wake' (Expl 74:ii[2016] 129-32). In his chapter on 'Suttree, Joyce, and Flaubert' (in Jillett, ed., Cormac McCarthy's Borders and Landscapes, pp. 163-73), Anthony Ullmann investigates McCarthy's novel in conjunction with The Temptation of St Anthony, setting out parallels between the former and 'Circe', by means of which he connects Suttree to Flaubert.

A miniature trend in 2016 saw a trio of work on Joyce and Nietzsche. JeanMichel Rabatés chapter, 'The Birth of Irish Modernism from the Spirit of Nietzscheanism (Yeats, Joyce, and Beckett)' in his essay collection, The Pathos of Distance: Affects of the Moderns (pp. 51-68), stakes a claim for a particularly Irish form of Nietzscheanism. Rabate states not only that Irish modernism can be defined by its 'Nietzschean quality', but that 'Irish modernism, caught in a Nietzschean moment, triggered an array of manifestations that were very different from their French counterpart' (p. 51). James McAdams portrays Dedalus as a failed Übermensch in 'The Failed Revolts of Stephen Dedalus: A Portrait of the Artist as a Young Man and Nietzschean Self-Overcoming' (Readings 2:i[2016] n.p.), whereas Sara Soleimani Karbalei and Roudabeh Bavarsad Ahmadi propose Farrington in 'Counterparts' as an illustration of ressentiment, in 'James Joyce's "Counterparts": A Dramatization of the Nietzschean Ressentiment' (Metaphors 1:i[2016] 15-25).

In many ways, 2016 was about material approaches to Joyce. From the genetic scholarship outlined above to historicist reading and material culture, the treatment of this concern produced a methodological plurality that nonetheless is linked by a common strand of interest, articulated variously as the contextual, the quotidian, or the empirical. Interrogating The Death of the Book: Modernist Novels and the Time of Reading, John Lurz takes both Ulysses and Finnegans Wake as case studies for the signal importance to modernism of its physical form. He suggests first that Ulysses interpolates the reader with the experience of its materiality, and sees a cognate interrelation in the way in which the text implicates the physical body with its own corpus. For Finnegans Wake, Lurz concentrates on the typography of the text to extend this physicality by arguing that the Wake's letters 'stage print in terms of holes and fragmentation' (p. 82). In doing so, he claims, they embody the fragmentation and temporal finitude, which Lurz identifies as the experience of reading. Joseph M. Hassett's augmenting of the body of scholarship on Ulysses, censorship, and the law in The Ulysses Trials: Beauty and Truth Meet the Law raises the historical spectre of the contemporary experience of reading Joyce. Hassett, a trained lawyer, focuses on the trials, their legal context, and the parties involved in the conflicts surrounding the publication of Ulysses. His account draws out the intricacies of contemporary obscenity and censorship laws and offers insight into the US legal scene and its role in the obstruction of the text. Maria Krager also addresses obscenity in 'Bilingual Obscenities: James Joyce, Ulysses, and the Linguistics of Taboo Words' (SNNTS 
48:iv[2016] 407-26), which suggests that Joyce's achievement of an ItalianEnglish bilingualism occasioned a change in stylistics towards an increased use of obscene language from Ulysses onwards. Enrico Terrinoni discusses Italian Joyce as well. In this case, Terrinoni considers his own ongoing translation with Fabio Pedone of Finnegans Wake, exploring the complexities of such a process, in 'Translating the "Plutiple": Awakening Joyce in Finnitalian' ( $T \& L$ 25:ii[2016] 213-21).

The concept of the 'ordinary' is central to Margot Norris's The Value of James Joyce, a reading that locates Joyce's value in a strand of textual humanism with foundations in the quotidian, the democratic, the emplaced, the admixture of classical and popular culture in his work, and its multiplicity of voices. Norris testifies to Joyce's 'remarkable generosity in his embrace of all that is human' (p. 2). In Ulysses Quotidianus: James Joyce's Inverse Histories of the Everyday, Jibu Mathew George also accesses this persistent concern of modernist studies with the 'everyday', reading it in light of newer trends in alternative history and materiality. He concentrates on the allencompassing detail of the novel as a series of 'micro-histories' through which to view concepts of the body, gender, economics, power, and materialism. George gestures to the possibility of an alter-present and a superseding of colonial history in the ephemera of everyday life. An insistence on material culture in the novel is also evident in Elizabeth Switaj, James Joyce's Teaching Life and Methods: Language and Pedagogy in A Portrait of the Artist as a Young Man, Ulysses, and Finnegans Wake, which argues for the centrality of Joyce's teaching experience to his later writing, stating that 'a better understanding of Joyce the pedagogue is well overdue' (p. xii). Switaj argues that Joyce is engaged in two types of 'language work' (p. xiv) through his teaching and writing, with the former influencing the latter, and that the coalescence of his radical approach to language with an anti-authoritarian pedagogical stance to its learning is performed in the oeuvre. She historicizes Joyce's teaching in the first chapter through a discussion of the Berlitz texts used in his classroom, before going on to link Joyce's linguistic experiments throughout his novels to that language-teaching and in relation to representations of pedagogy in the novels. Switaj argues for the application of the Berlitz method in A Portrait of the Artist as a Young Man, which focuses both on gaining language and the dynamics of the classroom, while suggesting that Ulysses represents language-learning, more specifically the appropriations and variations of English as experienced in a non-native setting. This attitude establishes an anti-authoritarian approach to learning that reaches its apogee in Finnegans Wake, in which Switaj takes 'Night Lessons' both as an exemplar of that pedagogical philosophy and as a literal lesson for the reader, who is taught to read the new Wakese. In The Real People of Joyce's Ulysses: A Biographical Guide, Vivien Igoe presents another version of the everyday in her comprehensive directory of the Dubliners who populate the novel, while Stanley Price extends the biographical beyond Dublin in James Joyce and Italo Svevo: The Story of a Friendship, detailing the Triestine relationship and work of both writers against the background of European modernity.

The notion of space and place is also important to Raphaël Ingelbein, who devotes two chapters of Irish Cultures of Travel: Writing on the Continent, 
1829-1914 to Joyce. In both 'Home or Abroad? "West Britons" and Continental Travel' (pp. 183-208) and "'Yes, the newspapers were right": Revisiting Tourism in Joyce's “The Dead"' (pp. 209-24), Ingelbein reads 'The Dead' as an exposition of the politics of travel within an Irish context. Layla Hendrow is also concerned with spatiality and proposes a gender-inflected spatial reading of 'Oxen of the Sun' and 'Circe' as constructions of gendered space through performance, in " Enter this antechamber of birth: An Exploration of the Hospital and the Brothel in James Joyce's Ulysses' (Watermark 10[2016] 114-30).

Turning towards the explicitly scientific, in "Nature the great greengrocer": Legumes, Genetics and Finnegans Wake' (AJIS 16[2016] 112-24) Donal Manning's reading is founded upon references to genetics within the Wake, and more specifically to their linking with allusions to food as a means of amplifying a common thematics around alienation and community. Andrzej Duszensko emphasizes the empirical in " Abnilhilization of the Etym": Joyce, Rutherford, and Particle Physics' (IUR 46:ii[2016] 275-86), which looks at references to Ernest Rutherford and the new physics in Book II of the Wake, noting similarities between its radical breakthroughs and Joyce's revolution of language.

Given that 2016 marked the commemoration of the centenary of the Easter Rising, there were also representations on this topic. Richard Barlow discusses Joyce's 'detached stance' (p. 18) on 1916 in 'Silent Exile? James Joyce and the Easter Rising' (Moving Worlds 16:i[2016] 17-29), locating the references to the rising in the Wake, where it is 'fleetingly registered' (p. 17), within a broader context of political engagement via the anti-imperialist drive of the novel. Maria-Daniella Dick's 'The Two Jameses: A Joycean Politics of Criticism as Commemoration' (ISR 24:iv[2016] 396-407) presents another doubling in the political moment of the Easter Rising and the pairing of Jameses Connolly and Joyce, using this interconnection to discuss the politics of recent criticism on Joyce and nationalism. Vincent $\mathrm{J}$. Cheng appraises history more widely from the perspective of memory studies in 'Amnesia, Forgetting, and the Nation in James Joyce's Ulysses' (in Marcus et al., eds., pp. 335-49), interweaving a modernist history of forgetting drawn from Freud, Nietzsche, and Renan with the concept of a collective loss of memory, or 'national amnesia', designed to negotiate colonial trauma.

Unfortunately, A. Fargnoli and Michael Patrick Gillespie's critical edition of Exiles, Clara Mason's Mister Germ's Choice and Donald Phillip Verene's James Joyce and the Philosophers at Finnegans Wake were not made available for review. Whether conceived as an archive or an amnesiac past, it is clear that the output of Joyce studies in 2016 negotiates history deftly within the context of modern critical models.

\section{(d) D.H. Lawrence}

The highlight of 2016 publications on D.H. Lawrence was Andrew Harrison's The Life of D.H. Lawrence. Despite the great abundance of biographies written about Lawrence, including the recent three-volume Cambridge 
biography by John Worthen, Mark Kinkead-Weekes, and David Ellis and the earlier, innovative three-volume composite biography by Edward Nehls, details about Lawrence's life continue to surface. 'Several new biographical discoveries', Harrison writes, 'have been incorporated into the book, and where it has proved helpful I have made reference to the letters and postcards written by Lawrence which have come to light since the publication of the final volume of the Cambridge Letters' (p. xx). And Harrison states that he pays particular attention to Lawrence's literary dealings in this biography 'to show just how hard he worked to sustain his career as a professional writer' (p. xx).

Harrison organizes the book into seven parts representing different periods in Lawrence's life. Part I covers Lawrence's birth, his early childhood, his friendship with Jessie Chambers, his education, his teaching career, and the writing and publishing of his first novels, including The White Peacock [1911] and The Trespasser [1912]. An example of some new biographical material, one of the book's best features, is the use of a letter published in the Journal of D.H. Lawrence Studies in 2011. Harrison points out that Lawrence signs “"D.H.L." on his earliest surviving postcard of August 1903, written to Lettice Anna Berry, the stepdaughter of one of his maternal aunts (he was 17 years old at the time); he makes the same gesture in a postcard to his mother of 12 June 1905 ' and 'suggests a desire for distinction in Lawrence as the youngest son' (p. 13). In contrast, Harrison notes that Lawrence's father went by the more informal Art, and his brother by Ern or Ernie. In another section, however, Harrison glosses over Lawrence's experience with the publisher Heinemann concerning a required modification to The White Peacock, saying that Lawrence received 'an urgent request ... for a last-minute change to the phrasing of a short passage', and 'dealt with it straight away' (p. 54). This is explained further in 'The Bad Side of Books', which Lawrence wrote for Edward McDonald's A Bibliography of the Writings of D.H. Lawrence [1925]. In that piece, Lawrence discusses having to replace 'objectionable' wording with 'harmless words'. This move by Heinemann is significant in the history of Lawrence, not just because of his forced change of sexually suggestive language, but because it shows the beginnings of a pattern of conflict that Lawrence had with publishers and authorities throughout his career.

Part II covers the publication of Sons and Lovers [1913]; the beginnings of Lawrence's relationship with the then-married Frieda Weekley; and the new couple's travels outside the country, including their stay Germany and residence adjacent to Lake Garda in Italy. While in Gargnano, Lawrence would often drink at a local pub, really someone's living room, where, Harrison writes, 'Lawrence enjoyed watching the family interactions ("They are all so warm with life")'. Such experiences showed Lawrence 'a very different form of working-class life to the one he was accustomed to in England, and it made him wonder why English life was "so shabby", (p. 96).

Part III deals with the Great War; Lawrence feeling trapped in England; the publication and subsequent obscenity trial of The Rainbow [1915]; and the destruction of remaining copies of the novel in November 1915. 'Lawrence alternated', Harrison observes, 'between hopelessness and the desire to fight for a new audience. On 15 November he sent the manuscript of The Rainbow 
to Ottoline [Morrell] and told her to burn it if she did not want it: "I don't want to see it any more", (p. 145).

Part IV covers Lawrence's stay at Taormina, Italy, and the publication of Women in Love [1920], The Lost Girl [1920], and Aaron's Rod [1922]. Harrison writes of the negative criticism of Women in Love, including a call for officials to take action against the novel. Harrison writes, 'Although Lawrence had left England behind in a literal sense, his memories of the war-time prosecution of The Rainbow and its consequences were not so easily exorcised: they cast a long shadow over the reception of his work' (p. 225). Part V relates Lawrence's travels to Ceylon, Australia, the United States, and Mexico, and the publication of Kangaroo [1923], Birds, Beasts, and Flowers [1923], and The Boy in the Bush [1924], which he co-authored with Mollie Skinner. Lawrence also met Mabel Dodge Luhan in Taos, New Mexico, where Luhan would give Frieda a 160-acre ranch, which became known at the Kiowa Ranch (p. 277). The Lawrences returned the favour by giving Luhan the manuscript of Sons and Lovers. Harrison writes that 'Lawrence enjoyed immersing himself in the hard physical labour of creating a home. He reflected on these experiences in an essay entitled "Pan in America", in which he compares the satisfaction of getting heat and shelter from the natural resources at one's disposal to the bland conveniences of the modern home' (p. 277).

Part VI covers a period in which Lawrence returned to England and Italy, and The Plumed Serpent [1926] was published. Much of this period was spent working on the first two drafts of Lady Chatterley's Lover. For that, he drew from his visit to England. Harrison writes, 'Lawrence's recent experience of class conflict in England had touched him very deeply indeed; in the new novel, he sought to address this situation and-quite characteristically- to explore ways in which it might be overcome' (p. 328). Part VII describes the final three years of Lawrence's life, including his foray into private publishing with both Lady Chatterley's Lover [1928] and an unexpurgated version of Pansies [1929], and time in Italy and France. During his time in Italy, Lawrence visited Etruscan ruins with Earl Brewster. Harrison writes that Lawrence 'found evidence of a collective sensual awareness of nature, and appreciation of physical intimacy, which he had been exploring at a personal level in the first two versions of Lady Chatterley's Lover' (p. 342). This period included plenty of time visiting Aldous and Maria Huxley, who were with him when he died on 2 March 1930. Harrison offers more than one version of Lawrence's final words: Maria Huxley said Lawrence told her, 'Maria, Maria, don't let me die'; while Frieda claimed he said 'I am better now' after being given an injection of morphine for his pain (p. 403).

Neil Roberts's hybrid of biography and textual history, Sons and Lovers: The Biography of a Novel chronicles the events in Lawrence's life during the time he produced four drafts of what would become the semi-autobiographical Sons and Lovers. The introduction explains, "The "biography" of Sons and Lovers shows us that the novel was shaped by literal dialogues, first with Jessie Chambers and later with Frieda Lawrence .... The novel that is ostensibly about his past bears traces of the life that he was going on living as he wrote' (p. 3). The style that Roberts employs draws from both personal accounts and letters, and cross-references via Sons and Lovers. In chapter 1 Roberts writes 
that 'during the years of his [Lawrence's] youth and early manhood, when his creative power was nascent and in its infancy, it was Jessie who stimulated and encouraged him' (p. 12), and this chapter draws extensively on Chambers's account of her shared youth with Lawrence in D.H. Lawrence: A Personal Record, which was published in 1935, five years after Lawrence died at the age of 44. With some caveats concerning the split in their relationship and her ability to be objective, Roberts calls Chambers's biography 'the most complete account of his [Lawrence's] early years' (p. 3).

Chapter 2 deals with the failed sexual experiences Lawrence had with Chambers and their role in informing the 'Test on Miriam' chapter in Sons and Lovers. Concerning 'The Saga of Siegmund', which eventually became Lawrence's second novel, The Trespasser, Roberts notes that Lawrence received advice from Ford Madox Hueffer to write more in the impersonal style of Gustave Flaubert or Ivan Turgenev (p. 61). 'What survives of the second draft', Robert writes, 'does not read as if it was written to a Flaubertian model. There is almost no evidence in Lawrence's own writing that he ever held such an opinion' (p. 61). Chapter 3 recounts the drafting, after breaking up with Chambers, of the first version of Paul Morel, although only a chapter plan remains. This period included his mother becoming sick and dying, which caused Lawrence to abandon his writing of the novel. The chapter also includes an account of a fragment titled 'Matilda' that Lawrence worked on and left unfinished.

Chapter 4 describes the drafting of 'Paul Morel II', which included an engagement with Louie Burrows. Lawrence's writing during this period incorporated a soft portrayal of the mother with a harsh one of the father, who, in the draft, kills one of his sons. Even though he had broken up with Chambers, Lawrence still turned to her again to review he draft. In chapter 5, Roberts credits Chambers's critiques with helping to transform the draft into something greater. During this period Lawrence had a bout of pneumonia, through which he did not work on any drafts of the novel. The chapter recounts Lawrence connecting with Edward Garnett, who was important later on with Sons and Lovers. Roberts states, "More immediately, by sending "Paul Morel" to Jessie, Lawrence reconnected with his most important female reader' (p. 83). Chapter 6 describes Lawrence's return to his home town, Eastwood, to work on the novel. Although Chambers was back in his life during this time and Lawrence relied on her efforts reading the draft, Roberts notes that Lawrence eventually met the most important woman in his life, the then-married Frieda Weekley. After Lawrence and Frieda left the country, it would be the final time Lawrence and Chambers would see each other.

Chapter 7 relates how Paul Morel was rejected by Heinemann, and Lawrence worked to rewrite the novel extensively as Sons and Lovers under the guidance of Garnett. While Garnett's notes on the novel have not survived, socalled 'preparatory jottings' have (p. 131). Roberts notes that 'These relate to the "Test on Miriam" and "Passion" chapters, and there are two main themes. One is a criticism of dialogue as "cheap", "affected" and not ringing true. This probably relates mainly to the scenes in which Paul is showing off to Clara before their relationship becomes intimate' ( $p$. 131). The final chapter describes cuts made by Garnett to the manuscript slated to be published by 
Duckworth. The cuts totalled about 10 per cent of the book. Among the changes, Garnett reduced the part Paul's brother, William, plays in the novel. Regarding 'sexual explicitness', Roberts notes, this 'caused surprisingly few problems, and these changes scarcely disturb the novel's overall effect. When Paul makes love to Miriam the word "thighs" is replaced by "body", and "naked" is deleted, as is the information that Paul "threw off his things", (p. 160). An epilogue also mentions the novel The Rathe Primrose, which Chambers wrote, shared with Lawrence, and then destroyed.

Peter Balbert's D.H. Lawrence and the Marriage Matrix: Intertextual Adventures in Conflict, Renewal, and Transcendence is a straightforward examination of eight works by Lawrence with a special focus on marriage in them. Balbert writes in his foreword that 'Marriage thus functions, in effect, as both the obsessive subject and the thematic center of Lawrence's writing, shaping the plots and tensions of his novels and stories as well as reflecting the visionary imperative of the "passionate struggle into conscious being" that his characters attempt to achieve' (p. 1). Balbert states that he prefers to use close reading, history, and rhetorical analysis to inform his interpretations of Lawrence's books (p. 2).

To begin the chapter 'The Dark Secret and the Coccygeal Continuum, 1918-1920: From Oedipus to Debasement to Renewal in The Lost Girl', Balbert cites a December 1918 letter Lawrence wrote to Katherine Mansfield in which he states his "susceptibility to the "devouring mother" syndrome' (p. 12). Balbert says it is not surprising given the characteristic texture of his work: a consistent and accessible integration of biography and visionary art that remains central to his achievement as man and artist' (p. 12). He uses that information in his analysis of The Lost Girl. Among his observations, Balbert asserts that Lawrence's descriptions of the aggressive Ciccio having sex with Alvina suggests anal intercourse. Balbert writes, 'Lawrence emphasizes in his fiction and non-fiction the innate power of a sexual relationship to liberate, purge, and ultimately transform the respective lovers. The sex in this scene offers an extreme and discomforting example of that transformative potential ... Lawrence's narrative perspective on a virtual rape seems inadequate by any standard today of reasonable consent' (p. 42).

In 'Depression and Renewal at the Border-Line: Balder, Hemingway, and The Captain's Doll', Balbert explores the mental condition of Captain Hepburn, for example after his wife's death. Balbert writes, 'Part of his sadness after the accident must be attributed to guilt over the heavy burden of his marital dilemma: he had felt trapped not by a wife he despised, but by a wife he now realizes was equally trapped in their doomed marriage' (p. 69). Balbert discusses the scene on the glacier of Hepburn conquering his fears as similar 'in imagery, rhythm, and restraint' to what the future Ernest Hemingway would create in his Nick Adams stories (p. 84). In 'Freud, Frazer, and the Palimpsestic Texture: Dreams and the Heaviness of Male Destiny in The Fox', Balbert points out that when Lawrence was working on The Fox he had recently read Frazer's The Golden Bough and a book on Freud, in addition to finishing work on Fantasia of the Unconscious (pp. 90-1). Balbert notes that 'when salient aspects of Lawrence's life and marriage are engraved on a foundation of Lawrentian doctrine that for him is consciously 
supported by Frazer and unconsciously illuminated by Freud, the result of such a matrix is a kind of palimpsestic fiction as the various inscriptions of influence on Lawrence compete for priority' (p. 91).

In 'Thirteen Ways of Looking at The Ladybird: D.H. Lawrence, Lady Cynthia Asquith, and the Incremental Structure of Seduction', Balbert mentions that 'there is insufficient speculation on the full texture of Lawrence's invested but often frustrating friendship with Lady Cynthia Asquith' (p. 124). Balbert continues, saying 'A close, linear reading of the text, combined with relevant speculation on Cynthia's intimate life and her relationship to Lawrence, may provide a means to break through the relative silence about the symbolic ramifications and biographical nuances of' The Ladybird (p. 124). Balbert calls the novella 'the most angry, patriarchal, and resolute of the three excellent novellas' that Lawrence writes in 1921 (p. 127). Those also include The Captain's Doll and The Fox. In the chapter, 'From Panophilia to Phallophobia: Sublimation, Projection, and Renewal in St. Mawr', Balbert notes this was a difficult period in Lawrence's life when he experienced feelings of abandonment by his wife because of her need to return to England to be with her children (pp. 153-4). This was followed by sexual frustration and jealousy (p. 155). This, of course, fed into St. Mawr, the atmosphere of which Balbert describes as 'emasculated libido and contorted gender-definition' (p. 157).

In the chapter 'Pan and the Appleyness of Landscape: Dread of the Procreative Body in "The Princess", Balbert links the essays 'Pan in America' and 'Introduction to These Paintings', which were written before and after 'The Princess'. 'In their emphasis on the desexualized body and the often contested relations between men and women', Balbert says, 'both essays offer insight about the configuration of the marriage matrix in this often admired but relatively unexamined tale of idiosyncratic courtship and deadly conflict' (p. 181). 'Impotence, Renewal, and the Honorable Beast: The Aesthetics of the Fourth Dimension in The Virgin and the Gipsy' considers Lawrence's health when he wrote The Virgin and the Gipsy (p. 209). Among the scenes that Balbert discusses is 'that presumed lack of sex between the willing virgin and the experienced gipsy in that private attic heaven' (p. 241). It has been documented that Lawrence was likely impotent at this time and Balbert asks, 'for this recuperating and committed man, compromised lover, and embattled artist, is it not understandable for him to insist that a sensual and intimate closeness can rival the penetrating heat of lust?' (p. 241).

'From Lady Chatterley's Lover to The Deer Park: Marriage, Renewal, and the Dialectic of Erotic Risk' draws parallels between Lawrence's work and that of Norman Mailer, stating that 'While both writers extol the institution of marriage and acknowledge the challenges it presents, they also remain leery of any extended erotic affair that is built on ex-without-love' (p. 256). In his criticism of the times in which Lawrence was living, Balbert quotes from Lady Chatterley's Lover and argues that 'Lawrence defends the urgency of his own most controversial novel by reiterating an important epithet: "Never was an age more sentimental, more devoid of any real feeling, more exaggerated in false feeling, than our own. Sentimentality and counterfeit feeling have become a sort of game, everybody trying to outdo his neighbor", (p. 249). It is up to 
the artist to help correct this. Balbert notes that Mailer echoes Lawrence when he writes, 'The final purpose of art is to intensify, even, if necessary, to exacerbate, the moral consciousness of people' (p. 246). In 'Unarticulated Synergy and Unfashionable Transcendence: Teaching, Research, and the Quest for Something,, Balbert takes readers back to when he was an undergraduate student at the University of Michigan and was inspired by his professor, Jim Gindin. Much of the chapter is about the qualities to which professors should aspire, while a final chapter, discusses the value of research and the variety of ways in which a professor in a department can get bogged down.

In The Forgotten Film Adaptations of D.H. Lawrence's Short Stories, Jason Mark Ward examines an infrequently pursued subject concerning Lawrence. The introduction claims that Ward's approach, 'building on recent advances in adaptation studies, looks beyond ideas of fidelity to emphasize how each film adaptation functions as a creative response that foregrounds the significance of the fluid text, the reader, transtextuality and genre' (p. 2). On Lawrence as a short-story writer, Ward says, 'In order to adhere to strict limitations on the word count in magazines, modern short story writers such as Lawrence stripped the prose down through multiple revisions to create tone and content through the juxtaposition of images' (p. 4). Ward mentions that some people have quibbled over whether Lawrence's short stories can be considered modernist. Unlike Joyce, who used a stream-of-consciousness approach, at least in his longer works, 'Lawrence advocated a different understanding of consciousness that expresses its physical vibrancy and mutability' (p. 7). Ward says that film during the modernist period was regarded as anti-intellectual, and Lawrence was even hostile towards the genre (p. 8).

Chapter 1 explains how Ward's approach differs from previous work in this field, such as Jane Jaffe Young's D.H. Lawrence on Screen and Louis Greiff's Fifty Years on Film (p. 33). Ward advocates 'a genetic criticism-based approach, which considers how texts evolve and mutate over time, can be found in current adaptation studies and, as will be demonstrated here, it offers an alternative to criticism rooted in outmoded notions such as fidelity and intentionality' (p. 35). Chapter 2 notes that there are six versions of Lawrence's short story 'Odour of Chrysanthemums', and argues that Mark Partridge's thirty-minute Odour of Chrysanthemums [2002] is the 'first film interpretation of a Lawrence story that exists in many versions' (p. 59). Ward may mean short story here rather than any of Lawrence's stories, such as his novels, some of which have multiple versions. Partridge's film is notable, Ward observes, for 'its evocative use of candlelight and firelight, its attractive heroine, its refined and flattering deployment of shallow focus, the generally slow movement of the camera and use of classical instrumentation on the score' (p. 3). Chapter 3 considers Robert Burgos's 1983 television adaptation, The Horse-Dealer's Daughter. Ward writes that the film 'adds a significant layer to the palimpsest of "The Horse- Dealer's Daughter" because of its relocation to America, which draws particular attention to the importance of genre in adaptation' (p. 97). Chapter 4 covers film adaptations dating from 1949 to 2010, and Ward states that all of these films "draw on elements of the horror genre because within the story is a "monster" (the rocking horse) that destroys the status 
quo, and as Colin Odell and Michelle Le Blanc explain of the horror genre, "At the rotten core of any horror lies the monster, the perpetrator of the dread and fear that elicits an emotional response to the film", (p. 157).

In the introduction to her edited collection, D.H. Lawrence: New Critical Perspectives and Cultural Translation, Simonetta de Filippis notes that Lawrence has garnered significant critical attention throughout the decades. She attributes this to the 'force of his thought, his courageous challenge to the most important values of Western industrial society, his rejection of England and its bourgeois values, his choice to live in exile, his never-ending quest for lost vital meanings, his open-mindedness in coming into contact with different worlds and cultures', and more (p. 1). The articles that De Filippis uses in the book were presented in earlier forms at the thirteenth International D.H. Lawrence Conference in Gargnano, Italy, where Lawrence and Frieda stayed from September 1912 to April 1913. With fifteen chapters, the book is split into two parts with two subsections each.

The first part, 'Theoretical Perspectives', includes the subsections 'A Philosophical Focus' and 'New Critical Readings'. The philosophical subsection includes Masashi Asai's 'How to Have Meaningful Relationships with the Other: Lawrence, Sade, and Bataille', Sergio Crapiz's 'Dancing Bodies: D.H. Lawrence and Antonin Artaud's Poetics of Cruelty', Indrek Männiste's 'D.H. Lawrence: Nature, Technology, and the Sense of Enframing', Jim Phelps's " "Flesh cometh only out of flesh": Darwinian Considerations of D.H. Lawrence', and Youngjoo Son's 'Why Matter Matters: Things and Beings in D.H. Lawrence'. The subsection 'New Critical Readings' includes 'Identity, Performance, and Ritual in The Lost Girl' by Flora de Giovanni, 'The Animal in D.H. Lawrence: A Struggle against Anthropocentricism’ by Jamie Johnson, 'Transnational, Postcolonial D.H. Lawrence: Coloniser, Colonialist, or Assimilationist?' by Feroza Jussawalla, 'Hybridity and the Postcolonial Solution in D.H. Lawrence's The Plumed Serpent' by Andrew Keese, and 'Revising Women in Love: Lawrence and the "Over-Emphatic Explicitness" of Theory' by Laurence Steven. The second part, 'Cultural Translation', includes the subsections 'Lawrence and Translation' and 'Translating Lawrence'. The first includes 'Found in Translation: Lawrence's Fascination with Verga's "Red-Headed Brat", by Jane Costin, "D.H. Lawrence and Cultural Mediation' by Simonetta de Filippis, and "Translation is no equation": D.H. Lawrence and the Art of the Original' by Judith Ruderman. 'Translating Lawrence' includes 'Lady Chatterley Films as Cultural Translation' by Jill Franks and 'Translating Lawrence: A Personal Experience with an Elusive Fox' by Stefania Michelucci.

The year also included four issues of journals dedicated to Lawrence. In the United States, two issues of D.H. Lawrence Review were published. The first is a timely celebration of Lawrence's poetry, taking advantage of the two-volume Cambridge edition of Lawrence's Poems [2013]. The editor of that work, Christopher Pollnitz, contributed 'Using the Cambridge Poems and Auditing Lawrence's Sacred Dramas' (DHLR 40:ii[2015] 11-33), which supplies a personal account of how he edited Poems and the issues he confronted as he guided scholars on the book. He also provides insight into the poems by situating them in a discussion of Lawrence's fiction and essays. He writes, 
'Shedding further light on Lawrence's historical and art-historical sources can thus re-illumine the last vessel in what can be seen as a fleet, the succession of verse notebooks that bore his poetry towards an end or a transformation' (p. 27). While it is not an article, scholars of Lawrence's poetry will find Holly A. Laird's 'Bibliography of Scholarship on the Poetry of D.H. Lawrence' (DHLR 40:ii[2016] 128-37) to be an indispensable guide.

The issue also includes Annalise Grice's " "That'll help perhaps to advertise me": Lawrence's "The Georgian Renaissance" Review in Rhythm' (DHLR 40:ii[2016] 34-53); Bethan Jones's 'Pivotal Poems: Turning Back to Lawrence's Bay' (DHLR 40:ii[2015] 54-71); 'A Praying Poetic "I"' by Elise Brault-Dreux (DHLR 40:ii[2015] 72-83); Dawid W. de Villiers's " "Shadow of all things": Oceanic Alterity in the Poetry of D.H. Lawrence' (DHLR 40:ii[2015] 84-102); Nak-chung Paik's 'Lawrentian Buddhism? An Attempt at a Literal Reading of "The Ship of Death", (DHLR 40:ii[2015] 103-19); and Sandra M. Gilbert's 'Darkness at Dawn: From "Bavarian Gentians" to "Aubade", (DHLR 40:ii[2015] 120-7).

The next issue of D.H. Lawrence Review includes more extensive versions of articles presented at the thirteenth International D.H. Lawrence Conference in Gargnano in 2014. In 'Where (in What Company) Does Lawrence Belong?' (DHLR 41:i[2016] 45-62), Garry Watson provides an insightful analysis drawing on his decades as a scholar on Lawrence to situate the eponymous author and his thinking among nineteenth-century and modernist philosophers and writers. Watson also builds on the observations of the late F.R. Leavis concerning Lawrence, writing that "while Lawrence shared two of his three main positives (the importance of attending to the demands of the soul and of cultivating friendship) with other modernists (Nietzsche on friendship, for example), he is pretty much alone in his commitment to the third one, a marriage based on passion' (p. 51). That is what he had in common with the writers from the nineteenth century, such as Jane Austen and George Eliot. Also in the issue are Neil Roberts's 'Jessie Chambers, Frieda Lawrence, and the Rewriting of Sons and Lovers' (DHLR 41:i[2016] 1-20) and 'Embodied Love: D.H. Lawrence, Modernity, and Pregnancy' by Candis Bond (DHLR 41:i[2016] 21-44), as well as Julianne Newmark's 'D.H. Lawrence and Networks of American Literary Criticism' (DHLR 41:i[2016] 63-88), Mark Taylor's 'Henry Bergson's Creative Evolution and the Interaction between Humankind and the Environment in D.H. Lawrence's Australian Fiction' (DHLR 41:i[2016] 89-107), and Jack Stewart's 'Lawrence's Ecological Vision in Nottinghamshire and Tuscany’ (DHLR 41:i[2016] 108-33).

In the UK, the Journal of D.H. Lawrence Studies published one issue. Sue Reid writes in her editor's note that this issue explores 'myriad interconnections that Lawrence made in his life and in his art'. In " "A propos of the war": D.H. Lawrence's "All of Us", (JDHLS 4:i[2016] 25-46), Lee M. Jenkins properly situates a mostly neglected poetic work, All of $U s$, which was rejected for publication and only recovered in the 2013 Cambridge edition of Lawrence's Poems. This collection from 1916 is complicated because it represents Lawrence's translation of Egyptian fellaheen (labourer) songs from a previous translation into German, made by Heinrich Schäfer. The poems are basically Lawrence's appropriations of the originals for his own purposes. 
'The proximity of love and death in the fellaheen songs', Jenkins writes, 'which had reflected Lawrence's personal circumstances when he first translated them in 1910, is now recoded to speak to the collective as well as individual experience of loss brought about by the war' (p. 27). Jenkins reflects on the poems' place among other works about the First World War and the nature of translation as it relates to modernism, and provides some consideration to postcolonial theory. In 'Lorenzo at "The Theatre": Meeting Actors and Audience' (JDHLS 4:i[2016] 99-120), Nick Ceramella also focuses on a work from 1916, 'The Theatre'. Although initially written in 1913 about Lawrence's experience with the theatre in Gargnano, this was later revised. Ceramella relates Lawrence's experiences as a dramatist and his philosophical views about blood and spiritual consciousness through observations of the Italians in the Gargnano theatre. In the course of the essay, Ceramella says, we see 'Lawrence's interest in national character, particularly the differences between northern and southern European nations, which he draws out ... through his comparison between the Norwegian and Italian playwrights-Henrik Ibsen and Gabriele D’Annunzio' (p. 102).

Other articles from this issue include John Worthen and Andrew Harrison's 'Further Letters of D.H. Lawrence' (JDHLS 4:i[2016] 7-10); 'Five Poets of the Present on D.H. Lawrence: Sarah Corbett, John McAuliffe, Deryn ReesJones, Neil Rollinson, and Jeffrey Wainwright', curated by Howard J. Booth (JDHLS 4:i[2016] 11-24); Bethan Jones's 'Depravity, Abuse, and Homoerotic Desire in Billy Budd and "The Prussian Officer", (JDHLS 4:i[2016] 47-72); Earl G. Ingersoll's “"Ausdruckstanz" and "Ars Amatoria”: D.H. Lawrence and the Interrelated Arts of Dance and Love' (JDHLS 4:i[2016] 73-98); James Moran's 'Lawrence's Plays on the Stage: An Evolution from 2009 to 2016' (JDHLS 4:i[2016] 121-38); and 'Bankruptcy in "The Horse-Dealer's Daughter", by Shirley Bricout (JDHLS 4:i[2016] 139-42)

In France, an issue of Études Lawrenciennes also appeared in 2016. Among notable inclusions, Sarah Bouttier's 'The Geometrics of Education in D.H. Lawrence' (EL 47:i[2016] 30 paras.) tracks the positions Lawrence takes on corporal punishment and the movement against physical punishment of any kind. She aims 'to present the reasons given by Lawrence for his condemnation of both traditional and progressive education' (para. 5) and her critique includes The Rainbow, 'Education of the People', and Fantasia of the Unconscious. In 'Encountering Foreignness: A Transformation of Self' (EL 47:i[2016] 17 paras.), Fiona Fleming examines various works by Lawrence to see how he represents change in European characters from their experiences with foreigners. Other articles include Jeff Wallace's 'Educability and Art: D.H. Lawrence, Paul Cézanne, Herbert Read' (EL 47:i[2016] 20 paras.); 'Self and Sequence: Lawrence's "The Schoolmaster"' by Keith Cushman (EL 47:i[2016] 47 paras.); Shirley Bricout's 'Children of Adam and Eve: Parental Education in D.H. Lawrence's Novels' (EL 47:i[2016] 34 paras.); Juliette Feyel's 'Lawrence, Education and Corporal Punishment' (EL 47:i[2016] 28 paras.); Brigitte Macadre-Nguyên's 'Daughters in Love: Reflections on a Woman's Education in The Rainbow' (EL 47:i[2016] 35 paras.); Elise BraultDreux's 'Books between the Covers - The Rainbow, Women in Love and Lady Chatterley's Lover' (EL 47:i[2016] 38 paras.); Michael Bell's 'Goethe and 
Lawrence: Bildung and Wholeness' (EL 47:i[2016] 30 paras.); Jacqueline Gouirand's 'Knowledge and Salvation in Schopenhauer and D.H. Lawrence' (EL 47:i[2016] 33 paras.); Jonathan Long's 'Lawrence and His History Books: From Reader to Writer' (EL 47:i[2016] 23 paras.); and Gaku Iwai's 'Did Lawrence Like or Hate the Germans? Wartime Discourse on War and Peace in Movements in European History' (EL 47:i[2016] 41 paras.).

\section{(e) Virginia Woolf}

It was a prolific year for Woolf scholarship, with the publication of a number of monographs and edited collections. Clara Jones's monograph Virginia Woolf: Ambivalent Activist stands out in making a really substantial contribution to our understanding of Woolf's politics. Challenging the critical acceptance of Woolf's own 'account of herself as an outsider to conventional forms of political and social activism' (p. 2), Jones draws upon a wealth of historical material in order to demonstrate the range and commitment of Woolf's political activities. Chapter 1 looks at Woolf's role in the adult education movement through her teaching at Morley College, identifying a degree of class anxiety in Woolf's attitudes towards her lower-middle-class pupils, before going on to situate Woolf's teaching of history in the context of contemporary debates within the discipline. In chapter 2, Jones provides convincing evidence to support Naomi Black's claim that Woolf campaigned for the People's Suffrage Federation, a marginal group within the suffragist movement, a revelation that allows Jones to reassess the attitudes towards women's suffrage campaigners expressed in Woolf's works. What appear to be satirical and dismissive representations of women's suffrage campaigners are in fact critiques of the class-bound, conservative, and often militaristic nature of the mainstream suffrage movement. This is a truly ground-breaking chapter, and one which presents a challenge to those who see Woolf as neglecting class concerns in her pursuit of feminist aims. Chapter 3 interrogates the complexity of Woolf's feelings towards the Women's Cooperative Guild, once again aided by illuminating archival research. The final chapter is perhaps the most 'ambivalent', identifying a mixture of solidarity and suspicion in Woolf's relationship with the (often conservative and nationalistic) Women's Institute and its village members. The solidarity can be traced in the talk Woolf gave to the WI about the Dreadnought hoax which, Jones argues, invites the women villagers to collude in Woolf's subversive, pacifist vision, as in Three Guineas. The suspicion, meanwhile, is present in Between the Acts, in which Woolf satirizes the WI's pursuit of a particular form of 'democracy' that involved the suppression of class antagonism.

Madelyn Detloff's The Value of Virginia Woolf is a bold piece of criticism which seeks to consider the 'value' that Woolf has for contemporary society by applying various philosophical and ethical concepts to her work. Detloff does not subscribe to any ahistorical definition of 'value': as her extremely lucid introduction explains, the book draws upon Barbara Herrnstein Smith's argument that value is 'conferred through communal processes', and is always open to 'contestation' and 'remaking' (pp. 1-2). Thus, while the book relies 
heavily upon close reading, Detloff makes it clear that her readings are culturally and historically specific. Chapter 1 examines the Greek concept of 'eudaemonia', with which Woolf would have been familiar, Detloff argues, through her reading of G.E. Moore and Walter Pater. Chapter 2 employs Woolf's own concept of 'incandescence' which, in A Room of One's Own, she defines as 'disinterestedness' (p. 31). There appears to be a certain circularity in applying Woolf's own term to her work, albeit mixed with later philosophy. However, it does enable Detloff to draw a profitable link between $A$ Room of One's Own and Three Guineas, by arguing that the former's concept of 'incandescence' has significant resemblances to 'the outsider standpoint that Woolf cultivates' in her later feminist polemic (p. 34). In chapter 3, on 'Interdependence', Detloff provides a new perspective upon the oft-discussed dialectic of individuality and interdependence in Woolf's representations of human life, relating them to modern complexity theory and its study of 'complex adaptive systems' (p. 52). Detloff concludes the chapter with an extremely convincing 'crip theory' reading of The Years which explores how particular bodies and lives are characterized as 'deviant' through the exertion of 'biopower' (p. 58). Both this chapter and the next, on 'Civilization and Barbarism', contain a subtle and balanced analysis of some of the problematic aspects of Woolf's texts, particularly those that have been read as ableist and racist.

Kathleen Heininge's Reflections: Virginia Woolf and Her Quaker Aunt, Caroline Stephen forms part of a growing body of work questioning the critical consensus that Woolf was a materialist, atheist writer. Heininge aims to demonstrate Woolf's spiritualism by identifying 'affinities' between Woolf's writings and her aunt's influential accounts of the philosophy of Quakerism. However, the affinities that Heininge identifies are generally more political than spiritual, largely involving Caroline Stephen's rejection of patriarchal and Church authority. That Stephen provided Woolf with a model of female resistance seems highly probable; whether this means that Woolf absorbed her spiritual beliefs is more questionable. Often, the book reads more like a list of Stephen's and Woolf's views on the topic of each chapter (which range from 'Dress' to 'Women's Roles') than an analysis of Stephen's influence on Woolf. The book is consequently more useful in recuperating Stephen as a pioneering, radical woman writer than in shedding any light on Woolf's religious beliefs. The chapters on 'Silence and Speaking' and on 'Light', which look in detail at Woolf's marginal annotations of her copy of Stephen's book Quaker Strongholds, are by far the most convincing in the book. The first argues that Stephen's emphasis on silence as a form of communication in Quakerism can be traced in Woolf's depictions of silence as enabling interspecies communication in Flush, and as epiphanic in Orlando (pp. 128-9). The chapter on 'Light' relates Stephen's preoccupation with an intermittent 'inner light' to Woolf's depictions of the intermittent, relative nature of understanding. These chapters provide a new perspective on important motifs in Woolf's writing without quite succeeding in demonstrating that Woolf 'was not as closed to the concept of God and God's light as hitherto assumed' (p. 171).

The second volume of Barbara Lounsberry's ambitious survey of Woolf's career as a diarist, Virginia Woolf's Modernist Path: Her Middle Diaries and 
the Diaries She Read, was published in 2016. Lounsberry argues that the diaries of Woolf's 'middle' period are characterized by the 'modernist inward turn' of her contemporaneous fiction (p. 2). The book is rather long and repetitive, largely due to Lounsberry's decision to review Woolf's diaries chronologically by year. The difficulty of summarizing the content of the diary of a given year in any coherent way leads Lounsberry to employ such loose categories as 'the soul', 'the female', and 'the male' as descriptors of style. In her first chapter, 'Crisis Calls for a New Diary Audience and Purpose', Lounsberry argues that in 1917 and 1918 Woolf underwent a crisis of confidence in her female mentor figures, particularly Janet Case, and that she consequently invented the persona of 'Elderly Virginia' as a new projected audience for her diaries. The next two chapters, 'New Diary Realms' and 'Jealousy, Illness and Diary Rescue', are particularly helpful in tracing John Evelyn's and Anton Chekhov's diaries as important models for Woolf. 'Voice in Motion', meanwhile, makes the interesting claim that Tant' Alie of Transvaal: Her Diary, 1880-1902, the diary of a South African woman living through the Boer War, influenced the early stages of Mrs Dalloway's composition. Lounsberry's resort to psychoanalytical interpretations of Woolf's life can grate: in 'Rush, Urgency, Wound, and Rescue' she argues that Woolf's 1925 diary represents 'a regression to childhood', and that Vita Sackville-West is a 'strong, motherly figure' who can 'rescue' Woolf from this 'fall' (pp. 124-7). In 'Renewed Diary Experiment' she makes a more convincing claim: that there are significant resonances between the lives of Woolf and Beatrice Potter Webb, particularly in their publishing work, involvement in the co-operative and socialist movements, and common interest in the role of economics in art. The next chapter, 'The Loose-Leaf Diary', is one of the most useful in the book, considering the diary's existence as physical object. Finally, the last chapter paves the way for Lounsberry's next instalment, asserting that in 1928 Woolf stood at an artistic 'crossroad' between 'nonfiction' and 'fiction', and 'the external and the internal' (p. 205).

Kathryn Simpson's Woolf: A Guide for the Perplexed offers an up-to-date, accessible, and fully referenced account of the current state of Woolf criticism. Simpson's analyses tread rather well-worn paths (her account of Woolf's narrative technique, for example, looks at the oft-explored aeroplane scene in Mrs Dalloway) so the book will be of limited value to the hardened critic, but it provides an excellent introduction to Woolf studies. Chapter 1, 'Woolf's Modernism', provides an able if somewhat familiar account of Woolf's essays on modernist aesthetics, 'Mr Bennett and Mrs Brown' and 'Modern Fiction', which evades the trap of taking Woolf's rejection of 'materialism' too much at face value. Chapters 2 and 3 deal with Woolf's formal experimentation, drawing apt connections with contemporary politics and technological developments. Chapter 4, 'Characterization', highlights Woolf's ambivalence towards Freudianism, while rather unexpectedly alighting upon Woolf's littlediscussed short story 'In the Orchard' as an example of her experimentation with character. The final two chapters give highly nuanced accounts of Woolf's politics. Chapter 5, 'Gender, Sexuality and Class', highlights the contradiction between A Room of One's Own's attention to socioeconomic conditions and its often essentialist view of gender. This chapter also contains 
an interesting reading of the working-class figures in To the Lighthouse against the background of the General Strike. Finally, chapter 6, 'Empire and Jewishness', explores what are arguably the most problematic areas of Woolf's politics. Simpson does not attempt to provide a resolved view of Woolf's attitude towards racial 'others', highlighting instead her contradictory mixture of critique of and complicity in imperialist and racist attitudes.

This year also saw the publication of a new biography of Woolf. Part of a Critical Lives series, Ira Nadel's Virginia Woolf is a short and accessible book, which employs the engaging if not entirely novel method of approaching Woolf's life via the various houses in which she lived. Nadel makes heavy use of quotations from letters, an approach that has a certain strength in allowing the figures in Woolf's life to speak for themselves. The book is severely limited, however, by a curious sense of historical context (the choice to foreground the sinking of the Titanic, for example, seems a little bizarre) and by a tendency to interpret Woolf's life and works predominantly in terms of her childhood sexual abuse and her suicide. Chapter 1, focusing on Hyde Park Gate, provides somewhat unorthodox portraits of Woolf's relationships, overlooking her father's oppressive behaviour and arguing that Woolf's relationships with women were an attempt to 'compensate' for her sexual abuse and a substitute for maternal affection (pp. 38-9). Chapters 2 and 3, on 46 Gordon Square and 29 Fitzroy Square, highlight important friendships in Woolf's life, including Roger Fry, Clive Bell, and the female connections who furthered Woolf's journalistic career, while chapter 4 provides a rather poorly informed account of Woolf's politics, identifying Leonard Woolf as the 'principal influence' on her politics (p. 97) and citing Woolf's non-attendance at several suffrage demonstrations as evidence of political disengagement. Chapters 5, 6, and 7 offer some interesting readings of Woolf's use of form, as well as useful summaries of contemporary reviews. Chapter 8, on Monk's House, imposes a narrative of decline on Woolf's final years, tracing the deaths of friends, negative comments by critics (though most of the comments cited are from before the publication of The Years which, as Nadel notes, was a critical success), and the threat of the Second World War as foreshadowings of Woolf's approaching demise.

Kelly Sultzbach's Ecocriticism in the Modernist Imagination: Forster, Woolf, and Auden is an important addition to the growing body of ecocritical readings of Woolf's texts, while the choice to focus on three writers not often grouped together contributes to the new modernist studies' project of questioning received notions of modernist experimentation by drawing new trajectories and making new connections. Sultzbach seeks to construct a 'green literary modernism', in which modernism's attentiveness to the boundaries of language is associated with an attempt to include non-human voices (pp. 1-3). Her nuanced introduction addresses key ethical questions, and, importantly, contends that ecocritical readings should not ignore the problematic attitudes of the authors they examine. She argues that 'demarcations, differences, and exclusions' are just as much the material of ecocriticism as utopian representations of unity with nature (p. 7). The section on Woolf begins by examining Woolf's literary-critical essays, arguing that they mirror the 'ecophenomenology' of Maurice Merleau-Ponty in prioritizing the 
representation of nature and 'embodied perception' (pp. 91-2). After a series of perceptive ecomaterialist readings of Flush, 'Kew Gardens', and 'Thunder at Wembley', the section concludes with an analysis of To the Lighthouse which productively suggests that the novel's gaps and multiple perspectives enable a representation of unexpressed, non-human subjectivities.

Several books considered Woolf's relationship to other writers' texts, as critic, publisher, and reader. The chapter on Woolf in Theodore Leinwand's The Great William: Writers Reading Shakespeare offers a meandering survey of Woolf's comments on Shakespeare in her letters, essays, diaries, and reading notebooks which never finds its way to an overarching analysis. However, multiple facets of Woolf's reading of Shakespeare emerge: her appreciation of the physicality of his writing, the role of his work in her relationship with her brother Thoby, her 'unmediated' access to his plays while ill (p. 73), and, finally, her identification with him as a fellow professional writer. Liza Knapp's Anna Karenina and Others: Tolstoy's Labyrinth of Plots, an intertextual study of Tolstoy's use of multiple plotlines, concludes with a reading of Mrs Dalloway as a response to what Woolf saw as Tolstoy's failure to bring together the two central plotlines of Anna Karenina. Knapp persuasively argues that the relation of Clarissa and Septimus, like that of Anna and Levin, provokes unanswered but vital questions about moral responsibility and the nature of sympathy. Lise Jaillant's " Introductions by Eminent Writers": T.S. Eliot and Virginia Woolf in the Oxford World's Classics Series' (in Wilson, ed., The Book World, pp. 52-80), looks at the introductions Eliot and Woolf wrote for the Oxford World's Classics editions of, respectively, The Moonstone and A Sentimental Journey. These introductions mark a rapprochement between modernism and the establishment which at first seems incongruous, but becomes explicable when placed in the context of the contemporary literary marketplace and the history of the World's Classics' management. Claire Battershill's essay 'Genre at the Hogarth Press' (in Wilson, ed., pp. 117-33), meanwhile, argues that the need for generic labels was at once a constraint for the Hogarth Press, and 'an opportunity for reflections on the nature of genre and its role in the world of books' (p. 133).

Woolf also featured prominently in studies of the role of the material object in modernism. Two chapters of John Lurz's The Death of the Book centre on close readings of Jacob's Room and The Waves. Lurz identifies the multiple references to pages, books, letters, and newspapers in these novels as drawing attention to the books' status as objects, thus implicating the reader in the limited temporal existence of the book as cultural form. Though Lurz is somewhat in thrall to his own argumentative framework, the book is valuable in revealing the attention Woolf pays to the materiality of her own literary productions. Thomas S. Davis's The Extinct Scene also foregrounds the importance of the physical object to Woolf. A chapter on Woolf's The Years and Christopher Isherwood's Goodbye to Berlin demonstrates how the two novels mark a crisis in the notion of historical progress, instead depicting a 'recursive historicism' (p. 91) rooted in the repetitions of everyday life and represented through everyday objects. For Roger S. Foster, meanwhile, Woolf's objects have an ethical significance. A chapter of his book Adorno and Philosophical Modernism: The Inside of Things suggests that her novels enact 
the dissolution of the 'theoretical subject' in favour of an experiencing, sensing self, brought into a relation of intimacy with the object-world. Foster also uncovers important parallels between Woolf and Adorno, demonstrating how both use individual experience as a way of uncovering the violence that lies behind appeals to 'reason' and 'proportion' by those in authority. Finally, Lorraine Sim's Ordinary Matters: Modernist Women's Literature and Photography examines 'the value, import and richness of the quotidian' for various modernist women writers and photographers (p. 3). A chapter on Woolf and Gertrude Stein argues that the two writers assert the value of objects in opposition to capitalism's tendency to 'instrumentalize' them (p. 69), and contains a close reading of To the Lighthouse that convincingly highlights the importance of objects in forging connections between characters.

In the field of women's writing, Jana Rivers Norton's The DemeterPersephone Myth as Writing Ritual in the Lives of Literary Women looks at the experience of writing as a therapeutic ritual, arguing that Woolf, Elizabeth Bishop, Alice James, and Edith Wharton all re-enact the myth of Demeter and Persephone, using their writing practice as a psychic journey into Hades and back. The chapter on Woolf focuses particularly on her representation of maternal figures and of water, arguing that Woolf mythologizes her own life in her writings. While the form of the chapter is bold-Rivers Norton intersperses her criticism of Woolf with fictionalized accounts of her own experiences - its critical clout is somewhat limited by the confused role of mythology in its argument. Mythology is at once a deliberate feature of Woolf's art, an interpretative tool for understanding her trauma, and, somehow, an inevitable pattern that her life follows. A more rigorously historicist account of narrative as therapy is found in Antonio Monegal's 'Shell-Shocked Legacies: Narratives of Trauma in Virginia Woolf, W.H.R. Rivers and Pat Barker' (in Pla, Fuentes, and Montero, eds., A Civil War of Words: The Cultural Impact of the Great War in Catalonia, Spain, Europe and a Glance at Latin America, pp. 177-94). Monegal discusses the use of narrative as a therapeutic practice by the early twentieth-century neurologist W.H.R. Rivers, arguing that Woolf's Mrs Dalloway and Barker's Regeneration foreground the expression of traumatic memories through narrative. By contrast, Marisa Sestito's 'The Lady and the Soldier: Virginia Woolf and the Great War' (in Bianchi and Ludbrook, eds., Living War, Thinking Peace (1914-1924): Women's Experiences, Feminist Thought, and International Relations, pp. 93-106), a survey of the First World War as it features in Woolf's diaries and novels, shares with Jana Rivers Norton's chapter an ahistoricist conception of illness, as well as a tendency to resort to Woolf's mental illness as a catch-all explanation for her narrative choices.

Sheela Banerjee's 'Spectral Poetics in Virginia Woolf's The Waves' (in Radford, Walton, and Anderson, eds., Modernist Women Writers and Spirituality: A Piercing Darkness, pp. 153-68), like Kathleen Heininge's book discussed above, prioritizes the spiritual dimensions of Woolf's work, reading The Waves via The Divine Comedy and T.S. Eliot in order to demonstrate that the novel unifies the spiritual realm with everyday experience. The strength of Banerjee's essay is in its close attention to the linguistic patterning of The Waves, through which she identifies 'a pattern of unity 
between the characters that becomes visible in intermittent flashes' (p. 159). Camelia Raghinaru's 'World War I and Messianic Voids in Virginia Woolf's To the Lighthouse' (in Nanette Norris, ed., Great War Modernism: Artistic Response in the Context of War, 1914-1918, pp. 89-101) similarly conceives of Woolf's writing as negotiating with a transcendent cosmic unity. Raghinaru draws upon Giorgio Agamben's idea of 'messianic time', arguing that the First World War alters the temporal conception of To the Lighthouse, bringing about a (continually deferred) possibility of transcendence.

Two books about literary representations of London also contain chapters on Woolf. Jesse Oak Taylor's The Sky of Our Manufacture: The London Fog in British Fiction from Dickens to Woolf reads literary representations of urban climates as undermining the distinction between nature and society and thus shedding light upon the geological epoch of the 'anthropocene'. The chapter on Woolf contains a particularly enlightening reading of Orlando as an example of 'climatic modernism'. Nick Hubble's 'Common People: Class, Gender and Social Change in the London Fiction of Virginia Woolf, John Sommerfield and Zadie Smith' (in Hubble and Tew, eds., London in Contemporary British Fiction: The City Beyond the City, pp. 195-210) takes a more traditionally political approach to the metropolis. Following Michael Tratner's study of the importance of the 'emergence of a modern mass society' to modernist literature (p. 199), Hubble argues that Mrs Dalloway, as well as Sommerfield's May Day and Smith's $N W$, enacts 'a liberating shift from bourgeois subjectivity to an intersectional intersubjectivity’ (p. 202).

Brenda Helt and Madelyn Detloff's edited collection Queer Bloomsbury is a landmark work in modernist queer studies which conceives of the Bloomsbury Group's reconfiguration of everyday spaces and modes of living as an ethical and aesthetic project. New essays are combined with classics of Bloomsbury criticism such as Carolyn Heilbrun's 'The Bloomsbury Group' [1968] and Christopher Reed's 'Bloomsbury Bashing' [1991], printed with new introductions that provide helpful contextual detail. One new essay in the volume is dedicated to Woolf (though she also features in Regina Marler's entertaining essay, 'The Bloomsbury Love Triangle' (pp. 135-48), which makes the convincing case that, for Bloomsbury, the triangle functioned as a stabilizing, mutually supportive form of connection). Kimberly Engdahl Coates's 'Virginia Woolf's Queer Time and Place: Wartime London and a World Aslant' (pp. 276-91) is a fascinating essay which draws productively upon Sara Ahmed's work on 'queer phenomenology' in its analysis of Woolf's depictions of wartime London. The essay argues that amid Woolf's depictions of a heteronormative, oppressive wartime society are odd moments in which characters are able to occupy 'queer' orientations in relation to time and space, enabling them to form new and radical connections with others. The essay is extraordinarily convincing given its broad scope; it takes in Jacob's Room, Mrs Dalloway, The Waves, and The Years, combining close readings with an impressive grasp of form.

Jessica Berman's edited collection, A Companion to Virginia Woolf, provides an invaluable introduction to Woolf for a new generation of scholars, while also containing some productive new readings. The book draws upon the new modernist studies' focus on technology, mass culture, and the global networks 
of modernism. Part I, 'Textual Encounters', surveys each of Woolf's novels in turn, from Emma Sutton's persuasive account of Woolf's anti-imperialist intervention in epistemologies of sound in The Voyage Out to Marina MacKay's reading of Between the Acts in relation to mass culture, which foregrounds the novel's anxieties about the limitations of communication. The strongest essays in this section are those which do not attempt a complete survey of the novel in question, instead concentrating their energies on a specific argument. While Paul K. Saint-Amour's essay on Mrs Dalloway and Elizabeth Outka's essay on Night and Day are ambitious attempts to systematize the novels (as, respectively, the encapsulation of various dichotomies and an exemplar of the 'Vicmod mode'), Derek Ryan's chapter on 'Orlando's Queer Animals' is a sustained and subtle analysis employing intertextual readings to demonstrate that Woolf's queering of sexuality in Orlando is bound up with an equally radical queering of species. Other startling new readings appear in Jane Goldman's chapter on Flush, which draws upon original historical material pertaining to the activism of the 'notorious feminist and anti-vivisectionist', Lizzie Lind-af-Hageby (p. 167), and in Anna Snaith's chapter on The Years, which ably articulates the multiple temporalities that structure the novel, from 'monads' which unite past and present in a single moment (p. 144), to the technique of 'temporal diffusion' in which particular images become 'unanchored' from their historical moment (pp. 147-8). Vincent Sherry's chapter on Jacob's Room similarly foregrounds form, reading the novel's technique of omission in the context of debates within the liberalist movement, while Jane Garrity's chapter on The Waves and Maud Ellmann's chapter on To the Lighthouse effectively employ specific motifs (the 'globe' and the 'passage' respectively) as gateways into the historical and cultural contexts of the novels. The section also reviews Woolf's non-fictional works. While ably reviewing their subject-matter, chapters by Alison Booth, Anne E. Fernald, and Laura Marcus on biography, the essays, diaries, and letters, and the shorter fiction are necessarily prevented by their broad scope from coming to any overarching conclusion. However, Jessica Berman offers a convincing reading of the formal experimentation in Three Guineas, while Susan Stanford Friedman's fascinating and fertile reading of $A$ Room of One's Own situates Woolf's polemic within a global feminist network, elucidating its connections with the lives and work of three prominent Bengali writers.

Part II, 'Approaching Woolf', surveys a wide variety of theoretical frameworks that have been applied to Woolf's texts. These range from the political, as in Jean Mills's subtle and persuasive essay on Woolf and class and Pamela L. Caughie and Melanie Micir's self-reflexive accounts of, respectively, Woolf and feminism and 'Queer Woolf', to the historical and cultural, as in Maggie Humm's chapter on 'Woolf and the Visual'. Sarah Cole's chapter on war argues that Woolf's novels are constructed around a binary of war and peace, which Cole aligns, somewhat problematically, with the binary of nature and civilization. Cole's argument is contradicted by chapters by Christina Alt and Bonnie Kime Scott that argue that Woolf's representations of nature and culture tend to deconstruct boundaries and resist categories. Ravit Reichman and Madelyn Detloff's chapters stand out in offering fresh perspectives on 
how power is articulated and resisted in Woolf's works. Reichman's wideranging analysis of Woolf's treatment of law employs perceptive close readings in order to argue that Woolf persistently rejects law in favour of a wider concept of 'justice', and, in particular, of 'care' for those whom the law fails to protect. Detloff, meanwhile, reads Woolf through the lens of 'crip theory', analysing how particular bodies in Woolf's work are caught up in, and resist, networks of biopower. Finally, Mark Hussey's chapter surveys the use of digital tools in the study of Woolf, arguing that the most useful tools are those which seek to provide material for, rather than to replace, subjective critical analysis.

Part III, 'Woolf in the World', explores Woolf's engagement with various spaces and networks - domestic, urban, and global. The most effective chapters in this section are those which examine the co-constitutive relationships between these spaces. Andrew Thacker's chapter on 'Woolf and Geography', for example, employs Henri Lefebvre's work on 'the interlinked nature of diverse social spaces' (p. 419) in order to argue that Woolf maps imperial geographies onto London's urban space, while Claire Battershill and Helen Southworth's chapter offers an enlightening analysis of the ways in which the Hogarth Press balanced personal relationships and commercial interests in its negotiation of international publishing rights. Tamar Katz provides an able analysis of Woolf's 'urban rhythms', while Nels Pearson's chapter, 'Woolf's Spatial Aesthetics and Postcolonial Critique', intervenes productively in debates about Woolf's relationship with imperialism, exposing how her representations of space and identity, even when overtly critical of empire, still rely upon the binary of an imperialistic 'order' and a fluid, chaotic, colonized 'elsewhere', thus erasing the 'multiple historical narratives' and 'local experiences' of many cultures (p. 438). Less convincing is Jesse Wolfe's chapter on 'intimacy', which relies on sweeping links between Woolf's life and work. Finally, chapters by Geneviève Brassard, Supriya Chaudhuri, and Laura Lojo-Rodríguez examine the translation and global reception of Woolf's works. Chaudhuri's account of the Indian Progressive Writers' Association's critical interactions with British modernism is particularly fascinating, as is Lojo-Rodríguez's analysis of Victoria Ocampo's work in uniting Woolf's writings with Argentinian feminism.

Frances Spalding gave the annual Virginia Woolf Birthday Lecture in 2016, on the topic of Virginia Woolf and Tristram Shandy. The lecture is too brief to cover all of the connections that could be made between Woolf and Laurence Sterne, but highlights some interesting parallels between their narrative techniques. Analysis of the narrativization of John Locke's 'association of ideas' in Tristram Shandy and Mrs Dalloway (pp. 3-4) is followed by an illuminating discussion of metafictional commentary and hyperbole in $A$ Room of One's Own, techniques which, as Spalding suggests, Woolf may have borrowed from Sterne.

This year saw a particularly wide range of journal articles on multiple aspects of Woolf's writing. Her interrogation of the relationship between human and non-human and her relevance to posthumanist conceptions of identity were particularly prominent. A special issue of Modernism/Modernity on 'Modernist Inhumanisms' foregrounded Woolf, with an introduction by 
Aaron Jaffe, 'Who's Afraid of the Inhuman Woolf?' (Mo/Mo 23[2016] 491513), taking A Room of One's Own as a starting point for an exploration of modernism's preoccupation with inhuman scales. Charles M. Tung's article in the same issue, 'Baddest Modernism: The Scales and Lines of Inhuman Time' (Mo/Mo 23[2016] 515-38), reads Woolf in relation to the science fiction writer Olaf Stapledon and the biologist J.B.S. Haldane. Woolf's articulation of the non-human also preoccupied other journals: Nicole Rizzuto's 'Maritime Modernism: The Aqueous Form of Virginia Woolf's The Waves' (ModCult 11[2016] 268-92), provides a lucid account of how Woolf resists imperialistic techno-scientific and legal mappings of the sea by depicting it as a space beyond human experience, while Payal Taneja, 'Gift-Giving and Domesticating the Upper-Class Pooch in Flush' (Mosaic 49:i[2016] 129-44), analyses the various hierarchies of power-gender, class, and species - that intersect in the novella. Finally, Leanna Lostoski's article, " Imaginations of the strangest kind": The Vital Materialism of Virginia Woolf" (JMMLA 49:i[2016] 53-74), draws upon Jane Bennett's concept of 'vital materialism' to argue that Woolf depicts non-living matter as inextricably linked to living matter, and as having its own agency.

The construction of spaces, both national and domestic, was also a particular preoccupation, forming the focus of two articles in English Studies. Maria J. Lopez's innovative article, 'The Gothic, the Abject and the Monstrous: A Revision of National Identity in Virginia Woolf's Between the Acts' (ES 97[2016] 493-509), persuasively argues that Woolf uses Gothic tropes in her final novel-monstrosity, liminality, the intrusion of the foreign - in order to undermine the idea of a stable national identity. Allan Johnson's article on domestic space, "'The doors would be taken off their hinges": Space, Place, and Architectural Absence in Virginia Woolf' (ES 97[2016] 412-19), similarly deals with liminality and the deconstruction of stable spaces. An article by Sara Crangle in Modernism/Modernity, 'Out of the Archive: Woolfian Domestic Economies' (Mo/Mo 23[2016] 141-76), takes a more biographical approach to domestic space. Crangle's article is an illuminating survey of Virginia and Leonard Woolf's meticulous records of their domestic expenditures, health, and social engagements in their pocket diaries. She focuses particularly on Leonard's records of his wife's menstrual cycle, noting their 'paternalism', but also placing them in the context of contemporary writings on menstruation.

Woolf's treatment of time was also the object of considerable attention. Cedric Van Dijck's 'Time on the Pulse: Affective Encounters with the Wristwatch in the Literature of Modernism and the First World War' (ModCult 11[2016] 161-78) looks at how Woolf and Siegfried Sassoon use the wristwatch as a symbol of the internalization of an oppressive temporality imposed by war. The article is notable for extending the boundaries of modernism to encompass war writing, which, Van Dijck argues, similarly inscribes an 'affective' response to modernity. Like Camelia Raghinaru's chapter discussed above, Frances L. Restuccia's 'A Messianic Aesthetic: Lily Briscoe's Vision' (Genre 49[2016] 1-25) applies the notion of 'messianic time' to To the Lighthouse, arguing that the novel depicts a 'nonteleological' form of salvation that embraces destruction and decay. Woolf's engagement with 
religious conceptions is also examined by David Sherman in 'Woolf's Secular Imaginary' (Mo/Mo 23[2016] 711-31). Through close readings of Woolf's use of free indirect discourse, Sherman shows that religious sentiment is always disowned and displaced rather than being located in a single viewpoint, mirroring the circumscription of religious experience to particular domains in secular societies.

Woolf also made an appearance in several feminist journals and articles. Kristin Czarnecki's "'Strong women make strong nations": Women, Literature and Sovereignty in Paula Gunn Allen and Virginia Woolf' (JFemS 11[2016] 46 paras.) undertakes an intersectional analysis of Woolf's promotion of feminist histories in A Room of One's Own alongside Paula Gunn Allen's celebration of female-centric Native American cultures in The Sacred Hoop. Intersecting forms of oppression are also the focus of Kathleen Renk's article, "Blackberrying in the sun"? Modernism and the Ageing Woman in Rhys's Good Morning, Midnight, Woolf's Mrs Dalloway and Sackville-West's All Passion Spent' (Women 27[2016] 317-28), which argues that, in their depiction of ageing women, the three writers create an alternative modernism that challenges the ageism and sexism of their society. Two further articles focus on A Room of One's Own, with Anna-Klara Bojo's 'Topos Taxi: Michel Foucault and Virginia Woolf on Two Modern Grammars of Love' (FemT 17[2016] 21-34) considering Woolf's use of the taxi as a symbol of romantic union, and Margarita E. Sánchez Cuervo's 'The Appeal to Audience through Figures of Thought in Virginia Woolf's Feminist Essays' (Renascence 68[2016] 127-43) identifying Woolf's use of rhetorical figures as a means of engaging her audience.

Several articles shed new light upon Woolf's literary and historical influences. Janine Utell's article in Life Writing, 'View from the Sickroom: Virginia Woolf, Dorothy Wordsworth, and Writing Women's Lives of Illness' ( $L W$ 13[2016] 27-45), persuasively argues that for both Woolf and Wordsworth illness opened up a space of creativity, heightened perception, and transgression. George Rylands emerged as another under-appreciated influence on Woolf in Emily Kopley's article 'Virginia Woolf's Conversations with George Rylands: Context for A Room of One's Own and "Craftsmanship", (RES 67[2016] 946-69), while Marea Mitchell's article in the Chaucer Review, "The details of life and the pulsing of affect": Virginia Woolf's Middle English Texts' (ChauR 51[2016] 107-29), identifies Woolf as a model modern reader of Chaucer, who exemplifies how his texts can be appropriated by those outside the masculine tradition. Another article excavating important historical contexts for Woolf is Clara Jones's 'Virginia Stephen at the Dr. Williams's Library' (Women 27[2016] 125-36), which draws upon archival material in order to consider how Woolf's membership of a mostly female, lower-middle-class reading community inflected her early essays and fiction.

There were also extensive analyses of Woolf's literary and cultural legacies, from Martin Ferguson's discussion, in 'Virginia Woolf and "the Hermaphrodite": A Feminist Fan of Orlando and Critic of Roger Fry' (ES 97[2016] 277-97), of the prison reformer and feminist Mary Louisa Gordon as a reader of Woolf, to Jennifer P. Nesbitt's piece on Woolf's (non-)appearance 
in a mainstream television programme, 'The Absent Presence of Virginia Woolf: Queering Downton Abbey' (JPC 49[2016] 250-70). Lindsay Starck's 'The Matter of Literary Memory: Virginia Woolf's Mrs Dalloway and Ian McEwan's Saturday' (Adaptation 9[2016] 328-44) and Erin Penner's 'For Those "Who could not bear to look directly at the slaughter": Morrison's Home and the Novels of Faulkner and Woolf' (AAR 49[2016] 343-59) consider two recent novels as reworkings of Mrs Dalloway, while Alberto Fernández Carbajal's article in the Journal of Commonwealth Literature, 'On Being Queer and Postcolonial: Reading Zadie Smith's $N W$ through Virginia Woolf's Mrs Dalloway' (JCL 51[2016] 76-91), identifies commonality in Woolf's and Smith's depictions of thwarted 'female homosociality', while remaining attentive to the differences between the two texts, particularly in their treatment of ethnicity and class.

The 2016 issue of Woolf Studies Annual contains four articles making significant contributions to Woolf studies. Emily Dalgarno's 'Virginia Woolf Reinvents the Socratic Dialogue' (WStA 22[2016] 1-20) is a convincing consideration of Woolf as a reader of Plato which combines attentive close readings with an awareness of historical context in order to argue that, unlike contemporary commentators who tended to read Plato's texts as 'univocal philosophical treatises' (p. 1), Woolf prioritized their dialogic form. In 'Was Virginia Woolf a Snob? The Case of Aristocratic Portraits in Orlando' (WStA 22[2016] 21-40), Christine Fouirnaies unearths historical details about the real subjects of the portraits in Orlando, persuasively suggesting that the images constitute a critique of the aristocracy. J. Ashley Foster's article, 'Writing in the "White Light of Truth": History, Ethics, and Community in Virginia Woolf's Between the Acts' (WStA 22[2016] 41-73), traces evidence of a Quaker spiritualism within Woolf's representation of community in Between the Acts. Like Kathleen Heininge (discussed above), Foster focuses on political resonances, convincingly arguing that Quakerism's focus on 'the interconnectedness of being', social justice, and pacifism makes it an important 'philosophical frame' for Woolf, one which connects apparent oppositions in her work, particularly materialism and spiritualism, and individuality and community. Finally, Clara Jones's 'Virginia Woolf and "The Villa Jones" (1931)' (WStA 22[2016] 75-95) analyses the political significance of an unpublished letter from one of Woolf's notebooks. (The article also contains a facsimile and transcript of the letter.) Through Jones's nuanced analysis of Woolf's use of voice, the letter, which, as Jones notes, initially appears to be a classist diatribe against middle-class rural developers, emerges as a complex consideration of the debates surrounding interwar ruralism and state intervention.

The Virginia Woolf Miscellany published three issues in 2016, each containing a varied collection of valuable and perceptive short essays. Guest-edited by Ann Martin, issue 88 had the theme of 'Virginia Woolf in the Modern Machine Age', and included discussions of the radio, the motor car, and the commercial milk industry. Particularly notable in this issue are Ria Banerjee's use of Walter Benjamin to elucidate the radical uses to which Woolf puts the medium of the letter in 'The Uprising of the Anecdotes: Women's Letters and Mass-Produced News in Jacob's Room and Three 
Guineas' (VWM 88[2016] 11-14) and Jeremy Lakoff's article 'Virginia Woolf's (Absent) Radio' ( $V W M$ 88[2016] 19-20), which relates the radio to the combination of immateriality and embodiment in Woolf's depictions of identity. The issue also contains a reflective piece by Michèle Pridmore-Brown, 'Thinking through Virginia Woolf: New Technologies and the Virtues of Leaning Sideways' ( $V W M$ 88[2016] 25-8), in which Pridmore-Brown connects her influential research on Woolf and radio with her more recent work on maternal 'timing'. Drawing upon a wide range of cultural and scientific reference-points, Pridmore-Brown argues that Woolf's depiction of silence in Between the Acts, as well as her representations in her feminist essays of women postponing motherhood, disrupt imposed temporal schemes and allow room for 'untried or unfixed identities' (p. 26). Issues 89 and 90 of the Virginia Woolf Miscellany were also published in 2016, as a double issue. In issue 89, Alexandra DeLuise's subtle analysis of the role of windows and mirrors in enabling self-expression for homosexual characters in Woolf and Katherine Mansfield, 'Panes of Glass: Windows and Mirrors in Between the Acts and "Bliss", (VWM 89[2016] 29-31), is particularly noteworthy. Guest-edited by Cheryl Hindrichs on the theme 'Virginia Woolf and Illness', issue 90 contains a range of illuminating interpretations of Woolf's essay 'On Being Ill', as well as considerations of Flush, Mrs Dalloway, and The Years. Claire Barber-Stetson's article, 'On Being Ill in the Twenty-First Century' (VWM 90[2016] 48-50), stands out in having the potential to transform our understanding of Woolf and illness by pointing the way towards a unification between disability studies and pathography. Another innovative analysis of 'On Being Ill' can be found in Elise Swinford's essay 'Gone Sideways: Woolf's Empathetic Sick Bed Travels' ( $V W M$ 90[2016] 51-3), which argues that Woolf reconfigures the relationship between the global and domestic by presenting travel as an affective, domestic experience, a reconfiguration that Swinford links to the Hogarth Press's project of publishing global authors in a domestic publishing house.

Finally, Woolf's enduring fertility and adaptability are evidenced by her appearance this year in journals within such disparate fields as art, architecture, and law. In the Oxford Art Journal, Catherine Grant's 'A Time of One's Own' (OxAJ 39[2016] 357-76) applies Woolf's arguments in A Room of One's Own to contemporary feminist art, while Marko Jobst's article, 'Writing Sensation: Deleuze, Literature, Architecture, and Virginia Woolf's The Waves' (JArch 21[2016] 57-67), identifies The Waves as a model for an architecture that foregrounds sensation and the self. Two articles articulate Woolf's relationship to law: Riley H. Floyd, "I must tell the whole world": Septimus Smith as Virginia Woolf's Legal Messenger' (ILJ 91[2016] 1473-92), uses Septimus's experiences in Mrs Dalloway to explore the disjuncture between what is legally sanctioned in war and what soldiers feel to be morally right, while Herschel Farbman's 'Corporate Personhood and Modernist “Impersonality": Woolf's Drama' (LawL 28[2016] 379-402) applies Woolf's exploration of non-human perspectives to current legal debates about the nature of 'personhood' (specifically in relation to corporations). 


\section{Post-1945 Fiction}

\section{(a) Fiction 1945-2000}

Following Bloomsbury's Contemporary Decades series in previous years, 2016 saw the publication of a range of texts attempting a similar systematic survey of contemporary literature. Edited by Peter Boxall and Bryan Cheyette, British and Irish Fiction since 1940 is the seventh volume in The Oxford History of the Novel in English and it offers a comprehensive overview of the period. Thirtythree topical chapters range from C.L. Innes's 'Migrant Fiction' (pp. 94-109) to Philip Tew on 'Comedy, Class, and Nation' (pp. 161-73), and from Peter Hunt on 'The Children's Novel' (pp. 310-27) to Sherryl Vint on 'Dystopian Science Fiction and the Return of the Gothic' (pp. 383-97). Kirsti Bohata also contributes to this volume, writing about 'Welsh Fiction in English: 1979, 1997, and After' (pp. 528-45), alongside scholars such as Peter Morey concentrating on black British and Asian fiction (pp. 466-79), Matthew Hart on Northern Irish and British nationalism (pp. 480-93), and Scott Hames and Derek Hand on contemporary Scottish and Irish fiction (pp. 494-511 and 51227). The collection is structured in four parts: '1940-1973'; 'Genres/ Subgenres'; '1973 to Present'; and 'Approaching the Twenty-First-Century Novel'. Boxall and Cheyette identify three significant periods in publishing: the Second World War and its aftermath; the oil crisis that followed the 1973 Arab-Israeli war and the ensuing reformation of the publishing industry; and finally the 2008 recession - which, they suggest, is responsible for accelerating the success of the ebook industry and electronic booksellers (p. 1). As such, the tripartite periodic division of the collection aptly reflects these concerns, focusing on and responding to periods of 'rapid social, technological, and economic change' (p. 1). Among significant critiques in this collection is the challenge to 'the supposed smallness of the post-war novel' (p. 7), and increased connectivity between the different periods discussed. Furthermore, by choosing to dedicate a section of the collection to genre and form, the editors and contributors aim to prompt dialogue between 'the literary (the supposedly universalized and transcendent form of the novel) and the generic (which is supposed to engage only with a particular aspect of experience)' (p. 13). In doing so, they demonstrate the extensive critical cross-over between the different sections of the collection as well as the distinct periods. To take one of the mission statements in the introduction, this volume 'belongs to a critical movement that is seeking to pass beyond postmodernism, and in so doing to reconstruct a material historical sensibility, without simply reverting to the historical models and paradigms that postmodern thinkers were rightly determined to overthrow' (p. 12).

This statement from Boxall and Cheyette presents a pertinent comparison to The Cambridge History of Postmodern Literature, edited by Brian McHale and Len Platt. Postmodern Literature presents a periodic approach to postmodernism. The first section focuses on the precursors of postmodernism, with Joe Bray on modernism (pp. 25-38), Robert Eaglestone on the First World War and the Holocaust (pp. 39-51), Theo D'haen on the end of the British empire (pp. 52-66), and Alan Nadel on the Cold War and its cultural effects 
(pp. 67-82). Contributors then analyse the role of postmodernism in the 'Long Sixties', with David R. Shumway on countercultures (pp. 112-26), John Johnston on mass mediation (pp. 95-111), and Thomas Docherty on the rise of theory (pp. 159-72). The section devoted to 1973-1991, entitled 'The Major Phase: Peak Postmodernism', includes Robyn Warhol on 'Second-Wave Feminism and After' (pp. 230-46), Martin Dines on LGBT 'subcultures' (pp. 247-61), Sara Upstone on postcolonialism (pp. 262-77), Elana Gomel on cyberpunk (pp. 353-68), and Len Platt Scottish nationalism and postmodernism (pp. 278-92). Finally, the 'Interregnum' period (1989-2001) ends the collection with a focus on global writing and digital culture, and an epilogue by Andrew Hoberek entitled '2001, 2008, and After' (pp. 497-514). With over thirty-five contributors and topics, this volume presents an intensely theoretical and wide-ranging survey of postmodernist literature and all its contradictions. The editors ask what 'kind of temporality can now begin to come into focus' with regard to postmodernism, and 'how we might begin to distinguish subperiods and locate internal thresholds, constituent movements within the postmodern movement' (p. 4).

Allan Hepburn's edited collection, Around 1945, provides a selection of critical essays analysing how British literature from the mid-twentieth century to the present day modelled and continues to model human rights. Released in 2016, as the UK government discussed withdrawing from the European Convention on Human Rights, the collection seems curiously prescient in its focus on the contemporary relevance of human and cultural universal rights, as played out in British literature. In the introduction to the collection, Allan Hepburn states that 'somewhere around 1945, thinking about citizenship moved away from national expressions of rights towards the universal applicability of rights' (p. 3). Such an opening prompts wider discussion of the human condition, and the 'prerogatives of citizenships' (p. 3). Structured in three parts ('Citizens', 'Violations', and 'Rights'), chapter topics range from Marina MacKay on citizenship in the English novel (pp. 29-47) to Melanie Micir on 'Women's Work' in historical novels of the mid-twentieth century (pp. 66-83), with Mitchell C. Brown on human rights in Graham Greene's The Third Man [1950] (pp. 197-215), Peter Kalliney on the confessional fiction of the Cold War period (pp. 240-61), and essays by Nadine Attewell (pp. 216-39) and Matthew Hart (pp. 262-78) on racial politics in the mid-twentieth century. Janice Ho's chapter, 'The Human and the Citizen in Joseph Conrad's The Secret Agent' (pp. 107-28), while technically outside the periodic scope of this review, remains the stand-out contribution to this collection, using Conrad's novel as a prompt to argue that the definition of 'the human' (p. 107) is dependent on concepts of cognitive normality, with specific reference to eugenic categorization of disability and so-called 'feeble-mindedness' in the twentieth century, and the ensuing connotations regarding the value of human life. Such debates have clear relevance to later twentieth-century literary and cultural engagement with concepts of disability and worth. Drawing on the work of Hannah Arendt and Giorgio Agamben, Ho presents Conrad as using sentimentalism surrounding Stevie's 'idiocy' (p. 108) to challenge biopolitical models of categorization that attempt to limit the citizenship and rights of individuals with cognitive disabilities. This original reading of The Secret 
Agent has wider significance for disability studies scholars, with greater complexity of political engagement than the trope of narrative prosthesisfocusing on the commonality of human experience and rights rather than ablebodied normality.

Sebastien Groes's British Fictions of the Sixties: The Making of the Swinging Decade overlaps with many of the concerns highlighted in the survey volumes mentioned above, addressing history and myth-making, gender and racial politics, postcolonialism, and literary experimentation. Building on The Making of London [2011], in which he discussed myth-making in literary representations of London, Groes argues that the British 1960s was 'an epistemological hinge movement that is clothed in myths implicated in shaping our understanding about the past, our present moment and the future' of contemporary culture (p. 1). Groes presents British Fictions of the Sixties as an attempt to demythologize the text and images of the 'decade of the Spectacle' (p. 1), and analyses what the $1960 \mathrm{~s}$ meant to a contemporary readership. Beginning with a chapter on 'authenticity and audiotape', which focuses on Nell Dunn's fiction, Groes engages with early reviews of Dunn's work, describing it as 'as authentic as a tape recorder' (p. 22), using deadpan narrative and audiotapes as tools that enabled women to 'appropriate, manipulate and broadcast their own voices' (p. 34) outwith dominant patriarchal narratives. Other highlights of the text include Groes's analysis of Muriel Spark's The Girl of Slender Means [1963] as representative of realist and politically subversive novels of the 1960s, and his contrasting chapter on 'The Extreme Sixties' and J.G. Ballard's The Atrocity Exhibition [1970], aiming to 'destroy organic plotting, narrative linearity and centralizing forces' in order to present radical uncertainty at the close of the 1960s.

Roberto del Valle Alcalá's British Working-Class Fiction: Narratives of Refusal and the Struggle against Work also opens with a focus on the midtwentieth century - presenting an ethically centred analysis of British literary reactions to work and labour from 1950 until the 2008 recession. Focused on the writing of Alan Sillitoe, David Storey, Nell Dunn, Pat Barker, James Kelman, Irvine Welsh, Monica Ali, and Joanna Kavenna, British WorkingClass Fiction aims to 'bring the antagonistic logic rehearsed by the Marxist analysis of work ... back to the central stage of literary critical concerns' (p. 2). del Valle Alcalá concludes that post-war capitalism, in its literary depictions, 'appropriates the social, neutralizing the transcendent exteriority represented by traditional working-class struggles ... by extending the realm of work, by turning work into an ineluctable social bond' (p. 172), with a strong over-determination of even the social elements of the working life.

Also concerned with capitalism and literary creation is Ken Gelder's New Directions in Popular Fiction: Genre, Distribution, Reproduction. Popular fiction has received increasing and at times controversial attention in the past few years, including David Glover and Scott McCracken's Cambridge Companion to Popular Culture [2012], Jayashree Kamblés Making Meaning in Popular Romance Fiction [2014], and the Bloomsbury Introduction to Popular Fiction, edited by Christine Berberich [2015]. In his introduction to New Directions (pp. 1-19), Gelder offers critical analysis of and reactions to popular fiction as 'internally fractured and ... vigorously contested' (p. 7), 
with an emphasis on "understanding the "popular" as a highly stratified set of niche market cultural practices' (p. 8). Divided into two parts, 'Histories of Popular Culture' and 'Authors, Distribution, (Re)Production', this edited collection spans works from across the twentieth and twenty-first centuries, alongside detailed discussion of earlier examples of popular fiction. This twopart structure enables contributors to analyse specific authors and texts, from Merrick Burrow on British spy thrillers (pp. 111-33) to Jeffrey Andrew Weinstock on the influence of Lovecraft on the 'new weird' (pp. 177-99), and Sabine Vanacker on Denise Mina's 'tartan noir' (pp. 222-38), alongside paratextual concerns around publication, reception, and the role of fandoms in contemporary popular fiction. This latter section sets the volume apart from Glover, McCracken, and Berberich's earlier collections, although Gelder's criticisms of the latter as 'reductive' (p. 3) seem excessive. The attention paid by contributors to publishing contexts, adaptation, and fandoms in popular fiction is significant in terms of wider growth in fandom and paratextual studies, and makes for engaging and provocative reading.

Michèle Mendelssohn and Denis Flannery's Alan Hollinghurst: Writing Under the Influence also provides readers with the first edited collection to analyse a contemporary author's full literary output. Featuring chapters by Bernard O'Donoghue and Michèle Mendelssohn on Alan Hollinghurst's poetry and Denis Flannery on his engagement with theatre, the chapters centred on fiction range from Angus Brown on the role of reading in Hollinghurst's early prose to Mendelssohn's account of the role of porn and parody in his work. John McLeod's chapter provides a useful foil to Brophy's discussion of Hollinghurst and empire in the previous collection, with The Swimming-Pool Library [1988] presented as a moral and ethical assessment of the British colonial past. Meanwhile, Julie Rivkin's analysis of the role of origin stories and history in The Stranger's Child [2011] and Henry James's The Aspern Papers [1888] provides interesting commentary on metafiction, history, and intertextuality in Hollinghurst's work. Joseph Ronan concentrates on the cultural role of bisexual camp, and Robert L. Caserio analyses the significance of literary genealogies and intertextuality in The Folding Star [1994] and The Spell [1998]. Geoff Gilbert discusses fantasy, sex, and spatial reality in Hollinghurst's fiction, while Alan O'Leary analyses the influence of cinema in The Swimming-Pool Library. Kaye Mitchell's " "Who are you? What the fuck are you doing here?": Queer Debates and Contemporary Connections' expands analysis of Hollinghurst's intertextuality from the Victorian and modernist to the contemporary, referencing Edmund White, Colm Tóibín, David Leavitt, Michael Cunningham, and late 1990s queer theorists. The collection ends with the transcript of 'What Can I Say? Secrets in Fiction and Biography', Hermione Lee's interview of Alan Hollinghurst as part of the Weinrebe Lectures at Wolfson College, Oxford, in 2012. While biography is not within the purview of this review, Hollinghurst's comments overlap strongly with new developments in biographical fiction-engaging with Hollinghurst's interest in 'writing about what happens to the memory, the name' of those who die young (commenting on First World War poets) (p. 192). 
Hollinghurst's interview leads into the critical arguments in favour of Michael Lackey's Biographical Fiction: A Reader, published by Bloomsbury. Including authors' reflections, forewords, lectures, interviews, and essays, this collection provides a broad survey of the spread of biographical fiction and its forebears and sets Georg Lukács's model of biographical fiction as a 'bastardized version of the historical novel' in dialogue with Paul Murray Kendall's concept of fictional biography as entirely separate from (and less than) 'legitimate biography' (p. 1). In presenting this anthology, Lackey intends to present 'the official arrival' of biofiction, as 'emancipated ... from both historical fiction and life writing, and [which] has charted a narrative space uniquely its own' (p. 3). Lackey's Biographical Fiction will provide a useful primer to students studying life-writing or biofiction, and be a useful complement to the growing critical attention paid to biographical fiction.

Also published by Bloomsbury, Sarah Lonsdale's The Journalist in British Fiction and Film: Guarding the Guardians from 1900 to the Present analyses overlaps between fictional and non-fictional writing. Of the novels discussed in Lonsdale's monograph, an estimated 66 per cent were written by journalists; Lonsdale positions these texts as 'valuable snapshots' of twentieth-century culture, engaged as they are in dual literary production (p. 5). Thus Lonsdale argues that novels about journalism published since the 1970s show little confidence in the 'benign side' of the press, in contrast to the presentation of the media in earlier works - a reflection of changing market and social pressures (p. 10). To take one example, Lonsdale analyses George Orwell's Nineteen Eighty-Four [1949] not only as dystopian fiction, but also as a text deeply concerned with contemporary publishing and journalism. Orwell wrote the novel during the Royal Commission hearings, and Lonsdale highlights the significance of a cultural context where the British press was being castigated for 'its failure to fulfil its most fundamental duty in a liberal democracy: to help produce, through articulating divergent views of public opinion, an enlightened public which could conduct its civic duty in full knowledge of events' (p. 162). Also worth singling out is Lonsdale's chapter on women journalists and writers in the twentieth century, 'From Plucky Pioneers to "Dish Bitches": The "Problem" of Women Journalists'. This features some unsurprising, but nonetheless depressing, statistics about the marginalization of women in twentieth-century journalism: women made up 17 per cent of the workforce in 1931; 20 per cent in 1961; 25 per cent in 1971-the BBC introduced the Marriage Bar in 1932 deliberately to prevent the progression of married women. Lonsdale also challenges Bourdieu's model of cultural production as it pertains to women journalists and writers, suggesting that the authors she discusses in this chapter use their novels to mirror gender struggles and discrimination in the journalistic workplace. In doing so, they protest women's confinement to "soft" features and celebrity trivia' (p. 186). Finally, continuing this strand of research into experimental overlaps between fiction and other literary forms, Mike Ashley's Science Fiction Rebels: The Story of the Science-Fiction Magazines from 1981 to 1990 details the development of counter-culture science fiction 'zines', analysing a range of short genre fiction from the period as part of his meticulous and lively study of science fiction zines in the late twentieth century. 


\section{(b) Fiction after 2000}

This year saw four interconnected thematic currents run through almost all contemporary literary scholarship: the posthuman; spatiality; utopia and futurity; and history and memory. Two volumes from the Cambridge University Press consolidated these themes: Bruce Clarke and Manuela Rossini edited the Cambridge Companion to Literature and the Posthuman, while the publication of Brian McHale and Len Platt's Cambridge History of Postmodern Literature seems to have marked the consignment of postmodernism to history. Plenty of the texts under review here express explicit and implicit anxieties around what comes after postmodernism to constitute the now.

Contemporary Literature offered only two contributions to scholarship on post-2000 British and Irish literature during 2016. Emily Johansen's 'The Neoliberal Gothic: Gone Girl, Broken Harbor, and the Terror of Everyday Life' (ConL 57:i[2016] 1-29) is an excellent article. Following Stephen Shapiro, Johansen explains that the Gothic 'emerges as particularly potent at times of both crises in and shifting intensifications of capital' and identifies the ongoing crisis of neoliberalism as such a time (p. 31). Analysing Gillian Flynn's Gone Girl [2012] and Tana French's Broken Harbor [2012] as Gothic fictions specific to the neoliberal moment, Johansen argues that there is no traditional Gothic return here, no escape short of a 'more radical overhaul of the structures of everyday life' (p. 31). Johansen homes in on a theme that recurs in many other works reviewed: a hollow, uncertain futurity. Benjamin Bergholtz's "Certainty in its purest form": Globalization, Fundamentalism and Narrative in Zadie Smith's White Teeth' (ConL 57:iv[2016] 541-68) successfully takes an Adornian approach to the novel's aporia of fundamentalism as an alluring but inadequate response to globalization, and argues that the violent marriage of the two has proven to be prescient.

Derek Lee's 'The Politics of Fairyland: Neil Gaiman and the Enchantments of Anti-Bildungsroman' (Crit 57:v[2016] 552-64) analyses Gaiman's response to the realist Bildungsroman as a generic innovation that reconsiders both humanity's relationship with capitalist society and the role of fantasy in contemporary life. Lee's heady utopian reading of Gaiman as reconfiguring 'Marxist scholarship itself' might seem like an overstatement that weakens an otherwise interesting article justifiably seeking to reclaim fantasy from the unrelenting clutches of Darko Suvin (p. 553). Erin O'Dwyer enacts a playful and clever Lacanian reading of Ian McEwan's Atonement as a contemporary epistolary novel in 'Of Letters, Love and Lack' (Crit 57:ii[2016] 178-90). In 'Salman Rushdie from Postmodernism and Postcolonialism to Cosmopolitanism: Toward a Global(ized) Literature?' (Crit 57:iv[2016] 43347), Arijana Luburić-Cvijanović and Nina Muždeka examine the ways that Salman Rushdie's work evades classification in the era of 'post-theory' (p. 433). The hybridity of cultures, traditions, and genres they identify is a contemporary thematic present in some form in all of the literary analyses here under review.

Due to change of publishers and the accompanying move to the open-access Open Library of Humanities platform, C21 Literature: Journal of 21st-Century 
Writings only put out a single issue in 2016. Daniel Weston's 'Contemporary Poetic Ecologies and a Return to Form' (C21 4:i[2016] 5) argues that critical responses to ecologically oriented poetry are overlooking 'traditional' poetic forms, and elucidates his assertion that the lyric (and associated forms) is necessary for understanding contemporary ecopoetry by analysing the firstperson pronoun in Jo Shapcott, Jen Hadfield, and Kathleen Jamie. In many ways, Weston's article acts as an interesting companion piece to Sam Solnick's book-length study, Poetry and the Anthropocene, which approaches ecology through the poetry of Ted Hughes, Derek Mahon, and J.H. Prynne. Aris Mousoutzanis's 'Network Fictions and the Global Unhomely' (C21 4:i[2016] 7) makes a striking case for the notion of the 'global unhomely', a rewriting of Freud's theory of the uncanny, that reconceptualizes the tension between global flows and local cultures that many 'network fictions' explore as an encounter between the strange and familiar. Mousoutzanis uses this notion to gesture towards the spatial dislocations and temporal disruptions central to the experience of globalization.

Katy Shaw's " "Local Hells" and State Crimes: Place, Politics, and Deviance in David Peace's Red Riding Quartet' (in Pepper and Schmid, eds., Globalization and the State in Contemporary Crime Fiction, pp. 59-77) analyses the experience of globalization mediated by the state and its enforcers. This essay examines tensions in spatial order to interrogate the deployment of state power in the service of economic neoliberalism and the inherent corruption of private-public partnerships. This is an invaluable chapter that suggests that "mapping a conflict between the community and the local, the state and the neoliberal' is well served by a (re)mapping of place as historical (p. 75). The Quartet's crime scenes, spaces in which everything is loaded with significance, emphasize the importance of place in critiques of a neoliberalism, which subsists on creative destruction.

In Rethinking Race and Identity in Contemporary British Fiction, Sara Upstone explores the interconnected themes of utopia and futurity that underpin a great deal of literary analysis in 2016. The book provides a timely account of post-racial utopia and a comprehensive survey of race in contemporary British literature. She covers a wide and inclusive range of authors, from Hari Kunzru and Zadie Smith to Andrea Levy, Alex Wheatle, Helen Oyeyemi, and more. Her nuanced, incisive readings give none of these authors short shrift. Indeed, the deft analytical movements Upstone is able to make across texts firm up the sheer importance of analysing post-racial utopianism in contemporary British literature. This book argues that 'contemporary British fiction ... plays an important part in gesturing towards the possible future of a transformed social landscape' and that this is 'facilitated by specific and strategic uses of literary form' (p. 11). Upstone reads contemporary realist fictions as a reconfiguring of utopia. Taking up Jameson's critique that 'the real cannot be superseded so that the utopia ultimately comments only on the futility of its own discourse', she argues that the realist text actually relies upon the 'maintenance of the real' and the integration of future possibility (p. 14).

Upstone responds to criticism of the post-racial as 'unrealistic' by nuancing the idea of the post-racial itself: it becomes a project to 'deny the primacy of 
biology' and look to the future without eroding past or present inequalities and violence (p. 47). It is here that the book sometimes falls short. Utopia might be a process, but here the nature of this process is never entirely clear. Upstone admits, in the final chapter, that the previous six have presented the post-racial as 'the stuff of dreams' (p. 134). She goes on to argue that 'even at the most depressing moments in recent British history what appears utopian has seemingly forced its way ... into the present' with stories of mixed-race solidarity and post-racial friendships (p. 134). In the year since the book's publication, racism has resurged, or perhaps more accurately unveiled itself, with an aggression that makes this utopia seem farther away than ever. These heartening moments of humanity, while engendering hope, do not touch on the structural elements of racism. Indeed, in presenting a 'potential solution [that] exists only-but tangibly - in the imagination', the utopian thought of the previous chapters risks inadvertently reproducing the structures of capitalist ideology, itself promising a tangible but not-yet equilibrium to justify present inequalities (p. 58). Some intersectionality with Bloch, and Marxist analysis of utopia more generally, might help to flesh out the utopian process, but Upstone's Rethinking Race is already doing so much interesting work. This should not, therefore, detract from what is undeniably an excellent and thorough study of race and identity in contemporary British fiction so much as present further paths for research and discourse.

Gylphi's Contemporary Writers: Critical Essays series has done an enormous amount for contemporary British fiction. Having published excellent collections in 2015 on David Mitchell and China Miéville, the series lived up to its own high standards in 2016 with the arrival of collections on Adam Roberts, Rupert Thomson, and Tom McCarthy. These collections, even in their very form, showcase the potential of contemporary literary study: they are all born out of conferences which the authors themselves attended, and the three collections begin with forewords by the authors on the experience of being the subject of study.

Under the brilliant editorship of Christos Callow Jr. and Anna McFarlane, Adam Roberts: Critical Essays bridges the perceived gap between science fiction and 'literary' fiction. In their introduction the editors unpack the tendency to split Roberts into 'different beasts': the academic, the sciencefiction author, and the satirist. It becomes clear that these things are not separable, and this neatly underpins the challenges that this volume makes to the fixity of genre and notions of authorship. The collection is split into four parts: 'Alienating Characters', 'Political Interventions', 'Ludic Authorship', and 'Intertextual Networks'. Part I opens with Farah Mendlesohn diagnosing almost all of Roberts's protagonists with dissociative personality disorder, and homing in on sociopathic tendencies in the science-fiction genre more generally. Michelle Yost takes up Roberts's alienating characters and argues that his novels function as contemporary Menippean satires of religious and political extremism. She argues that it is 'almost invariable' that extremism in Roberts's novels 'result[s] in dystopian nightmares' (p. 56). These dystopias are 'ironic glimpses into our own present', perhaps the cynical comrades to Sara Upstone's realist utopias. Niall Harrison continues the interrogation of estranging protagonists, considering its impact on the critical and popular 
reception of Roberts's fiction. Harrison considers the changing responses to Roberts's work as a demonstration of the science-fiction field's tendency to 'solve a writer' through genre may 'reify patterns into rules' (p. 75). We might usefully extend this as a precaution to those who desire to solve contemporary literature after postmodernism.

Part II sees Anna McFarlane consider Isaac Asimov's Foundation [1942-93] series as an intertext to Jack Glass [2012] that elucidates 'a move from Newtonian physics to chaos theory' (p. 14). In political terms this is a movement away from 'the mass', but not at the expense of the masses. McFarlane uses the plurality of individuals and demands that made up Occupy as an example of this. She argues that Jack Glass breaks with the cyclical time and binding teleology of linear history present in Foundation and 'hints at revolutionary potential without ever consummating this potential within its pages' (p. 99). Catherine Parry close-reads By Light Alone [2011] to consider the political implications of persisting inequality in this fictional postscarcity society. The essay suggests that the commonly understood utopia of post-scarcity falls apart in the face of an ideology driven by consumption and manufactured demand, which Parry maps onto the contemporary moment. Thomas Wellmann concludes Part II by considering the extent to which New Model Army [2010] functions as an allegory of European-style democracy.

The third section pays homage to Roberts's genre play and parody with two experimental essays. Paul Graham Raven analyses a fictional critical response to New Model Army. The essay is wide-ranging, touching on network theory, digitization, utopia, authorship, language, and anarchism. It is an entertaining read that interrogates the role of the academic in the contemporary, particularly where texts (and authors) springboard political argument. Andrew M. Butler follows up by foregrounding the tensions of 'reading through' the author by conflating the lives and works of various authors called Adam Roberts. From this vantage point, he gestures towards Roberts's fiction as meta-commentaries on various genres that push generic boundaries. As if to answer some of the disjunctive questions around critique raised by Crowe, Butler concludes that critics 'must say clearly what Roberts ${ }^{\mathrm{TM}}$ says obscurely ... The birth of the critic must be [at] the cost of the death of the author' (p. 182). The final section of Adam Roberts takes up Roberts's intertextuality, as Glyn Morgan argues that Roberts's work demands intertextual reading while remaining 'on the right side of obfuscation' and remaining accessible (p. 206). Paul March-Russell concludes the collection by reading Jack Glass alongside Golden Age crime fictions, arguing that Roberts's genre subversion 'asserts the vitality of genre fiction', undoing the oversimplified homogenization postmodern critics have tended to ascribe to the detective fiction genre (p. 226).

Rupert Thomson: Critical Essays, edited by Rebecca Pohl and Christopher Vardy, echoes the Roberts volume with its interest in genre experimentation. Pohl and Vardy's introductory chapter suggests Thomson's 'generic instability' as a 'metaphor for contemporary fiction in the wake of "high" postmodernism [and] its many displaced currents and crossovers' (p. 12). These crossovers are formally reflected in the choice not to divide the collection's essays, and rather let their varied theoretical approaches stand in 
unison. The first two chapters focus on Divided Kingdom [2005]. Robert Duggan considers the spatiality of security in Divided Kingdom through Gaston Bachelard, and identifies Thomson's 'preoccupation with borders and leaving' (p. 19). He deploys Michel de Certeau's The Practice of Everyday Life [1984] to position the novel as a 'spatial story' in which the protagonist's 'tour' is 'placed in opposition to the state's system of separation and division' (pp. 38-9). Iain Robinson follows up by tackling space through a Foucauldian lens, interrogating the way that spatial borders rupture identity. He considers the psychogeographer's subconscious as a method for resisting spatial politics. Together these essays point to the ways that we 'read' space, critically or otherwise. This raises crucial questions about the potential for engendering ways of reading late capitalism's spatial creative destruction. These are timely essays not only with regard to their political context, but in their contribution to an emergent scholarship on spatiality in contemporary literature.

Christopher Vardy's astute analysis of childhood in Death of a Murderer [2007] looks to the children abused, trapped, or living unstable lives to strip away received cultural conceptions of 'the child' as a bearer of futurity and possibility. Vardy denies the ostensibly utopian reading of the future, by way of the next generation, as always inevitably progressive. This refiguring of a recurrent symbol opens up critique of the contemporary moment increasingly defined by precarity, in which 'innovation' is divorced from social and material needs (look no further than Tesla, or the Silicon Valley 'tech entrepreneurs'). Continuing the focus on Death of a Murderer, Rhona Gordon follows up with a chapter on haunting and/as memory that meditates on reductive binary moralism. The following two essays echo their predecessor's avenues of interest through the lens of affect theory. Kaye Mitchell takes up the recurrence of abuse in Thomson's oeuvre in an analysis of shame and identity in The Book of Revelation [2000], while Rebecca Pohl considers the affective dimension of the spatial through atmosphere in The Insult [1996]. The collection closes neatly with John McAuliffe pondering the effect of Thomson's autobiographical writing on the process of reading his fiction, and drawing together questions raised throughout the volume.

Tom McCarthy: Critical Essays, edited by Dennis Duncan, closes Gylphi's Contemporary Writers series for 2016 with virtuosity. Reflecting on McCarthy's foreword, Duncan considers the two states of the contemporary living author: 'the post-Barthesian ... ghost at the banquet' and the 'authoras-Messiah' (p. 4). McCarthy and, curiously, both Roberts and Thomson, describe their experiences of the conferences as the former, but the content of the critical essays series attests to the value of their presence. Just like the literary theory brought to bear on their work, these authors refuse oversimplified binary opposition: they are both dead and not dead.

McCarthy became a big name in contemporary British fiction quickly in the wake of his 2005 debut novel Remainder. This collection, the first single-author study on McCarthy, comfortably lives up to the critical weight that his name carries. Henderson Downing's opening essay looks at McCarthy's art projects prior to the publication of Remainder. He invokes Mark Fisher in his analysis of 'crackle' as a disruption that brings to mind the artificiality of recording, connotes a broken sense of time, and veils 'the official "signal" in noise' 
(p. 35). These disruptions occur and recur in all of the collected critical responses to McCarthy, and the chapters even generatively disrupt each other. Sam Slote grapples with the impossibility of capturing the authentic, while Milly Weaver considers the ways that Remainder responds to the influence of digital culture, itself often feigning authenticity, by imitating non-textual media. Nick Lavery looks at the novel's representations of the posthuman that is at least partially defined by technology (and, by extension, digital culture). Martin Eve argues for McCarthy's stylistic debt to postmodernism in a rich and exhaustive reading of $C$ 's [2010] disorienting style and metanarrative moments. Sebastien Groes, on the other hand, reads Remainder's depiction of post-traumatic stress disorder as a 'move beyond postmodernism through a revaluation of Modernist obsessions such as memory' (p. 150). Taken together, these chapters suggest that any movement beyond postmodernism is also, inexorably, a movement through it. Mark Blacklock posits spatiality as the key to the literary turn which McCarthy represents, and Gil Partington highlights the charged significance of fictional space in Remainder. This turn to the spatial could unify Groes's and Eve's arguments alongside Arne De Boever's and Andrew Gibson's return to the material. They both align Remainder with speculative realism. De Boever reads the novel as an attempt to write 'the material debris of the real' (p. 203) and Gibson coins the term 'new inhumanisms' to account for McCarthy's experimentation in the contemporary moment where 'presentism has apparently come under threat' (p. 228). The collection as a whole taps into a recurring theme in 2016's literary theorizing: the materiality of a futurity now uncertain and no longer possibly externalized.

Heather J. Hicks's The Post-Apocalyptic Novel in the Twenty-First Century: Modernity beyond Salvage approaches the genre's usual suspects (David Mitchell, Jeanette Winterson, Margaret Atwood, Colson Whitehead) through their intertextuality with Daniel Defoe's Robinson Crusoe [1719]. A promising opening considers Crusoe as an 'avatar of modernity' that attempts to reconstruct his modern life (p. 1). Hicks argues that, while influenced by postmodern aesthetics, these post-apocalyptic texts 'torque toward modern ideology' (p. 5). The comprehensive review of post-apocalyptic theory and fiction, as well as close readings of the text themselves, are an invaluable resource, particularly in teaching. The problem comes when this argument of and for postmodern modernism does not seem to go anywhere, though that may be the point of a modernity beyond salvage. Hicks foregrounds Winterson's ultimate ambivalence regarding the 'problems of post-apocalyptic change' and shifts the burden of responsibility to the individual as it is the self 'that must change or chart its own, internal, return' (p. 103). In her analysis of Cloud Atlas [2004] Hicks aligns Mitchell's authorial voice with that of Adam Ewing, leaving little room for distance, ironic or otherwise, and argues the indeterminate but inevitable truth 'that particular contemporary models of time and subjectivity may bear on whether the human species endures' (p. 76). In her conclusion, Hicks makes bold claims around futurity, namely that postapocalyptic fiction combats a sense of disconnection with the future by 'projecting its vision past the eschatos' (p. 165). Notwithstanding the fact that this seems to limit future possibility to near-absolute destruction, this argument relies on the problem of futurity being one of disconnection when 
it might be better understood as one of connection to a future at best uncertain and at worst hopeless.

Class and capital haunt many of the works reviewed so far, so Roberto del Valle Alcalá's monograph, British Working-Class Fiction, is a welcome direct address to neoliberalism. del Valle Alcalá deploys Mario Tronti and Antonio Negri to read the expansion of work under capitalism onto a selection of postwar British texts, although he does not really explain his method of textual selection. The monograph is at its best when tackling post-2000 literature, and its final chapter, on precarity in Monica Ali's In the Kitchen [2009] and Joanna Kavenna's Inglorious [2007], sees del Valle Alcalá confidently navigate Deleuze to invoke a counter-strategy of dislocation from capitalism's rearticulation of the subject through 'a decidedly meta-subjective gesture of affirmative precariousness' to 'restore the self-valorizing horizon posited by the old proletarian subject of the refusal of work' (p. 169).

Irmtraud Huber's Present-Tense Narration in Contemporary Fiction: A Narratological Overview delivers on the promise of its title. Huber surveys a wide range of authors that are predominantly but not exclusively British and Irish, including Hilary Mantel, David Mitchell, Colm Tóibín, John Burnside, and Anne Enright. She compellingly makes her case for the prevalence of present-tense narration in contemporary fiction, and analyses its heterogeneous deployment. Each chapter discusses a different narratological deployment of the present tense, beginning with its use as frame for a past-tense narrative. Sometimes this early analysis is simplistic, but it is nonetheless a useful overview, and an important foundation for arguments in later chapters. In chapter 6, Huber tackles texts that 'directly engage with the basic conundrum of present-tense narration: namely that it is impossible to experience and narrate at the same time' (p. 70). There are echoes here, in narratological form, of the impossibility of authenticity, and the material debris of the real, that ran through Tom McCarthy: Critical Essays.

Literary studies of space and place take centre stage in London in Contemporary British Fiction, edited by Nick Hubble and Philip Tew. This comprehensive collection of essays offers analyses of historic, specific, and alternative spatialities of London to take on the hollowing out of the city by the language of the international free market. Without denying the roles that uneven development and its vanguard of gentrification play in the shaping and reshaping of the city, Hubble and Tew assert that 'London is never just its economy, cannot be reduced to the City of London' or even to its present condition (p. 3). Highlights include Nick Bentley's analysis of Martin Amis's Yellow Dog [2003] as a London novel hardened by the international reach of 9/11 (pp. 195-210), and Susan Alice Fischer's chapter on the ways in which Ali Smith's The Accidental [2005] shines a light on the gap between country and city, public and 'ordinary' life, and reality and simulacrum (pp. 35-48). Mark P. Williams identifies the importance of London to almost all of China Miéville's fiction (pp. 177-94). He terms the fictional city of New Crobuzon an 'alter-London' not only because it topographically mirrors London, but because its place names evoke historical and present locales (p. 178). He goes on to define other spaces in Miéville's fiction: 'Un-Londons', fantastical hidden places 'under or unseen by the real London', and 'Ab-Londons', places 
that by transformative means move away 'from the familiar London and towards something definitively more estranging' (p. 179). By working across Miéville's oeuvre, Williams argues that the everyday effects of the spatial are hidden and revealed only through cognitive estrangements. This recalls, and reiterates, the questions around 'reading' space sparked by Duggan and Robinson's work on Divided Kingdom. Throughout the collection, London is an ever-changing intersubjective space of a kind that recalls Anna McFarlane's analysis of Adam Roberts's Jack Glass: it is both individual and mass.

Martin Paul Eve's Literature against Criticism: University English and Contemporary Fiction in Conflict makes explicit something that the form of Gylphi's Contemporary Writers series continually suggests: a competition of sorts between contemporary novelists and university English. Eve argues that this interaction manifests in contemporary fiction 'through a specific anticipation of an academic discourse-community as an idealised reader-community' (p. 18). Some contemporary novels, in this regard, pre-empt an academic reader, misdirecting readers with specific academic knowledge. Academic discourse is, Eve contends, deployed as a deliberate textual strategy by the works he analyses to "claim a "literary" quality for the work' (p. 19). Despite the extent to which the academy is, in this regard, woven into 'literary' works, Eve asserts that the 'processes that shape value in the literary sphere ... are mostly based on the market, with academic aesthetic judgement forming only a weaker correlative portion of the gatekeeping system' (p. 22). He explores the impact that a shortage of academic labour time has on the bottlenecking of 'literary' canon formation, whereby academics bestow cultural prestige by canonizing texts that are pre-filtered by publishers trying to anticipate market trends. The resulting 'lack of academic engagement with the conditions of possibility for the publication of contemporary fiction' helps to account for the 'hostility of some contemporary literary fiction toward the academy' (p. 28). Eve mounts an impressive rescue of metafiction from the clutches of criticism that it is self-indulgent, radically rethinking it as 'art that, from within the art itself, questions the contemporary conditions of aesthetic and critical possibility for art and fiction' (p. 35). In a series of insightful readings of literary fiction, including Tom McCarthy, Jennifer Egan, and Sarah Waters, Literature against Criticism strides confidently into a future in which academic authority is dethroned and the relationship between writer and critic is radically redefined through entanglement. This is an incredibly important book, not only for the field of contemporary literary studies but in its demands for the critical self-reflection of those who practise within it.

The rest of this section is by William Baker.

'What Happened to Our Difference? Howard Jacobson's $J$ '. This dystopian novel published in 2014 is the subject of Wit Pietrzak's essay in Explorations: A Journal of Language and Literature (Explorations 4[2016] 97-109). Pietrzak focuses on the treatment of individual differences, and conformity in the postapocalyptic world depicted in Jacobson's powerful fiction. Pietrzak writes that his 'essay explores Howard Jacobson's latest novel " $J$ " with a view to demonstrating that the homogenous society that is depicted in it functions on the principle of exclusion of difference and repression of individuality'. The essay claims 'that the novel plays with the conventions of the genre of 
postapocalypse in order to emphasize that what constitutes the core of humanity is our capacity for embodying and expressing difference even though that difference at the same time remains a crucial reason behind our predicament' (p. 1). $J$ is also the subject of Ruth Gilbert's 'No Outlines': From Dystopia to Heterotopia in Howard Jacobson's $J$ ' (Journal of European Popular Culture 7:i[2016] 9-19), in a special issue devoted to 'The Promised Land: Utopia and Dystopia in Contemporary British Jewish Literature'. For Gilbert 'a dystopian reading of Howard Jacobson's 2014 novel, $J$, is not necessarily the only way in which to reflect on both the inner and outer topographies of the narrative'. Instead she draws upon 'Foucault's brief, but intriguing, thoughts on heterotopia'. They suggest 'that this kind of heterotopian thinking potentially opens up a deconstructive questioning of terms such as utopia and dystopia'. Specifically, Gilbert 'teases out some of the ways in which Jewishness intersects with these themes'. Gilbert perceptively writes, 'Jacobson presents a sustained exploration of Jewishness, an identity that is placed, simultaneously, at both the centre and the edges of the text' (p. 9).

An intertextual perspective on Jacobson's novel is provided by Mike Wicombe in his 'A Comedy of Eruvs: (Re)Locating Jewish Identity in Michael Chabon's The Yiddish Policemen's Union and Howard Jacobson's J' (Shofar 34:iv[2016] 29-51), in a special issued devoted to 'Rethinking Exile, Center, and Diaspora in Modern Jewish Culture'. According to Wicombe, 'Michael Chabon's The Yiddish Policemen's Union ... and Howard Jacobson's J ... are novels fixated on the survival of Jewish identity in hostile environments'. Wicombe explores 'the scholarly reception of these novels to form a defense of their narrative complexity', with a focus 'on themes relating to space and place ... arguing that the depiction of home spaces in these novels allows for the concept of the eruv to become a guiding principle in the construction of both' of their 'narratives'. An 'eruv' is a boundary designating a space for Orthodox Jewish observance. Wicombe's 'close reading of homes in these novels through the lens of eruv ... exposes unexpected parallels between these vastly different writers, at the same time that it allows scholars to more easily fit these works into their authors' respective oeuvres. As such, these home spaces are argued to be "eruvic spaces" that serve a key narrative function in both texts, in turn enabling a reevaluation of the novels themselves' (p. 29).

Other novels by Jacobson that engaged critics in 2016 include The Finkler Question [2010], which was awarded the Man Booker Prize in 2010. Christoph Houswitschka's " "Show me a novel that's not comic ...": Howard Jacobson's The Finkler Question' (Anglistik 27:i[2016] 45-59) appears in a special issue, 'Focus on Comic Representations in Post-Millennial British and Irish Fiction'. Houswitschka applies to the novel Jacobson's perception of humour expressed most fully in his 1997 study Seriously Funny: From the Ridiculous to the Sublime and Jacobson's sense that The Finkler Question is 'not really about Jewishness but love' (cited p. 45). Peter Lawson, in his 'The Promised Land: Utopia and Dystopia in Contemporary Anglo-Jewish Literature' (YEJLS 3:i[2016] 183-201), in a special issue on 'Europäisch-jüdische Utopien', discusses The Finkler Question with other works such as Linda Grant's When I Lived in Modern Times [2000], novels by Clive Sinclair, and poetry by 
Elaine Feinstein in their relationship to utopianism. Lawson considers the concepts of 'utopia and dystopia in their specific English and Jewish and hybrid Anglo-Jewish literary contexts' (p. 183). A relatively critically neglected Jacobson novel is the subject of the fourth chapter, 'Sexual Sets: The Act of Love' of Ben Davis's Sex, Time, and Space in Contemporary Fiction: Exceptional Intercourse (pp. 103-40). Ben Davis notes, prior to entering into a detailed analysis of the novel, that the decisive moment in Howard Jacobson's The Act of Love [occurs] when Felix Quinn, a Marylebone antiquarian bookseller, is made acutely aware of his sexual predilections. In an analeptically narrated sequence, Felix describes the pleasure he experiences as he watches a Cuban doctor treat his wife whilst they are on honeymoon in Florida.' Davis adds: 'of equal import as the disastrous honeymoon night in [Ian McEwan's] On Chesil Beach', published the year previously, 'this momentous occasion confirms to Felix his proclivity for "cuckoldage" [Act of Love, p. 240], and lays it bare for the reader' (pp. 103-4).

The year 2016 witnessed the publication of another Jacobson novel, Shylock Is My Name. For Lucasta Miller, writing in the Independent on 21 January 2016, 'This novel is a highly rhetorical artefact whose rigour and vigour reside in the dialogue, the voices, and the subtlety of argument. But under the stylized characterization and intellectual pyrotechnics, Jacobson explores some heartfelt psychological insights into family conflicts, friendship, and what makes a decent human being, a mensch: the novel is also very funny.' For Miller, Jacobson 'is a master of shifting tones, from the satirical to the serious' and very witty too.

Kalooki Nights [2006] and other Jacobson novels engage Nadia Valman in her 'Jewish Fictions' (in Boxall and Cheyette, eds., pp. 347-67). According to Valman, 'the over-determination of post-war Jewish male sexuality is a repeated theme in Jacobson's fiction' as instanced by 'Oliver Walzer's desire to be for Lorna Beachley "hers to do with as she chose" [The Mighty Walzer [1999], p. 235], to Maxi Glickman [in Kalooki Nights] who prefers his women Aryan and haughty, Jacobson's narrators actively seek humiliation'. Jacobson's Kalooki Nights 'dwells on this theme most insistently of all, through its exploration of the formation of the sexual identity of the narrator and his Orthodox childhood friend Manny Washinsky, who reappears in Manchester after a lengthy prison term having murdered his parents by gassing' (p. 357).

\section{Pre-1950 Drama}

Coverage of early twentieth-century drama is limited to critical work on George Bernard Shaw this year. We hope to cover any gaps created by this in next year's volume.

While the plays of George Bernard Shaw remain widely available in print, this has not always been the case with his non-dramatic works. During 2016, however, renewed interest in Shaw's multifarious essays, speeches, critical pieces, and political tracts was confirmed by the welcome publication of the Critical Shaw series under the general editorship of Leonard Conolly. 
Comprising five different volumes, each contains a selection of critical essays on different subjects (religion, politics, theatre, music, and literature), with a brief but illuminating introduction, a chronology, and a bibliography. The texts are annotated succinctly with italicized parenthetical commentaries, which ensures quick contextualization while maximizing ease of reading. In all, the specific scope of each volume is mostly framed by the selection of texts. Conolly's On Politics stresses how 'the subjects Shaw addressed in his numerous political books, speeches, essays, and broadcasts continue to have a familiar ring: income inequality, corporate excess, unemployment, dysfunctional government, political ideologies, totalitarian regimes, poverty, gender discrimination, the role of the state, the inefficiency of democracy, war, nationalism, party politics' (p. 9). Dorothy Hadfield's On Theatre uncovers the different dimensions of Shaw's activities within the theatre business: his stance as a critic, his ideas as a producer and director, and his creed as a playwright. A novel outlook stems from the realization that, as Hadfield puts it, 'Shaw's legacy to theatre is much more than just his plays, impressive as they are. In his non-dramatic writings about theatre, Shaw demonstrates his ardent belief in the theatre as a vital social institution that needs to be nurtured both artistically and practically' (p. 21).

Michel Pharand's volume, On Religion, benefits greatly from succinct and helpful editorial material; otherwise, understanding the multitude of religious sources that Shaw draws from would necessitate Shaw's own quasi-eidetic memory. Furthermore, the mere sources are embedded in a complex network of reversals and anti-climactic modifications. Indeed, as Pharand explains, 'in speech after essay after preface, Shaw relentlessly scrutinizes doctrines and dogma, only to find most of them in need of reform - or scrapping altogether' (p. 8). Brigitte Bogar and Christopher Innes's On Music provides the best example of the intricate connections that each of these topics has for Shaw. This volume ranges from the personal childhood trauma inflicted on Shaw as a consequence of his mother's ménage à trois with his singing teacher, George Vandeleur Lee, to how he first made a name for himself as a music critic under the pseudonym Corno di Bassetto. It also incorporates Shaw's Wagner phase, culminating in 'The Perfect Wagnerite'. Bogar and Innes publish for the first time Vandeleur Lee's 'The Voice', a teaching monograph on singing and vocal physiology that was annotated by Shaw after Lee's premature death. Gustavo A. Rodríguez Martín's On Literature focuses primarily on Shaw's relatively obscure years as a book reviewer (some of his early pieces were published unsigned), when he honed his critical faculties and his sharp (sometimes scathing) style. This book also contains some of the milestones of Shaw's later career (he would publish reviews until the year of his death), such as his introduction to a 1911 edition of Hard Times.

Another measure of the growing interest in Shaw's non-dramatic writings is the inclusion of several sections of selected essays in the Handbook of the Irish Revival: An Anthology of Irish Cultural and Political Writings 1891-1922, edited by Declan Kiberd and P.J. Mathews. The texts included here range from the unusually lyrical 'A Visit to Skellig Michael' to the downright political 'Safe Holidays in Ireland', published in the aftermath of the Irish War of Independence. In a similar vein, one can get a good overview of Shaw's 
economic theories regarding income inequality in Peter Gahan's introduction to 'Six Fabian Lectures on Redistribution of Income' (ShawR 36:i[2016] 10-52). This brings to the fore a series of lectures whose importance has only been obscured 'by the impact ... of the Great War' (p. 10). These lectures offer great examples of Shaw's oral style, often containing expressions 'which would be ruthlessly expunged in written texts' (p. 14).

As usual, however, the majority of scholarship on Shaw's criticism has focused on his career as a theatre critic, especially his pieces on Henrik Ibsen. Julie Holledge, Jonathan Bollen, Frode Helland, and Joanne Tompkins's $A$ Global Doll's House: Ibsen and Distant Visions exemplifies the central position Shaw occupies for Ibsen critics. This study pays special attention to Shaw's writing about the four major Ibsenite actresses in Britain: Janet Achurch, Florence Farr, Marion Lea, and Elizabeth Robins. A more restricted scope is to be found in Chibuzo Onunkwo and Prince Ugochukwu Ihemegbulam's 'A Modernist Reading of Henrik Ibsen's A Doll's House and George Bernard Shaw's Mrs Warren's Profession' (IJSSHR 6:iv[2016] 212-25). The approach is relatively novel in that parallelisms have usually been drawn in the past between Candida and A Doll's House. The authors see elements of modernism in 'the questioning of authorities, the historical language that is radically intransitive, and the ambiguity of language' (p. 224). In this regard, one of the main tenets of the essay is that both texts can thus be read as modernist because 'modernism remains fundamentally a discourse of thought' (p. 218).

The stature of Shaw as a public intellectual was second to none in his lifetime, and he remains one of the milestones of social, political, and literary thought. In literary terms, as drama was his milieu, Shaw gained a hearing as a committed advocate of the 'New Drama' that sought to revitalize and revolutionize theatre in Britain. This is the main focus of the passages Irene Morra devotes to Shaw in her Verse Drama in England, 1900-2015: Art, Modernity and the National Stage, which also briefly comments on The Admirable Bashville (pp. 73-4). Shaw, Morra notes, promoted the New Drama because he saw in it '(or [in] the dramatic preface) the potential to instigate social reform, primarily by addressing and exposing the absurdity of social hypocrisy, complacency and entrenched institutions' (p. 42). But the image we have of Shaw as a public intellectual is largely shaped by his interaction with other prominent figures of the British intelligentsia. Among them, Chesterton stands out as one who would frequently cross swords with Shaw in the press or on the platform. The ongoing debate between these two figures is addressed in Alasdair McIntyre's 'Writing as Social Disclosure: A Hundred Years Ago and Now' (in Fives and Breen, eds., Philosophy and Political Engagement: Reflections in the Public Sphere, pp. 99-116). It is interesting to note that, in general, the audience of these extended debates was 'as great a part of the reading and theatre-going public as [the debaters] could persuade to attend to them by the exercise of their literary and dramatic skills' (p. 102). In the specific case in question, Shaw advanced the view that 'we need economic expertise to understand the causes of poverty, but it is to philosophy that we must look if we are to evaluate our responses to it and the damage that both it itself and inadequate responses to it do to human beings' (p. 104). Although the dissection of Shaw's philosophical ideas (based on Nietzsche and 
Schopenhauer) is interesting in its own right, McIntyre's chapter pivots around what we are missing because of the 'absence of such debates' one hundred years later (p. 109).

Much recent work on Shaw has focused on the sociopolitical sources of his writings. During 2016 this emerged in a themed volume of the journal $S H A W$ on 'Shaw and Money', guest-edited by Audrey McNamara and Nelson O'C. Ritschel. The whole volume analyses the 'problems Shaw outlined, and worked to rectify' (p. 4). Still, some of the essays provide much-needed economic information that facilitates the reading of some plays whose exegesis largely depends on how one interprets the money sums that appear in them. That is what Bernard F. Dukore's 'How Much? Understanding Money in Major Barbara' (ShawR 36:i[2016] 73-81) and Gustavo A. Rodríguez Martín's 'Bernard Shaw Adjusted for Inflation' (ShawR 36:i[2016] 82-106) seek to clarify. Two other central aspects of this themed issue are also covered in two different essays. Thus, Stephen Watt's 'Negative Affect and Shaw's Psychology of Money' (ShawR 36:i[2016] 53-72) investigates the conscious or unconscious associations that money had for Shaw, largely in terms of 'money and feeling, the lack of it and negative feeling' (p. 60). Similarly, Christa Zorn's 'Shaw's Staging of Capitalism' (ShawR 36:i[2016] 142-63) provides a specific analysis of how 'the dehumanizing influence of finance capitalism' (p. 142) and other negative aspects of money can be perceived in Heartbreak House. The Shavian take on philanthropy and charity is examined in Al Lyons's 'GBS as Philanthropist and Social Entrepreneur' (ShawR 36:i[2016] 107-23), which argues that 'Shaw viewed personal acts of charity as an expression of an individual's values and interests, rather than as a social obligation' (p. 109). Similar themes are also examined in Kay Li's 'Philanthropy, Inheritances and Legacies' (ShawR 36:i[2016] 164-85), which draws parallels between Shaw's visit to the mansion of Sir Robert Ho Tung in 1933 and how Shaw modelled the setting and characters of Buoyant Billions in light of 'Shavian paradoxes on philanthropy, inheritance, and legacies' (p. 164). Finally, David Clare's 'Landlord-Tenant (Non)Relations' (ShawR 36:i[2016] 142-63) connects 'the disgust Shaw felt from his youth over the unjust relations between Irish landlords and tenants' (p. 125) to how 'five of his plays are informed by his early exposure to tenement slums' (p. 137).

Another common topic that is often brought up in appraisals of Shaw's political stance is his support for the Russian Revolution and, later, Stalinism. This year, it is refreshing to find amidst this scholarly tradition a book that includes a lucid, novel analysis of Shaw's opinions about Soviet Russia. Specifically, Claire Warden's Migrating Modernist Performance: British Theatrical Travels through Russia makes insightful claims about Annajanska ('far more ambivalent about the Revolution than one might initially expect') and how it is a reflection of 'the playwright's own confused state of mind' (p. 119).

If we continue with the intersection between politics and literature, several studies have pointed out real or symbolic connections between the Shavian dramatic text and pressing issues of his times. In relation to the Irish Question, Alexandra Poulain devotes chapter 5 of Irish Drama, Modernity and the Passion Play (pp. 75-91) to reading Saint Joan in the 
context of post-independence Ireland' (p. 83). She convincingly argues that Joan's nationalism 'gestures towards an inclusive, non-sectarian, nonpatriarchal construction of the emerging nation' (p. 78). David Clare's Bernard Shaw's Irish Outlook covers Shaw's 'Irishness' in depth, ranging across the very Shavian 'hostility aimed at the English by Irish Anglicans' (p. 41) that on occasion crystallizes in a "plan of criticizing English Phariseeism' (p. 106) to Shaw's own 'problematic relationship with the idea of Diasporic Irishness' (p. 28). Of course, in view of Shaw's 'habit of regularly disparaging the English in his plays, one could argue that most of his English characters are, on some level, Stage English' (p. 77). After all, 'Britishness need not be a cause for exclusion from the [Irish] Revival-indeed, it is (to a great extent) a reason for inclusion', which allows the author to 'examine the ways in which Shaw fulfils even the traditional definitions of a Revival writer' (p. 129).

Other Shaw plays that allow for political analyses include Pygmalion. Jeffrey M. Brown's 'Acting in the Politics of Print: A "Monster of Illiteracy" in the Published Pygmalion' (in Herren, ed., Text \& Presentation, 2016, pp. 124-42) explores the fact that 'the play's interest in theatricality is both aesthetic and political' (p. 132). Elsewhere, Bernard F. Dukore's 'Playing Kings, Ultimatums, and Abdications: The Apple Cart and To Play the King' (Comparatist 40[2016] 267-83) shows how the two works 'enlighten facets' of each other, as they both depict 'a prime minister [who] opposes a king who has difficulty performing the role of king in a constitutional monarchy' (p. 267), despite their differing denouements. Similarly, John Bull's Other Island is the object of study in chapter 7 of Angus Fletcher's Comic Democracies: From Ancient Athens to the American Republic (pp. 136-54). Here, the author revives Ahmad il-Far's Riwayat Ibn il-Balad and John Bull's Other Island as works 'that responded to a notorious instance of modern democratic imperialism: the Denshawai Incident of 1906' (p. 137).

Shaw's political thought is inextricably linked to his philosophy and religious creed (or lack thereof). In this regard, Nietzsche is perhaps the single most significant influence in the philosophy of Shaw. Chapter 5 of David Kornhaber's The Birth of Theatre from the Spirit of Philosophy: Nietzsche and the Modern Drama provides a detailed account of this influence, arguing that 'the genealogy of Major Barbara must begin with The Birth of Tragedy' (p. 119). Kornhaber does acknowledge differences: contra Nietzsche, Shaw believed that 'a proper theatre was recoverable' and held that 'Nietzsche was wrong not to imagine a form of theatre capable of doing the philosophical work that he expected of it' (p. 125). Nevertheless Kornhaber observes that the philosophy ascribed to the Salvation Army in Major Barbara 'looks remarkably similar in its basic formulations to the manner in which Gilles Deleuze describes Nietzsche's own metaphysic' (p. 129).

In criticism of individual plays, the core of Shaw's canon receives, unsurprisingly, the most attention from critics and scholars. Jean Reynolds uses a metadramatic approach in 'Shaw's Pygmalion: The Play's the Thing' (ShawR 36:ii[2016] 238-55) in order to explore 'the role-playing and performance issues' of the play (p. 238), in a play whose very title 'generates widespread expectations for a marriage between Pygmalion and Galatea' (p. 244). The essay 'Shaw's Way with Fanny's Untitled Play', by Bernard F. 
Dukore (ELT 59:i[2016] 25-43), 'removes the inner play, supposedly written by the heroine of Shaw's frame play, from the parentheses of its frame and deals with it in its own right' (p. 25). Another adaptation of a Shaw play, this time a musical, is the subject of Derek McGovern's 'A Minister's Wife: A Bittersweet Adaptation of a "Pleasant Play", (ShawR 36:ii[2016) 215-37). Despite the excision of Burgess, 'all but three of the songs contain lyrics at least partially adapted from Shaw's dialogue' (p. 220) in Candida. At times, it is also noted, the dialogue 'sounds either too modern or too distinctively American to be convincingly of its period and setting' (p. 227). Allan Johnson delves into 'Shaw's sustained fascination in domestic architectural space' (p. 203) in "Architectural Space and the Failures of "Complete" Houses in Heartbreak House' (ShawR 36:ii[2016] 203-14). The play's 'striking tonal quality develops and supports the wider portrayal of architectural completeness and the nature of returning home' (p. 209).

Shaw's idiosyncratic style has puzzled (and, one would presume, infuriated) translators ever since the first foreign-language versions of his plays were published. The traductological difficulties his translators have faced are the building bricks of a scholarly tradition that has again contributed a great deal to Shaw scholarship in 2016. Agnieszka Adamowicz-Pośpiech combines translation and cultural reception in 'Revisiting G.B. Shaw's Mrs Warren's Profession: Differences in Cultural Reception and Translation in England, the United States, and Poland' (in Adamowicz-Pośpiech and MametMichalkiewicz, eds., Translation in Culture, pp. 151-71). Here, the key concept is the dissemination of the 'woman question' in different cultures and languages through Shaw's drama of ideas. The differences are striking (though understandable) in the different geographical areas under scrutiny, although Poland is the central element in the essay and the others are generally used for comparative purposes. It is interesting to note, for example, that in Poland 'turmoil in the theatre did not result from the polemics over the artistic value of the play and even less so from its ideological content' (p. 162). Also, the translation into Polish involved, among other things, that 'descriptive sentences [were] crossed out and replaced with short sentences expressing sharply the action on the stage' (p. 166). A similar sense of cultural estrangement is perceived in the assessment of Pygmalion in Egypt, in Wessam Elmeligi's 'It Is Not Just Phonetics and Aristocrats-It Is Sexuality and Politics: The Adaptation of Bernard Shaw's Pygmalion in the Egyptian Theatre' (in Aaltonen and Ibrahim, eds., Rewriting Narratives in Egyptian Theatre: Translation, Performance, Politics, pp. 245-59). The central elements in the adaptation include 'thematic Egyptianization' in order to suit 'the Egyptian socio-political context of the 1960s' under Nasserism (p. 245) and the use of Modern Standard Arabic and Egyptian Colloquial Arabic to depict the two central linguistic varieties in the play (p. 252).

Two monographs published in 2016 that address translation, cultural adaptation, and reception are Kay Li's Bernard Shaw's Bridges to Chinese Culture and Rosalie Rahal Haddad's Bernard Shaw in Brazil: The Reception of Theatrical Productions, 1927-2013. Li's book explores 'how Chinese angles form powerful cultural bridges connecting Shaw and his contemporaries to China' (p. 1). 'Angles' is a key concept here, because the content of the 
different chapters specifically illustrates how understanding the 'Chinese angles' is the key to understanding Shaw's reception in China. This is, firstly, because of Shaw's own view of the Chinese and how he 'upset the ways in which China was seen in England' (p. 24), but also because of the specific cultural elements that inform the translation and adaptation of his plays. For example, a production of Mrs Warren's Profession in China in 1920 was unsuccessful largely because 'the producers clearly missed the proper pace at which Shaw's dialogue should be delivered' (p. 72). Another connection with orientalism is drawn by David A. Radavich in 'Eastern Paradox in Bernard Shaw's Major Barbara' (ShawR 36:ii[2016] 256-71), where the author illustrates the 'glittering clusters of oppositions [that] swirl around each other in this Taoist fashion' (p. 258).

Rosalie Rahal Haddad, in turn, analyses all the productions of Shaw plays (some of them were staged by foreign companies) in Rio de Janeiro and São Paulo until 2013. The author comments on all the aspects necessary to provide the right cultural framework: from the 'lack of drama schools and lazy spectators' (p. 23) in the 1950s to the 'devastating effect on the country's cultural life' (p. 147) of the military dictatorship between 1964 and 1985. In addition, Haddad illustrates how 'often in Brazilian culture, the adaptation of works from other cultures is achieved by means of an appropriation which might be described as carnivalesque' (p. 91). This is not to imply that there was no scholarship of merit on Shaw by Brazilian authors. For example, Haddad quotes extensively from the lecture delivered by Barbara Heliodora, 'undoubtedly one of Brazil's best drama critics' (p. 88), in 1960 - a significant milestone in a country where Shaw 'is much better known for his witticisms than for the serious ideas he debated in his work' (p. 48).

If matters of style make Shaw's works an interesting subject for translation scholars, much the same happens with researchers who specialize on the different branches of linguistics. Ever since seminal works in the late 1970s and early 1980s demonstrated the suitability of dramatic dialogue for research into discourse analysis and other areas of linguistic enquiry, many of Shaw's plays have been addressed from a linguistic perspective. Not surprisingly, pragmatics and sociolinguistics are the most common methodological frameworks. Shi Yunxia, for example, uses Bousfield's impoliteness model in order to study 'Impoliteness in Plot Development in G.B. Shaw's Pygmalion' (in Hale and Zhang, eds., Proceedings of the Fifth Northeast Asia International Symposium on Language, Literature and Translation, pp. 283-8). This paper analyses 'Liza's impolite challenges to Higgins' (p. 285) as part of her learning process, to the extent that looking into 'the impoliteness of the characters in different stages of the play can reveal the conflict, its development, and, ultimately, the development of the plot' (p. 287). Elsewhere, Salam Hakeem and Hoshang Mustafa explore 'Conversational Implicatures in Shaw's How He Lied to Her Husband' (JHS 20:iv[2016] 42-8). This playlet is particularly well suited for this kind of analysis, given that, 'due to the deceptive nature of the play, it tends to include numerous instances of violation and flouting of the conversational maxims' (p. 43) of the Gricean Cooperative Principle. In the field of psycholinguistics, Abbas Fadhil Lutfi and Heibat Shaker Qadir describe the concept of 'Construals in Shaw's Arms and the Man' (IJEI 
3:i[2016] 133-65) and illustrate it using examples from the play. Hypothesizing that 'playwrights use the same cognitive semantic devices that are used in everyday life language' (p. 133), they argue that construals imply that 'the same situation or event can be linguistically encoded in different ways' (p. 151). In this regard, elements like conceptualization and vantage point are fundamental for the study of Shaw's dramatic language.

Among the several film adaptations of Shaw's plays, Douglas McFarland focuses on 'Genre and Charisma in Shaw's Major Barbara' (in Palmer and Conner, eds., Screening Modern Irish Fiction and Drama, pp. 73-88). The key to the play and its adaptation, McFarland argues, hinges on 'the relationship between the modernist theatre Shaw helped to create and his identity as an Irish expatriate' (p. 73). Although Shaw and Pascal tried to use 'a traditional generic framework' and relied on 'the charisma of its star' (p. 80), the film was 'a failure [that] cost Shaw upwards of $£ 20,000$ ' (p. 86). Shaw's status as a popular icon of culture is due in no small part to the success of the musical adaptation of Pygmalion: My Fair Lady. Keith Garebian's Lerner and Loewe's My Fair Lady contains considerable material about the relationship between the Broadway hit and Shaw's play. In the movie version, Rex Harrison 'wanted to be true to Shaw' and 'lost respect for the passage[s]' that were not originally in Shaw's text (p. 43). Garebian also ponders the implied 'happy romantic ending' (p. 55), a subject of heated debate among critics.

Comparative studies have also been published recently where Shaw provides a yardstick against which another playwright is measured, or else where Shaw is a seminal influence for other writers. A bit of both approaches is to be found in John A. Bertolini's The Case for Terence Rattigan, Playwright, although it is observed that Rattigan 'responded to Shaw in such highly ambivalent ways that it would be difficult to epitomize or even to summarize their relationship' (p. 20). It suffices to say, for illustrative purposes, that Candida is 'Shaw's most Rattiganesque play' (p. 23), and echoes of this play in French Without Tears are discussed in greater detail. Bertolini also draws attention to the fact that Rattigan often had intellectual and artistic conflicts with Shaw. A closer (at least politically) kinship connects Shaw and Turkish playwright Orhan Asena. In his monograph on Politics and Drama: Change, Challenge and Transition in Bernard Shaw and Orhan Asena, Önder Çakirtas establishes coherent parallelisms between the politics of Turkey and Britain, the political evolution of both playwrights, and their respective political languages in drama. Çakirtas argues that 'Shaw's urge to transmit his political messages reflects his idealism' (p. 150), whereas to some extent Asena 'endorses the political realities that go well with the politics of writing', although 'his language often contains the very accuracy and dynamism that he sponsored' (p. 171) - differences shaped by their ideological evolutions as writers and thinkers, which were not limited to their respective zeitgeists. Shaw, for example, in 'nearly ... all of his plays, tackles the social illnesses of communities, and the gender equality issue and the subject of poverty are basic to all his writings' (p. 85).

The significance of Shaw's dramatic canon can also be gauged by how (often) his plays are used as 'textbooks' for educational purposes. In this regard, Kathleen Perkins showcases a paradigmatic case study in 'Down the 
SoTL Rabbit Hole: Using a Phenomenological Approach to Parse the Development of Student Actors' (T\&LInq 4:i[2016] 1-10). Here, data collected during 'the rehearsal and performance processes of a production of Heartbreak House' (p. 6) are used to answer research questions about 'the performances of two contrasting audition monologues, looking at the transformation between characters and of vocal, physical, and emotional life' (p. 5). Similarly, Candice Brown studies how actors can be trained to act Shaw in 'Using Punctuation to Facilitate Comedy in the Plays of George Bernard Shaw and Beyond' (in Olsen, ed., Acting Comedy, pp. 46-56). Since 'an author's use of punctuation is intrinsic to any well-written text', Shaw's very peculiar punctuation makes his plays 'the ideal springboard' (p. 47) for the author's didactic techniques based on the concept of Intrinsic Shavian Cadence. This, she explains, demonstrates 'how essential ideas are revealed to an actor by examining the punctuation in the plays of Shaw' (p. 48).

Shaw's connections with leading intellectual figures of the twentieth century spread into all domains of human pursuit. Richard Crockatt's Einstein and Twentieth-Century Politics: 'A Salutary Moral Influence' shows how there was a 'sort of artistic kinship with Einstein' despite Shaw's 'limited ... understanding of physics' (p. 25). A less well-known connection with a foreign intellectual is part of David Jiménez Torres's Ramiro de Maeztu and England: Imaginaries, Realities and Repercussions of a Cultural Encounter, where we learn about the admiration that the Spanish writer and journalist professed for Shaw. Maeztu probably 'first mentioned George Bernard Shaw in a Spanish setting' (p. 48) and, 'despite his criticism of Shaw's pacifist position during the Great War' (p. 135), he acknowledged Shaw as 'the model of the modus operandi of the new British intellectual' (p. 58).

There is also an objective, quantifiable dimension to Shaw's role as a public intellectual. His influential role in the shaping of the educated variety of the English language that is now commonly known as BBC English forms a substantial element in Jürg R. Schwyter's Dictating to the Mob: The History of the BBC Advisory Committee on Spoken English. Shaw appears in much of the relevant correspondence quoted in the book because, as chairman of the original Advisory Committee, he had a big say in its policies and in the choice of his successor. Shaw knew he had to resign because he was 'beginning to forget people's names quite ridiculously' (p. 108), but when Logan Pearsall Smith was suggested for the position, he stormed: 'Damn it all, Logan's an American!' (p. 113). In addition, the book sheds some light on how 'the quest for a standard' (p. 187) was carried out, although for Shaw there was no 'incorrect or correct pronunciation of the English language' (p. 175).

The combination of Shaw's political, historical, and dramatic ideas forms the core of Gautam Sengupta's Myriad-Minded Shaw: Perspectives on Shavian Drama (Politics, War and History). Unfortunately, this study is interspersed with over-generalizations and misleading inaccuracies, such as the problematic claim that 'Shaw never did choose to write directly on political themes, or on forms of government as such, till The Apple Cart' (p. 1). In fairness, Sengupta's ideas on how 'short-sighted' Shaw was about 'the capitalist forces at work behind wars' (p. 87) are more effective. 
Reflecting growing interest in medical circles about The Doctor's Dilemma, Theodore Alston and David Carr's 'George Bernard Shaw on Anaesthesia' (JAH 2:ii[2016] 37-41) summarizes Shaw's views on the medical profession at large and the use of anaesthesia, including his own experience of ether ('I wasn't sick afterwards, only rather drunk', p. 40). An editorial by Shaw scholar John Bertolini precedes the essay. It contextualizes Shaw's 'thoughtprovoking' ideas and explains how they provide 'strong evidence of his humanity in the humor contained in his writing' (p. 33). At the intersection of the medical profession and politics, L.W. Conolly's 'Ashes to Ashes: The Politics of Shaw's Death' (ShawR 36:ii[2016] 290-305) recounts how Shaw was very close to being buried 'in Westminster Abbey or in St. Patrick's Cathedral in Dublin' (p. 291) in an unsuccessful plan that involved the highest political and religious offices in Britain.

Among the secondary sources, the only major volume of canonical critical essays that devotes substantial space to Shaw's works is Brad Kent's edition of The Selected Essays of Sean O'Faolain. Although this contains only one strictly Shavian essay ('Shaw's Prefaces'), Shaw is also a central figure in the essays on censorship and in those that paint a retrospective of Irish literature: 'Shaw, like the later O'Casey, was interested in the whole international world-problem of a reorganised society' (p. 217).

Other passing references to Shaw and his work elsewhere include Jed Rasula's brief discussion, in History of a Shiver, of Shaw as a forerunner of 'Wagnerism without Wagner' which, to Shaw, 'had become a cult' (p. 12), and The Cambridge History of Modernism, which uses Shaw as an example of 'progressive drama' (p. 353). Finally, scholars in search of further work on Shaw may wish to consult the 'Continuing Checklist of Shaviana' (ShawR 36:ii[2016] 339-411), edited by Gustavo A. Rodríguez Martín (which contains over 450 entries across six sections).

\section{Post-1950 Drama}

This has been a relatively quiet year in respect to work on British drama, with only one monograph and one edited collection being produced in 2016. The main area of activity has been within the realm of journal articles.

A special edition of the journal Contemporary Theatre Review this year was devoted to the work of Simon Stephens, one of the most prolific and highprofile of contemporary British dramatists. Catherine Love's 'New Perspectives on Home: Simon Stephens and Authorship in British Theatre' (CTR 26:iii[2016] 319-27) considers the effects produced by Stephens's immersion in German theatre culture, with his work more frequently previewing there than in the UK. In particular, Love draws attention to how Stephens's attitudes to theatre have changed as a result this exposure to the German director-led model regarding 'his receptiveness to radically different productions of his texts' (p. 320). Benjamin Fowler's " Draining the English Channel": The European Revolution in Three Kingdoms and Three Keynotes (by Simon Stephens, David Lan, and Edward Bond)' (CTR 26:iii[2016] 328-36) follows on from Love's article by continuing the debate 
about how the work of British playwrights changes when produced within a German theatrical culture. Although Fowler sees such encounters as overwhelmingly positive, he acknowledges the perceptive critique in Edward Bond's keynote speech, given at Bochum in Germany, on his reaction to Sebastian Nübling's production of Stephens's Three Kingdoms [2012] when it came to the Lyric Theatre Hammersmith in London. Whereas theatre bloggers such as Andrew Haydon excitedly proclaimed this a landmark moment in British theatre, Bond's more considered view saw the production as being hijacked by a director-led approach, producing what he calls 'a theatre of symptoms' (p. 332) and a voyeuristic celebration of misogynistic violence. Sophie Nield's 'Reading Three Kingdoms as Woman: Criticism, Misogyny and Representation' (CTR 26:iii[2016] 396-9) also observes that the praise for the production emanating from several high-profile theatre blogs either ignored or only partially took account of the problematic representation of women in Nübling's production. Nield, however, argues that in the context of performance, rather than being blatantly misogynistic, the production was 'more or less entirely uninterested in women' (p. 397). Adam J. Ledger's ' "It's not about fucking it up": The Trial of Ubu, the Text, and the Director' (CTR 26:iii[2016] 345-56) defends this poorly received 2012 production directed by Katie Mitchell through a comparison with the 2010 German-Dutch coproduction between Toneelgroep and Schauspielhaus Essen directed by Sebastian Nübling. Ledger argues that the two productions represent different approaches to directing, and both met with Stephens's full approval, so undermining UK critics' assumptions and reinforcing what Ledger calls, 'a playful performise' (p. 348). In her article " Changing the conversation": Simon Stephens, Sean Holmes, and Secret Theatre' (CTR 26:iii[2016] 337-44), Jacqueline Bolton is also interested in how Stephens's work as a playwright has impacted on directorial practices in the UK. Bolton observes that, together with Sean Holmes at the Lyric Hammersmith, Stephens has brought about a questioning of established directing practice in the UK. This, Bolton observes, along with others in the CTR volume, has emerged out of Stephens's experience of working in European theatre and its incorporation of the ensemble, longer rehearsal periods, and emphasis on the creative team attending rehearsals and on how the roles of different creative bodies intermingle for the good of the production. Seda Ilter's 'Simon Stephens Beyond Europe: Pornography on the Turkish Stage' (CTR 26:iii[2016] 365-75) looks at the cultural differences that arose when this production was mounted in Turkey in comparison to its first two productions in Germany and the UK. Ilter observes that the Istanbul production makes references to its own home grown terrorist attacks in 2003 as well as the July 2005 bombings in London. At the same time, Ilter also notes that the reception of the play in Turkey was mixed, with some critics complaining that it had little in common with Turkish cultural values. The volume concludes with an interview, "This is why I'm really excited by British theatre in the next five years": David Barnett in Conversation with Simon Stephens' (CTR 26:iii[2016] 311-18).

The year 2016 saw the death of playwright Arnold Wesker. This was marked by an appreciation by Simon Trussler, 'Remembering Arnold Wesker: Loose Connections from Left Field' (NTQ 32:iv[2016] 391-4), that gives a 
sympathetic and affectionate overview of his career as both a dramatist and a political and social activist, as well as of Wesker's own contributions to the journals Theatre Quarterly and New Theatre Quarterly in the 1970s and 1980s. Anne Etienne's "'Visions don't work"? The Role of Wesker's Theatre and Centre 42 in 1960s British Culture' (STP 36:ii[2016] 130-44) revisits Wesker's ambitious Centre 42 project, which attempted to bring culture to a wider demographic through the trade union movement. Although Wesker resigned from Centre 42 in 1970, Etienne argues that a longer and more enduring legacy has subsequently emerged from the endeavour itself and informed Wesker's own playwriting during the 1960s. Etienne also reassesses the drama Wesker produced in the Centre 42 period, concluding that, apart from the positive reception of Chips with Everything [1962], subsequent work met with decidedly mixed reviews. Yet in her reassessment Etienne argues that the narrative of Wesker's decline as the 1960s progressed does not take into account some of his bold experiments with new styles and forms. Etienne concludes that the main problem for Centre 42 as a venture was its inability to escape out of London. With a concentration of resources invested in the Roundhouse, this resulted in a situation where 'rather than staging $\mathrm{C} 42$, the Roundhouse consumed it' (p. 141), and where events related to Centre 42 were comparatively rare as the venue was instead hired out for rock concerts and experimental theatre companies.

Two theatre-related articles on the work of Samuel Beckett were produced this year in the Journal of Beckett Studies. David Pattie's " Let what happens happen": The Whitelaw Archive' (JBeckS 25:ii[2016] 206-24) focuses on the archive of actress Billie Whitelaw, which has recently been acquired by the University of Reading. Pattie argues that the most interesting items of the collection are Whitelaw's working documents for acting in specific Beckett productions, which goes beyond their usefulness at the time to what Pattie calls 'the Beckettian performance legacy at the moment of its formation' (p. 208). Pattie goes on to discuss how this legacy was continued, such as the coaching Whitelaw provided to the actress Lisa Dwan in her performance of Not $I$ in 2005. The article also looks at two case studies, Not I [1972] and Happy Days [1961], outlining and demonstrating through archival materials Whitelaw's methodology as both actress and interpreter of the text, and exploring the system of notation that she employed to create a 'carefully scored piece of physical theatre' (p. 219). In the same issue, Cal RevelyCalder's 'Racine Lighting Beckett' (JBeckS 25:ii[2016] 225-42) traces the influence of the seventeenth-century French dramatist on Beckett's writing. This, Calder argues, appears most strongly in Happy Days and Come and Go [1965], not only through textual allusions, but also the use of minimal lighting and the attention paid to the choreography of characters' entrances and exits.

Siân Adiseshiah and Louise LePage's Twenty-First Century Drama: What Happens Now is a major collection of essays, most of which tackle a broad range of issues and themes in contemporary British playwriting. Elaine Aston's 'Room for Realism?' (pp. 17-36) assesses Fiona Evans's Scarborough [2008], Lucy Kirkwood's NSFW [2012], and Anupama Chandrasekar's Free Outgoing [2007], in order to make a case for realism being an effective way of showing the feminist subject when pitched against neoliberal forces. Aston also 
argues that the term 'realism' itself in twenty-first-century drama has now transmuted into what she calls 'viral realism' (p. 33) when compared to older forms used in 'conservatively formed, phallocentric uses of the genre' (p. 32). Chris Megson's 'Beyond Belief: British Theatre and the "Re-enchantment of the World"' (pp. 37-57) looks at a variety of plays in the last seven years and contends that with an ethical turn in many of the subjects tackled-such as multiculturalism, the crisis of late capitalism, and globalization-comes a 'placing [of] belief at the centre of theatrical scrutiny' (p. 42). Two plays, Lucy Prebble's Enron [2009] and Mike Bartlett's 13 [2011], are scrutinized for the ways in which characters' behaviour is predicated on belief systems. Paola Botham's 'The Twenty-First-Century History Play' (pp. 81-103) provides an account and explanation for the revival of the form in recent years in her analysis of Howard Brenton's Anne Boleyn [2010], David Greig's Dunsinane [2010], and James Graham's This House [2012]. Botham sees these three plays as Brechtian in their shared usage of the past to address the present, although none of them lose or manipulate historical knowledge in the ways that postmodernism dispenses with historical narrative. Louise Owen's 'Back to the Future: Gendering the Economy in Twenty-First-Century Drama' (pp. 10728) looks at David Eldridge's Market Boy [2006], Dennis Kelly's Love and Money [2006], Lucy Prebble's Enron [2009], and David Hare's The Power of Yes [2009]. In this essay, Owen discusses how Eldridge's and Kelly's plays reveal different perspectives on localism in terms of their reaction to Thatcherism, while Hare and Prebble consider wider global financial markets. Owen also examines her chosen case studies through the prism of how economics and capital operate through gender and sexuality. Siân Adiseshiah's "Chavs", "Gypos" and "Scum"? Class in Twenty-First-Century Drama' (pp. 149-72) notes the return to issues of class and particularly the working class in recent British drama. Using Jez Butterworth's Jerusalem [2009], Simon Stephens's Port [2002], and Gillian Slovo's The Riots [2011] as examples, Adiseshiah assesses to what degree class as a term is measured in relation to notions of middle-class politesse, and how far they resist these imposed social standards. Butterworth's play is also the subject of Nadine Holdsworth's 'These Green and Pleasant Lands: Travellers, Gypsies and the Lament for England in Jez Butterworth's Jerusalem' (pp. 175-90). Here, Holdsworth rightly points out that British theatre has generally overlooked the representation of gypsies and travellers. She acknowledges that, in Jerusalem, Butterworth has created a more complex and nuanced character of the gypsy in the charismatic figure of Johnny 'Rooster' Byron, one that does much to dispel stereotypes that have recently been promulgated in the media. The essay also goes on to explore the reasons for the success of the play, attributing this to its meditation on Englishness as well as the identification of it by critics as a 'state-of-the-nation' play. Trish Reid's "'Sexy kilts with attitude": Scottish Theatre in the Twenty-First Century' (pp. 191-211) is also concerned with nationality in respect of the different ways Scottish theatre has identified itself through political engagement since 2000 through the work of the National Theatre of Scotland (NTS). Reid argues that the project behind the NTS's inauguration had earlier been influenced by the opening of the Scottish parliament in 1999. Plays discussed include Rona Munro's trilogy, The James 
Plays [2014], Kerian Hurley's Raton [2013-14], and The Great Yes, No, Don't Know 5 Minute Theatre Show [2014], all of which demonstrate various alternatives to theatrical presentation, ranging from metropolitan centres to local performance venues. The chapter also provides a very useful overview of the work of the NTS to date, including an informative discussion on the history of its best-known production, Blackwatch [2006]. Mary Luckhurst's 'The New Genetics, Genocide and Caryl Churchill' (pp. 239-54) looks at Churchill's Far Away [2000] and A Number [2004]. This essay explores the ways they discuss new reproductive technologies, including cloning as a metaphor within acting and repetition through performance. Luckhurst concludes, 'the new genetics poses a worrying concept [with] the human being as cultural capital' (p. 254). Finally, Una Chaudhuri's 'AnthropoScenes: Staging Climate Chaos in the Drama of Bad Ideas' (pp. 303-21) also considers Churchill's Far Away to be a dystopian play about the consequences of the disruption of ecology by the anthropocene.

Irene Morra's Verse Drama in England, 1900-2015 is a comprehensive survey of the intermittent fortunes of this very particular style of theatre. Although Mike Bartlett's blank-verse play Charles III [2014] enjoyed commercial success, Morra observes that attempts by dramatists since 2003 to use verse, such as Joanna Lauren's Five Gold Rings [2003] or Michael Frayn's Afterlife [2006], have been notable critical failures. The brief flowering of the form in the late 1940s and early 1950s is discussed in the work of Ronald Duncan, Christopher Fry (through a case study of his 1948 play The Lady's Not for Burning), and T.S Eliot, with some detailed close readings of The Cocktail Party [1954], which, Morra argues, stands as a forerunner, in its subversion of conventional dramatic form, to Harold Pinter's early work (p. 164). Of especial interest is Morra's argument that verse drama was snuffed out by George Devine in his establishment of the English Stage Company at the Royal Court in 1955, despite Ronald Duncan's central role in helping to set up the company. Morra sees this as ironic, and in her call for wider recognition of Duncan's work rightly points out that while Devine's early advocacy of new continental drama was equally endorsed by Duncan, his attempts at promoting verse drama were extinguished by Devine in favour of the realism of Osborne, Wesker, and the other 'Angry Young Men'. A later chapter looks at the work of one of these dramatists, John Arden, who in later collaborations with his wife Margaretta D'Arcy, such as The Island of the Mighty [1972], in fact experimented with verse drama. Subsequent chapters look at the work of Steven Berkoff, Caryl Churchill (though her 1985 play Serious Money) and Tony Harrison.

The remainder of this section is by William Baker.

There were five items to report published in 2016 on Harold Pinter. Aloysia Rousseau, in a special section on 'Destabilising Comic Boundaries' in Études britanniques contemporaines, writes on 'Harold Pinter's The Birthday Party (1958) and The Dumb Waiter (1960) or the Intermingling of Farce and Menace' (EBC [Dec. 2016] online). She reflects on the comic implications of 'black humour' (p. 51) and its relationship to threat and malice in two of Pinter's early plays. David Tucker's " "That first last look in the shadows": Beckett's Legacies for Harold Pinter' (in Tucker and McTighe, eds., Staging 
Beckett in Great Britain, pp. 193-208) focuses on Pinter's relationship to Beckett and Pinter's unfilmed dramatic adaptation The Proust Screenplay [1972] and its stage adaptation as Remembrance of Things Past at the Cottesloe Theatre late in 2002. Urša Gavez gives an account of 'The Reception of Harold Pinter's Plays in Slovenia between 1999 and 2014' (ELOPE 13:ii[2016] 51-61), in a special issue devoted to 'Time at the End of Times'. Qin Lin and William Baker, in their 'Pinter's Poetry: A Diachronic Analysis' (Style 50:ii[2016] 158-71), write on a neglected area of Pinter's work and one that he took very seriously. They examine changes in Pinter's 'poetry by analysing and contextualizing his representative pieces in different periods'. Qin Lin and Baker contend that Pinter's poetry on the whole underwent a shift from a 'baroque style' (p. 160) in his youth to a 'plain style' (p. 165) in his later years. Obsessed with language and influenced by such writers as Dylan Thomas and W.S. Graham, much of Pinter's early poetry from the 1950s to the 1970s appears elaborate, obscure, and complicated. With the passing of time, 'his poetry becomes clearer, briefer, and more intelligible, especially in the 1990s and beyond. The transformation is closely connected with his life experience. Examining this change helps us better understand the development of Pinter's poetic career' (p. 158). A most perceptive and illuminating Pinter critic, Katherine H. Burkman, in her The Drama of the Double: Permeable Boundaries, devotes two chapters to Pinter. In her fourth chapter, 'Harold Pinter's Death in Venice and Life in Victoria Station [1982]' (pp. 59-75), she observes that 'The Myths of Dionysus and Narcissus overlap as well as they inform the doubling in ... Pinter's [1990] film The Comfort of Strangers' (p. 59). Her ninth chapter is on 'Oedipus and Demeter: Pinter's A Slight Ache [1960]' (pp. 143-51). Burkman writes of Pinter and his critics that 'although his plays have a surface degree of realism, they are often informed by ritual patterns and mythic undertones' (p. 143).

Five items also to report from 2016 on Tom Stoppard. Phillip Zapkin, in his 'Compromised Epistemologies: The Ethics of Historiographic Metatheatre in Tom Stoppard's Travesties and Arcadia' (MD 59:iii[20] 306-26), is concerned with the role of metadiscourse and its relationship to historiography, especially in Travesties [1974] and Arcadia [1993]. For Zapkin, 'Stoppard uses historiographic metatheatre to question the efficacy of historical narratives: plays such as Travesties directly address the constructed texture of history.' Zapkin says: 'partially because the 1809 scenes in Arcadia are naturalistic, critics generally accept' the drama 'as presenting a "real" history'; however, he cautions that 'taking anything in Stoppard's play at face value is a crucial mistake. Instead, we should read Arcadia as participating in a self-consciously destabilizing cultural project building a historiography of error-like Travesties, but through a less obviously constructed historiographic metatheatre.' This is 'a reading that prompts us to reconsider standard narratives of Stoppard's development as a playwright of epistemological uncertainty'. For Zapkin, 'part of Stoppard's joyous humour in Arcadia goes beyond satirizing' the character 'Bernard and extends to the critical misreadings through which we, as critics, reproduce Bernard's unreliable thesis and, like him, risk convincing ourselves that we are right'. Consequently, 'taking Arcadia at face value undermines the ethical imperative to uncertainty and multiplicity inherent in 
historiographic metatheatre, an ethic that runs through both dramas' (p. 306). Stoppard's latest theatrical venture to date is the subject of William Baker's 'Tom Stoppard's The Hard Problem: A Consideration' (FWLS 8:i[2016] 2840), published in a special issue devoted to 'Transnational Ethical Literary Criticism Studies'. Baker, following his explication of the background of the 2015 drama and its relationship to Stoppard's previous plays, 'follows closely the evolution of its plot from an ethical critical perspective: the issues of why and how the characters in the play are in the situation in which they find themselves'. This article is 'probably the first to appear in print' examining The Hard Problem and its eleven scenes' (p. 28). The Real Inspector Hound [1968], a very early play of Stoppard, is the subject of Kevin Drzakowki's 'Secret Guilt of an Artist: The Real Inspector Hound and Tom Stoppard's Political Voice' which appears in the online journal Časopis za Književnost, Kulturu i Književno Prevođenje / A Journal of Literature, Culture and Literary Translation (CKKKP 1:vi[2016]). The emphasis is on the treatment of art in the play and its relationship to politics: the approach is biographical. A later play, The Real Thing [1982], and a different approach, an intertextual one, is found in Lida Krüger's " "Stop putting words in my mouth!": Undermining the Binary between the Actual and the Fictional' (NTQ 32:iii[20] 244-55). Krüger compares the role of dramatic illusion, fictionality in The Real Thing, and Sam Holcroft's 2011 drama Edgar and Annabel. For Krüger, 'the distinction between fictionality and actuality takes on a special significance in the theatre, which contains two frames simultaneously: a fictional and an actual'. She adds that, 'although the presence of these frames is integral to performance, the demarcation between them often becomes blurred'. Both Stoppard's play and Holcroft's 'problematize the relationship between an actor and the character that he or she portrays'. In addition, 'while Stoppard's characters sometimes indulge in fictional portrayals, Holcroft's embody additional characters out of a sense of duty and commitment to a political cause. Although the stakes of keeping the illusion in place are seemingly much higher in Holcroft's play, both suggest that the blurring of the line between the actual and the fictional is not only inevitable, but also potentially dangerous' (p. 244). Barbara Dancygier writes on Arcadia in her 'Multimodality and Theatre: Material Objects, Bodies and Language' (in Blair, Cook, and Turner, eds., Theatre, Performance and Cognition: Languages, Bodies, and Ecologies, pp. 21-39). She compares the role of the human body and the use of props and their relationship to space in productions of Stoppard's play with productions of Shakespeare's Richard II and Julius Caesar.

\section{British Poetry 1900-1950}

\section{(a) General}

Centennial work on the poetry of the First World War continued during 2016, although perhaps not at the pace and volume of previous years. One of the larger and more energetic contributions to scholarship, Nanette Norris's edited collection Great War Modernism: Artistic Response in the Context of 
War, 1914-1918, aims to assimilate the benefits of new modernist studies within our understanding of the First World War and move beyond standard accounts of the 'men of 1914' (p. 1). A majority of the volume focuses upon prose by the likes of Virginia Woolf, Ford Madox Ford, and D.H. Lawrence, but poetry does feature in some places. Travis L. Martin considers 'Modernism's Role in Stabilizing War Narratives through Poetry' (pp. 20726) via readings of David Jones, Brian Turner, and others; Norris herself writes on 'H.D. and the Secrets of Redemption' (pp. 103-18); and, in concert with the volume's general ambitions, James Brown's 'Rosenberg's Half Life: Between Romanticism and Modernism' (pp. 161-83) seeks to detach the poetry of Isaac Rosenberg from the work of some of his contemporaries and claim him as a modernist. This project is, however, complex: Brown's readings trace affinities and allusions to elements from the Romantic poetry of Keats and Wordsworth in order to indicate their transformation. Thoughtful, attentive readings of Rosenberg's diction reveal in this way patterns of continuity and rupture with his poetic past, such that Brown is tempted to coin the term 'Keatsian modernism' (p. 179). This won't do, he notes, but it is a reflection of 'the connectedness between romanticism and modernism' that Brown describes (p. 179).

Elsewhere, Jahan Ramazani's " "Cosmopolitan Sympathies": Poetry of the First Global War' (Mo/Mo 23:iv[2016] 855-74) offers sensitive readings of poems by Isaac Rosenberg, Thomas Hardy, Robert Service, Mary Borden, and Wilfred Owen that demonstrate a capacity to look beyond the limitations of imperialist and nationalist ideologies in their representations of war. Taking his cue from Rosenberg's 'Break of Day in the Trenches', Ramazani identifies 'the cosmopolitan potentialities of poetry', uncovering in these texts 'literary spaces for enacting, and reflecting on, transnational imaginative solidarities' (p. 856). This potential, the article concludes, may be particularly pertinent at the present moment.

As ever, the work of Wilfred Owen and Siegfried Sassoon tends to dominate discussion of poetry from the First World War. Edward Eason's 'Conjugal Friendship in the Creation of Wilfred Owen's "Anthem for Doomed Youth", (ELT 59:i[2016] 76-86) revisits Siegfried Sassoon's poetic mentoring of Wilfred Owen through a theory of 'conjugal friendship', derived from work by George Haggarty on Plato's Symposium. Deploying a close reading of Sassoon's suggestions for revisions to 'Anthem for Doomed Youth', Eason argues that this textual relationship 'enshrine[s] their intimacy in a queer temporality that counters the military authority co-ordinating wartime violence' (p. 69). Exploring similar territory, Mark Cyr's 'The Conscientious Killer: Wilfred Owen's "Strange Meeting", (TSLL 58:i[2016] 108-28) traces the biographical events leading up to Owen's composition of 'Strange Meeting' in March 1918. Cyr reads the poem as an expression of Owen's ambivalence about his involvement with the war that leans towards a stronger sense of his duty to return to the front. In contrast, Stephen J. Summers's 'Sassoon's Wartime Ethics: Satire, Sarcasm, and the Rhetoric of Poetic Protest' (Rhet $R$ 35:iv[2016] 308-21) cites Habermas on the necessity for 'a speaker's good-faith efforts to reach a consensus with a listener' (p. 310) in order to question the effectiveness of Sassoon's use of sarcasm in poems such as 'They' and 'The Hero'. Sassoon 
may have felt frustration with the conduct of the war, Summers explains, but his resort to sarcasm and irony was 'unethical communication' (p. 312).

Cedric Van Dijck's 'Time on the Pulse: Affective Encounters with the Wristwatch in the Literature of Modernism and the First World War' (ModCult 11:ii[2016] 161-78) contends that the wristwatch has been overlooked in critical accounts of modernism and time. Accordingly, the article reads Siegfried Sassoon's 'Attack' alongside Robert Graves's Goodbye to All That and To the Lighthouse by Virginia Woolf, emphasizing the role of 'sensuous' and 'tactile' contact (p. 168) with time through the figure of the wristwatch. In Sassoon's poem, Van Dijck argues, the wristwatch figures both an intimate, physical experience of time and the ordered time of official military life. Sassoon and Edmund Blunden feature briefly in Michael West's wide-ranging and comparative article, 'Did World War I Foster Distinctly "Spectatorial" Attitudes in Writers?' (CLS 53:i[2016] 78-113). Exploring the tendency of some British writers to 'seek salvation from the war in spectatorial detachment' (p. 83), West cites 'Sassoon's capacity for ironic spectatorship' (p. 81) and discerns an intensity of detailed perception in Blunden's poetry, before exploring similar issues across a broad international cast of writers and poets.

Finally, Ezekiel Black's 'Troubling Glory: The Uncertain Language of Shift of World War I' (WarL\&A 28[2016] 1-10) offers a general account of the war that seeks to probe critical commonplaces. In particular, Black seeks to introduce 'nuance' (p. 6) into our understanding of the war poets as a group and the influence of their output upon a 'language shift' whereby the discourse of war became more stark and realistic. It seems obvious to point out that language use varied between poets and between classes and categories of soldiers, but Black is concerned that 'educators' fall into these universal abstractions, and warns in conclusion that we 'must resist the temptation to claim that language shifted because of World War I' (p. 9).

Tragically killed during the war at the battle of Arras, Edward Thomas continues to garner a small but steady amount of critical interest. Rowan Middleton's 'Edward Thomas, Poetry and the Languages of Nature' (English 65:ccli[2016] 310-29) draws on Antony Easthope and Jeffrey Side's theories of 'empiricist poetics' (p. 312) in relation to Thomas's poetry of nature. Exploring the influence of Wordsworth here, Middleton argues that the power of Thomas's work lies in its recreation of 'the slow destruction of the English rural environment and its culture' (p. 313) and the way that Thomas intimates the effects of this upon the relationships between humans and nature. This depends on the poet's capacity to choose the right words and the right form to convey the particularities of a scene or experience, and the readings here are dense with examples of Thomas's nuanced and precise diction. James Riding's 'A Geographical Biography of a Nature Writer' (CulG 23:iii[2016] 387-99) takes a slightly different, more literal approach to Thomas's connections with nature. This article describes the author's own attempts to revisit landscapes and scenes on the South Downs and in east Hampshire that were dear to Thomas, tracing routes derived from The Heart of England [1906] and other pieces of nature writing. Riding mixes his own experiences with biographical 
anecdotes and poetry from Thomas's life as an act of 'geographical biography' or 'cultural geography' (p. 388).

Anna Catherine Stenning's 'Edward Thomas's "Ecstasy": An Unpublished Essay' (EIC 66:iv[2016] 466-87) reproduces in full for the first time Thomas's manuscript essay 'Ecstasy' from 1913. Stenning prefaces the text of the essay by placing it in the context of the work of William James, Edward Carpenter, and others. Thomas's defence of 'non-religious experiences of ecstasy' as 'at least kindred to a genuine mystical experience' (p. 467) has obvious implications for our understanding of his nature poetry, and Stenning draws heavily on work by Peter Howarth which makes this connection in greater detail.

The poetry and criticism of William Empson enjoyed a brief critical vogue a few years ago, with the publication of John Haffenden's two-volume biography. Since then, work on Empson has slowed to a trickle of articles and essays. In 2016, however, this changed dramatically with the publication of The Face of the Buddha, edited by Rupert Arrowsmith. Empson himself believed the manuscript to this work lost - abandoned in the back of a taxi by a drunken friend in 1947. In 2005, however, it turned up unexpectedly in archives at the British Library and has now been edited by Rupert Arrowsmith for Oxford University Press. The book presents the results of over a decade of travels around East Asia and America, during which Empson took photographs and notes relating to sculptures of the Buddha. This might seem to have limited interest for anyone concerned with his poetry, except that driving Empson's fascination was a theory about the asymmetry he perceived in the face of the Buddha. This was, he speculated, a means of 'combining things that seem incompatible' (p. 81). His amateur account of sculpture and religion is suffused, then, with the kind of insights that characterize both Empson's poetry and his critical writings. 'Life', Empson remarked in a note to his poem 'Bacchus', 'involves maintaining oneself between contradictions that can't be solved by analysis.' This thought and Empson's feeling for linguistic and moral complexities inform his poetry and criticism in different ways. Something similar is implicit in his approach to statues of the Buddha in this book. Like much of Empson's work, this is an odd volume - eccentric in parts, quaint, and yet moving and insightful. Arrowsmith's editing is tactful in its interventions, but scholarly and well-informed.

Empson also features amongst the intellectual figures discussed by Stefan Collini in Common Writing: Essays on Literary Culture and Public Debate. A chapter, derived from reviews of John Haffenden's biography and Christopher Hilliard's account of the Scrutiny movement, sets Empson alongside his contemporary F.R. Leavis, although Collini resists the temptation to revise this previously published material into closer comparison of the respective merits of the two (pp. 83-100).

As ever the writings of W.H. Auden continue to attract a steady stream of critical interest. His poetry is granted a prominent position in Grief \& Meter: Elegies for Poets after Auden, Sally Connolly's eloquent and finely observed study of the elegy for a poet as a genre, a mode and, above all, a form. Her introduction (pp. 1-32) begins with Auden, and Connolly devotes a chapter (pp. 33-63) to reading 'In Memory of W.B Yeats' as 'the touchstone 
genealogical elegy of the twentieth century and beyond' (p. 33). Subsequent chapters explore the working out of Auden's influence in poetry by Joseph Brodsky, John Berryman, Robert Lowell, and Seamus Heaney. This choice of poets reveals Connolly's opening image of Auden on the steamship to America in January 1939 as a kind of conceptual pun for her interest in transatlantic poetics. As well as a lively account of elegiac form that draws on wellestablished work in this area by Peter Sacks, Connolly also offers her deft close readings as a corrective to the 'distant reading' of genres and forms offered by Franco Moretti and others (p. 4).

Kelly Sultzbach devotes a chapter of Ecocriticism in the Modernist Imagination to Auden (pp. 146-92) as part of her broader account of 'a modernist environmental consciousness' (p. 3). Alongside Virginia Woolf and E.M. Forster, Auden features here as someone who poses 'knotty problems of agency and representation' (p. 3) in relation to nature and natural phenomena. Specifically, her account of Auden seeks to redress a neglect of his works by ecocritics through a reading of his representation of human animals. Sultzbach does not, then, reinvent Auden as a nature poet so much as locate his interest in 'the line that connects human and nonhuman interests' in relation to the broader philosophical and political concerns of ecocriticism as a field (p. 147). References to animals in his later poetry are used by Sultzbach to probe the mental, physical, and ethical differences between man and beast. Her analysis of poems such as 'Bestiaries are out', 'The Sabbath', and 'Two Bestiaries' reveals that while Auden does not avoid anthropomorphism, his poetry is capable of resisting anthropocentrism.

Sultzbach and Connolly grant considerable space to Auden's work amidst the development of a larger important argument or theme within a monograph. But his work also attracted occasional interest within more diverse collections of scholarship in 2016. Amongst the essays in James Williams and Matthew Bevis's edited collection, Edward Lear and the Play of Poetry, Seamus Perry's 'Auden's Lear' (pp. 300-16) locates a sonnet devoted to Edward Lear by Auden in 1939 in relation to the poet's lifelong love for Lear's poetry and interest in his biography. Auden was inclined, Perry suggests, to exaggerate aspects of Lear's misery for his own purposes, but this insightful essay makes a persuasive case for placing Lear amongst the writers "whom Auden adopts in the attempt to envisage a poetry that grows from human unhappiness, transforming those unhappy preconditions utterly yet somehow without betraying or forgetting them' (p. 314). Perry's essay is sensitive and productively thoughtful and thought-provoking about the work of both poets.

Marcel Sarot's 'Transformative Poetry: A Case Study of W.H. Auden's "Musée des Beaux Arts" and General Conclusions' (Perichoresis 14:1i[2016] 81-97) retreads some familiar ground, setting out the visual inspirations for one of Auden's most famous poems and tracing its origins in Auden's direct experience of conflict. Citing 'The Hidden Law', another, near-contemporary, poem by Auden, Sarot argues, however, that 'Musée des Beaux Arts' should be seen in light of the poet's imminent conversion to Christianity. The fall of Icarus in the painting by Bruegel which sparked the poem is intimately linked, 
for Sarot, with the martyrdom of Christ, and Auden's meditation on responses to suffering is bound up in this too.

In addition to Auden's poetic output, his activities as a librettist attracted some attention during 2016. Herbert Lindenberger's 'Stravinsky, Auden and the Mid-Century Modernism of The Rake's Progress' (in Begam and Smith, eds., Modernism and Opera, pp. 271-89) outlines the consonance between the music of Stravinsky and the poetic forms contrived by Auden and his partner Chester Kallman for The Rake's Progress in 1951. Disavowing 'self-expressive indulgences', these artists, Lindenberger suggests, shared a 'neoclassical aesthetic' which represented 'an attempt to expunge whatever Romantic elements they might be tempted to allow into their work' (p. 285). Matthew Paul Carlson's 'Opera Addict: The Rake's Progress and W.H. Auden's Operatic Theory' (UTQ 85:i[2016] 69-93) also examines The Rake's Progress, but where Lindenberger takes a broader, biographical approach, Carlson investigates more closely the tensions between Auden's theory and practice of writing for operatic performance. The article scrutinizes collaborative work on the libretto with Chester Kallman, juxtaposing it with Auden's critical and reflective writings on opera, as well as tracing various allusions to Milton and the New Testament. The Rake's Progress, Carlson concludes, offers a 'profound exploration of music's relation to temporality and subjectivity' (p. 90). Rodney Stenning Edgecombe's 'Three Musical Sources for Auden's "Lullaby", (ANQ 29:iii[2016] 177-80) combines musicological analysis, close reading, and biographical information about the poet's formative tastes in music and opera to trace the origins of Auden's poem in Wagner's Tannhäuser, Auber's La Muette de Portici, and a hymn by Bishop Mant.

Finally, Lyndsey Stonebridge's 'Statelessness and the Poetry of the Borderline: André Green, W.H. Auden, and Yousif M. Qasmiyeh' (in McLoughlin, Feigel, and Martin, eds., Writing War, Writing Lives, pp. 11336) juxtaposes Auden's increasing disaffection with British society before the Second World War and eventual self-exile to America with the work of a contemporary Palestinian poet based in Oxford. Stonebridge uses André Green and Jacqueline Rose here to theorize the condition of statelessness. While the images in 'Look, Stranger' contain and 'enable the experience of separation', the article argues, 'they must also navigate the still indistinct territories of the borderline' (p. 124).

The poetry of Rudyard Kipling features at the heart of Alexander Bubb's rather strange project, Meeting Without Knowing It: Kipling and Yeats at the Fin de Siecle (also reviewed in Section 2(a) above)-an experiment in comparative biography. Kipling and Yeats, Bubb notes, may never have spoken to each other, and shared few values, but nevertheless, he argues, they had concerns in common. Bubb's phrase for this is 'Estranged but oddly proximate' (p. 12) and his prose is full of paradox, referring to the relationship between these writers as 'an unintentional collaboration, an unacknowledged rivalry' (p. 13). The thrust of the book is sequential comparison of phases in their lives, so there are chapters here which compare the childhood experiences of Kipling and Yeats, their respective experiences of London and literary 
society there, and their reception as increasingly popular writers, stopping at 1906.

Elsewhere, critical writing on Kipling's poetry seemed scarce during 2016, with the possible exception of Judith Plotz's 'Kipling and the Use of Poetry' (KJ 90[2016] 49-62), which describes the 'prosimetric conversation between poetry and prose' in Puck of Pook's Hill [1906] and Rewards and Fairies [1910] (p. 49). Still, even here Plotz's subject is Kipling's use of poetry by other people as well as himself to foreshadow and shed light on narrative elements in his fantasy stories for children. For Kipling, the juxtaposition of prose and poetic forms, Plotz suggests, helped gesture towards the 'multiplicity and stress of the world around and within' his stories (p. 60).

Marion Thain devotes half a chapter to the poetry of Thomas Hardy (he shares the other half with Alice Meynell) in The Lyric Poem and Aestheticism, her study of the lyric as the rising form of modernity at the end of the nineteenth century (pp. 153-71). Together, Meynell and Hardy serve Thain as case studies in what she describes as 'lyric's awareness of its own spatial embodiment' (p. 7). Starting with Meynell's fondness for poetic pauses, which she sees as intimately connected with the space occupied by her poetry upon the page, Thain argues for reading this in phenomenological terms. Turning to Hardy, his 'lyric space', she suggests, offers a locus where "the lyric "you" is simultaneously understood in relation to the lyric "I" and acknowledged as other and independent and essentially unknown to it' (p. 159). Deft readings follow of 'Old Furniture' and 'The Minute before Meeting' that manage to combine close attention to prosody and mise-en-page while moving between the formal registers of philosophy and the poignancy of Hardy's and Meynell's deep sense of isolation.

Although Hardy's novels seem to interest contributors to the Hardy Society Journal more than his poetry, it still continues to yield articles and notes of interest. Mark Edwards's short piece, 'The Naming of Thomas Hardy's "Drummer Hodge", (THSJ 12:ii[2016] 42-6), suggests that the name and content of Hardy's poem may have been inspired by a satirical essay from 1843 by Douglas Jerrold. James Booth writes at greater length in 'Hardy and Larkin: Poetry vs. the Novel' (THSJ 12:i[2016] 24-43) to trace the effect of Hardy's poetry and novels upon Philip Larkin. While confirming Larkin's own account of Hardy's importance and influence, Booth stresses important, deeper, differences between the 'literary sensibilities' of both writers (p. 39). In the same issue Keith Wilson's 'What Tess Meant to Hardy, and Why' (THSJ $12: \mathrm{i}[2016]$ 44-65) ranges beyond Hardy's most famous novel to explore his intense imaginative engagement with the protagonist of Tess of the D'Urbervilles and its impact upon his practice as a poet. For Wilson this is manifest in 'ideas about the nature of human consciousness' (p. 62) and the problems and responsibilities associated with representing it, as found in works such as 'Tess's Lament' and 'At Castle Boterel'. Finally, 'Hardy's "The Ruined Maid": A Refutation of William Tait's Magdalenism' (THSJ 12:i[2016] 66-9), by Ashby Bland Crowther, seeks to place Hardy's response to hypocritical Christian evangelists in specific historical context. Crowther's note reads 'The Ruined Maid' as a direct refutation of the Edinburgh surgeon William Tait's account of prostitution. 


\section{(b) T.S. Eliot}

The largest contribution to T.S. Eliot studies during 2016 was the sixth volume in the ongoing edition of the poet's letters, edited and annotated in copious scholarly detail by John Haffenden. Reviewers have noted plaintively that previous volumes in this series consist largely of workaday material from Eliot's career as an editor and publisher, but this volume covers the years 1932 and 1933, during which Eliot instigated a separation from his first wife, Vivienne. He took this dramatic step while making an extended stay in America, where he held the Charles Eliot Norton Professorship in Poetry at Harvard. This personal drama plays out amongst the polite rejection letters to would-be poets and notes to his secretary commissioning reviews for the Criterion. The volume supplies letters from Vivienne too, which become increasingly fraught as her husband's plans become clear. As with other volumes in this series, Eliot sheds relatively little light upon his craft within his correspondence, but there is a strong biographical interest here. Haffenden's notes supplement this with detailed ancillary material about, for example, Eliot's withdrawal to the countryside in order to avoid Vivienne upon his return to England and some of the legal arrangements and negotiations. It's a curious and fascinating volume to read.

Given how many of Eliot's letters are taken up with the business of commissioning and rejecting books and articles, it may be surprising that the new edition of his correspondence features very little in Nicola Wilson's The Book World, an edited collection of essays on the publication, sale, and distribution of books during the first half of the twentieth century. Perhaps the scholarship of Haffenden and others in this area has yet to percolate through to the work of book historians. Eliot's presence in Wilson's volume is limited to Lise Jaillant's essay about the introductions written by Eliot and Virginia Woolf to editions of Wilkie Collins's The Moonstone and Laurence Sterne's $A$ Sentimental Journey respectively, in the Oxford World's Classics series (pp. 52-82). Jaillant locates these prefatory writings in the larger history of World's Classics; she connects them to series editor Humphrey Milford's understanding of the advertising value of the names of these modernist writers for a middle-class audience. Eliot's activities as both a poet and an editor also feature in passing in Eric Bulson's Little Magazine, World Form which offers a reassessment of Eliot's negotiations regarding the first publication of The Waste Land with two periodicals on either side of the Atlantic, the Criterion and the Dial (pp. 92-102). Bulson connects the resulting differences of text, punctuation, and typography between these two publications to a broader argument about the developing nature of transatlantic periodical networks and 'form'.

It was a year rich in edited collections of essays on Eliot. Edited by Frances Dickey and John Morgenstern, The Edinburgh Companion to T.S. Eliot and the Arts is a lengthy and substantial contribution to the field. The editors have divided the volume into three thematic sections, each accompanied by a short editorial overview of the topic and the essays therein. But it opens with a preface from Ron Schuchard which surveys Eliot's encounter with the visual arts through various patrons and patronesses (Isabella Gardner in Boston; 
Ottoline Morrell at Garsington), before considering his experience of artistic censorship.

In the first section, on visual arts, Frances Dickey explores Eliot's introduction to japonisme at the Museum of Fine Arts in Boston when he was an undergraduate at Harvard. Dickey's essay thoughtfully connects this to the early poem sequence 'Mandarins', setting out the possibility of seeing this poem ekphrastically as a progress through a museum. Nancy Hargrove seeks to expand our understanding of Eliot's exposure to Asian philosophical and spiritual ideas beyond his graduate studies under Josiah Royce. Her contribution lays out Eastern holdings at ethnographic exhibitions in the Louvre and British Museum that Eliot may have encountered during his visit to Europe in 1910. Focused on another early poem, 'Afternoon', Michael Coyle's essay supplies historical and contextual information about the rise of the British Museum and especially its holdings from Assyria. In this way, Coyle connects Eliot's poetic of treatment of women visiting these works with a specific historical moment in museum culture and the archaeology of knowledge.

John Morgenstern's contribution traces the influence of the art historian Matthew Stewart Prichard on Eliot's early aesthetics, arguing that Prichard's Bergsonian appreciations of Matisse shaped early poems such as 'Bacchus and Ariadne: 2nd Debate between the Body and Soul'. He concludes, however, by indicating some of the ways that 'multiple layers of ekphrasis' in the opening sections of 'A Game of Chess' (p. 65) surpass Prichard's theories. Anne Stillman's essay on Italian painting is less closely focused on particular biographical or historical contexts than other contributions to this section, but it is more sharply focused on the poems themselves, and all the more insightful for this. Stillman draws particular attention to the unsettling effects evoked by Eliot's practice of allusion in relation to visual sources.

Joshua Mabie's essay on London's church architecture revisits old arguments about Eliot's attitude towards the past by considering his view of attempts to restore or destroy city churches, such as St Magnus Martyr and St Mary Woolnoth. As a young man Eliot viewed these churches as 'stable artifacts that maintain a link to a less corrupt, more beautiful past' (p. 76), but Mabie shows that he arrived at a different view in the 1950s. Later in life, Eliot came to see that restoration might involve change and adaptation too.

The second section of the collection treats Eliot's interest in music - a more obvious preoccupation, from his early poetry to Four Quartets. Frances Dickey's essay sets the proliferation of musical references in the Inventions notebook (including the title) against the rich musical culture of Boston during the period of Eliot's studies at Harvard. Dickey explores the ambivalence or mixed feelings about music in these early poems and traces the influence here of Eliot's tutor Irving Babbitt and the writer and critic James Huneker. The latter's collection of short stories, Melomaniacs [1902], Dickey argues, constitutes 'an important context for and analogue to' Eliot's early poetry' (p. 113). Adrian Paterson's contribution examines 'the receptions and paratexts through which Wagner enters The Waste Land' (p. 122), ranging from the German composer's reception in France during the nineteenth century to modernist responses to Wagner in London before and during the 
publication of Eliot's poem in the 1920s. As well as drawing out these contexts, Paterson deftly delineates the ways the sounds of Wagner's vocal music register within the fabric of The Waste Land itself. Katherine Hobbs examines Wagner's influence on Eliot too, but adopts a highly specific approach: she identifies the role played by the character of Kundry in Parsifal as central to The Waste Land and to Eliot's creation of a multi-faceted female figure at the poem's core. Some of the connections Hobbs cites are more attenuated than others, but many of her arguments are plausible.

Turning to Stravinsky, T. Austin Graham argues that Eliot was ahead of his contemporaries in his appreciation of works such as The Rite of Spring. Graham then explores affinities and connections between the Russian composer's most famous work and The Waste Land, before concluding that the two artists shared an understanding of the relation between sound and history. Moving away from Western classical music, Steven Tracey considers jazz, drawing connections and comparisons between Eliot, Louis Armstrong, and Ralph Ellison. A detailed account of Armstrong's playing is compared to the 'dazzling, dizzying, seemingly improvisatory weaving of [Eliot's] material [in The Waste Land] into a seemingly impossible, always surprising whole' (p. 165). In contrast to Tracey, Aakanksha Virkar-Yates turns back to Wagner in order to explore his influence on the later poetry of Four Quartets through the presence of a Schopenhauerian aesthetics of music. Drawing heavily on Wagner too, Michelle Witen's contribution explores Eliot's creation of 'musical patterning' in Four Quartets (p. 204), placing this in the context of the rise of 'absolute music' during the nineteenth century and the capacity for increased dynamic range fostered by technological developments in the manufacture of various musical instruments. Witen concludes with a reading of repetition and pattern in 'East Coker'.

Barry Faulk's essay examines Eliot's interest in music hall as a means of exploring the value of comedy in his work and the ways in which comedy relates to modernism more generally. Faulk ranges widely, taking in theories of the comic by Freud, Bergson, Baudelaire, and Wyndham Lewis, as well as music hall performance by Marie Lloyd and Walter Benjamin's contemporary interest in surrealism. 'Eliot's dialectical notion of modern comedy', Faulk argues, 'was shared by the European avant-garde of his day' (p. 190).

Anthony Cuda provides an account of the private theatrical company, the Phoenix Society, and its chequered history of attempts to revive various seventeenth-century works, from Webster to Dryden, during the 1920s. Eliot wrote commentary on their efforts in the Dial and elsewhere, as Cuda records, and their dramaturgical practice may have informed his own thinking about the relation between theatre and verse in Sweeney Agonistes. Susan Jones's contribution examines the influence of dance upon Eliot, using it as a 'provocative thread' (p. 227) that links the prosody of early poems, such as 'La Figlia che Piange', Mallarmé's transformative vision of poetic subjectivity, inspired by the performances of Loie Fuller, the music of Stravinsky and choreography of Massine in the Russian ballets, and the paradoxical 'still point of the turning world' in Four Quartets.

A third section in the volume, devoted to Eliot and media, begins with David Trotter's fascinating account of 'media' as a concept. Starting from 
Hegel, Trotter explores "how far our own association of the term "medium" with communications technologies is from the associations developed in literary and philosophical discourse at the time when Eliot began to frame The Waste Land' (p. 256). He then picks his way deftly and with assurance through Eliot's youthful studies in Bergson towards a growing self-consciousness about 'media' in the cinematography of Cecil B. De Mille. The director's fascination with scenes of feminine toilette offers Trotter a point of entry to a speculative reading of the scene of Fresca's toilette in discarded drafting from The Waste Land.

Eliot's poetry was shaped, Malobika Sarkar claims, by 'the inescapable reality of the phonograph's influence' (p. 262). Sarkar's contribution offers a history of the phonograph and its transformative effect upon our appreciation of sound, before exploring allusions to the gramophone in Eliot's poetry and criticism. This concludes with a reading of the rhythmic soundscape of The Waste Land as transformed by Eliot's sensitivity to the gramophone. With a collection of such length, there are bound to be points of overlap and moments that sparkle less than others, but The Edinburgh Companion to T.S. Eliot and the Arts contains much that is new and insightful and will no doubt inspire further research across the areas it delineates.

Renewing or revising a standard critical anthology such as the Cambridge Companion series offers a chance to assess what has changed in the intervening period. Edited by A. David Moody, the previous Cambridge Companion to T.S. Eliot was published in 1994, but the New Cambridge Companion to T.S. Eliot, edited by Jason Harding, only really contains one essay that rises to this challenge: Gail McDonald's contribution on 'Gender and Sexuality' begins by pointing out the absence of her topic from the previous collection and emphasizing the influence of the new modernist studies upon our understanding of Eliot. In fact, while McDonald touches upon Eliot's life and work, her essay is more strongly a reflection upon the changing critical scene, one which considers responses to Eliot's poetry more than the work itself. Happily, the other essays in volume are more solidly engaged with his writings and, as a whole, these approaches complement each other. The collection may not break much new ground, but it is a highly useful critical resource for students of Eliot's work and a strong successor to the previous volume.

Editor Jason Harding offers an overview of Eliot's life and biography. Michael O'Neill provides an account of 'allusion and form' across the poetry, which credits the 'mingling of attitudes' (p. 27) resulting from Eliot's allusive practices, charts the dramatic value of Eliot's rhythm, and lays out the uncertainties he generated through rhyme. O'Neill's approach in terms of allusion provides the volume with a thematic core, and many of the essays probe one or more of Eliot's sources. Anne Stillman's fine-tuned contribution on Prufrock and other Observations locates cross-connections between the poems in Eliot's first collection through a common vocabulary of words and situations. Rick de Villiers's essay on the quatrain poems finds them 'driven by a desire for seriousness' (p. 65), whereas Lawrence Rainey traces different structures of voice in The Waste Land, focusing upon the influence of the typist novel as a genre upon Eliot's presentation of the tensions between the 
'automatic' activity of work and self-identity or self-respect. Sarah Kennedy reads Ash Wednesday as caught between an impulse towards 'poetic selfconstruction' and 'spiritual self-absorption' (p. 95), while Steve Ellis explores the relation between religion and history in Four Quartets, describing the challenge, as Eliot saw it, of transcending time-bound human experience. Four Quartets, Ellis concludes, 'by no means washes its hands of the political and historical situation' (p. 113).

Anthony Cuda surveys the verse drama, outlining Eliot's position as 'a critic and theorist of the stage, profoundly concerned with the state of contemporary theatre and determined to change its direction' (p. 116). Helen Thaventhiran explores Eliot's career as a literary critic, scrutinizing the 'Eliotic swerve' (p. 132), namely his deployment of litotic negative forms and logical inconsistencies to confound the reader and drive home a point. In comparison, John Xiros Cooper examines Eliot as a social critic, establishing his opposition to the substitution of 'culture' for religion and 'resistance to the advance of secularism and its accompanying materialist values' (p. 147). Jewel Spears Brooker takes advantage of the recent publication of Eliot's graduate essays in the ongoing edition of his Complete Prose to provide a detailed and thoughtful account of his responses to Henri Bergson and F.H. Bradley. Barry Spurr closes the volume with an essay on Eliot's Anglo-Catholicism which criticizes those who fail 'to take the poet at his word' (p. 187). Eliot's turn to the AngloCatholic Church was not, Spurr urges, a 'conversion' but something more gradual. Accordingly, Spurr argues, we should read The Waste Land as 'at least as much a "Christian" poem as Four Quartets' (p. 188).

Barry Spurr's work also enjoys prominent positioning in Scott Freer and Michael Bell's edited collection, Religion and Myth in T.S. Eliot's Poetry, which contains a stimulating range of essays on Eliot's religious interests. Spurr's essay on Eliot and Anglo-Catholicism starts in a combative mode, singling out John Haffenden for perpetuating a divide between Eliot's output before and after his open declarations of religious affinity. Curiously, Spurr doesn't substantiate the claim, made here and in his contribution to Harding's volume, that 'the continuities in Eliot's oeuvre, thematically and technically, are more remarkable than any striking change of manner and vision' (p. 2). Instead, this essay provides a thoughtful and conscientious delineation of the specific nature of Eliot's poetic commitment to Anglo-Catholicism, from his fascination with liturgical cycles to his thoughts and feelings about doctrines of incarnation. Tony Sharpe's contribution begins with the negative reactions towards Eliot's public confessions of Christian faith expressed by contemporary modernists such as Virginia Woolf. Citing Graham Hough's accusation of dogmatism, Sharpe then explores tensions between poetry and doctrine in Four Quartets and the verses Eliot wrote for The Rock. Andy Mousley's contribution draws a title, 'Felt Significance', from the work of F.R. Leavis. Contemporary criticism, Mousley suggests, focuses upon material and ideological factors at the expense of attending to what Leavis called 'life'. His essay offers readings of 'Prufrock' and Four Quartets in an attempt to achieve 'the reconsecration of literature's ability to minister to life' (p. 50). Michael Bell's contribution situates Eliot's poetry in relation to a broader conception of modernist mythopoeia, drawing on work by Matthew Arnold, 
Nietzsche, Freud, and J.G. Frazer to provide historical and intellectual context. In The Waste Land, Bell argues, myth functions as 'a place-holder for religious belief, rather than the mythopoeic precipitate of its loss' (p. 73). Four Quartets, on the other hand, remains resistant to Arnoldian humanism and aestheticism, invoking 'by poetic means a vividly felt intuition of an alternative order of being' (p. 74).

Scott Freer's contribution to this volume begins with the influence of Baudelaire upon Eliot, exploring the role of 'ennui' in the poetry. The Frenchman's vision of cosmopolitan apathy provided Eliot with the basis for a vision of ennui as 'an unorthodox and uncompromising vision of evil' which also derives from medieval notions of 'acedia - spiritual apathy — being dead to the world and oneself' (p. 77). Freer then traces these notions across Eliot's work from 'The Hollow Men' to Four Quartets. Joanna Rzepa examines Eliot's concern with the realities of incarnation, through a reading of 'The Journey of the Magi'. Rzepa sets this in context with Eliot's extended conversation about theological matters with John Middleton Murry in print and via correspondence. In turn, she places their disagreements in relation to contemporary modernist theology in the early years of the twentieth century and Eliot's formative reading of Lancelot Andrewes during the 1920s.

Jeremy Diaper's essay locates Eliot's 'Religious Agrarianism' in relation to the organic husbandry movement, tracing his connections with the New English Weekly. Eliot's interest in 'the cultivation of the soil', Diaper argues, 'was directly related to the opportunity it presented for spiritual rebirth and the renewal of a Christian sensibility' (p. 130). But Diaper also discerns mixed feelings on Eliot's part towards 'merely countrified' forms of existence, lacking in spiritual rigour (p. 139). Matthew Geary's contribution, on 'Maternal Allegory' in Ash Wednesday, builds on previous work by Elizabeth Daumer in order to identify 'the spiritualised presence of the mother' within Eliot's poem 'in eschatological-allegorical moments of faith under conditions of melancholia, death and doubt' (p. 147). Geary founds his claims in evidence from typescript drafts of Ash Wednesday and a reading of Walter Benjamin's theory of tragedy. Finally, the collection concludes with Lynda Kong's deeply personal description of Eliot's influence upon her own 'spiritual quest' (p. 176) and conversion to Christianity. She draws on Charles Taylor's account of the current 'secular age' to explore Eliot's sensitivities to the lived experience of religious belief and the difficulties this poses.

Beyond such edited collections, several critics chose to centre chapters or parts of chapters on Eliot, within a longer work. W. David Soud devotes a chapter of his monograph on modernism and theology, Divine Cartographies: God, History and Poiesis in W.B. Yeats, David Jones and T.S. Eliot, to what he describes as 'The Dialectical Poetics of Four Quartets' (pp. 147-216). Specifically, Soud traces the influence of Karl Barthes's theology upon Eliot during the 1930s through his activities as an editor and critic for the Criterion, before offering a reading of Four Quartets in terms of Barthesian dialectics.

A chapter on Eliot concludes Ranjan Ghosh's Transcultural Poetics and the Concept of the Poet: From Philip Sidney to T.S. Eliot (pp. 147-76), offering 'a transhabitual understanding of the platinum poet' (p. 157). Ghosh's definitions of 'trans-habit' are slippery, even contradictory, but that may be the 
point: 'trans-habit' seems to be a way of acknowledging the hardening of experience into habit at the same time as understanding an oppositional power within 'habitual modes of seeing, doing and thinking' that leads to the modern and the new (p. 168). As such, Ghosh is indebted to sources and thinkers as various as Jacques Derrida and Buddhist, Hindu, and Jain teachings on the concept of 'tarka' (p. 4). This work has clear applications for re-examining the mixture of the monumental and the dynamic in Eliot's understanding of 'tradition'.

Eliot's post-war writings on culture feature prominently in the third chapter of Terry Eagleton's Culture, which concludes by contrasting him with Raymond Williams regarding their views on the degree to which historical societies can be brought to consciousness of culture. For Eliot, Eagleton suggests, a common culture is 'commonly shared', whereas Williams conceived of it as 'commonly made' (p. 94). Amongst the essays and articles collected in Common Writing, Stefan Collini's lucid and informed writings on public intellectual culture in Britain, chapter 2 derives from previously published reviews of the first two volumes of Eliot's Letters and A.D. Moody's biography of Ezra Pound (pp. 37-64). With characteristic poise and style, Collini re-treads some familiar ground, outlining Eliot and Pound's collaborative interactions, tracing Eliot's activities as editor of the Criterion, and pondering his flirtation with a university career while delivering the Clark Lectures at Trinity College, Cambridge during 1926.

Martin Hampton's 'T.S.E. and the TES: Eliot and Educationalism' (ModCult 11:ii[2016] 206-24) also examines Eliot's career as a public intellectual, tracing the poet's 'neglected though intriguing relationship' with H.C. Dent, the editor of the Times Educational Supplement (p. 207). Dent used his editorship to push a radical educationalist view, but moved in some of the same circles as Eliot, and the two men became involved in open, public debate within both the TES and Notes towards the Definition of Culture. At stake, Hampton suggests, were significant, but cordial differences of opinion about the nature of organized state intervention in the moral development of individuals. The implications are broad, and Hampton's argument takes in Eliot's 'deliberation of historical time and the multitude of potentialities through which one's responsibility to the future becomes manifest' within Four Quartets as well as Eliot's critical prose (p. 216).

Duncan MacKay's 'Eliot's Scientific “Tendencies" in 1919' (PNR 42:vi[2016] 26-9) seeks to challenge the notion that Eliot took only a limited interest in the dramatic developments in science and physics during the first decades of the twentieth century. Building on work by Michael Whitworth, MacKay traces Eliot's active interest in theories of relativity and scientific knowledge through his social connections to figures such as J.W.N. Sullivan, Arthur Eddington, and Bertrand Russell, and his involvement with periodicals such as the Athenaeum, English Review and the New Age. This short piece is nicely rooted in historical facts, such that it indicates how much more there may be still to say in this area.

Eliot features too within particular contributions to broader, themed collections of essays. In the wake of recent work by Vincent Sherry and Kristin Mahoney, Reconnecting Aestheticism and Modernism, edited by Bénédicte 
Coste, Catherine Delyfer, and Christine Reynier, seeks to re-examine 'historiographical assumptions' about the influence of the fin de siècle upon modernism. Contributions by Elisa Bizzotto (pp. 31-44) and Rainer Emig (pp. 45-55) feature Eliot with varying degrees of focus. Bizzotto's essay cites the influence of Arthur Symons upon Eliot in order to make a case for 'recrediting' his impact on modernism; Emig places Eliot alongside Gerard Manley Hopkins, Lionel Johnson, and Ezra Pound as part of a larger argument about the place of 'excess and waste' (p. 46) within the 'repressed decadent inheritance of modernism' (p. 53).

Almost neurotically sensitive about the risk of overstatement, Anne Stillman's 'T.S. Eliot plays Edward Lear' (in Williams and Bevis, eds., pp. 260-80) doesn't offer an argument so much as 'some coincidences of atmosphere' (p. 275). Stillman provides a dense collection of shared verbal and figurative motifs and interests across the writings (and drawings) of Eliot and Lear. The most resonant and suggestive material here catches the ways in which the poetry of both men can shift rapidly from the comical to a more serious note, or vice versa.

As the digitization of literary texts increases, so do opportunities for performing computer-driven analyses of those texts. The influence of these techniques upon our understanding of modernism is the subject of Shawna Ross and James O'Sullivan's edited collection, Reading Modernism with Machines: Digital Humanities and Modernist Literature, within which Adam James Bradley's contribution, 'In the End Was the Word: A Computational Approach to T.S. Eliot's Diction' (pp. 185-202), deploys a 'whole-corpus approach' (p. 199) to the analysis of Eliot's lexis. Bradley assembles a database of language usage from Victorian poets, the Georgian poets, and the works of George Herbert and John Donne, in order to evaluate claims that Eliot's poetic diction implemented a break from the kind of verse sponsored by Harold Monroe in the Georgian Poets anthologies. This database is then crossreferenced with data from the Oxford English Dictionary in order to establish patterns of use relative to the historical origins of words used. On this basis, Eliot's diction, Bradley shows, is much closer to that of his precursors in terms of his linguistic usage than he might have acknowledged.

Digitization has also been key to the continuing survival of many academic journals, where Eliot's poetry continues to attract critical scrutiny from a variety of perspectives. Anna Aresi's 'Dante in T.S. Eliot's Four Quartets: Vision, Mysticism, and the Mind's Journey to God' (L\&T 30:iv[2016] 398-409) argues that the influence of Dante upon Four Quartets should be understood in terms of Bernard of Clairvaux's 'distinction between consideration and contemplation' (p. 400) for a better understanding of links between Eliot's poem and the Divine Comedy as forms of spiritual journey. Nicoletta Asciuto also explores Eliot's debt to Dante in 'The Sun Also Sets: The Violet Hour in T.S. Eliot's The Waste Land' (LitI 18:ii[2016] 150-65). This starts by describing Eliot's concern with finding the precise word to describe twilight conditions of light. Asciuto then reads reference to 'the violet hour' in The Waste Land as 'Eliot's intentional recreation of Dante's purgatorial atmospheres' (p. 151). Amongst other things, this allows her to establish suggestive connections between the figure of the typist in 'The Fire Sermon' and Beatrice d'Este, the 
neglectful wife of Nino Visconti in Dante's Purgatorio. Elsewhere, in 'Bergsonian Memory and Simultaneity in the Poetry of T.S. Eliot and César Vallejo' (FMLS 52:i[2016] 43-55), Asciuto compares Eliot with his Peruvian contemporary César Vallejo through their mutual concern with the poetic forms of memory. Common ground, Asciuto argues, can be found through the work of the French philosopher Henri Bergson, which 'permeated early twentieth-century culture' (p. 45).

Sean Dempsey's "Set my lands in order": States of Exception, the Cinematic, and The Waste Land' (Mosaic 49:i[2016] 111-27) assembles a patchwork of theoretical material, from Kant to Jacques Rancière, MerleauPonty, and recent work on Eliot and film by David Trotter and Susan MacCabe, to argue that The Waste Land can 'be experienced as an occasion of dissensus' in which disruption to the workings of 'everyday habits and practices' is 'suddenly experienced as a source of joy' (p. 121). Reading the poem, Dempsey suggests, is to be guided towards this experience by Eliot's 'expert hand'.

Starting from Romantic tradition, Tony Sharpe's 'Unbearable Lightness: Some Modern Instances in Auden, Stevens and Eliot' (Romanticism 22:iii[2016] 312-21) explores and unpicks the association between bad and good and the antithesis of darkness and light in poetry by Auden, Wallace Stevens, and T.S. Eliot., This article culminates in a discussion of the patterns of light and shade in 'East Coker' from Eliot's Four Quartets, although, historically, this is amongst the earlier modern poetry under discussion.

Two short articles by David-Antoine Williams explore links between Eliot and the Oxford English Dictionary: 'The "Oxford Dictionary" in T.S. Eliot' (N\&Q 63:ii[2016] 293-6) sketches the poet's interest in questions of definitions. Williams tracks Eliot's usage of the Shorter Oxford English Dictionary, the New English Dictionary, and the Concise Oxford English Dictionary, pointing out that Eliot wasn't always clear about which he was using. 'Muddy' on such matters, Eliot was both concerned about linguistic 'chaos' and intrigued by the 'wobbliness' created by language change (p. 296). In comparison, 'T.S. Eliot in the Oxford English Dictionary' (N\&Q 63:ii[2016] 296-301) examines the frequency with which Eliot is cited in the $O E D$. Williams cites the enthusiasm of Robert Burchfield (editor of the second edition of the $O E D$ ) for Eliot, as well as active efforts by Eliot's wife and the critic Helen Gardner to secure attestations for the poet's usage.

In 'Phlebus in Glastonbury: A Phoenician Sailor in the Tin Trade' (YER 31:iii-iv[2016] 39-44), Russell Elliott Murphy explores the hinterland to 'Death by Water', connecting the figure of Phlebus to Joseph of Arimathea, via the grail myth and an earlier version of the poem in French.

Carla Sofia Ferreira, 'Seeing through French Eyes: Vers Libre in Whitman, Laforgue, and Eliot' (CQ 45:i[2016] 20-41) traces lines of affiliation and influence amongst Walt Whitman, Jules Laforgue, and Eliot. Starting with Laforgue's translations of Whitman, Ferreira traces the American poet's influence upon Laforgue in the form of punning points of contact between the English and French language. More controversially, Ferreira claims that Eliot's apparent poetic reconciliation with Whitman in the 1940s requires us to 
see him as Eliot's 'inevitable grandfather' (p. 34). But the point is urged through Laforgue's influence upon Eliot's practice of vers libre.

William Q. Malcuit's 'The Poetics of Political Failure: Eliot's Antiliberalism in an American Context' (TCL 62:i[2016] 75-95) also examines Eliot in relation to Whitman, comparing 'The Love Song of J. Alfred Prufrock' to The Song of Myself in order to reinsert Eliot into 'the American poetic tradition that most importantly structures his early poems' (p. 75). For Malcuit, Whitman's presentation of urban subjectivities isn't so much an inspiration as a provocation for Eliot in the formation of an 'antiliberal position' (p. 77)

William Anthony Connolly's 'Raids on the Inarticulate: T.S. Eliot's Four Quartets and God' (YER 31:iii-iv[2016] 3-19) offers a general sequential survey of the poems in Four Quartets, exploring their presentation of 'apophatism, the rhetoric of negative theory' (p. 4) through a number of theological sources. In 'The Formal and Moral Challenges of T.S. Eliot's Murder in the Cathedral' (Logos 19:i[2016] 167-203), James Matthew Wilson explores the 'historical contexts and intellectual genesis' (p. 167) of 'Eliot's formally wrenching play' (p. 197) in order to emphasize its engagement with 'the permanent truths that govern our existence' (p. 198) derived from the poet's religious understanding.

\section{British Poetry Post-1950}

This year saw the publication of two major surveys of post-war poetry in the same series: The Cambridge Companion to British and Irish Poetry, 1945-2010, edited by Edward Larrissy, and The Cambridge Companion to British Black and Asian Literature (1945-2010), edited by Deirdre Osborne. Both volumes exhibit what has increasingly become a hallmark of this series: a judicious balance between an authoritative overview (the expected roll-call of major schools and figures, national poetries within Britain, race, class, and gender) and a gathering of neglected and under-examined material. In the introduction, Larrissy does not underestimate the profound impact of the Movement on post-war poetry, offering a dichotomy-cum-spectrum in the form of 'empirical/mythological' approaches to the poet's own material as a governing feature of the period (p. 3). Nevertheless, he intimates antinomies to this pervasive schematization of poetry after modernism which are taken up in several essays in the book. If the pattern, overall, may seem to be a series of reactions and counter-reactions, the nexuses in terms of unexplored latent influence, and the embeddedness of poetry within institutions and markets which these essays suggest are compelling. C.D. Blanton's essay, 'Poets of the Forties and Early Fifties: The Last Romantics?' is an implicit apologia for the 1940s and 1950s neo-Romantic and New Apocalypse poetry against which the poets of the Movement set their faces. He begins with an outrider, the sui generis F.T. Prince, before considering Dylan Thomas as a presiding genius and probing the affiliations of poets such as Keith Douglas, John HeathStubbs, and Sidney Keyes, who wrote in Yeatsian strain in an introduction to the 1941 anthology Eight Oxford Poets, 'we are all ... Romantic writers'. Blanton's crucial point in the essay is that this belated strain of Romantic 
imagination docked the original's transcendental and totalizing reach (p. 15). His chapter joins an ongoing recuperation of this period and the loose coterie which straddled the war years: William Wooten's 'Friendship and the Gift in the Poetry of George Barker, W.S. Graham, Dylan Thomas, and Vernon Watkins' (English 65:ii[2016] 115-37) theorizes this inter-generational exchange through the metaphor of gift economy; and the PN Review published James Keery's 'One from the Groves of Academe, the Other from Bohemia's Seaport' on David Wright and Movement-antagonist, Donald Davie (PNR 43:i[2016] 23-6), and Henry King's 'Literary Enough?' (PNR 42:v[2016] 70-2) on John Heath-Stubbs.

In Larrissy's collection, Fran Brearton's " "In a between world": Northern Irish Poetry' offers a reflexive examination of the anthological rationale (and inevitable controversy either way) involved in whether to include or exclude Northern Irish poetry in 'British' anthologies. Jon Glover's 'Poetry's Outward Forms: Groups, Workshops, Readings, Publishers' gives a fascinating account of the emergence of institutional frameworks for post-war poetry, including the Gregory Fellowships at the University of Leeds and the shadow cast by Philip Hobsbaum and The Group. Natalie Pollard's 'Stretching the Lyric: The Anthology Wars, Martianism and After', a sparky account of taste, branding, and literary consumption, focuses on Andrew Motion and Blake Morrison's controversial Penguin Book of Contemporary British Poetry [1982] and the market (and marketed) dominance of Martianism and the New Generation poets. This essay builds on Pollard's previous study of lyric address in terms of literary economics, Speaking to You [2012]. Patrick Deane's 'The Movement: Poetry and the Reading Public' gives a brisk, nuanced overview of Larkin's domain. 'Survivors from Before the War: Late Modernists and Poets of the 1930s' by John Matthias examines the Auden generation and modernist remnants such as Basil Bunting and David Jones. 'Beyond All This Fiddle: Hughes, Hill, Tomlinson and Fisher' by Eric Falci complicates A. Alvarez's critical interventions of the 1960s, examining the way poets of the era conform to (Hughes), complicate (Hill and Tomlinson), or evade (Fisher) Alvarez's categories. Cornelia Gräbner's 'Poetry and Performance: The Mersey Poets, the International Poetry Incarnation and Performance Poetry' provides an engaging snapshot of the performative energies of poetry influenced by the Beats. In 'High Late-Modernists or Postmodernists? Vanguard and Linguistically Innovative British Poetries since 1960', Simon Perril gives a comprehensive idea of the contours of avant-garde poetry. Sandie Byrne's 'Poetry and Class' focuses on the vexed navigations of class and education in Tony Harrison, Ken Smith, Tom Pickard, Don Paterson, Douglas Dunn, and Liz Lochhead.

In 'Scottish Poetry, 1945-2010', Alan Riach charts an iconic group of seven post-war poets headed by Hugh MacDiarmid, as well as the wellsprings of Gaelic writing, experiments in multimedia, and hybrid Scottish identities. Katie Gramich's 'Welsh Poetry since 1945' adopts a similar approach, taking in less familiar poets such as the surrealist-influenced Glyn Jones, Lynette Roberts, and Alison Bielski, with 'praise poetry' (p. 166) pitched as a key Welsh mode. In 'Poetry, Feminism, Gender, and Women's Experience', Jan Montefiore troubles the notion that there is a 'ghettoization' inherent in a 
'feminist poetics' by examining the relative strengths and weaknesses of that argument in relation to influential anthologies of women poets. Fiona Becket's 'Ecopoetics and Poetry' conducts a gripping study of Jon Silkin's political poetry as forming the basis of a "contiguity between "nature" and "man", (p. 215), and finally, 'Poetry and the City' by Peter Barry develops a thesis on urban poetics, taking in situationist practices (made feasible by grant funding) of such 'urban epic' experiments as Zoë Skoulding's Metropoetica (p. 238).

Larrissy's Cambridge Companion also includes Sarah Lawson Welsh's 'Black British Poetry', which celebrates among other things the radical black presses of the 1960s and 1970s, such as New Beacon Books, and Kamau Brathwaite's collective, the Caribbean Artists Movement. The Cambridge Companion to British Black and Asian Literature is similarly strong on the experimental and innovative poetics of black British writers. It explores the way in which, as editor Deirdre Osborne puts it in her introduction, 'British black and Asian writers have claimed their cultural citizenship in the face of ... disregard, and transformed the English language itself, to better equip it as a vehicle for rendering the multiple, multicultural viewpoints in contemporary British society' (p. 2). Essays addressing post-war poetry include 'Liberationist Political Poetics' by Birgit Neumann (pp. 59-76), which focuses on the ways in which post-war British Caribbean poetry redefines the terrain by drawing on 'the sonic dimensions of black oral tradition' (p. 73). 'British Black and LGBTQ Writing' by Kanika Batra (pp. 159-76) examines Labi Siffre's black queer poetics as an overlooked area in critical literary histories. Corinne Fowler's 'The Poetics and Politics of Spoken Word Poetry' (pp. 177-92) exemplifies the broad approaches adopted in the book, reading the intersections and dynamic exchange between the British Poetry Revival and black spoken-word poetry as dismantling binaries, such as regional or transnational ones (p. 180). Romana Huk's contribution, 'Genre Crossings: Rewriting "the Lyric" in Innovative Black British Poetry', argues that black British poets came to resent being pigeonholed as performance poets, an "othering" association that emerged partly from a postmodern suspicion of the lyric. Huk excavates D.S. Marriott's 'post-postmodern' rehabilitation of the lyric for unironic purposes, the poet's experience of the 'disavowal' (p. 234) of 'forgotten black suffering': a buried collectivity within the personal lyric (p. 237). Her judicious quotations from John Wilkinson's sensitive readings of Marriott, as well as a discussion of the latter's debt to Prynne, indicate the centrality of black British poetics to the avant-garde, while Huk's essay itself is a model of the extremely current critical debates surrounding the status of the lyric, a conversation that is decidedly inflected by avant-garde impulses.

One significant early foray into this territory was reissued in 2016 by Tony Frazer's Shearsman Books, which continues to be a powerhouse for significant critical studies of the post-war poetic vanguard. First published in 1978, Veronica Forrest-Thomson's Poetic Artifice: A Theory of Twentieth-Century Poetry disputes the idea that poets have access to 'reality in its unmediated state', insisting instead that it is poetry's duty to vindicate 'all the rhythmic, phonetic, verbal and logical devices' (p. 33) that are its especial jurisdiction. It is instructive to find - almost four decades on - that the problem of the lyric ' $\mathrm{I}$ ' continues to squat stubbornly on the critical scene (as in Huk's essay), but it is 
also salutary to reflect on how Forrest-Thomson's interrogations of reductive poetic paraphrase of the external world are now put to radically different uses: at least one reviewer pondered what the author of Poetic Artifice would have to say confronted with a work such as Claudia Rankine's Citizen, a genredefying 'lyric' which is nothing if not exercised by the 'external world' of racial prejudice.

Shearsman also published a Festschrift for J.H. Prynne's eightieth birthday. For the Future, edited by Ian Brinton, drew ire from some quarters on social media for its ratio of women contributors to men, with someone waggishly touting a Prynne for Girls primer. The handsome book contains illuminating memoir-vignettes by former students: Brinton's introduction includes a detailed discussion of Prynne's seminar notes, including an excerpt from one of these entitled 'Post-Romantic Mind' on Henry Mayhew's mid-Victorian opus London Labour and the London Poor [1851]. This involved discussion views the eminent Victorian's incompatible moral presentiments as correlative to, if not derivative from, the jumbling of perception afforded by urban crowding (pp. 10-15). David Herd's "To take the whole condition of something": On Prynne Reading Olson' investigates Prynne's 'vantage' (situatedness as a reader) in his reorientation of Olson's Maximus poems in a lecture at Simon Fraser University on 27 July 1971. Michael Tencer's 'Notes on "Es Lebe der König", provides a close reading of Prynne's elegy for Paul Celan, which in the spirit of those Cambridge seminars 'is not designed to harass ... into a particular channel of consideration' (p. 6). Michael Haslam contributes a brief memoir, 'Prynne's Gold'. Michael Grant's ' "Mixing memory and desire": Eliot and the Subjectile' is an intriguing essay (prompted by a pedagogical strategy of Prynne's decades past) on the future anterior and Eliot. In 'And You Too', Anthony Barnett remembers publishing Prynne's debut. Harry Gilonis's 'Looking At/Looking For J.H. Prynne's "Stone Lake", focuses on Prynne's Sino-poetics. 'A Bash in the Tunnel' provides a joint memoir by Ian Friend and Richard Humphreys. Another reminiscence, by John Wilkinson, 'I Staircase, Gonville and Caius', centres on his tutor's 'hospitality and secrecy' (p. 84). John Hall's 'Learning from Jeremy Prynne, 1963-1967-An Autobiographical Sketch' is another student memoir. Peter Larkin writes on Prynne's botany in 'If Flowers of Language Will (Have) Been a Language of Flowers: Trials of Florescence in the Poems of J.H. Prynne'. Nigel Wheale's faceted gem of an essay, 'madrigalian / brightness: Renaissance Prynne', is declared 'Heidegger-free' (p. 123). Masahiko Abe writes on interpreting the work via Cubist practices in 'J.H. Prynne and Grid'. Matthew Hall's " "Assuming banishment for lost time back across nullity": On Opening Acrylic Tips' complements the postcolonial treatment of the poem in his article, 'Terra Nullius: Colonial Violence in Prynne's Acrylic Tips' (JBIIP 8:i[2016] 5 paras.). Anthony Mellors writes on Prynne's avant-garde distribution networks in 'wynsum wong: J.H. Prynne Inside and Outside The English Intelligencer'. Peter Riley's bouquet for the florilegium is a lyrical memoir, 'It was also...' Peter Hughes's " "Possente spirto": On First Reading Prynne' provides a personal account of an impassioned reader. Ian Brinton writes on Andrew Crozier's role in the letterpress publication of Prynne's Brass, in 'Brass Nearly Off'. Peter Gizzi's 'Introduction for The White Stones (NYRB 
Edition)' is also reprinted here. David Caddy discusses Prynne's influence on his practice as an editor in 'To a Reader'. Joseph Persad provides a review essay of the 2015 Bloodaxe collection in "For the for you / and these to hold": Receiving J.H. Prynne's Poems'. Finally, 'Hearing Light', Iain Sinclair's elegy for the decade from 1968 to 1979 , hints at a mode common to several critical pieces on this period that were published this year. Also in 2016, the Paris Review published the first major interview with Prynne in its 'The Art of Poetry' series (ParisR 218:iii[2016] 1-23), covering unfamiliar or easily forgotten aspects of his poetic evolution. These include his early tutelage under Donald Davie, whose scholarly responsibility and answerability remained an example, as opposed to the 'crackpot' dereliction of unruly figures such as Pound (p. 7). New avenues for investigation are opened by this interview, against the grain of more familiar avant-garde narratives.

Prynne is, unsurprisingly, a luminary in several other critical works appearing in 2016 on the British avant-garde. The most significant of these is another offering by Shearsman: Clasp: Late Modernist Poetry in London in the 1970s, edited by Robert Hampson and Ken Edwards. The rhizomatic emergence of experimental poetry displaces any reductive narrative in this assemblage of essays and reminiscences, where a key feature is the attention paid to the multifarious institutional and organizational supports. These include Mottram's 'infiltration' of the Poetry Society, of course, but also Bob Cobbing's Writers Forum, art colleges, independent bookshops, and various small presses (pp. 9-12). Clive Bush's essay, 'Challenging the "Little England" Consensus in British Poetry: Eric Mottram, Poetry Review and Talus', focuses on the 'reciprocal' aspects of Anglo-American poetic exchange spearheaded by Mottram in that decade (p. 17). Paul A. Green's 'In the Poetry Zones' delves into the 'zones of amazement' of the underground scene, including its interzones, such as the 'sibylline tones of David Gascoyne' mingling with punk ranters at the Angels of Fire festival in November 1983 (p. 23). John Welch's 'Back Then' recounts meeting Anthony Howell at Norman Hidden's Poetry Workshop, and the 'do-it-yourself' character of much poetic endeavour including Howell's co-operative magazine, Wallpaper (p. 29). Lawrence Upton provides a colourful, partisan account of the 'poetry wars' in 'So Many Things'. In 'Tangled Up in Politics', Elaine Randell recalls navigating those treacherous waters with her then-husband Barry MacSweeney, as members of the Poetry Society. She offers an intriguing vignette of rumoured CIA men lingering around its meetings at the White House pub (p. 39). In 'Working with Bob Cobbing through the 1970s', Paula Claire tenders a eulogy to Cobbing's work with the Writers Forum, including an account of an organpowered recital of his concrete poem 15 Shakespeare Kaku at Southwark Cathedral in 1972. Valerie Soar's 'Whispers from the Past' commends the archival acquisitions of avant-garde little magazines undertaken by her husband Geoffrey as librarian of UCL's special collections department in the 1970s. Anthony Howell's 'Beige Leather Trousers, Orange Dungarees' revisits the magic of the Film Co-Op and Robert Janz's studio, both housed in 'the Dairy' in north-west London. In a discernible thread of this year's critical work on the British avant-garde, Iain Sinclair's 'Hackney Stopover: Rage in the Eastern Heaven' critiques the chthonic nationalist implications of 
marketing the vanguard under the banner of 'Albion', alluding intriguingly to BNP cells operating out of dubious indie bookshops with that tag (p. 60). Tony Lopez's 'Brixton, Wivenhoe, Gonville \& Caius' provides a personal topography of the scene, and encounters with John Ashbery. Robert Hampson explores the underground vitality of British modernism and the avant-garde debt to MacDiarmid and Bunting consolidated by their presence at the 1974 Modern British Poetry conference at the Polytechnic of Central London, in 'King's College and the PCL Poetry Conferences'. In 'A Good Decade for Getting Lost: London in the 1970s', David Miller recounts his emigration from Australia and entrance into the London avant-garde, including homage to Robert Lax, and Miller's affiliations with other antipodean poets in the city. Another immigrant encounter with the counter-culture and in particular the Association of Little Presses is revealed in Robert Vas Dias's 'My Baptism by Fire'. Will Rowe's essay, 'The Translation Workshop and Ecuatorial Magazine', provides a fascinating insight into the workshop and its associated print forum, based at KCL, and the significance of translated Latin American poetry to the British avant-garde. In 'Poetry in the 1970s', Stephen Watts provides a helpful personal checklist of the range of supporting networks to experimental poetry, including important second-hand bookshops such as Compendium, access to university libraries, and Bengali poetry emerging in the East End. P.C. Fencott supplies a quirky facsimile (untitled) of a typescript, showing an annotated mix of essay and collage as a mimesis of that very process in his collaborations with Cobbing on a North American tour in 1982. In 'Lower Green Farm', Ken Edwards writes elegiacally about several attempts at creating poetic communes, including the eponymous farm in Orpington. Peter Barry recounts the difficulty of his personal mission to achieve a détente between that world and the academic critical industry in 'Climbing the Twisty Staircase: "London 1970-85"', Robert Sheppard laments the surprising lack of funding for the capital's underground scene in comparison to its regional counterparts in 'Took Chances in London Traffic'. Gavin Selerie celebrates the fusion of media and breakdown of different artistic categories in 'Kaleidoscope of Spirits', including the multimedia experience of a London Contemporary Dance Theatre event at Sadler's Wells in the late 1970s. Gilbert Adair's 'Islands and Affiliations: Sub-Voicive' looks at that collective's history and pooling of readers and audiences with King's College. Frances Presley's 'Experimental Poetry and Feminism? London 198086 ' mounts a critique of the male-dominated inner circles of the underground and explores the ambivalent attitudes towards feminist poetry on the part of women experimental poets she otherwise admired, which she believes were occasionally (but not always) warranted. Finally, John Muckle accounts for the origins of yet another controversial anthology, The New British Poetry [1988]. The book contains a brief but well-chosen bibliography and the essays' footnotes are awash with intriguing points of departure, making it essential reading for anyone interested in getting to grips with post-war poetry and the avant-garde.

Ian Brinton also edited John Riley: Selected Poetry and Prose. Tragically murdered in 1978, Riley helped set up the Grosseteste Review and its press. He was associated with the Cambridge school, and later became a fixture in the 
Leeds poetry scene, which has begun to receive more critical attention. Assembling what Ian Duhig calls in his preface Riley's 'poetry-in-prose alchemical experiments' (p. 8), the volume also contains an introductory essay by Brinton which illuminates Riley's theological inheritances, from Grosseteste's treatise De Luce to his conversion to Russian Orthodoxy shortly before his untimely death. It also reveals Prynne's intriguing worry that Riley's 'Czargrad' would be dismissed as 'maudlin theism ... cathected into the lyric stream' (p. 13). However, from the selection Brinton has brought together it seems that Riley is not easily 'cathected' to any project. The prose assembled is idiosyncratic, hybrid, a strannik's mysticism: neither critical nor annexable from criticism. A short ars poetica which reads like spiritual maxims contains the rueful dictum, "when a man wishes to destroy himself, he cultivates objectivity' (p. 110). Riley emerges as a compelling and marginal figure who merits a wider readership.

Elsewhere, Ross Hair's fascinating study Avant Folk: Small Press Poetry Networks from 1950 to Present conducts a transatlantic-localist investigation of the rural fringes of the avant-garde in the post-war years, centring upon the small-press poetry networks valiantly and eccentrically maintained by committed individuals, such as 'Scottish Futurist' Ian Hamilton Finlay's Wild Hawthorn Press and Stuart Mills's Nottingham-based Tarasque Press. These figures, Hair argues, 'incorporated modernist poetry forms and strategies with discerning uses of regional dialect, demotic culture, and craft practices' (p. 3), harnessing print techniques that emphasized simplicity and calm. Other figures of interest in the book include Thomas A. Clark and Simon Cutts. Hair's study is a welcome contribution to the considerable interest in periodical and small-press networks that has emerged out of modernist studies, and is yet to properly take wing in post-1950 studies. Jeremy Reed's I Heard It through the Grapevine: Asa Benveniste and Trigram Press is another personal mapping of one such small, London-based press and its maverick poet-founder, which valued artists working in conditions of exile.

David Herd's 'Declining National Culture: The Dislocated Poetics of a Various Art' (PNR 42:iv[2016] 29-34) focuses on Andrew Crozier's anthological drive away from a narrow national frame. Similarly, James Cummins's "The history of Ireland he knew before he went to school": The Irish Tom Raworth' (IUR 46:i[2016] 158-70) explores this avant-garde poet's Irish roots. Cummins reviews the anti-Treaty affiliations of his mother, the Irish Catholic tinges to his work, and Raworth's bicultural critique of the nationalistic tendencies of The English Intelligencer: 'I don't really see any reason in terms like "English poet", (p. 168). Allen Fisher's collection, Imperfect Fit: Aesthetic Function, Facture \& Perception in Art and Writing Since 1950 republishes essays written between 1985 and 2011, formalizing in one book what is essentially Fisher's riff on reader-response theory. This is extrapolated more broadly to include proprioceptive encounters with any art, influenced by trends in what is most often referred to as 'complexity studies', and eclectically enriched by Fisher's broad reading in Foucault, theoretical biology, Outsider art, and Heidegger. Charles Olson, however, is the major theoretical influence on Fisher's poetics. Fisher posits that decoherence- the misrecognition of patterns implicit in both the 'facture' (creation) and 
perception of art-is an inevitable, and salutary aspect of the 'aesthetic function', something he describes as 'confidence in lack' (p. 18). Chapter 3, 'Necessary Business: Aesthetics and Patterns of Connectedness: Reading Works by cris cheek, Eric Mottram, and J.H. Prynne', applies these concerns to the specific 'damage' caused to the aesthetic function in an era of 'ochlocracy, a mob rule signified by an emphatic interest in power, mass opinion, and singularity' (p. 44). Fisher links up in a surprising way to Pollard's accounts (discussed above) of much more media-savvy poets of the succeeding generation on the saturation of poetics by questions of appeal, consumption, and 'making it new'.

We remain firmly vexed twixt those questions in two hefty volumes reissued by Shearsman, although published previously by other presses: The Failure of Conservatism in Modern British Poetry and Centre and Periphery in Modern British Poetry, both by Andrew Duncan. The first of these is a celebration of innovative poetry in the 1960s and 1970s that challenged what Duncan reads as an innately conservative mainstream tendency in British poetry to continually rededicate moribund practices as 'new', while also recognizing in a new foreword that 'I suspect that both the mainstream and the Underground positions have collapsed, and that young poets now are faced by a strange and unexplained situation' (p. 26). The second book adapts the same countercultural model to examine regional experimentalism versus metropolitan establishment. Duncan evinces a raucous and enthusiastic one-man-band style of criticism, which is, sometimes, catching: 'everyone in the EngLit business shares the same staple culture, the same carbohydrate pack of texts and clever remarks. But people from Oxford have more of it' (p. 19).

Perhaps one of the most vital, undervalued, of those figures mentioned in Duncan's books is Christopher Middleton, a formidable translator (most notably from the German of Robert Walser) and a challenging poet. Middleton's death in November 2015 prompted tributes in the PN Review. Drew Milne's 'Noisemakers of Now' (PNR 42:iv[2016] 48-52) is a review essay of Middleton's Collected Later Poems [2014] that places Middleton, in his own words, 'somewhere between Brecht and Mallarmé', while noting that the fact that each of his poems remains 'singular and sovereign' may well account for the relative paucity of critical work (p. 47). In " "If there was a snake here, I'd apologise", (PNR 42:iv[2016] 54-5), John Clegg provides a comparative reading of Middleton's poem 'Coral Snake' and the animal poetry of D.H. Lawrence. The composer Michael Hersch discusses his setting of some Middleton poems to music in 'Reflections on Christopher Middleton' (PNR 42:iv[2016] 55-6). Thomas Loewenstein's 'On Christopher Middleton' (PNR 42:iv[2016] 57-8) focuses on the early collection Torse 3 and Middleton's 'work beyond Anglophone boundaries'. For Middleton, 'experiment and tradition', Loewenstein claims, 'were no longer antinomies' (p. 55). Finally, Marius Kociejowski offers a moving recollection of their friendship in 'The Very Rich Hours of Christopher Middleton' (PNR 42:iv[2016] 59-61).

On 30 June 2016 Geoffrey Hill died, 'suddenly, and without dread or pain', according to the announcement on social media by his wife, the librettist and priest Alice Goodman. In response, Agenda, a magazine that had championed Hill throughout his long career, dedicated a 'Homage to Geoffrey Hill'. 
W.S. Milne proffers a vivid eulogy, 'Geoffrey Hill: 1932-2016' (Agenda 50:iii[2016] 16-20), in which he remembers Hill berating the printer of his Agenda Editions The Mystery of the Charity of Charles Péguy for a sloping 'I' in his surname on the spine: 'I've looked at this closely... and it's definitely leaning to the left' (p. 17). Stephen Romer's tribute, 'The Voice of the Heckler' (Agenda 50:i-ii[2016] 22-4) draws attention to a metaphor Hill used for his poetry in a less well-known lecture on poetry and war: a new Israeli tank that redirects fire back on the enemy. Clive Wilmer's 'Geoffrey Hill: Scattered Reminiscences' (Agenda 50:i-ii[2016] 27-31) provides more than it promises in terms of critical acuity. Wilmer, for instance, nominates the word 'pinnacled' as the making of Hill's poem 'Merlin', for retaining a sense of polis though Camelot has long tumbled to seed (p. 27). William Bedford contributes a very short personal tribute 'Geoffrey Hill: In Memoriam' (Agenda 50:i-ii[2016] 33). Peter Carpenter provides a personal reading of Hill's King Log and account of his impact on fellow Cambridge students in the 1980s in 'Geoffrey Hill: The Lost Amazing Crown' (Agenda 50:i-ii[2016] 34-8). The artist Keith Grant writes about Hill sitting for his portrait, in 'Geoffrey Hill: A God-Given Inspiration' (Agenda 50:i-ii[2016] 41-2). Martin Caseley recollects a reading from The Daybooks, in 'Geoffrey Hill: A Reading at Aldeburgh, 2009' (Agenda 50:i-ii[2016] 45-6). Finally, Peter Dale gives a short but illuminating fragment on Hill's involvement in the literary scene of Soho's pubs in the 1950s, in 'Two Anecdotes' (Agenda 50:i-ii[2016] 48).

Even before his sudden death, Hill was the subject of numerous critical works in 2016. Alex Pestell's monograph, Geoffrey Hill: The Drama of Reason takes its title from a trope Hill found in Coleridge, which he associated with 'the antiphonal voice of the heckler' (p. 32). Pestell's book treats Hill's poetics as a kind of creative epistemology responding to various aspects of dialogue as the central feature of assessing the grounds for objectivity, which is a (potentially chimerical) good to be definitively distinguished from, and wrested out of, the 'primary objective world' (p. 9). Pestell dwells at length in his introduction on Hill's "The Conscious Mind's Intelligible Structure": A Debate', a seminal uncollected essay published in 1971/2 in Agenda, and argues convincingly that it contains 'in nuce' the thematic and formal preoccupations of a lifetime: poetic-critical thinking as dramatic orchestration, reflexive, contextual, and perhaps most importantly, mimetic. Chapter 1 examines Hill's Coleridgean antiphonal voices, going beyond the popularity of this figure to describe Hill's style to examine it, not as 'a pantomimed soliloquy' but as a clash of 'historical planes of intellectual activity' (p. 38). Chapter 2 continues to analyse the Romantic poet's intellectual influence on Hill. Pestell finds that Coleridge's concept of the 'tautegorical, position that concept is activated by form, tends towards a consolatory solipsistic quietism in Hill' (p. 66). Exploring Hill's reading of T.H. Green and his poem Speech! Speech!, chapter 3 stages a Sidneian confrontation between poetry and abstract, utilitarian tendencies within philosophy. Chapter 4 examines Hill's emulation of F.H. Bradley's conditionality, 'non-resolution', as a desideratum in asking the question, 'What is a Bradleian poem?' (pp. 106-7). Chapters 6 and 7 focus on Hill's engagements with Ezra Pound and their distinct yet comparable senses of 'diagnosis' (as opposed to poetry exhibiting 'symptoms'). 
Pestell offers forensic analysis of the ways in which Hill places strict limits on the imaginative polis that poetry's diagnostic powers are capable of creating (pp. 146-7). These sections on Pound round off with a provocative arbitration between critical apologies and Hill's recoil from Pound's poetics, in order to consider how Hill's reception probes the 'coexistence of rage and creativity' (p. 179). The deft handling of tremendously difficult questions concerning politics and poetics in these two chapters is recommended reading for anyone seeking to get to grips with such vexed terrain. Chapter 7 both acquits and accuses Hill of Tom Paulin's infamous charges, levelled in the London Review of Books in April 1985, that Hill's imagination was 'shabby and reactionary' aestheticism (p. 181). The final chapter sees Hill's post-Canaan work as a shift in his annexation of poetry's proper stance towards civil society, and an exploration of the paradox at the heart of 'intrinsic value' as a desideratum. Hill, Pestell argues, both defends the aporia of such a criterion-its constitution by the contingent, and immediate revelations of value - a move that Peter Robinson has described as 'theological' (p. 211). This is a book of serious ambition and critical probity, and merits attention.

Several articles on Hill also appeared. Travis Helms's 'Alienated Majesty (Redux): Geoffrey Hill and a "Theology of Language", (Book 2.0 6:i-ii[2016] 97-108) provides an introductory contextualization of Hill's critical thought in terms of a theological poetics. In 'Finding Consonance in the Disparities: Geoffrey Hill, John Milton, and Modernist Poetics' (MLR 111:iii[2016] 66583), Steven Matthews attempts to account for the bewildering Poundian project of Hill's late work in The Daybooks. Matthews considers Milton 'a modernist avant la lettre' (p. 667), whose technical example in deployment of line endings and enjambments as both yoking together and holding apart bequeaths to Hill an awkward poetics adequate to the patterned difficulty of modernity and a syntax that draws together dislocation (p. 677). Karl O'Hanlon's " Noble in his grandiose confusions": Yeats and Coriolanus in the Poetry of Geoffrey Hill' (English 65:ccl[2016] 211-33) examines the allusive connection between Yeats and Shakespeare's play in Hill's later work, in light of the latter's insistence that the play is crucial for understanding 'the presence of polyphony' in the politics of modernist style (p. 233). O'Hanlon also harnesses unpublished material, including drafts of Hill's major sonnet sequence 'Funeral Music', to argue for the influence of a poet often thought of as confessional on one who has publicly excoriated such displays, in " The violent and formal dancers": John Berryman and Geoffrey Hill' ( $C Q$ 45:iii[2016] 208-23). In “"The changed measures of light": Post-Romanticism and Geoffrey Hill' (Romanticism 22:iii[2016] 331-40), Michael O’Neill returns to legacies that occupied him in The All-Sustaining Air [2007]. This article revisits the post-Romantic 'predicament' of Hill in terms of the guilt of writing poetry which is only expiable in that same process with recourse to the poet's images of light as a Romantic trope of change, deferred revelation. Anthony Rowland's article 'Reading Holocaust Poetry: Singularity and Geoffrey Hill's "September Song", (TPr 30:i[2016] 69-88) uses Derek Attridge's concept of literature as an 'event' to query whether close reading may betray poetry to unethical stances, such as when an ingenuous piece of bravura reduces a poem on atrocity to verbal pyrotechnics. Rowland argues that if silence after the 
Holocaust is not possible, aestheticizing violence may be resisted by adopting an 'awkward poetics' which admits 'the problems of representation within the texts' themselves. Hill succeeds, Rowland suggests, in doing this in 'September Song' (p. 70). In 'Wales and the Spirit: Geoffrey Hill's Oraclau /Oracles' (L\&T 30:i[2016] 1-14), Stefan Hawlin sees Hill as writing an anti-materialist 'boldly Christian and humanistic poetic sequence' centring on how Anglo-Welsh biculturalism may displace secular narratives. In its distilled focus, however, Hawlin's argument does not take account of Hill's animus to Christianity throughout his late work. Finally, the sermon-cum-lecture preached by the former archbishop of Canterbury, Rowan Williams, at Hill's funeral returns to the insistently 'ethical' character of Hill's work (PNR 43:ii[2016] 8-9).

There were monographs and articles on several of the poets who appeared with Hill in A. Alvarez's anthology New Poetry [1962], as well as a few scattered publications on the Movement poets whose sway Alvarez sought to dismantle. Palgrave published Philip Larkin by Robert Evans in their Readers' Guide to Essential Criticism series, an introductory chronological overview of Larkin which charts his contemporary reception with a tight assemblage of reviews and critiques by contemporaries such as Charles Tomlinson and Richard Murphy. Craig MacKenzie's short article 'Philip Larkin's Vision of the Future in "Church Going": What the Manuscripts Can Tell Us' (Expl 74:iii[2016] 173-6) argues that drafts of the poem show an even starker suggestion of dystopic regression towards superstitious atavism. James Underwood's article " "A kind of homosexual relation, disguised": Larkin's Letters to Monica Jones' (English 65:ccxlviii[2016] 38-57) eschews an authorcentred approach to resituate Larkin's personal correspondence to his lover as the projection of a textual identity, particularly paying attention to allusion and intertextuality. Underwood reads Larkin's immersion in the prosaic details of the everyday ('I have four rolls of pink toilet paper on my low table') as the assumption of an old-maidish persona, which is extrapolated into Larkin's 'particular version of lesbian femininity' (p. 53). In 'Larkin Aloud' (LitI 18:ii[2016] 168-79), Andrew Hodgson plumbs the depths of Larkin's exploitation of ambiguity between the printed poem and its voicing, paying particular attention to the ways in which his numerous recordings miss something of the 'mordant and sad' movement on the page. Another poet associated with the Movement receives a reappraisal by John Greening in 'Everything Should Mean: The Poetry of D.J. Enright' (PNR 43:i[2016] 33-6), in which his colonialism is indicted, the unsuspected religious colourings to his poetry are adumbrated, and, overall, there is a positive reckoning with his ars poetica: 'Everything should mean, never mind how humbly' (p. 78).

Following on from the furore of Jonathan Bate's biography, 2016 saw sustained interest in the presiding genius of Alvarez's 'extremist poetry', Ted Hughes. In 'Disclosing the World: Parousia in the Poetry of Ted Hughes' (L\&T 30:iii[2016] 265-77), Janne Stigen Drangsholt argues that Hughes mounts an assault on the spiritual valences of Western metaphysics, using the idea of parousia to probe the ways in which Hughes's religious thought (a blind spot in existing studies) centres around an 'ontotheological' recuperation of divine presence (p. 267). Michael Nott's article 'Ted Hughes's and Fay Godwin's Elmet: The Remains of Photography' (W\&I 32:iii[2016] 264-74) 
focuses on the evolution between the original collaboration between poet and photographer in 1979 to the later revised edition, Elmet [1994], arguing that Hughes later came to see his poetry as subservient, 'trapped', in his own words, 'in the focus of the photograph' (p. 271). Anthony Rowland's 'A Dialectic of Forgetting: János Pilinszky and Ted Hughes' (CL 68:i[2016] 46-58) assesses an alternating current of influence between Hughes and the Hungarian poet based on a shared species of necessary forgetting. Paul Bentley's monograph, Ted Hughes, Class and Violence is passionate about its subject, although some of its readings seem eccentric: 'Pike' is deconstructed as a unruly exploration of Ireland as England's unpalatable unconscious, 'a demonised, goblinish power'. This subtext seems to be supported by little more than its colouring, 'green tigering the gold' (p. 65). Nevertheless, Bentley does succeed in complicating critical dismissals of Hughes as a poet who eschews political and social concerns for a retreat into myth by exploring suggestive threads hitherto under-explored. This includes confrontation between Hughes's South Yorkshire background and Cambridge, and 'a repressed or veiled political dimension' in his laureateship (p. 98), which erupts in poems such as 'The Best Worker in Europe'. Situating them against the miners' strike, Bentley argues convincingly for an ambivalence in Hughes's political aesthetics between an identification as a 'simple honest Northerner' and antipathy to Arthur Scargill's Marxism (p. 100). Similarly, he attempts to deconstruct a reductive binary reception of the respective classicisms of Hughes (royalist, mythic) and Tony Harrison (republican, political). For Bentley, Hughes's renovated Anglo-Saxon alliterative verse and marginal writings reveal a working-class disdain, shared with Harrison, towards received pronunciation. If Bentley protests too much at times, his intervention does serve to helpfully problematize the poetics of a poet who has of late been seen as politically and personally beyond the pale.

The British class system and Tony Harrison is also the subject of Agata Handley's Constructing Identity: Continuity, Otherness and Revolt in the Poetry of Tony Harrison. This theory-inflected study grapples with Harrison's position 'at the friction point of two cultures' (p. 11): his working-class background and his grammar-school education out of it. Following Zygmunt Bauman, she reads Harrison as writing of individual and social identity precisely at the point where such a question becomes inevitable, "where a man is pulled out of "wherever could pass for his natural habitat", (p. 68). The thrust of her chronological exploration of Harrison's writing on the theme of identity is away from any lyric sense of the private self, towards what Harrison describes rhetorically and self-accusingly in his translations of the fourthcentury poet Palladas ('where's the public good in what you write?', p. 191). As with Hill's poetry, this zeal for the public good arguably stems from the Leeds poetry scene that formed around Jon Silkin's magazine, Stand. Silkin has received more attention of late (see Fiona Becket's essay in Larrissy's Cambridge Companion) and Jeremy Munday's article 'Jon Silkin as Anthologist, Editor, and Translator' (T\&L 25:i[2016] 84-106) draws on his substantial archive in the Brotherton Library to attempt a 'micro-history' of translating in the twentieth century (p. 85). Particular attention is paid to Silkin's projected, but uncompleted, anthology of Hebrew poetry, a fractious 
undertaking that witnessed major arguments with his collaborators. This process was repeated in work towards a Japanese anthology, where he harangues his interlocutor, 'you make harsh and terse what IS NOT IN THE TEXT', complaining 'everyone sounds like Ashbery' (p. 103). For Silkin, so Munday's 'micro-history' suggests, an ethical responsibility for translating the original was also weighted towards language firmly moored in social and political realities.

Roy Fisher's Slakki: New and Neglected Poems, arranged by Peter Robinson for Bloodaxe Books, carries a reflection by the author entitled 'Roy Fisher on the Nature of Neglect' (pp. 73-5) which focuses on his juvenilia, and (another elegy) the vanishing of the busy, adventurous world of the late-modernist small presses in the 1980s and 1990s. It also contains a bibliography of these less well-known poems that will prove useful to future scholars of Fisher and of little magazines of the post-war period alike. Ian Pople also explored the ekphrastic beginnings of Fisher's 1966 prose work, The Ship's Orchestra, including its Noah's ark woodcut illustration in the Fulcrum Press edition from David Jones, and its debt to Picasso's Three Musicians, in 'Roy Fisher, The Ship's Orchestra' (PNR 42:v[2016] 60-3).

Older survivors of modernism writing well in to the later decades of the twentieth century were well served by publications in 2016. Long awaited, The Poems of Basil Bunting, edited by Don Share, was published by Faber over six decades after Eliot refused to publish Bunting's poetry. Share's variorum edition publishes in one volume poems Bunting published or intended to publish in his lifetime, poems published posthumously by his editor, and fragments that illuminate his published work. In addition to providing all traceable textual variants, Share's editorial apparatus is formidable, and includes excerpts from Bunting's correspondence, transcriptions of recorded readings, publishing histories, and historical source material including the Northumbrian wellsprings of his language. For all that the book comes in at just under 600 pages, the editorial hand is nimble, largely due to the marshalling of an excellent introduction. Owing a methodological debt to John Haffenden's edition of William Empson, Share's innovation lies in correlating material within the annotations with Bunting's personal library held at the University of Buffalo, and his transcribed integration of recorded material with print versions of the poems (p. xxii). Doubtless a discipline inculcated during his studentship under Geoffrey Hill and Christopher Ricks at Boston University, the Oxford English Dictionary and the Northumbrian elements of Wright's English Dialect Dictionary are constantly fed into Share's annotations, which are in the main richly rewarding. Indeed, etymological shades of meaning that Share might have missed became a theme in the letters pages of the Times Literary Supplement in the weeks after this volume was reviewed there. Several reviewers also noticed typographical errors, which are doubtless frustrating for an editor who sets out 'to rectify anomalies in the printing of Basil Bunting's poems' (p. xiii), but these have been corrected since the first print run. To take Bunting's most celebrated poem as a test case, Share's annotations haul in the affinities of the poem with the unconscious 'ancient Quaker life' (p. 328); its debts to cynghanedd in Welsh prosody; its epigraph from the Libro de Alexandre; the tinctures of dialect words 
(tape, oxter, thole-pins, kelt); biographical information from unpublished and remote sources on its inspiration Peggy Greenbank, and much more besides. An article on Basil Bunting's Persian translations also appeared: Simon Patton and Omid Azadibougar's 'Basil Bunting's Versions of Manuchehri Damghani' ( $T \& L$ 25:iii[2016] 339-62) focuses on how Bunting adapted technical knowledge from these experiments to his own verse. With a volume of Bunting's prose edited by Share to come and a forthcoming edition of the letters, it would seem that critical work on the poet is just beginning.

Hugh MacDiarmid is represented by essays in two books on Scottish literature published in 2016. Unsurprisingly, giving the combined fallouts of the 2014 Scottish independence referendum and subsequently Brexit, Scottish post-war poetry has received attention in both books in terms of political and social ideas of identity. Andrew Monnickendam's 'The Nature of Aesthetics in the Work of Mary Brunton, Hugh MacDiarmid and Alasdair Gray' (in Brown, Clark, and Jarazo-Álvarez, eds., Taking Liberties: Scottish Literature and Expressions of Freedom, pp. 93-110) recasts the familiar lineaments of MacDiarmid's nationalism in a subtle comparison of his concerns with Mary Ramsay's Calvin and Art [1938]. This includes dissent from the opinion that would lay all the ills of Scottish philistinism at Calvin's door. There is also in this volume an admirable essay by José-Miguel Alonso-Giráldez on the 'Scottish and Galician Background in Pearse Hutchinson's Poetry: Freedom, Identity, and Literary Landscapes' (pp. 187-212), which fruitfully resituates the important translator in Scottish (as well as northern Spanish) contexts as opposed to his usual placement in Irish literature. In Community in Modern Scottish Literature, edited by Scott Lyall, the editor's contribution, 'Hugh MacDiarmid's Impossible Community' (pp. 1-24), defends the poet from caricature as an extremist, rejecting Kailyard stereotypes as impossible while defending an equally impossible political community, singular and spiritual. This volume also contains Emma Dymock's 'Speaking for Oneself and Others: Real and Imagined Communities in Gaelic Poetry from the Nineteenth Century to the Present' (pp. 61-81), which considers Sorley MacLean's melding of tradition and innovation and his awareness of 'the disapproving gaze of the community' (p. 75). Dymock also glances at Derick Thomson, Iain Crichton Smith, and Angus Peter Campbell. Questions of Scottish identity in terms of religion are also at play in Maria Fengler's chapter, 'Aspects of Catholic Spirituality in George Mackay Brown' (in Zirra and Potter eds., The Literary Avatars of Christian Sacramentality, Theology and Practical Life in Recent Modernity, pp. 105-18), which examines Mackay Brown's idea of Orkney and Scotland as 'a Knox-ruined nation', the rhythms of Orcadian farming as allegories of Christ's Passion and Resurrection (pp. 110-11), and the sacramentality of local patterns of living.

MacDiarmid's sometime nemesis, Edwin Morgan, is the subject of Monika Kocot's Playing Games of Sense in Edwin Morgan's Writing, which celebrates and interrogates in equal measure the protean, mercurial, earthy fecundity of Morgan's 'cultural transgression' governed by different rules of play. Attuned to Bakhtin's dialogism and Derridean ideas of play and différance, Kocot organizes her material around these 'rules', such as the 'morphodynamics' (fluid shape) of his 'emergent' visual-concrete poems exploring semantic 
boundaries and indeterminacy of meaning (p. 55). The figure of 'the whittrick' (a changeling, weasel-like trickster) comes to stand for pre-eminent features of Morgan's writing: fluid identity, devious invention, and incessant process (p. 128). It is itself an apt emblem of Kocot's evident zest in the mercurial playground of Morgan's writing, which occasionally gets mired in a queasy blend of 'rules' from radically different theorists. Morgan also features in Jamie Hilder's Designed Words for a Designed World: The International Concrete Poetry Movement, 1955-1971, which unfortunately did not arrive in time for review. James McGonigal's 'Poets Post-War: G.S. Fraser and Edwin Morgan' (PNR 42:vi[2016] 81-4) compares Morgan's resumption of civilian life (he was a pacifist combat medic) with that of his fellow Glaswegian poet, Fraser, and their intersecting correspondences with Max Jacobs, Laura Riding, and Veronica Forrest-Thomson.

Another giant national poet who straddled the war years was R.S. Thomas. After his death in 2000, two seminal works of art criticism by Herbert Read, Art Now [1933] and Surrealism [1936], were discovered on Thomas's shelves, with a few dozen ekphrastic poems responding to modern art works wedged in to the pages. These are published alongside images of the art that inspired them in Bloodaxe's handsome volume Too Brave to Dream: Encounters with Modern Art, edited by Tony Brown and Ian Walford Davies. This contains an illuminating introduction, which collates interviews and other writings to chart Thomas's profound wariness about the validity of what he considered to be attempts 'to comment and draw out extended meanings' of the originals 'in a way which most of the painters would have found reprehensible' (p. 10). Nevertheless, the centrality of attention and painterly 'looking' that governs Thomas's entire oeuvre is drawn out in this rich selection from his unpublished poems.

More recent poetry received attention in 2016 in ways that nevertheless accentuated the rich resources of earlier traditions, as well as exemplifying several critical trends identified in the latter half of Larrissy's Cambridge Companion, including ecopoetics, gender, the literary marketplace, and consumption. Heather O'Donoghue's 'A Place in Time: Old Norse Myth and Contemporary Poetry in English and Scots' (in Quinn and Cipolla, eds., Studies in the Transmission and Reception of Old Norse Literature: The Hyperborean Muse in European Culture, pp. 277-94) uses Bakhtin's concept of the 'chronotype' to examine how the intersections of specific locus and mythic time intersect in contemporary poetries from Ian Duhig, Kathleen Jamie, Don Paterson, Pauline Stainer, and Robert Robertson. Stainer in particular is found to show the most sustained use of Norse myth, 'the dense allusiveness of her work' and its religious themes bearing clear affinities with that of David Jones (pp. 281-3). Eleanore Widger's 'The "Specific Evidentness" of Radical Landscape Poetry' (English 65:ccli[2016] 363-86) conducts a phenomenological reading of the ecopoetics of Mark Dickinson, Peter Larkin, Zoë Skoulding, Mark Goodwin, Elisabeth Bletsoe, and Harriet Tarlo, arguing that the drive for naming and terminology involved with specific places demands that the reader complete 'a rich trail of connections and dissonances' on the nature of experiencing place as much as fixing and naming that experience (p. 366). Jane Dowson's Carol Ann Duffy: Poet for Our Times is the first 
monograph of its kind on the career of the current poet laureate and first woman to hold the post. Dowson posits the epithet 'Duffyesque' to chart key aspects of Duffy's craft, including a feminist discourse that avoids essentialization, her urban muse, a 'lens of social justice', and a representative quality of the 'Noughties' just as Larkin may be heard as the repressed and conservative voice of the 1950s (pp. 26-30). Dowson reads key volumes such as The World's Wife and its panoply of women etched out of the masculinist narratives of myth, fairy tale, and folk culture as a celebration of feminist difference, one that inhabits the same cultural moment of retort to the misogyny of Freudian mystification of female desire and pleasure as the Spice Girls (p. 136). Duffy's role as laureate is also considered, with Dowson arguing that 'she establishes a public voice that does not sacrifice her integrity and poetic independence' (p. 155). Shelley Roche-Jacques's article " 'Out of the forest I come": Lyric and Dramatic Tension in The World's Wife' ( $L \& L$ 25:iv[2016] 363-75) also concentrates on this visible but under-studied poet, probing ways in which dramatic monologue may be a useful way of conceptualizing to what degree the 'pragmatic-governed situation' of poetry may be said to exist, pace J.L. Austin (p. 374).

Following on from the appearance of his controversial poem 'Gatwick' in the London Review of Books, Craig Raine's book of critical essays $M y$ Grandmother's Glass Eye: A Look at Poetry has proven only slightly less divisive. Reviews have concentrated on Raine's essential animus: the waging of critical vendettas and his tendency to appear more passionate about others' misreadings than about poems themselves. The eponymous eye of this collection is skewed away from the work towards questions of commodity: 'how does [poetry] sell itself?' he wonders on the very first page. A dispiriting answer follows, amidst the stage-managed mauling of fellow critics, such as Christopher Ricks, John Carey, and Tom Paulin.

Regrettably, a copy of Sam Solnick's Poetry and the Anthropocene: Ecology, Biology and Technology in Contemporary British and Irish Poetry did not arrive in time for review.

\section{Irish Poetry}

Three years on, the tide of critical appraisals occasioned by the death of Seamus Heaney still flowed strongly in 2016. Eugene O'Brien's edited collection, The Soul Exceeds its Circumstances: The Later Poetry of Seamus Heaney, contains sixteen new essays by well-known scholars on Heaney's lyrics, from the time of Seeing Things [1991] to Human Chain [2010]. This volume has its origins in the editor's discovery, while compiling a bibliography of Heaney criticism, that there was a relative paucity of work on the poet's later writings compared to the earlier work. The collection takes a suitably posthumous orientation, beginning at the end with a section on Heaney's poetry and death. The opening essay, Andrew J. Auge's 'Surviving Death in Heaney's Human Chain' begins with the disquiet that Heaney's 2009 statement that death meant 'extinction' caused in some quarters. Here, Auge reads the poems of Heaney's final volume as testaments to the idea that 'human 
connections - the bonds of care and love linking the living and the dead ... allow death to be faced, withstood and survived' (p. 30). Magdalena Kay's 'Death and Everyman: Imagining a "Not Unwelcoming Emptiness", sees Heaney taking a step towards a new understanding of death, as an '(unpolitical) realm of emptiness' in The Haw Lantern [1987]. Kay goes on to present Heaney's poetry as evincing an increasing imagining of death as a loss of subjectivity, something that would cut 'him loose from the history, politics, familial ties, and stories constituting the substance of the self' (p. 69). Helen Vendler's contribution to the volume, simply entitled 'Squarings', is a characteristically finely tuned reflection on the implications of Heaney's different poetic forms. In it, Vendler sensitively makes the case for the downto-earth nature of that most aerial of Heaney's volumes, pointing out that its tendencies towards self-correction and the plain-spoken counterbalance its more footloose energies.

In the second part of the book on Heaney's later style, Michael R. Molino's 'The Freed Speech of "Equivocal Words": Seamus Heaney's Door into the Light' takes its starting point in the pluralist language of the Good Friday Agreement, comparing its both/and formulations to those favoured by the poet. From that starting point, this chapter becomes a study of how the characteristic equivocations of Heaney's language allowed him to encompass both bitter realism and salutary hope in the same poems. Neil Corcoran's 'Happening Once for Ever: Heaney's Late Style' looks at the stylistic and theological identifiers in the poet's late work. Corcoran writes that, at its best, this poetry achieved 'intensely simple lyric concentration, limpidity and lucidity' (p. 126). In this chapter, Corcoran also examines Heaney's engagement in poetry and prose with other poets who (for good or ill) had notable late phases in their careers, Wordsworth, Eliot, and Yeats among them. (The title of the piece is itself an intertextual nod, being taken from a proleptic elegy for Heaney by Derek Mahon.) Meg Tyler's “The whole of me a-patter": Image, Feeling, and Finding Form in Heaney's Late Work' pays close attention to Heaney's late use of the sonnet form. It includes, among other things, a useful close comparison between the version of Heaney's 'Polish Sleepers' that was originally published in the New Yorker, and the one that came out in District and Circle.

The third part of O'Brien's collection, 'Translation and Transnational Poetics', begins with Michael Parker's " "Renewed, transfigured, in another pattern": Metaphor and Displacement in Seamus Heaney's Human Chain'. In this chapter Parker pays close attention to Heaney's careful patterning of sounds in his translations, pointing up Heaney's extraordinary decision to 'Derrycize' his late translations by removing references to their original farflung settings. The late Elmer Kennedy-Andrews, in 'The Reluctant Transatlanticist: "Like a weeping willow inclined to the appetites of gravity", examines the temporally and physically far-away locations that Heaney has engaged with in order to better understand his native ground. These places include 'Iron Age Jutland and Viking Dublin, eastern Europe and Stalinist Russia', as well as 'the archaic Gaelic and classical worlds ... America and the Caribbean' (p. 173). The section closes with Bernard O'Donoghue's 'Crediting Marvels or Taking Responsibility: Vocation and Declarations of Intent by 
Seamus Heaney after Seeing Things'. In this piece, O'Donoghue steers a middle course between readings of Heaney's work that emphasize its political engagements and those that identify the lack of the same. It includes an enlightening look at an early version of 'The Flight Path' published in the $P N$ Review.

Part IV of the book, entitled 'Luminous Things and Gifts', starts with Henry Hart's 'Seamus Heaney's Gifts', a piece that begins with a detailed reflection on the gift of a pen that Heaney took with him on his first day at St Columb's, his boarding school in Derry. Hart goes on to describe what a twoedged entity the gift can be in Heaney's work, and balances its associations with inspiration with its burdensome requirements for reciprocity. Richard Rankin Russell is one of several critics (Stephen Regan and Harry Clifton among them) who have recently made objects central to their analyses of Heaney's work. His essay, " "Deep down things": The Inner Lives of Things in Later Heaney', provides an illuminating history of the 'thing' in modern poetry. For Russell, Heaney's " "thing poems" attempt to suture the long-held Western divide between res (thing) and verbum (word)' (p. 241). Stephen Regan's " "Door into the light": The Later Poems of Seamus Heaney' covers the same ground as his piece in Romanticism (reviewed below), this time taking its title from a letter from Heaney to Brian Friel, in which he wrote of his hoped-for direction of travel after the publication of North [1975].

The fifth and last part of the book begins with Moynagh Sullivan's " "Scatter-eyed / And daunted": The "Matrixial Gaze in Seeing Things", in which Sullivan uses 'matrixial theory', a psychoanalytic concept that ties responses to artworks to late prenatal experiences, as a lens to examine Heaney's 1991 collection. In the chapter, Sullivan foregrounds the maternal lineage of a volume that has hitherto more often been discussed in terms of that oedipal agon, the death of the father. In "Beyond maps and atlases": Transfiguration and Immanence in the Later Poems of Seamus Heaney', Daniel Tobin focuses on how Heaney's lifelong urge to re-see the mundane in elevated or transcendent condition manifests itself in his late volumes, in particular his 2010 collection Human Chain. Rand Brandes's 'The Poetics of Reverie and Revelation in the Last Poems' looks at Heaney's poetry from a Bachelardian angle, seeing his pre-reflective childhood experiences as his most valuable poetic resources. For Brandes, the preternatural vividness with which Heaney's work summons the past is not so much evidence of the poet's powers of recall as of his power to re-experience: 'Heaney does not remember or recall the anima childhood as much as he relives it as an interiority, immediacy, and intensity that have come to signify his poetic genius' (p. 333). The book closes with Eugene O'Brien's “"The door stands open": Liminal Spaces in the Later Heaney' (pp. 348-69), a suggestive piece that dwells on the empty space as resource and image in Heaney's work. It gathers and amplifies many of the themes that earlier chapters explored: on memory, transcendence, and the notion that even seemingly empty spaces can be 'alive and signalling too' (p. 366). This book contains many new departures that are sure to be followed up by critics in the future.

Richard Rankin Russell's Seamus Heaney: An Introduction takes a declared interest in Heaney's stances on the ethics of writing and the role of the writer. 
This book follows on from many of the critical concerns that Russell has explored in his other works on Heaney, particularly Heaney's poetry's relationship to issues of peace and violence, his deployment of poetic forms, and his fidelity to his region of origin. This is a wide-ranging and comprehensive guide, but its particular strengths lie in its analyses of work from the extremes of Heaney's career. Russell is enlighteningly detailed about Heaney's recollections of his own early self; he is also among the first scholars to provide careful, knowledgeable readings of the last poems. Although this is an introduction, and perhaps aimed at undergraduate students, it is no mere compendium of existing interpretations. Because of Russell's deep familiarity with out-of-the-way interviews and archival material, there is plenty of fresh food for thought here.

Eugene O'Brien's Seamus Heaney as Aesthetic Thinker: A Study of the Prose is the second book-length study of Heaney's prose in as many years, coming hot on the heels of John Dennison's 2015 monograph. However, the two studies are complementary rather than duplicative: whereas Dennison's interests lie in the tonal and structural echoes of Christianity that Heaney's prose contains, O'Brien's interests are situated more in the theoretical than the theological realms of philosophy. Also, unlike Dennison, O'Brien's chapters are broadly thematic rather than chronological, the first one situating Heaney as an aesthetician alongside other twentieth-century philosophical thinkers, Lacan and Heidegger prominent among them. The second chapter, on space, covers similar ground to O'Brien's earlier work, Seamus Heaney and the Place of Writing [2002], examining the border-crossing and boundary-blurring that are such marked features of Heaney's imagination. The third chapter, on the idea of 'fields of force' in Heaney's prose, explores both the political and more numinous senses of this term. Another chapter centres on Heaney's ambiguous positioning in relation to the politics of Northern Ireland, making comparisons to the precarious positions occupied by his eastern European exemplars. The next chapter returns to the matter of place, looking at Heaney's depiction of terrain alongside works by Patrick Kavanagh and William Wordsworth. And the final chapter is on the idea of translation in its widest sense, referring to the movement between languages and also the spaces between 'the societal and the personal, the local and the global, and the cultural and the political' (p. 265).

Several journal articles on Heaney's work also appeared in 2016. Kevin Murphy's 'Heaney Translating Heaney: Coupling and Uncoupling the Human Chain' (TSLL 58[2016] 352-68) is a thoughtful meditation on the role of translation in the poet's work. As in the last chapter of O'Brien's book, this is examined in its sense of the importation of imagery and ideas from another medium (as in the case of P.V. Glob's Bog People), but mainly in its sense of engagement with another language (as in Heaney's famous version of Beowulf). It focuses on Heaney's last collection, showing how he engrafted incidents from his own life onto texts originally written in Latin, French, Italian, and Irish. Rosie Lavan's 'Seamus Heaney and the Audience' (EIC 66[2016] 54-71) is, among other things, an examination of the decisions and negotiations the poet made in giving public readings of his work. As an inveterate reader, this was a significant part of Heaney's working life. 
As Lavan shows through her use of draft materials, readings created strains and tensions for Heaney on occasions when his knowledge of his audience and his fidelity to other locations pulled him in opposite directions. This article also considers the role of drama in Heaney's writing life, and brings to light hard-to-get-at sources, such as accompanying notes for productions of his plays. As in previous years, Stephen Regan brought out a beautifully rendered meditation on Seamus Heaney's poetry, this time on the uses of light as an image, entitled 'Lux Perpetua: The Poetry of Seamus Heaney, from Door into the Dark to Electric Light' (Romanticism 22[2016] 322-30). In this article, Regan discusses the sources of Heaney's images of light, including Larkin, Yeats, Keats, and Wordsworth. The piece sensitively traces the successive appearances of the light of initiation of the early poems, the subdued lights of political turmoil, and the fuller illuminations that characterize Heaney's later work.

The title of Chris Arthur's “ "Coincidences, graces, gifts”: Seamus Heaney, a Personal Turas' (SR 124[2016] 99-113) contains an Irish word that refers to a pilgrimage, particularly one to a holy well. It is a memory-piece on reading Heaney in Northern Ireland during the Troubles. Arthur offers a valuable insight into how Heaney's work was seen in the dark days of the mid-1970s. The author recalls that, while living in Scotland, reading Heaney's poetry was 'a statement of my Ulster provenance, and a distancing of myself both from the Protestant mainstream in which I'd been raised and from the violence of the Troubles' (pp. 103-4). Among the thoughtful vignettes that make up this piece, Arthur calls Heaney a 'voice aware of, but never overwhelmed by, those venomous antipathies that threatened to sully and eclipse' (p. 105). This turns out to be something of a turas of Arthur's own, one that takes him back to Heaney's books and the circumstances in which he read them. It is at the tailend of the Heaney memory-pieces that were published so thickly in 2015. M. Reza Ghorbanian's 'Subjectivity as Alterity in Seamus Heaney's Poetry' (Mosaic 49[2016] 113-32) is a densely written piece that touches on notions of the collective unconscious and Lacanian ideas of identity-formation in relation to Heaney's work. Though it contains some perceptive writing on the rulebreaking, border-crossing Sweeney as an avatar for Heaney's own shifting identity, there is perhaps more terminology on display here than engagement with the contexts of Heaney's work. As a result, the piece contains some incorrect assertions, for example that Catholic schoolchildren, 'although officially British ... do not have access to the English literary tradition' (p. 119). This would have come as a surprise to Heaney, who was taught the 'English literary tradition' at his Catholic grammar school, St Columb's, and who went on to teach the same tradition to other Catholic schoolchildren in Belfast (as he recalls in his poem 'The Real Names').

Anne Karhio's 'Slight Return': Paul Muldoon's Poetics of Place sets out its chief preoccupation at the start of its metacritical introduction: the slippage between word and world that has conditioned so much post-Wittgenstein linguistic philosophy. In the same introduction, she describes her aim 'to move away from the central paradigm of identity and Irishness in cultural studies' (p. 7). Despite this assertion, Karhio never loses sight of what Trevor Joyce called the 'recognisably Irish furniture' that occupies Muldoon's work. 
Throughout the book, Karhio slips deftly between the places and spaces that appear in Muldoon's poetry and the poet's engagements with (among other things), naming, topography, music, nostalgia, and the digital. The final chapter, with its focus on information technology, contains a salutary reminder that, in spite of the fact that technology has brought us closer to the sources of Muldoon's densely allusional poems, readers are still no nearer to divining their meanings.

Other poets from Northern Ireland strongly featured in one of the two new online journals in the field of Irish studies that emerged in 2016: The Review of Irish Studies in Europe. Timothy C. Baker's 'Second Time Round: Fugal Memory in Ciaran Carson's For All We Know' (RISE 1[2016] 1-17) examines the use of the fugue form in Carson's work. It takes as its starting point Carson's intriguing epigraph, which Carson himself takes from Glenn Gould's 1964 essay on the fugue, explaining how the form 'arouses some primeval curiosity which seeks to uncover in the relations of statement and answer, of challenge and response ... the secret of those still, desert places which hold the clues to man's destiny' (p. 1). Shane Alcobia-Murphy's " "Living so far from words": Intertextuality, Trauma and the Post-Shoah World in Medbh McGuckian's Blaris Moor' (RISE 1[2016] 18-35) examines the Northern Irish poet's most recent collection in the light of Alcobia-Murphy's long fascination with the sources of her often collagistic poems. Beginning with Marjorie Perloff's ideas of 'unoriginal genius', he goes on to discuss how McGuckian's sources for this collection show that it is written in the shadow of trauma, suffering, and, in particular, the long after-effects of the Holocaust. Adam Hanna's 'Louis MacNeice's Remote Houses' (RISE 1[2016] 36-47) examines several of MacNeice's poems from the tumultuous second half of the 1930s. It argues that, although the remote houses in MacNeice's poems set in the Hebrides, Iceland, and rural Ireland seem to be unlikely locations for engagement with wider issues, they reflect his own self-questioning about matters that include the ascendancy of rapacious, acquisitive materialism, and the responsibilities engendered by the rise of European fascism.

MacNeice's life and work came in for sustained attention in Christopher J. Fauske's Louis MacNeice: In a Between World, a monograph that offers a primarily biographical approach to the Belfast-born poet and radio dramatist. Its nine short chapters, as its title suggests, keep a close focus on the theme of liminality. The in-between states that Fauske discusses are those between war and peace, country and city, Ireland and England, Ireland's northern and southern polities, and the USA and Europe. A particularly interesting chapter covers MacNeice's long poem 'Autumn Journal', placing it in the context of his self-questioning about the public role a poet should play in wartime. Though the author is so fond of quotations that they at times threaten to overwhelm his argument, this is nevertheless a valuable study. As a biographically based critical work, Fauske's book gives richly detailed contexts for work in each phase of MacNeice's career. It contains much that is new and interesting about the life as well as the poetry.

Though studies of poetry from Northern Ireland in 2016 tended to be on the better-known names, criticism written about poets with origins elsewhere in Ireland often shone light on less familiar work. This was especially true of a 
special issue of the Irish University Review that focuses on Irish experimental poetry. It is an excursion across less-trodden fields that yields much original and valuable material. It opens with a tribute to the late Michael Smith from his friend and collaborator Trevor Joyce, with whom he founded the New Writers' Press. Joyce's piece reminisces about their beginnings as poets and publishers in the late 1960s, vividly evoking the Dublin milieu where the small cadre that formed the vanguard of Irish experimental poetry came together. The epistolary form of Michael Smith's 'Translation \& Reality: A Letter to the Poet Trevor Joyce' (IUR 46:i[2016] 4-9) underscores the sense that experimental poetry in Ireland is a finely woven social as well as artistic tapestry. In his letter, Smith sets out the distinction between a Dadaist or Surrealist creation of a 'private solipsistic world', and contrasts this approach to the work of Beckett and Trevor Joyce himself, whom Smith sees as 'concerned with tackling a perceived discrepancy between language usage and the reality to which it purports to refer' (p. 6). David Lloyd's useful introduction gives a guide to the preoccupations of the edition as a whole, ones that include the decentring of the lyric 'I'; the justifiability of poetry that so foregrounds its own unknowable status; the reimagining of a poem as a process rather than a product; and the resistance that linguistic experiment offers to the language of monetization and calculation. The first substantial essay, 'Against Irish Modernism' by Francis Hutton-Williams (IUR 46:i[2016] 20-37), provides a valuable survey of the cultural conditions of the Irish Free State, questioning both the use and applicability of the term 'modernism' to Irish art. HuttonWilliams takes issue with the over-use of the term, and draws attention to the ways in which modernist experimentation was stifled by conditions in the state. The next essay, 'Modernism, Empiricism, and Rationalism' (IUR 46:i[2016] 38-47) by Geoffrey Squires, begins with an examination of the lineaments of the modernity out of which modernism arose, and suggests that, given the periodicity of the term 'modernism', alternative criteria of 'empiricism' and 'rationalism' might be adopted in discussions of poetry.

J.C.C. Mays's 'The Third Walker' (IUR 46:i[2016] 48-62) looks closely at two recent publications by the experimental poets Billy Mills and Catherine Walsh, and attempts to account for the dynamics that keep such poets marginal in comparison with their more widely recognized peers. Alex Davis's 'Paper \& Place: The Poetry of Billy Mills' (IUR 46:i[2016] 63-74) continues the examination of Mills's work, showing how his engagement with terrain through words shows an acute consciousness of the limitations of both verbal and cartographic arts. Davis convincingly links this feature of Mills's poetry with the interest in 'nonlinear form' that his criticism espouses. Claire Bracken's 'Nomadic Ethics: Gender and Class in Catherine Walsh's City West' (IUR 46:i[2016] 75-88) reprises the prominent linkage in this edition between experimental poetry and a dissident stance towards prevalent socio-economic structures. In this article, Bracken argues that the Dublin presented in Walsh's poetry posits a fluid nomadism against the stony environs of late capitalism. Kit Fryatt's 'The Poetics of Elegy in Maurice Scully's Humming' (IUR 46:i[2016] 89-104) considers how Scully, a poet for whom self-effacement is a form of credo, negotiates the challenges of that paradoxically selfabsorbed form, the elegy. Romana Huk continues the focus on Scully in 
“"Out past / Self-dramatization”: Maurice Scully's Several Dances' (IUR 46[2016] 105-8), an essay that looks at Scully's work in the light of the ways in which experimental Irish poetry has developed in recent decades. In this essay, Huk links Scully's choice of imagery to his preferred formal techniques, noting his 'repeated recourse to metaphorical webs, like spider webs' (p. 137).

Niamh O'Mahony's " "Releasing the chaos of energies": Communicating the Concurrences in Trevor Joyce's Appropriative Poems' (IUR 46:i[2016] 119-31) looks at the role of the borrowed in the poetry of Trevor Joyce. O'Mahony addresses (among other things) the charge that such work lacks a vital impulse that non-appropriated work does not. In writing about this subject in relation to Joyce, O'Mahony usefully extends a critical conversation which in recent years has, in Irish poetry, centred on the work of Medbh McGuckian. Marthine Satris's 'Codex Vitae: The Material Poetics of Randolph Healy's "Arbor Vitae", (IUR 46:i[2016] 132-44) shows how the long Irish poetic traditions of protest and dissent are, in Healy's work, brought into alignment with an experimental poetics of process. Kenneth Keating's 'Repetition and Alterity: Geoffrey Squires's "Texts for Screen", (IUR 46:i[2016] 145-57) examines a number of digital works that, rather than being simulacrums of a paper original, "embrac[e] the technology central to their construction' (p. 145). James Cummins's " "The history of Ireland he knew before he went to school": The Irish Tom Raworth' (IUR 46:i[2016] 15870) brings to light the impress that Ireland has made on a poet who is typically identified as an Englishman in a chiefly American milieu. Rachel Warriner's 'Image and Witness in Maggie O'Sullivan's A Natural History in 3 Incomplete Parts and POINT.BLANK.RANGE' (IUR 46:1[2016] 171-82) explores the point at which experimental poetry and visual art bleed into each other. Warriner looks at poems from the 1980s in which language itself is obscured and effaced. The piece concludes that O'Sullivan's work is 'a sincere testimony to an alternative way of perceiving and interpreting the world' (p. 181). In its consistent and lively engagement with issues of capitalism, subjectivity, and canonicity, this volume shows the possibilities that lie in the exploration of new areas of Irish poetry.

Paige Reynolds's Modernist Afterlives in Irish Literature and Culture contains several important contributions to the field of Irish modernist poetry studies. Lucy Collins's essay, "I knew what it meant / Not to be at all": Death and the (Modernist) Afterlife in the Work of Irish Women Poets in the 1940s' (pp. 23-34) adds to the wealth of scholarship on pre-1970s Irish poetry by women that Collins has already produced. In this essay, Collins stakes a claim for Rhoda Coghill, Mary Devenport O'Neill, and Sheila Wingfield as modernists, owing to their combination of 'formal regularity with glimpses of ... fragmented subjectivity' (p. 25). She begins by noting the exclusion of women from the structures of canon-formation in postindependence Ireland, and goes on to link the preoccupation with mortality in their work to their (well-founded) fears of future literary effacement. Alex Davis's 'Modernist Topoi and Late Modernist Praxis in Recent Irish Poetry (with Special Reference to the Work of David Lloyd)' (pp. 61-74) makes a useful distinction at its outset between Irish poets (like Seamus Heaney and Derek Mahon) who engage with modernism primarily through references to 
writers and images associated with the movement, and those who (like David Lloyd, the subject of this article), partake in a 'productive appropriation of earlier modernist praxes' (p. 61). Along the way to discussing Lloyd's work, Davis gives a thoroughgoing insight into the course of Pound's influence in Irish poetry, proposing a date for his figurative arrival ashore that is a good six decades earlier than the one suggested by Edna Longley. Davis goes on to delineate the ways in which Lloyd's work represents a continuation of modernist experiments, showing how he rejects a post-Yeatsian neo-bardic posture. Leah Flack's "Whatever is given / Can always be reimagined": Seamus Heaney's Indefinite Modernism' (pp. 35-48) sees Heaney as taking a typically equivocal attitude towards the canonical modernist duo of Eliot and Pound, arguing for Mandelstam's importance to him as a less inhibiting presence.

David Wheatley also wrote on an Irish modernist poet in 2016, in a two-part article entitled 'Aspermatic Days and Nights: Samuel Beckett and an AntiGenealogy of Contemporary Irish Poetry' (PNR 42:iii[2016] 48-53 and PNR 42:iv[2016] 68-73). Wheatley situates the 'comic anti-natalism' of Samuel Beckett's poetry in the context of the ideals and conditions of the Free State Ireland of which he became a citizen as an adolescent. Throughout the article he shows convincingly the obsessive nature of Beckett's returns to ideas of natality, degeneracy, and parturition. Next, Wheatley combines ideas of procreation and generation with more metaphorical notions of poetic genealogies and successions among Irish poets. While counter-traditions of Irish poetry that link Beckett with other 1930s poets have been tried before, Wheatley attempts the more unusual act of tracing a lineage through subsequent generations. This is not, as he admits, altogether possible: 'radical Irish poetics, if such a thing even exists, follows no academic clock or generational deadlines' (p. 70). This leads Wheatley to the original argument that the gapped nature of the Irish avant-garde is one of its enabling conditions. He is thoughtful, too, about the potentially reductive nature of seeking out poetic genealogies, and gently suggests that Beckett's bifurcation of Irish poets into 'antiquarians' and 'others' does not do justice to the complexity of those who were lumped in with either group.

The online journal International Yeats Studies represents a welcome new addition to Yeats scholarship. Suitably for a new Yeats journal that was launched in 2016, 'Easter, 1916' features heavily as both poem and event. The title of Margaret Mills Harper's essay, 'Words for Music? Perhaps' (IYS [2016] 1-12), introduces a question mark at an apposite point in the title of Yeats's 1932 Cuala Press collection. This article explores the themes from this volume as counterpoints to the philosophical 'system' Yeats detailed in A Vision. James Pethica's " Easter, 1916" at Its Centennial: Maud Gonne, Augusta Gregory and the Evolution of the Poem' (IYS [2016] 30-48) takes its starting point in the fact that no early draft of the poem survives: the date Yeats appended to it, '25 September 1916', comes relatively late in the poem's evolution. He points out that on this day Yeats was at Coole Park, and goes on to show the centrality to the poem of that house's owner, his long-time collaborator Lady Augusta Gregory. The volume also contains admirable textual research by Matthew Campbell in his essay 'Dating "Easter, 1916", 
(IYS [2016] 54-9). Campbell's article is a detailed look at a poem whose instability of designation is such that even the comma that he uses in the title has had a lengthy history of its own. Campbell follows a closely constructed timeline to demonstrate how 'Easter, 1916' is a poem 'about a date and around which many other dates have clustered' (p. 54).

Charles I. Armstrong's " Easter, 1916" and Trauma' (IYS [2016] 60-5) examines the canonical poem in the light of the developing field of trauma studies. In his article, Armstrong points out the traumatic elements of Yeats's responses to the Rising, in particular his compulsion to revisit: 'Did that play of mine send out / Certain men the English shot?', Yeats asked in a late work. Joseph Valente's 'The Bioaesthetics of "Easter, 1916"' (IYS [2016] 66-73) looks in detail at the narrative turnabouts this notoriously ambiguous and ambivalent poem contains, considering the work from the perspective of disability studies. Finally, Lucy McDiarmid's 'The Avian Rising: Yeats, Muldoon, and Others' (IYS [2016] 74-85) is an evocative look at the presence of birds in both the historical record and in poetic refigurings of the Rising. McDiarmid looks in particular at a new poem by Muldoon on the Rising in which birds feature heavily. She makes a convincing case that birds are such frequent presences in depictions of this time because 'imputing feelings to birds offered a form of emotional release' (p. 75).

This year's Yeats Annual honours a gift of rare Yeats volumes to University College Cork by Eamonn Cantwell and opens with an introduction by Warwick Gould entitled 'Yeats and His Books'. It is supplemented by a catalogue by University College Cork librarian Crónán O Doibhlin which makes clear the generosity of Cantwell's gift to the university. Its first substantial essay, R.F. Foster, "Philosophy and Passion": W.B. Yeats, Ireland and Europe' (YeA 20[2016] 71-97), examines Yeats's position in relation to Irish politics, elegantly rooting his later poems in the social and cultural contexts of their times. 'I believe', Foster writes, 'that several of his most apparently visionary or cerebral poems of the late 1920s are firmly rooted in the socio-political arguments of the day' (p. 84). Bernard O'Donoghue's 'Yeats the Love Poet' (YeA 20[2016] 97-118) provides a long view of the traditions of courtly love in Europe, before looking at the poetry of Yeats in their light, particularly his poems that touch on his (mostly) unrequited passion for Maud Gonne.

Helen Vendler's 'The Puzzle of Sequence: Two Political Poems' ( YeA 20[2016] 119-54) carries on in the vein that the critic established in her monograph Our Secret Discipline: Yeats and Lyric Form. Vendler argues for the meaningfulness of Yeats's formal choices in his mature sequences 'Nineteen Hundred and Nineteen' and 'Blood and the Moon'. Paul Muldoon's 'Moving on Silence: Yeats and the Refrain as Symbol' (YeA 20 [2016] 155-78) is a thoughtful and wide-ranging meditation on the nature of the refrain itself, characterizing it as 'the triumph over time, ecstasy in stasis', an element of poetry with 'a peculiar power ... to represent at once fixity and fracture, regularity and rupture, constancy and change' (p. 156). Following these ideas, he concludes by demonstrating how MacNeice made such a productive inheritance of Yeats's 'oddly dissociative', nursery-rhyme-like late refrains (p. 177). 
John Kelly's essay, economically entitled 'Eliot and Yeats' (YeA 20[2016] 179-228), begins with the critical nostrum that the two great cynosures of modernism named in its title were 'at best chary of each other and at worst antagonistic' (p. 179). Kelly goes on to do deft work in complicating this narrative, concluding by pointing out that 'the strategically important appearance of Yeats in Four Quartets, the care which Eliot took there in appropriating Yeats's voice [and] ... earlier examples of Yeats and Eliot defining their own poetic methods and ideas against those of the other' suggests a more fruitful interchange between the poets than has hitherto been recognized (p. 226). Overall, as in previous years, the giants Yeats and Heaney were solidly represented in Irish poetry criticism in 2016; however, there was a heartening abundance of works on less-explored poets as well.

\section{Books Reviewed}

Aaltonen, Sirkku, and Areeg Ibrahim, eds. Rewriting Narratives in Egyptian Theatre: Translation, Performance, Politics. Routledge. [2016] pp. 288. £110 ISBN 9781138946446.

Adamowicz-Pośpiech, Agnieszka, and Marta Mamet-Michalkiewicz, eds. Translation in Culture. WUO. [2016] pp. 206. £? ISBN 9788380127531.

Adiseshiah, Siân, and Louise LePage, eds. Twenty-First-Century Drama: What Happens Now. PalMac. [2016] pp. 364. £58 ISBN 9781137484031.

Ailwood, Sarah, and Melinda Harvey, eds. Katherine Mansfield and Literary Influence. EdinUP. [2015] pp. ix + 262. £75 ISBN 9781474404549.

Amiran, Eyal. Modernism and the Materiality of Texts. CUP. [2016] pp. xiv + 179. £80 ISBN 9781107136076.

Ashley, Mike. Science Fiction Rebels: The Story of the Science-Fiction Magazines from 1981 to 1990. LiverUP. [2016] pp. 384. £80 ISBN 97817 81382608.

Balbert, Peter. D.H. Lawrence and the Marriage Matrix: Intertextual Adventures in Conflict, Renewal, and Transcendence. CambridgeSP. [2016] pp. xii + 345. £52.99 ISBN 9781443893053.

Barrows, Adam. Time, Literature and Cartography after the Spatial Turn: The Chronomatic Imaginary. Palgrave. [2016] pp. xv + 178. £74.99 ISBN 97811 37569011.

Baxter, Katherine Isobel, and Robert Hampson, eds. Conrad and Language. EdinUP. [2016] pp. vii + 219. £55 ISBN 9781474403764.

Becquet, Alexandra, and Claire Davison, eds. Ford Madox Ford's Cosmopolis: Psycho-geography, Flânerie and the Cultures of Paris. Brill. [2016] pp. 250. $£ 59$ ISBN 9789004328365.

Begam, Richard, and Matthew Wilson Smith, eds. Modernism and Opera. JHUP. [2016] pp. ix + 378. £33.50 ISBN 9781421420622.

Bentley, Paul. Ted Hughes, Class and Violence. Bloomsbury. [2016]. pp. 168. $£ 28.99$ ISBN 9781441188168.

Berman, Jessica, ed. A Companion to Virginia Woolf. Wiley. [2016] pp. xiv + 502. £120 ISBN 9781118457887. 
Bertolini, John A. The Case for Terence Rattigan, Playwright. Palgrave. [2016] pp. xii + 229. £67.99 ISBN 9783319409962.

Gregory Betts, Paul Hjartarson, and Kristine Smitka, eds. Counterblasting Canada: Marshall McLuhan, Wyndham Lewis, Wilfred Watson, and Sheila Watson. UAlbertaP. [2016] pp. 376. £38.50 ISBN 9781772120370.

Bianchi, Bruna, and Geraldine Ludbrook, eds. Living War, Thinking Peace (1914-1924): Women's Experiences, Feminist Thought, and International Relations. CambridgeSP. [2016] pp. 290. £47.99 ISBN 9781443886840.

Blair, Rhonda, Amy Cook, and Mark Turner, eds. Theatre, Performance, and Cognition: Languages, Bodies, and Ecologies. Bloomsbury. [2016] pp. xi + 243. pb \$35.96 ISBN 9781472591784.

Bloom, Emily C. The Wireless Past: Anglo-Irish Writers and the BBC, 19311968. OUP. [2016] pp. 224. £50 ISBN 9780198749615.

Bogar, Brigitte, and Christopher Innes, eds. The Critical Shaw: On Music. Rosetta. [2016] pp. 305. pb £12.39 ISBN 9780795348945.

Bowlby, Rachel. Everyday Stories. OUP. [2016] pp. viii + 186. pb £14.99 ISBN 9780198727699.

Bowler, Rebecca. Literary Impressionism: Vision and Memory in Dorothy Richardson, Ford Madox Ford, H.D. and May Sinclair. Bloomsbury. [2016] pp. vii + 247. £28 ISBN 9781350063914.

Bowler, Rebecca, and Claire Drewery, eds. May Sinclair: Re-thinking Bodies and Minds. EdinUP. [2016] pp. 256. £75 ISBN 9781474415774.

Boxall, Peter, and Bryan Cheyette, eds. The Oxford History of the Novel in English, vol. 7: British and Irish Fiction since 1940. OUP. [2016] pp. 656. £125 ISBN 9780198749394.

Bradshaw, David, Laura Marcus, and Rebecca Roach, ed. Moving Modernisms: Motion, Technology, and Modernity. OUP. [2016] pp. 336. $£ 55$ ISBN 9780198714170.

Brennan, Michael G. Graham Greene: Political Writer. PalMac. [2016] pp. xxiv + 208. £58 ISBN 9781137343963.

Brinton, Ian, ed. For the Future: Poems \& Essays in Honour of J.H. Prynne on the Occasion of his 80th Birthday. Shearsman. [2016] pp. 241. £14.95 ISBN 9 781848614901.

Brinton, Ian, ed. John Riley: Selected Poetry and Prose. Shearsman. [2016] pp. 126. £9.95 ISBN 9781848614888.

Brown, Ian, David Clark, and Rubén Jarazo-Álvarez, eds. Taking Liberties: Scottish Literature and Expressions of Freedom. ASLS. [2016] pp. 240. $£ 15.49$ ISBN 9781908980212.

Brown, Tony, and Ian Walford Davies, eds. R.S. Thomas: Too Brave to Dream: Encounters with Modern Art. Bloodaxe. [2016] pp. 112. £12 ISBN 1780273074.

Bubb, Alexander. Meeting Without Knowing It: Kipling and Yeats at the Fin de Siècle. OUP. [2016] pp. xv + 272. £58.50 ISBN 9780198753872.

Bulson, Eric. Little Magazine, World Form. ColUP. [2016] pp. xii +333. $£ 49.95$ ISBN 9780231179768.

Burges, Joel, and Amy J. Elias, eds. Time: A Vocabulary of the Present. NYUP. [2016] pp. ix + 372. pb £24.99 ISBN 9781479874842. 
Burkman, Katherine H. The Drama of the Double: Permeable Boundaries. PalMac. [2016] pp. xv + 182. \$95 ISBN 9781137566065.

Çakirtas, Önder. Politics and Drama: Change, Challenge and Transition in Bernard Shaw and Orhan Asena. Apostolos. [2016] pp. 214. £18.99 ISBN 9 781910942536.

Callow, Christos Jr., and Anna McFarlane, eds. Adam Roberts: Critical Essays. Gylphi. [2016] pp. 249. pb £17.99 ISBN 9781780240428.

Chantler, Ashley, and Rob Hawkes, eds. War and the Mind: Ford Madox Ford's 'Parade's End', Modernism, and Psychology. EdinUP. [2015] pp. v + 186. £63 ISBN 9781474404570.

Clare, David. Bernard Shaw's Irish Outlook. PalMac. [2016] pp. 207. £60 ISBN 9781137543554.

Clarke, Bruce, and Manuela Rossini, eds. The Cambridge Companion to Literature and the Posthuman. CUP. [2016] pp. xxxiv + 226. pb £17.99 ISBN 9781107450615.

Collier, Patrick. Modern Print Artefacts: Textual Materiality and Literary Value in British Print Culture, 1890-1930. EdinUP. [2016] pp. 288. $£ 80$ ISBN 9781474413473.

Collini, Stefan. Common Writing: Essays on Literary Culture and Public Debate. OUP. [2016] pp. 354. £30 ISBN 9780198758969.

Connolly, Sally. Grief \& Meter: Elegies for Poets after Auden. UVirginiaP. [2016] pp. xiii + 254. £47.95 ISBN 9780813938646.

Conolly, L.W., ed. The Critical Shaw: On Politics. Rosetta. [2016] pp. 308. pb $£ 12.39$ ISBN 9780795348952.

Cooper, David, Christopher Donaldson, and Patricia Murrieta-Flores, eds. Literary Mapping in the Digital Age. Routledge. [2016] pp. 308. $£ 110$ ISBN 9781472441300 .

Coste, Bénédicte, Catherine Delyfer, and Christine Reynier, eds. Reconnecting Aestheticism and Modernism. Routledge. [2016] pp. vi + 210. £110 ISBN 9781138640771.

Crane, Ralph, Jane Stafford, and Mark Williams, eds. The Oxford History of the Novel in English, vol. 9: The World Novel in English to 1950. OUP. [2016] pp. xiv + 487. £95 ISBN 9780199609932.

Cranfield, Jonathan. Twentieth-Century Victorian: Arthur Conan Doyle and the 'Strand Magazine', 1891-1930. EdinUP. [2016] pp. 272. £75 ISBN 97814 74406758.

Crockatt, Richard. Einstein and Twentieth-Century Politics: 'A Salutary Moral Influence’. OUP. [2016] pp. 256. £25 ISBN 9780198785491.

Crowley, Ronan, and Dirk Van Hulle, eds. New Quotatoes: Exogenesis in the Digital Age. Rodopi. [2016] pp. 245. £60 ISBN 9789004319615.

Cuming, Emily. Housing Class and Gender Modern British Writing 1880-1920. CUP. [2016] pp. 264. £64.99 ISBN 9781316576830.

Davis, Ben. Sex, Time, and Space in Contemporary Fiction: Exceptional Intercourse. PalMac. [2016] pp. xviii + 178. \$95 ISBN 9781137485885.

Davis, Thomas S. The Extinct Scene: Late Modernism and Everyday Life. ColUP. [2016] pp. 328. £49.95 ISBN 9780231169424. 
De Filippis, Simonetta, ed. D.H. Lawrence: New Critical Perspectives and Cultural Translation. CambridgeSP. [2016] pp. xii + 373. £52.99 ISBN 9781443894449.

del Valle Alcalá, Roberto. British Working-Class Fiction: Narratives of Refusal and the Struggle against Work. Bloomsbury. [2016] pp. 208. hb £56 ISBN 9 78147427 3749, pb £26.09 ISBN 9781350044593.

Detloff, Madelyn. The Value of Virginia Woolf. CUP. [2016] pp. 132. £29.99 ISBN 9781107081505.

Dickey, Frances, and John D. Morgenstern, eds. The Edinburgh Companion to T.S. Eliot and the Arts. EdinUP. [2016] pp. 328. £125 ISBN 978147440 5287.

Dowson, Jane. Carol Ann Duffy: Poet for Our Times. Palgrave. [2016] pp. 256. $£ 50$ ISBN 9781137415639.

Duncan, Andrew. Centre and Periphery in Modern British Poetry. Shearsman. [2016] pp. 318. £14.95 ISBN 9781848614994.

Duncan, Andrew. The Failure of Conservatism in Modern British Poetry. Shearsman. [2016] pp. 374. £16.95. ISBN 9781848614987.

Duncan, Dennis, ed. Tom McCarthy: Critical Essays. Gylphi. [2016] pp. 268. pb £17.99 ISBN 9781780240602.

Eagleton, Terry, Culture. YaleUP. [2016] pp. ix + 177. £16.99 ISBN 97803 00218794.

Ehland, Christoph, and Cornelia Wächter, eds. Middlebrow and Gender, 18901945. Rodopi. [2016] pp. 284. £85 ISBN 9789004313361.

Evans, Robert C. Philip Larkin. Palgrave. [2016] pp. 184. £18.99 ISBN 97811 37517111.

Eve, Martin Paul. Literature against Criticism: University English and Contemporary Fiction in Conflict. Open Books. [2016] pp. 248. £29.95 ISBN 9781783742745.

Fargnoli, A. Nicholas, and Michael Patrick Gillespie, eds. Exiles: A Critical Edition. UFlorP. [2016] pp. 368. £74.95 ISBN 9780813061658.

Fauske, Christopher J. Louis MacNeice: In a Between World. IAP. [2016] pp. xii + 163. £65 ISBN 9781911024095.

Ferrall, Charles, and Dougal McNeill. Writing the 1926 General Strike: Literature, Culture, Politics. CUP. [2015] pp. ix + 225. £57 ISBN 97811 07100039.

Finke, Michael C., and Michael Holquist, eds. Approaches to Teaching the Works of Anton Chekhov. MLA. [2016] pp. 230. £36.95 ISBN 978160329 2672.

Fisher, Allen. Imperfect Fit: Aesthetic Function, Facture \& Perception in Art and Writing since 1950. UAlaP. [2016] pp. 302. £52.95 ISBN 978081735 8723.

Fives, Allyn, and Keith Breen, eds. Philosophy and Political Engagement: Reflections in the Public Sphere. PalMac. [2016] pp. xv + 275. £65 ISBN 9781137445865.

Fletcher, Angus. Comic Democracies: From Ancient Athens to the American Republic. JHUP. [2016] pp. 224. \$49.95 ISBN 9781421419343. 
Forrest-Thomson, Veronica. Poetic Artifice: A Theory of Twentieth-Century Poetry, ed. Gareth Farmer. Shearsman. [2016] pp. 238. £16.95 ISBN 97818 48614451.

Foster, Roger S. Adorno and Philosophical Modernism: The Inside of Things. Lexington. [2016] pp. 260. £60 ISBN 9781498525008.

Fraser, James Alexander. Joyce and Betrayal. PalMac. [2016] pp. viii +211. $£ 72$ ISBN 9781137595874.

Freer, Scott, and Michael Bell,, eds. Religion and Myth in T.S. Eliot's Poetry. CambridgeSP. [2016] pp. xix + 187. £47.99 ISBN 9781443894562.

Garebian, Keith. Lerner and Loewe's My Fair Lady. Routledge. [2016] pp. 104. $£ 84.70$ ISBN 9781138418189.

Gelder, Ken. New Directions in Popular Fiction: Genre, Distribution, Reproduction. PalMac. [2016] pp. 474. £67.99 ISBN 9781137523464.

George, Jibu Mathew. Ulysses Quotidianus: James Joyce's Inverse Histories of the Everyday. CambridgeSP. [2016] pp. 338. £52.99 ISBN 9781443887304.

Ghosh, Ranjan. Transcultural Poetics and the Concept of the Poet: From Philip Sidney to T.S. Eliot. Routledge. [2016] pp. xii + 196. £110 ISBN 978113882 6311.

Greenberg, Jonathan, and Nathan Waddell, eds. Brave New World: Contexts and Legacies. PalMac. [2016] pp. xxiii + 254. £55 ISBN 9781137445414.

Gregori, Eduardo, and Juan Herrero-Senés, eds. Avant-Garde Cultural Practices in Spain (1914-1936). Brill: Rodopi. [2016] pp. vi $+228 . £ 70.00$ ISBN 9789004310179.

Groes, Sebastian. British Fiction of the Sixties: The Making of the Swinging Decade. Bloomsbury. [2016] pp. 216. £59.50 ISBN 9780826495570.

Gross, Sabine, and Steve Ostovich,, eds. Time and Trace: Multidisciplinary Investigations of Temporality. Brill. [2016] pp. 260. £87 ISBN 978900431 5624.

Haddad, Rosalie Rahal. Bernard Shaw in Brazil: The Reception of the Theatrical Productions, 1927-2013. Lang. [2016] pp. xxxi + 276. £44 ISBN 9783035396140.

Hadfield, D.A., ed. The Critical Shaw: On Theatre. Rosetta. [2016] pp. 305. $£ 12.39$ ISBN 9780795348976.

Haffenden, John, ed. The Letters of T.S. Eliot, vol. 6: 1932-1933. Faber. [2016] pp. xlv + 847. £30 ISBN 9780571316342.

Hair, Ross. Avant Folk: Small Press Poetry Networks from 1950 to Present. LiverUP. [2016] pp. 256. £75 ISBN 9781781383292.

Hale, Brian, and Len Platt, eds. The Cambridge History of Postmodern Literature. CUP. [2016] pp. 552. £148 ISBN 9781107140271.

Hale, Lisa, and Jin Zhang, eds. Proceedings of the Fifth Northeast Asia International Symposium on Language, Literature and Translation. American Scholars. [2016] pp. 801. £? ISBN 9780986181795.

Hammill, Faye, and Mark Hussey. Modernism's Print Cultures. Bloomsbury. [2016] pp. viii + 220. pb £21.99 ISBN 9781472573254.

Hampson, Robert, and Ken Edwards, eds. Clasp: Late Modernist Poetry in London in the 1970s. Shearsman. [2016] pp. 168. £12.95 ISBN 978184861 4604. 
Handley, Agata. Constructing Identity: Continuity, Otherness and Revolt in the Poetry of Tony Harrison. Lang. [2016] pp. 216. £37.31 ISBN 978363165 8819.

Hanson, Clare, Gerri Kimber, and Todd Martin, eds. Katherine Mansfield and Psychology. EdinUP. [2016] pp. 224. £70 ISBN 9781474417532.

Harding, Jason, ed. The New Cambridge Companion to T.S. Eliot. CUP. [2016] pp. $\mathrm{xx}+218 . £ 49.99$ ISBN 9781139583411.

Hardy, Barbara. Ivy Compton-Burnett. EdinUP. [2016] pp. 192. £19.99 ISBN 9 781474401357.

Harrison, Andrew. The Life of D.H. Lawrence: A Critical Biography. Wiley. [2016] pp. xxii + 452. £60 ISBN 9780470654781.

Hassett, Joseph M. The Ulysses Trials: Beauty and Truth Meet the Law. Lilliput. [2016] pp. 221. £25 ISBN 9781843516682.

Hayot, Eric, and Rebecca L. Walkowitz, eds. A New Vocabulary for Global Modernism. ColUP. [2016] pp. vii + 305. pb £24.95 ISBN 9780231165211.

Heholt, Ruth, and Niamh Downing, eds. Haunted Landscapes: Super-Nature and the Environment. R\&L. [2016] pp. vi + 249. £24.99 ISBN 978178348 8827.

Heininge, Kathleen. Reflections: Virginia Woolf and Her Quaker Aunt, Caroline Stephen. Lang. [2016] pp. 186. £50 ISBN 9781433133299.

Helt, Brenda, and Madelyn Detloff, eds. Queer Bloomsbury. EdinUP. [2016] pp. xii + 298. hb £80 ISBN 978147440 1692, pb £24.99 ISBN 978147440 1708 .

Hepburn, Allan, ed. Around 1945: Literature, Citizenship, Rights. McG-QUP. [2016] pp. 313. \$31.46 ISBN 9780773547322.

Herren, Graley, ed. Text \& Presentation, 2016. McFarland. [2017] pp. 252. \$65.00 ISBN 9781476663357.

Hicks, Heather J. The Post-Apocalyptic Novel in the Twenty-First Century: Modernity beyond Salvage. Palgrave. [2016] pp. ix + 208. £58 ISBN 97811 37553669.

Holledge, Julie, Jonathan Bollen, Frode Helland, and Joanne Tompkins. A Global Doll's House: Ibsen and Distant Visions. PalMac. [2016] pp. xiii + 233. £67.99 ISBN 9781137438980.

Hubble, Nick, and Phillip Tew, eds. London in Contemporary British Fiction: The City Beyond the City. Bloomsbury. [2016] pp. 232. £76.50 ISBN 97814 41190192.

Huber, Irmtraud. Present-Tense Narration in Contemporary Fiction: A Narratological Overview. Palgrave. [2016] pp. vi + 123. £45 ISBN 97811 37562128.

Hutchinson, Ben. Lateness and Modern European Literature. OUP. [2016] pp. $\mathrm{x}+$ 392. $£ 60$ ISBN 9780198767695.

Igoe, Vivien. The Real People of Joyce's Ulysses: A Biographical Guide. UCDubP. [2016] pp. 380. £32 ISBN 9781910820063.

Ingelbien, Raphaël. Irish Cultures of Travel: Writing on the Continent, 18291914. PalMac. [2016] pp. ix + 252. £58 ISBN 9781137567840.

Jillett, Louise, ed. Cormac McCarthy's Borders and Landscapes. Bloomsbury. [2016] pp. 240. £82.99. ISBN 9781501319129. 
Jones, Clara. Virginia Woolf: Ambivalent Activist. EdinUP. [2016] pp. 246. 275 ISBN 9781474401920.

Kalliney, Peter. Modernism in a Global Context. Bloomsbury. [2016] pp. vi + 190. pb £21.99 ISBN 9781472569653.

Karhio, Anne. 'Slight Return': Paul Muldoon's Poetics of Place. Lang. [2016] pp. ix + 250. £40 ISBN 9783034319867.

Kent, Brad, ed. The Selected Essays of Sean O'Faolain. McG-QUP. [2016]) pp. 540. \$120 ISBN 9780773547766.

Kiberd, Declan, and P.J. Mathews, eds. Handbook of the Irish Revival: An Anthology of Irish Cultural and Political Writings 1891-1922. UNDP. [2016] pp. 506. \$125 ISBN 9780268101305.

Kimber, Gerri. Katherine Mansfield: The Early Years. EdinUP. [2016] pp. xxi + 283. £30 ISBN 9780748681457.

Kimber, Gerri, and Claire Davison, eds. The Collected Poems of Katherine Mansfield. EdinUP. [2016] pp. x + 205. £70 ISBN 9781474417273.

Kimber, Gerri, and Claire Davison, eds. The Diaries of Katherine Mansfield including Miscellaneous Works. EdinUP. [2016] pp. 520. £175 ISBN 97807 48685059.

Knapp, Liza. Anna Karenina and Others: Tolstoy's Labyrinth of Plots. UWiscP. [2016] pp. x + 326. \$79.95 ISBN 9780299307905.

Kocot, Monika. Playing Games of Sense in Edwin Morgan's Writing. Lang. [2016] pp. 218. £51.03 ISBN 9783653952377.

Kornhaber, David. The Birth of Theatre from the Spirit of Philosophy: Nietzsche and the Modern Drama. NorthWesternUP. [2016] pp. 256. \$99.95. ISBN 9780810132610.

Kosters, Onno, Tim Conley, and Peter de Voogd, eds. A Long the Krommerun: Selected Papers from the Utrecht James Joyce Symposium. Rodopi. [2016] pp. 205. £59 ISBN 9789004314450.

Lackey, Michael. Biographical Fiction: A Reader. Bloomsbury. [2016] pp. 488. $£ 19.59$ ISBN 9781501318009.

Laird, Holly A., ed. The History of British Women's Writing, 1880-1920. PalMac. [2016] pp. xxii + 313. £80 ISBN 9781137393791.

Larrissy, Edward, ed. The Cambridge Companion to British and Irish Poetry, 1945-2010. CUP. [2016] pp. 292. £54.99 ISBN 9781316111314.

Lehman, Robert S. Impossible Modernism: T.S. Eliot, Walter Benjamin, and the Critique of Historical Reason. StanfordUP. [2016] pp. xxvi + 241. £\$60 ISBN 9780804799041.

Leinwand, Theodore B. The Great William: Writers Reading Shakespeare. UChicP. [2016] pp. 240. \$35 ISBN 9780226367552.

Li, Kay. Bernard Shaw's Bridges to Chinese Culture. Palgrave. [2016] pp. xi + 215. £80 ISBN 9783319410029.

Lonsdale, Sarah. The Journalist in British Fiction and Film: Guarding the Guardians from 1900 to the Present. Bloomsbury. [2016] pp. 296. £15.39 ISBN 9781474220545.

Lounsberry, Barbara. Virginia Woolf's Modernist Path: Her Middle Diaries and the Diaries She Read. UFlorP. [2016] pp. 268. \$79.95 ISBN 978081306 2952. 
Lurz, John. The Death of the Book: Modernist Novels and the Time of Reading. FordUP. [2016] pp. 199. \$90 ISBN 9780823271016.

Lyall, Scott, ed. Community in Modern Scottish Literature. Brill. [2016] pp. 280. £78 ISBN 9789004317444.

Mannion, Elizabeth, ed. The Contemporary Irish Detective Novel. Palgrave. [2016] pp. xi + 168. £55.00 ISBN 9781137539397.

Marcus, Laura, Michèle Mendelssohn, and Kirsten E. Shepherd-Barr, eds. Late Victorian into Modern. OUP. [2016] pp. xvi + 656. £95 ISBN 97801 98704393.

Matz, Jesse. Lasting Impressions: The Legacies of Impressionism in Contemporary Culture. ColUP. [2016] pp. ix + 336. £49.95 ISBN 97802 31164061.

McHale, Brian, and Len Platt, eds. The Cambridge History of Postmodern Literature. CUP. [2016] pp. 539. £148 ISBN 9781107140271.

McHugh, Roland. Annotations to Finnegans Wake, 4th edn. JHUP. [2016] pp. 664. £33.50 ISBN 9781421419077.

McLoughlin, Kate, Lara Feigel, and Nancy Martin, eds. Writing War, Writing Lives. Routledge. [2016] pp. ix + 180. £76 ISBN 9781138693685.

Mendelssohn, Michèle, and Denis Flannery, eds. Alan Hollinghurst: Writing Under the Influence. ManUP. [2016] pp. 224. £70 ISBN 9780719097171.

Milthorpe, Naomi. Evelyn Waugh's Satires: Texts and Contexts. FDUP. [2016] pp. 196. £49.95 ISBN 9781611478747.

Morra, Irene. Verse Drama in England, 1900-2015: Art, Modernity and the National Stage. Bloomsbury. [2016] pp. 304. £63 ISBN 9781472580146.

Nadel, Ira. Virginia Woolf. Reaktion. [2016] pp. 216. £11.99 ISBN 978178023 6667.

Nilsson, Louis, David Damrosch, and Theo D'haen. Crime Fiction as World Literature. Bloomsbury. [2017] pp. 312. £23.99 ISBN 9781501319334.

Norris, Margot. The Value of James Joyce. CUP. [2016] pp. vi + 157. £29.99 ISBN 9781316443644.

Norris, Nanette, ed. Great War Modernism: Artistic Response in the Context of War, 1914-1918. FDUP. [2016] pp. 256. £54.95 ISBN 9781611478037.

O'Brien, Eugene. Seamus Heaney as Aesthetic Thinker: A Study of the Prose. SyracuseUP. [2016] pp. xiii + 320. £63.50 ISBN 9780815634607.

O'Brien, Eugene, ed. The Soul Exceeds Its Circumstances: The Later Poetry of Seamus Heaney. UNDP. [2016] pp. xiv + 403. £51.95 ISBN 978026810 0209.

Olsen, Christopher, ed. Acting Comedy. Routledge. [2016] pp. 180. £85 ISBN 9781138891401.

Osborne, Deirdre, ed. The Cambridge Companion to British Black and Asian Literature (1945-2010). CUP. [2016] pp. 320. £49.99 ISBN 978131650 4802.

David Owen, and Cristina Pividori, eds. Writings of Persuasion and Dissonance in the Great War. Brill. [2016] pp. xiv + 261. £78 ISBN 9789004314917.

Palmer, R. Barton, and Marc Conner, eds. Screening Modern Irish Fiction and Drama. PalMac. [2016] pp. xv + 254. £72 ISBN 9783319409276. 
Pepper, Andrew and David Schmid, eds. Globalization and the State in Contemporary Crime Fiction. PalMac. [2016] pp. 247. £89.99 ISBN 97811 37425737.

Pestell, Alex. Geoffrey Hill: The Drama of Reason. Lang. [2016] pp. 246. £55 ISBN 9783034318617.

Pharand, Michel W., ed. The Critical Shaw: On Religion. Rosetta. [2016] pp. 310. pb £12.39 ISBN 9780795346873.

Pla, Xavier, Maximiliano Fuentes, and Francesc Montero. A Civil War of Words: The Cultural Impact of the Great War in Catalonia, Spain, Europe and a Glance at Latin America. Lang. [2016] pp. 441. pb £55 ISBN 97830 34319508.

Pogorzelski, Randall J. Virgil and Joyce: Nationalism and Imperialism in the Aeneid and Ulysses. UWiscP. [2016] pp. 192. \$65 ISBN 9780299308001.

Pohl, Rebecca, and Christopher Vardy, eds. Rupert Thomson: Critical Essays. Gylphi. [2016] pp. 190. pb. £16.99 ISBN 9781780240572.

Poulain, Alexandra. Irish Drama, Modernity and the Passion Play. PalMac. [2016] pp. xii + 264. £67.99 ISBN 9781349949632.

Price, Stanley. James Joyce and Italo Svevo: The Story of a Friendship. Somerville. [2016] pp. 248. £14 ISBN 9780992736484.

Purdon, James. Modernist Informatics: Literature, Information, and the State. OUP. [2016] pp. xiv + 224. £48.49 ISBN 9780190211691.

Quinn, Judy, and Adele Cipolla, eds. Studies in the Transmission and Reception of Old Norse Literature: The Hyperborean Muse in European Culture. Brepols. [2016] pp. 365. £99.09 ISBN 9782503555539.

Rabaté, Jean-Michel. The Pathos of Distance: Affects of the Moderns. Bloomsbury. [2016] pp. 224. £19.99 ISBN 9781501307973.

Radford, Andrew, Heather Walton, and Elizabeth Anderson, eds. Modernist Women Writers and Spirituality: A Piercing Darkness. Palgrave. [2016] pp. x + 281. £72 ISBN 9781137530356.

Raine, Craig. My Grandmother's Glass Eye: A Look at Poetry. Atlantic. [2016] pp. 224. £25 ISBN 9781848872899.

Rasula, Jed. History of a Shiver: The Sublime Impudence of Modernism. OUP. [2016] pp. xii + 346. £29.99 ISBN 9780199396290.

Rau, Petra, ed. Long Shadows: The Second World War in British Fiction and Film. Northwestern University Press. [2016] pp. 320. \$34.95 ISBN 97808 10133297.

Raw, Laurence. Theatre of the People: Donald Wolfit's Shakespearean Productions 1937-1953. R\&L. [2016] pp. 240. \$85 ISBN 9781442257344.

Reed, Jeremy. I Heard It through the Grapevine: Asa Benveniste and Trigram Press. Shearsman. [2016] pp. 120. £9.95 ISBN 9781848614635.

Reynolds, Paige. Modernist Afterlives in Irish Literature and Culture. Anthem. [2016] pp. x + 202. £70 ISBN 9781783085736.

Rivers Norton, Jana. The Demeter-Persephone Myth as Writing Ritual in the Lives of Literary Women. CambridgeSP. [2016] pp. 205. £52.99 ISBN 97814 43801416.

Roberts, Neil. Sons and Lovers: The Biography of a Novel. LiverUP. [2016] pp. xii + 196. £75 ISBN 9781942954187. 
Robinson, James. Joyce's Dante: Exile, Memory and Community. CUP. [2016] pp. 242. £80 ISBN 9781107167414.

Robinson, Peter, ed. Slakki: New and Neglected Poems, by Roy Fisher. Bloodaxe. [2016] pp. 80. £9.95. 9781780373225.

Rodríguez Martín, Gustavo A., ed. The Critical Shaw: On Literature. Rosetta. [2016] pp. 253. pb £12.39 ISBN 9780795346866.

Rollyson, Carl. Confessions of a Serial Biographer. McFarland. [2016] pp. 256. $£ 27.95$ ISBN 9781476663258.

Rosen, Jeremy. Minor Characters Have Their Day: Genre and the Contemporary Literary Marketplace. ColUP. [2016] pp. x + 265. £49.95 ISBN 9780231177443.

Ross, Shawna, and James O'Sullivan, eds. Reading Modernism with Machines: Digital Humanities and Modernist Literature. PalMac. [2016] pp. xxi + 301. $£ 72$ ISBN 9781137595690.

Russell, Richard Rankin. Seamus Heaney: An Introduction. EdinUP. [2016] pp. viii + 297. £? ISBN 9781474401654.

Saint-Amour, Paul K. Tense Future: Modernism, Total War, Encyclopedic Form. OUP. [2015] pp. xiii + 347. £19.99 ISBN 9780190200954.

Schwyter, Jürg R. Dictating to the Mob: The History of the BBC Advisory Committee on Spoken English. OUP. [2016] pp. 256. £25 ISBN 978019873 6738.

Seltzer, Mark. The Official World. DukeUP. [2016] pp. 281. pb £20.99 ISBN 9 780822361008.

Sengupta, Gautam. Myriad-Minded Shaw: Perspectives on Shavian Drama (Politics, War and History). PHI. [2016] pp. ix + 144. pb. \$11.95 ISBN 9 788120352117.

Share, Don, ed. The Poems of Basil Bunting. Faber. [2016] pp. 624. £30 ISBN 9780571235001 .

Sherry, Vincent, ed. The Cambridge History of Modernism. CUP. [2016] pp. xxxiii + 929. £120 ISBN 9781107034693.

Sim, Lorraine. Ordinary Matters: Modernist Women's Literature and Photography. Bloomsbury. [2016] pp. 248. £80 ISBN 9781501314308.

Simpson, Kathryn. Woolf: A Guide for the Perplexed. Bloomsbury. [2016] pp. 197. £60 ISBN 9781441169020.

Snell, K.D.M. Spirits of Community: English Senses of Belonging and Loss, 1750-2000. Bloomsbury. [2016] pp. xii + 341. £28.99 ISBN 978147426 8844.

Solnick, Sam. Poetry and the Anthropocene: Ecology, Biology and Technology in Contemporary British and Irish Poetry. Routledge. [2016] pp. xii +224. $£ 99$ ISBN 9781138941687.

Soud, W. David. Divine Cartographies: God, History and Poiesis in W.B. Yeats, David Jones and T.S. Eliot. OUP. [2016] pp. 246. £60 ISBN 97801 98777779.

Spalding, Frances. Virginia Woolf and Tristram Shandy. VWSGB. [2016] pp. 18. £4 ISBN 9780955571794.

Stead, Lisa. Off to the Pictures: Cinemagoing, Women's Writing and Movie Culture in Interwar Britain. EdinUP. [2016] pp. 232. £70 ISBN 978074869 4884. 
Sultzbach, Kelly. Ecocriticism in the Modernist Imagination: Forster, Woolf, and Auden. CUP. [2016] pp. 250. £80 ISBN 9781107161412.

Switaj, Elizabeth. James Joyce's Teaching Life and Methods: Language and Pedagogy in A Portrait of the Artist as a Young Man, Ulysses, and Finnegans Wake. PalMac. [2016] pp. 158. £58 ISBN 9781137559890.

Taylor, Jesse O. The Sky of our Manufacture: The London Fog in British Fiction from Dickens to Woolf. UPVirginia. [2016] pp. 272. \$65 ISBN 97808 13937922.

Torres, David Jiménez. Ramiro de Maeztu and England: Imaginaries, Realities and Repercussions of a Cultural Encounter. B\&B. [2016] pp. 191. £60 ISBN 9 781855663121.

Tucker, David, and Trish McTighe, eds. Staging Beckett in Great Britain. Foreword James Knowlson. Bloomsbury. [2016] pp. xxvii + 258. \$114 ISBN 9781474240178.

Upstone, Sara. Rethinking Race and Identity in Contemporary British Fiction. Routledge. [2016] pp. xi + 191. £88 ISBN 9780415729192.

Van Hulle, Dirk. James Joyce's 'Work in Progress': Pre-Book Publications of Finnegans Wake Fragments. Routledge. [2016] pp. 294. £110 ISBN 97814 09465959.

Verene, Donald Phillip. James Joyce and the Philosophers at Finnegans Wake. NorthWesternUP. [2016] pp. xiv + 124. £91.95 ISBN 9780810133327.

Ward, Jason Mark. The Forgotten Film Adaptations of D.H. Lawrence's Short Stories. Rodopi. [2016] pp. vii + 277. €82 ISBN 9789004309043.

Warden, Claire. Migrating Modernist Performance: British Theatrical Travels through Russia. PalMac. [2016] pp. xi + 223. £72 ISBN 9781137385697.

Williams, James, and Matthew Bevis, eds. Edward Lear and the Play of Poetry. OUP. [2016] pp. xix + 381. £65 ISBN 9780198708568.

Wilson, Nicola, ed. The Book World: Selling and Distributing British Literature, 1900-1940. Brill. [2016] pp. xi + 221. £78 ISBN 978900431 5860.

Youngkin, Molly. British Women Writers and the Reception of Ancient Egypt, 1840-1910: Imperialist Representations of Egyptian Women. PalMac. [2016] pp. xxvii + 229. £70 ISBN 9781137570765.

Zirra, Ioanna, and Madeline Potter, eds. The Literary Avatars of Christian Sacramentality, Theology and Practical Life in Recent Modernity. Lang. [2016] pp. 169. £32 ISBN 9783631668887. 